\title{
PTEROMÁLIDOS DE LA COMUNIDAD DE MADRID: FAUNÍSTICA Y CATÁLOGO (HYMENOPTERA, CHALCIDOIDEA, PTEROMALIDAE) (*)
}

\author{
A. M. Garrido Torres (**) y J. L. Nieves-Aldrey $(* *)$ \\ RESUMEN
}

Se presenta la compilación de los resultados faunísticos de distintos trabajos de contribución al conocimiento de la familia Pteromalidae (Hym., Chalcidoidea) desarrollados por los autores, a lo largo de más de diez años, en la Comunidad Autónoma de Madrid. Se listan los 350 taxa de nivel específico encontrados en la CAM correspondientes a 9166 ejemplares de pteromálidos estudiados, un $97 \%$ de los cuales representan materiales colectados por los autores en distintos programas de muestreo. Se efectuaron tres programas principales de muestreo: con red de barrido entomólogico en 59 localidades de la CAM representativas de distintas comunidades vegetales; programa intensivo de muestreo con trampas Malaise en dos localidades de el Monte de El Pardo y sierra de Guadarrama y muestreo para el estudio de la comunidad parasitoide de pteromálidos asociada a agallas de cinípidos (Hym., Cynipidae). Se elabora el catálogo de las especies de la comunidad de Madrid. Frente a las 13 especies en 12 géneros previamente citadas, se catalogan 268 especies, incluidas en 92 géneros de 11 subfamilias. Un total de 30 géneros y 155 especies representan la primera cita para la fauna de la Península Ibérica, actualizándose el catálogo íbero-balear de los Pteromalidae a 324 especies frente a las 169 que incluía hasta ahora.

Para cada especie del catálogo se presentan unos breves comentarios sobre su distribución conocida, citas en la CM y en la P.I. y datos de su biología, bien propios o recabados de la bibliografía. Se presenta un apéndice final con la recopilación exhaustiva de los datos de cada registro del material estudiado.

Palabras clave: Catálogo, faunística, Pteromalidae, Península Ibérica, Madrid, El Pardo, trampas Malaise.

\section{SUMMARY}

\section{Pteromalids from the Autonomous Community of Madrid (CAM) (Spain): Faunistics and Catalogue (Hymenoptera: Chalcidoidea, Pteromalidae)}

Faunistic results are given, compiled from several works of contribution to the knowledge of the Pteromalidae (Hym., Chalcidoidea), carried out during more than ten years in the autonomous community of Madrid (CAM) (Spain). 350 level-species taxa found in the CAM, corresponding to 9166 individuals examined, are listed. The authors collected $97 \%$ of materials examined as a result of three sampling programs. Sweet net sampling of 59 selected sites of the CAM; intensive Malaise trapping of two natural areas in El Monte de El Pardo and Sierra de Guadarrama and sampling of the parasitoid pteromalid community associated to cynipid galls (Hym., Cynipidae). A catalogue of species of the CAM is presented. Contrasting with the 13 species in 12 genera previously recorded, 268 species in 92 genera and 11 subfamilies are catalogued. 30 genera and 155 species represent a new record the first published record for the Iberian Peninsula. The íbero-balear catalogue of the Pteromalidae is updated from 169 to 324 species.

For each species listed a short comments are presented on its known geographic distribution, existing records from the IB and CAM and biological data. Finally, an appendix is presented including full record data of the materials studied.

Key words: Catalogue, faunístics, Pteromalidae, Iberian Peninsula, Madrid, El Pardo, Malaise traps.

\footnotetext{
* Trabajo parcialmente subvencionado por la Consejería de Educación de la CAM, Proyecto C188/91 y por la DGICYT, Proyectos Fauna Ibérica I, II y III.

** Museo Nacional de Ciencias Naturales (CSIC). José Gutiérrez Abascal 2. Madrid 28006.
} 


\section{Introducción}

La familia Pteromalidae es una de las más diversas dentro del conjunto de 21 familias que integran los Chalcidoidea, a su vez, una de las superfamilias más importantes de himenópteros parasitoides, tradicionalmente incluidas en la sección Parasitica. Agrupa aproximadamente 3.100 especies conocidas, repartidas en 600 géneros (Gauld y Bolton, 1988; Gaston, 1993; Hanson, 1995), de las cuales alrededor de 1.000 son de distribución europea (Boucek y Rasplus, 1991) y sólo en el Reino Unido se han citado 532 (Gauld y Bolton, 1988). Teniendo en cuenta la gran diversidad de insectos que son atacados por los pteromálidos, estos parasitoides son un enemigo potencial de muchas plagas agrícolas y forestales y pueden actuar como controladores de muchas especies de insectos susceptibles de convertirse en plagas (Boucek y Rasplus, 1991). El conocimiento de la familia en la Península Ibérica es muy pobre. Una actualización del catálogo íberobalear, cifró en 94 el número de especies de pteromálidos citadas en la Península Ibérica (Garrido y Nieves-Aldrey, 1990); con posterioridad, esta cifra se ha visto incrementada con 75 nuevas especies recogidas en distintos trabajos (Graham, 1984, 1992a, 1992b, 1993; Heydon, 1989a; Falcó et al., 1990; Gijstwitj, 1990; Verdú, 1991; Garrido y Nieves-Aldrey, 1992a, 1992b; Askew, 1994; Pujade, 1994b; Askew y Blasco-Zumeta, 1997) pero, con todo, resulta una cifra aún muy baja si tenemos en cuenta que una estimación conservadora de los pteromálidos existentes en la Península Ibérica, a tenor de los datos conocidos de diversidad de la familia en otros países de Europa, no sería inferior con toda probabilidad a las 700 especies. Esta pobreza de datos sobre el grupo en nuestro país se debe a que, al igual que ocurre con la mayoría de los Hymenoptera "Parasitica", no ha contado con especialistas que se ocuparan de su estudio taxonómico. La excepción está representada por García Mercet (1910-1947) a quien se deben buena parte de las citas de pteromálidos existentes en España. En años recientes Nieves-Aldrey (1980, 1982a, 1982b, 1983a, 1983b, 1988) y Pujade (1983, 1985, 1992, 1994a, 1994b) han publicado algunos trabajos sobre la fauna de pteromálidos ligados a agallas de cinípidos (Hymenoptera, Cynipidae); el resto de las citas, se ha realizado de manera esporádica en un gran número de trabajos sueltos correspondientes a distintos autores nacionales y extranjeros.

Con el objetivo general de actualizar y contribuir a sentar las bases del conocimiento de la familia
Pteromalidae en España se planteó un estudio general de este grupo, incluyendo aspectos de faunística, taxonomía, biología y ecología, en la Comunidad de Madrid, que constituyó la memoria doctoral del primero de nosotros (Garrido, 1996). En este trabajo presentamos los resultados faunísticos incluyendo el catálogo de las especies de Pteromalidae de la Comunidad de Madrid. En trabajos posteriores se publicarán otros aspectos de biología y ecología de las especies. Al igual que para el resto de la Península Ibérica, el conocimiento previo sobre los pteromálidos de la Comunidad de Madrid era muy escaso ya que solamente habían sido citadas en el área de estudio 13 especies en 12 géneros (Garrido y Nieves-Aldrey, 1990).

\section{Materiales y Método}

El estudio faunístico y elaboración del catálogo de los Pteromalidae de la Comunidad de Madrid se ha basado en dos tipos de tareas.

- Revisión de citas previas y material existente en las colecciones del Museo Nacional de Ciencias Naturales de Madrid (MNCN). En la práctica esto ha exigido la actualización del catálogo de los pteromálidos de España.

- Realización de campañas de muestreo en la Comunidad de Madrid (CAM).

Los materiales de partida para la elaboración del catálogo han sido:

- Materiales, en su mayor parte no identificados, existentes en la colección del MNCN de Madrid, fundamentalmente procedentes de la colección Mercet.

- Materiales obtenidos de agallas de cinípidos colectadas por el segundo de nosotros en la CAM a lo largo de más de 10 años y material adicional de los autores.

- Materiales procedentes de un proyecto de inventario entomológico de dos áreas naturales de la CAM llevado a cabo entre los años 1988 a 1992, en su mayor parte colectados mediante trampas Malaise.

- Materiales de muestreos adicionales de los autores en la CAM.

Los métodos de muestreo utilizados han sido de dos tipos: activos y pasivos. Como método de captura activo se empleó la red entomológica de barrido, de diseño de Boucek (Noyes, 1982), utilizada durante intervalos de 10-15 minutos. Como métodos de captura pasivos se utilizaron trampas Malaise y trampas bandeja coloreadas de amarillo. 
Se realizaron tres tipos de muestreos:

- Muestreo en localidades seleccionadas de la CAM. Se colectaron pteromálidos en un conjunto de 59 localidades de la CAM representativas de distintas comunidades vegetales. Todas las localidades fueron visitadas al menos una vez al mes durante la primavera y el verano. Los muestreos se llevaron a cabo entre los años 1987-1994 con red entomológica de barrido, mangueando todo tipo de vegetación presente en la zona durante intervalos de 10-15 minutos.

- Muestreo para el estudio de la comunidad de pteromálidos asociados con agallas de cinípidos. La mayor parte del material estudiado fue colectado por el segundo de nosotros en el transcurso de sus estudios sobre la familia Cynipidae entre los años 1982 y 1994 en la CAM. Los insectos se obtuvieron por emergencia en las condiciones de laboratorio, a partir de agallas de cinípidos colectadas sobre distintas plantas hospedadoras en las localidades seleccionadas.

- Muestreo para el estudio comparado de dos taxocenosis en dos áreas naturales de la Comunidad. El muestreo se efectuó en dos áreas naturales de la CAM: La Estación Biogeológica de El Ventorrillo, situada en la vertiente sur del Puerto de Navacerrada, en la Sierra de Guadarrama, a unos 60 kilómetros al noroeste de Madrid; donde se han realizado muestreos periódicos en los años 1988 , 1989, 1990, 1991 y 1992 y El Monte de El Pardo, en la zona de El Goloso, situada a unos 13 kilómetros al norte de Madrid, donde se mantuvo instalada sin interrupción una trampa Malaise, desde abril de 1991 a abril de 1992.

La identificación del material hasta nivel de género se ha llevado a cabo mediante las claves de Peck, Boucek y Hoffer (1964), Graham (1969) y Boucek y Rasplus (1991), mientras que para la determinación de las especies hemos utilizado principalmente la obra de Graham (1969), además de una larga serie de trabajos específicos de distintos autores que aparecen recogidos en la bibliografía.

Todo el material de estudio, ha quedado depositado en las colecciones del MNCN. La relación completa del material estudiado se recoge en el apéndice final de este trabajo.

\section{Lista de especies estudiadas}

A continuación se listan los 350 taxa de nivel específico encontrados en la Comunidad de Madrid, correspondientes a 9.166 ejemplares de pteromálidos estudiados. De esta última cifra un $97,3 \%$ corresponde a los materiales colectados en distintos programas de muestreo, mientras que el $2,7 \%$ restante representa el material previamente existente en las colecciones del MNCN, fundamentalmente la colección Mercet.

Del total de taxa listados se ha podido identificar y nombrar un total de 268 especies, repartidas en 92 géneros incluidos en 11 subfamilias. La familia Pteromalidae es un grupo hiperdiverso de himenópteros parasitoides de difícil y aún deficientemente conocida taxonomía, que engloba numerosos géneros que necesitan revisión. La identificación de las especies de estos géneros es, por tanto, frecuentemente complicada e insegura. Por esta razón, un número relativamente amplio, 82 de los taxa listados, no han podido ser asignados a especies conocidas adoptándose en este caso, el criterio "minimalista" de adscripción a morfoespecies. Los géneros y especies que se citan por primera vez en la Península Ibérica figuran con el símbolo (*)

Cleonymus Latreille, 1809

\section{CLEONYMINAE}

CLEONYMINI

1. Cleonymus laticornis Walker, 1837

2. Cleonymus obscurus Walker, 1837

Notanisus Walker, 1837

3. Notanisus sexramosus (Erdös, 1946) $\left(^{*}\right)$

4. Notanisus versicolor Walker, 1837

Heydenia Förster, 1856 (*)

\section{HEYDENIINI}

5. Heydenia pretiosa Förster, $1856(*)$

CEINAE

Cea Walker, 1837

6. Cea pulicaris Walker, 1837

Spalangiopelta Masi, 1922

7. Spalangiopelta dudichi Erdös, 1955

8. Spalangiopelta procera Graham, $1966(*)$

\section{SPALANGIINAE}

Spalangia Latreille, $1805\left(^{*}\right)$

9. Spalangia fuscipes Nees, $1834(*)$

10. Spalangia subpunctata Förster, $1850(*)$

DIPARINAE

Dipara Walker, 1833

DIPARINI

11. Dipara petiolata Walker, 1833

\section{NEODIPARINAE}

Neodipara Erdös, 1955

12. Neodipara hispanica Hedqvist, 1971

EUNOTINAE

Eunotus Walker, 1834

13. Eunotus acutus Kurdjumov, 1912 (*)

14. Eunotus areolatus (Ratzeburg, 1848)

15. Eunotus cretaceus Walker, $1834(*)$

16. Eunotus nigriclavis (Förster, 1856) $(*)$

17. Eunotus obscurus Masi, 1931 (*)

Scutellista Motschulsky, 1859

18. Scutellista caerulea (Fonscolombe, 1832)

19. Scutellista nigra Mercet, 1910

20. Scutellista obscura (Förster, 1878) (*) 
Asaphes Walker, 1834

21. Asaphes suspensus (Nees, 1834)

22. Asaphes vulgaris Walker, 1834

\section{MISCOGASTERINAE}

Halticoptera Spinola 1811

23. Halticoptera aenea (Walker, 1833)

24. Halticoptera circulus (Walker, 1833)

Rhicnocoelia Graham, 1956

25. Rhicnocoelia constans (Walker, 1836)

26. Rhicnocoelia impar (Walker, 1836) $(*)$

27. Rhicnocoelia sp. ind.

Seladerma Walker, $1834(*)$

28. Seladerma diffine (Walker, 1833) $(*)$

29. Seladerma geniculatum (Zettersted, 1838) $\left(^{*}\right)$

30. Seladerma laetum Walker, $1834(*)$

31. Seladerma sp. ind.

Sphaeripalpus Förster, 1841

32. Sphaeripalpus fuscipes (Walker, 1833)

Miscogaster Walker, 1833

33. Miscogaster hortensis Walker, $1833(*)$

34. Miscogaster maculata Walker, 1833

35. Miscogaster rufipes Walker, $1833(*)$

Lamprotatus Westwood, $1833(*)$

36. Lamprotatus annularis Walker, $1833(*)$

37.Lamprotatus truncatus (Fonscolombe, 1832) (*)

Ammeia Delucchi, $1962(*)$

38. Ammeia pulchella Delucchi, $1962(*)$

Micradelus Walker, $1834(*)$

39. Micradelus acutus Graham, 1969 (*)

ORMOCERINAE

ORMOCERINI

Ormocerus Walker, 1834

40. Ormocerus latus Walker, 1834

41. Ormocerus vernalis Walker, 1834

\section{SYSTASINI}

Semiotellus Westwood, 1839

42. Semiotellus mundus (Walker, 1834) $\left(^{*}\right)$

Systasis Walker, 1834

43. Systasis angustula Graham, 1969 (*)

44. Systasis encyrtoides Walker, 1834

45. Systasis parvula Thomson, $1876(*)$

46. Systasis tenuicornis Walker, $1834(*)$

47. Género sp. ind. 1

\section{PIRENINAE}

Gastrancistrus Westwood, 1833

48. Gastrancistrus acontes Walker, $1840(*)$

49. Gastrancistrus acutus Walker, $1834\left(^{*}\right)$

50. Gastrancistrus autumnalis (Walker, 1834) (*)

51. Gastrancistrus crassus Walker, $1834\left(^{*}\right)$

52. Gastrancistrus glabellus (Nees, 1834) $(*)$

53. Gastrancistrus hamillus Walker, 1848 (*)

54. Gastrancistrus indivisus Graham, $1969(*)$

55. Gastrancistrus laticornis Walker, $1834(*)$

56. Gastrancistrus latifrons (Thomson, 1876) (*)

57. Gastrancistrus oporinus Graham, 1969 (*)

58. Gastrancistrus praecox Graham, $1969\left(^{*}\right)$

59. Gastrancistrus salicis (Nees, 1834) $(*)$

60. Gastrancistrus vagans Westwood, 1833

61. Gastrancistrus viridis Walker, 1834

62. Gastrancistrus sp. ind. 1

63. Gastrancistrus sp. ind. 2

64. Gastrancistrus sp. ind. 3

Macroglenes Westwood, $1834(*)$

65. Macroglenes chalibeus (Haliday, 1833) (*)

66. Macroglenes varicornis (Haliday, 1833) $(*)$

\section{PTEROMALINAE}

TRIGONODERINI

Plutothrix Förster, 1856

67. Plutothrix acuminata (Thomson, 1878)

68. Plutothrix bicolorata (Spinola, 1808)

69. Plutothrix trifasciata (Thomson, 1878)

Jansoniella Kerrich, 1957 (*)

70. Jansoniella ambigua Graham, $1969(*)$

71. Jansoniella sp. ind.

Platygerrhus Thomson, $1878(*)$

72. Platygerrhus dolosus (Walker, 1836) (*)

73. Platygerrhus maculatus Erdös, 1957 (*)

Gastracanthus Westwood, 1833 (*)

74. Gastracanthus pulcherrimus Westwood, $1833(*)$

\section{PTEROMALINI}

Sphegigaster Spinola, 1811

75. Sphegigaster brevicornis (Walker, 1833) (*)

76. Sphegigaster nigricornis (Nees, 1834)

77. Sphegigaster pallicornis (Spinola, 1808) (*)

Syntomopus Walker, $1833\left(^{*}\right)$

78. Syntomopus incisus Thomson, 1878 (*)

Notoglyptus Masi, 1922

79. Notoglyptus scutellaris (Dodd \& Girault, 1915)

Cyrtogaster Walker, 1833

80. Cyrtogaster clavicornis Walker, 1833

81. Cyrtogaster vulgaris Walker, 1833

Toxeuma Walker, $1833(*)$

82. Toxeuma fuscicorne Walker, 1833 (*)

Dinotiscus Ghesquière, 1946

83. Dinotiscus eupterus (Walker, 1836) (*)

Rhopalicus Förster 1856

84. Rhopalicus guttatus (Ratzeburg, 1844)

85. Rhopalicus quadratus (Ratzeburg, 1844) (*)

86. Rhopalicus tutela (Walker, 1836) $(*)$

Acrocormus Förster, $1856(*)$

87. Acrocormus semifasciatus Thomson, 1878 (*)

Cheiropachus Westwood, 1828

88. Cheiropachus quadrum (Fabricius, 1787)

Rhaphitelus Walker, 1834

89. Rhaphitelus maculatus Walker, 1834

Roptrocerus Ratzeburg, 1844

90. Roptrocerus xylophagorum (Ratzeburg, 1844)

Habritys Thomson, 1878

91. Habritys brevicornis (Ratzeburg, 1844)

Caenocrepis Thomson, $1878(*)$

92. Caenocrepis arenicola Thomson, 1878 (*)

Cyrtoptyx Delucchi, 1956

93. Cyrtoptyx latipes (Rondani, 1877) $\left(^{*}\right)$

94. Cyrtoptyx robustus (Masi, 1907)

Oxysychus Delucchi, $1956\left(^{*}\right)$

95. Oxysychus sp nr regnieri

Dinarmus Thomson, 1878

96. Dinarmus acutus Thomson, 1878

Dinarmoides Masi, $1924(*)$

97. Dinarmoides spilopterus Masi, 1924 (*)

Stenoselma Delucchi, 1956

98. Stenoselma nigrum Delucchi, 1956

Norbanus Walker, 1836

99. Norbanus cerasiops (Masi, 1922) $(*)$

100. Norbanus meridionalis (Masi, 1919) $(*)$

101. Norbanus obscurus (Masi, 1922) $(*)$

102. Norbanus scabriculus (Nees, 1834)

103. Norbanus (Picroscytoides) sp. ind.

104. Norbanus sp. ind. 1

105. Norbanus $s p$. ind. 2

106. Norbanus sp. ind. 3

Merisus Walker, 1835

107. Merisus splendidus Walker, 1835 (*) $^{*}$ 
Homoporus Thomson, 1878

108. Homoporus apharetus (Walker, 1839) (*)

109. Homoporus arestor (Walker, 1848)

110. Homoporus destructor (Say, 1817) (*)

111. Homoporus febriculosus (Girault, 1917) (*)

112. Homoporus sp. nr febriculosus

113. Homoporus fulviventris (Walker, 1835)

114. Homoporus gibbiscuta Thomson, 1878 (*)

115. Homoporus luniger (Nees, 1834)

116. Homoporus nubilipennis Garrido y Nieves-Aldrey, 1996 (*)

117. Homoporus nypsius (Walker, 1839)

118. Homoporus pulchripes Erdös, 1953 (*)

119. Homoporus semiluteus (Walker, 1872) (*)

120. Homoporus subniger (Walker, 1835)

121. Homoporus sp. ind.

Callitula Spinola, 1811

122. Callitula bicolor Spinola, 1811

Psilocera Walker, 1833

123. Psilocera confusa Graham, 1992 (*)

124. Psilocera crassispina (Thomson, 1878) (*)

125. Psilocera obscura (Walker, 1833) (*)

126. Psilocera seiugata Graham, 1992

127. Psilocera sp. ind.

Catolaccus Thomson, 1878 (*)

128. Catolaccus crassiceps (Masi, 1911) (*)

Psychophagus Mayr, 1904 (*)

129. Psychophagus omnivorus (Walker, 1835) (*)

Stenetra Masi, 1931 (*)

130. Stenetra hungarica (Szelényi, 1982) (*)

131. Stenetra ligustica Masi, 1931 (*)

Spilomalus Graham, 1956

132. Spilomalus dolichogaster Gijswijt \& Graham, 1986

133. Spilomalus quadrinota (Walker, 1835)

134. Spilomalus sp. ind.

Spintherus Thomson, 1878

135. Spintherus dubius (Nees, 1834)

Sceptrothelys Graham, 1956

136. Sceptrothelys grandiclava (Walker, 1835)

Pteromalus Swederus, 1795

137. Pteromalus albipennis Walker, 1835

138. Pteromalus altus (Walker, 1834) (*)

139. Pteromalus apum (Retzius, 1783) (*)

140. Pteromalus bedeguaris (Thomson, 1878)

141. Pteromalus sp. nr. bedeguaris

142. Pteromalus sp. nr. berylli

143. Pteromalus bifoveolatus Förster, 1861 (*)

144. Pteromalus brachygaster (Graham, 1969) (*)

145. Pteromalus cioni (Thomson, 1878) (*)

146. Pteromalus cionobius (Erdös, 1953) (*)

147. Pteromalus sp. $n r$ cionobius

148. Pteromalus dispar (Curtis, 1827) (*)

149. Pteromalus dolichurus (Thomson, 1878)

150. Pteromalus elevatus (Walker, 1834)

151. Pteromalus sp. $n r$. elevatus

152. Pteromalus fasciatus (Thomson, 1878) (*)

153. Pteromalus hieracii (Thomson, 1878)

154. Pteromalus intermedius (Walker, 1834)

155. Pteromalus isarchus Walker, 1839

156. Pteromalus musaeus Walker, 1844

157. Pteromalus platyphilus (Walker, 1836) (*)

158. Pteromalus puparum (Linnaeus, 1758)

159. Pteromalus semotus (Walker, 1834)

160. Pteromalus sequester Walker, 1835

161. Pteromalus sp. nr. sequester

162. Pteromalus smaragdus Graham, 1969 (*)

163. Pteromalus temporalis (Graham, 1969) (*)

164. Pteromalus tripolii (Graham, 1969) (*)

165. Pteromalus sp. $n r$. tripolii

152. Pteromalus varians (Spinola, 1808)
167. Pteromalus vibulennus (Walker, 1839) (*)

168. Pteromalus sp. ind. 1

169. Pteromalus sp. ind. 2

Phaenocytus Graham, 1969

170. Phaenocytus glechomae (Förster, 1841) (*)

Cecidostiba Thomson, 1878

171. Cecidostiba adana Askew, 1961

172. Cecidostiba atra Askew, 1975

173. Cecidostiba fungosa (Geoffroy, 1785)

174. Cecidostiba geganius (Walker, 1848)

175. Cecidostiba ilicina Nieves Aldrey \& Askew, 1988

176. Cecidostiba semifascia (Walker, 1835)

Hobbya Delucchi, 1957

177. Hobbya stenonota (Ratzeburg, 1848)

Caenacis Förster, 1859

178. Caenacis inflexa (Ratzeburg, 1848)

179. Caenacis lauta (Walker, 1835)

Ablaxia Delucchi, 1957 (*)

180. Ablaxia megachlora (Walker, 1835) (*)

Apelioma Delucchi, 1956 (*)

181. Apelioma restrictum Graham, 1961 (*)

Holcaeus Thomson, 1878 (*)

182. Holcaeus compresus (Walker, 1836) (*)

183. Holcaeus gorgasus (Walker, 1839) (*)

184. Holcaeus varro (Walker, 1839) (*)

185. Holcaeus (Cricellius) gracilentus Boucek, 1954 (*)

Kaleva Graham, 1957 (*)

186. Kaleva corynocera Graham, 1957 (*)

Stenomalina Ghesquière, 1946

187. Stenomalina communis (Nees, 1834) $(*)$

188. Stenomalina epistena (Walker, 1835)

189. Stenomalina fervida Graham, 1965 (*)

190. Stenomalina gracilis (Walker, 1834)

191. Stenomalina illudens (Walker, 1836)

192. Stenomalina laticeps (Walker, 1848) (*)

193. Stenomalina liparae (Giraud, 1863) (*)

194. Stenomalina sp. ind.

Chlorocytus Graham, 1956

195. Chlorocytus deschampsiae Graham, 1965 (*)

196. Chlorocytus diversus (Walker, 1836) (*)

197. Chlorocytus harmolitae Boucek, 1957 (*)

198. Chlorocytus pilosus Graham, 1965 (*)

199. Chlorocytus planus (Walker, 1834) (*)

200. Chlorocytus spenceri Graham, 1965

201. Chlorocytus spicatus (Walker, 1835)

202. Chlorocytus sp. ind. 1

203. Chlorocytus sp. ind. 2

204. Chlorocytus sp. ind. 3

205. Chlorocytus sp. ind. 4

206. Chlorocytus sp. ind. 5

207. Chlorocytus sp. ind. 6

208. Chlorocytus sp. ind. 7

209. Chlorocytus sp. ind. 8

210. Chlorocytus sp. ind. 9

211. Chlorocytus sp. ind. 10

212. Chlorocytus sp. ind. 11

213. Chlorocytus sp. ind. 12

214. Chlorocytus sp. ind. 13

215. Chlorocytus sp. ind. 14

216. Chlorocytus sp. ind. 15

217. Chlorocytus sp. ind. 16

218. Chlorocytus sp. ind. 17

219. Chlorocytus sp. ind. 18

220. Chlorocytus sp. ind. 19

221. Chlorocytus sp. ind. 20

Eumacepolus Graham, 1957

222. Eumacepolus obscurior Graham, 1961

223. Eumacepolus pulcher Graham, 1961 (*)

Mesopolobus Westwood, 1833 
224. Mesopolobus aequus (Walker, 1834) (*)

225. Mesopolobus amaenus (Walker, 1834)

226. Mesopolobus sp. nr. amaenus

227. Mesopolobus aspilus (Walker, 1835)

228. Mesopolobus diffinis (Walker, 1834)

229. Mesopolobus dubius (Walker, 1834)

230. Mesopolobus fasciiventris Westwood, 1833

231. Mesopolobus fuscipes (Walker, 1834) (*)

232. Mesopolobus graminum (Hard, 1950) (*)

233. Mesopolobus incultus (Walker, 1834) (*)

234. Mesopolobus juniperinus Rosen, 1958 (*)

235. Mesopolobus laticornis (Walker, 1834) (*)

236. Mesopolobus lichtensteini (Mayr, 1903)

237. Mesopolobus longicollis Graham, $1969(*)$

238. Mesopolobus maculicornis (Girault, 1863) (*)

239. Mesopolobus maculipennis (Mercet, 1923)

240. Mesopolobus mediterraneus (Mayr, 1903)

241. Mesopolobus meridionalis Garrido y Nieves-Aldrey, 1996 (*)

242. Mesopolobus morys (Walker, 1848) (*)

243. Mesopolobus nobilis (Walker, 1834) (*)

244. Mesopolobus prasinus (Walker, 1834) (*)

245. Mesopolobus sericeus (Forster, 1770)

246. Mesopolobus subfumatus (Ratzeburg, 1852) (*)

247. Mesopolobus szelenyii Boucek, 1974

248. Mesopolobus tarsatus (Nees, 1834)

249. Mesopolobus tibialis (Westwood, 1833)

250. Mesopolobus typographi (Ruschka, 1924) (*)

251. Mesopolobus xanthocerus (Thomson, 1878)

252. Mesopolobus sp. ind. 1

253. Mesopolobus sp. ind. 2

Meraporus Walker, 1834

254. Meraporus graminicola Walker, 1834

Lampoterma Graham, 1956 (*)

255. Lampoterma bianellatum Graham, 1969 (*)

256. Lampoterma sp. $n$ r. bianellatum

257. Lampoterma viride (Thomson, 1875) (*)

258. Lampoterma sp. $n r$. viride

Stinoplus Thomson, 1878

259. Stinoplus etearchus (Walker, 1848) (*)

260. Stinoplus sp. nr. etearchus

261. Stinoplus lapsanae Graham, 1969

Pseudocatolaccus Masi, 1908 (*)

262. Pseudocatolaccus nitescens (Walker, 1834) (*)

Rohatina Boucek, 1954

263. Rohatina monstrosa Boucek, 1954

Peridesmia Förster, 1856

264. Peridesmia discus (Walker, 1835)

Trichomalus Thomson, 1878

265. Trichomalus alonsoi Nieves Aldrey \& Garrido, 1994 (*)

266. Trichomalus sp. nr acuminatus

267. Trichomalus apertus (Walker, 1835)

268. Trichomalus bracteatus (Walker, 1835)

269. Trichomalus campestris (Walker, 1834)

270. Trichomalus conifer (Walker, 1836) (*)

271. Trichomalus conifer /gynetelus

272. Trichomalus sp. nr. conifer

273. Trichomalus coryphe (Walker, 1839) (*)

274. Trichomalus elongatus Delucchi \& Graham, 1956 (*)

275. Trichomalus flagellaris Graham, 1969

276. Trichomalus fulvipes (Walker, 1836)

277. Trichomalus gracilicornis (Zettersted, 1838)

278. Trichomalus gynetelus (Walker, 1835) (*)

279. Trichomalus helvipes (Walker, 1834)

280. Trichomalus sp. nr. helvipes 1

281. Trichomalus sp. $n$ r. helvipes 2

282. Trichomalus lepidus (Förster, 1841) (*)

283. Trichomalus lucidus (Walker, 1835) (*)

284. Trichomalus nanus (Walker, 1836) (*)

285. Trichomalus perfectus (Walker, 1835) (*)
286. Trichomalus pexatus (Walker, 1835)

287. Trichomalus posticus (Walker, 1834) (*)

288. Trichomalus robustus (Walker, 1835) (*)

289. Trichomalus rufinus (Walker, 1835) (*)

290. Trichomalus rugosus Delucchi \& Graham, 1956 (*)

291. Trichomalus sp. nr. rugosus

292. Trichomalus tenellus (Walker, 1834) (*)

293. Trichomalus sp. nr. tenellus

294. Trichomalus sp. ind. 1

295. Trichomalus sp. ind. 2

296. Trichomalus sp. ind. 3

297. Trichomalus sp. ind. 4

298. Trichomalus sp. ind. 5

299. Trichomalus sp. ind. 6

300. Trichomalus sp. ind. 7

301. Trichomalus sp. ind. 8

302. Trichomalus sp. ind. 9

303. Trichomalus sp. ind. 10

Trichomalopsis Crawford, 1913

304. Trichomalopsis acuminatus (Graham, 1969) (*)

305. Trichomalopsis albopilosus (Graham, 1969) (*)

306. Trichomalopsis caricicola (Graham, 1969) (*)

307. Trichomalopsis exigua (Walker, 1834)

308. Trichomalopsis hemiptera (Walker, 1836) (*)

309. Trichomalopsis littoralis (Graham, 1969) (*)

310. Trichomalopsis sp. $n$ r. pompicola

Tomicobia Ashmead, 1899 (*)

311. Tomicobia seitneri (Ruschka, 1924) (*)

Arthrolytus Thomson, 1878

312. Arthrolytus discoideus (Nees, 1834) (*)

313. Arthrolytus maculipennis (Walker, 1836) (*)

314. Arthrolytus nanus Askew \& Nieves Aldrey, 1982

Cyclogastrella Buboswki, 1938

315. Cyclogastrella clypealis Boucek, 1965

316. Cyclogastrella simplex (Walker, 1834) (*)

Dibrachys Förster, 1856

317. Dibrachys cavus (Walker, 1835)

318. Dibrachys fuscicornis (Walker, 1836) (*)

319. Dibrachys hians Boucek, 1965 (*)

320. Dibrachys lignicola Graham, 1969 (*)

Dibrachoides Kurdjumov, 1913 (*)

321. Dibrachoides dynastes (Förster, 1841) (*)

Kranophorus Graham, 1956

322. Kranophorus extentus (Walker, 1835)

Conomorium Masi, 1924

323. Conomorium amplum (Walker, 1835)

324. Conomorium pithyocampae Graham, 1992

Muscidifurax Girault \& Sanders, 1910

325. Muscidifurax raptor Girault \& Sanders, 1910

Hemitrichus Thomson, 1878

326. Hemitrichus oxygaster Boucek, 1965

327. Hemitrichus senilicus (Nees, 1834) (*)

Metastenus Walker, 1834 (*)

328. Metastenus concinnus Walker, $1834(*)$

Pachyneuron Walker, 1833

329. Pachyneuron aphidis (Bouché, 1834)

330. Pachyneuron formosum Walker, 1833

331. Pachyneuron grande Thomson, 1878 (*)

332. Pachyneuron muscarum (Linnaeus, 1758)

333. Pachyneuron solitarium (Hartig, 1838)

334. Pachyneuron sp. ind.

Euneura Walker, 1844 (*)

335. Euneura sopolis (Walker, 1840) (*)

Sedma Boucek, 1991 (*)

336. Sedma dispar Boucek, 1991 (*)

337. Género sp. ind. 1

338. Género sp. ind. 2

339. Género sp. ind. 3

340. Género sp. ind. 4 
341. Género sp ind 5

342. Género sp. ind. 6

343. Género sp. ind. 7

344. Género sp. ind. 8

345. Género sp. ind. 9

346. Género sp. ind. 10

347. Género sp. ind. 11

348. Género sp. ind. 12

\section{COLOTRECHNINAE}

Colotrechnus Thomson, 1878

349. Colotrechnus subcoeruleus Thomson, $1878(*)$

350. Colotrechnus viridis (Masi, 1921) (*)

\section{Catálogo de Pteromalidae de la Comunidad de Madrid}

En la confección del catálogo se han tenido en cuenta únicamente las especies identificadas plenamente en la lista anterior. El ordenamiento sistemático seguido es el reciente de Boucek (1988).

Como paso previo se elaboró un catálogo de los Pteromalidae de la Península Ibérica (Garrido y Nieves-Aldrey, 1990). En dicho catálogo se citan solamente 13 especies y 12 géneros de pteromálidos de la Comunidad de Madrid. Por contraste, en el presente catálogo de la Comunidad recogemos, una lista de 268 especies, en un total de 92 géneros, lo que supone un incremento del 2076\% y $766 \%$ respectivamente sobre las cifras previamente conocidas.

En total se han identificado 268 especies. Aproximadamente un $78 \%$ de las especies catalogadas pertenecen a la subfamilia Pteromalinae; siendo la representación del resto de las subfamilias muy inferior. Así, las especies pertenecientes a la subfamilia Cleonyminae constituyen un 1,8\% del total, las pertenecientes a la subfamilia Ceinae un $1,1 \%$, un $0,73 \%$ las especies incluidas en la subfamilia Spalangiinae, un 0,37\% las especies de las subfamilias Diparinae y Neodiparinae, un 2,9\% las especies incluidas en la subfamilia Eunotinae, un $0,73 \%$ las de la subfamilia Asaphinae, y ligeramente superior sería el número de especies incluidas en las subfamilias Ormocerinae y Pireninae que constituyen un $5,5 \%, 2,5 \%$ y $6 \%$ respectivamente, del total de las especies determinadas.

Para cada especie, brevemente se comentan los datos de distribución, citas en la Península Ibérica y en la Comunidad de Madrid y datos conocidos de biología, ya sean propios o recabados de la bibliografía. La relación exhaustiva de material estudiado de cada especie se puede encontrar en el apéndice final.

El catálogo íberobalear de los Pteromalidae de Garrido y Nieves-Aldrey (1990), incluía 94 especies. Sucesivas adiciones al catálogo (Heydon, 1989a; Falcó et al., 1990; Gijswijt, 1990, 1993; Garrido y Nieves-Aldrey, 1992a, 1992b; Verdú, 1992; Askew, 1994; Graham, 1994; Pujade, 1994a, 1994b; Askew y Blasco-Zumeta, 1997) incrementaron dicha cifra hasta las 169 especies. En la presente memoria se catalogan 92 géneros y 268 especies de los cuales un total de 155 especies y 31 géneros constituyen la primera cita para la Península Ibérica. Con estas nuevas citas, el catálogo íberobalear de los Pteromalidae, quedaría constituido por 324 especies representando, por tanto, las especies correspondientes a la Comunidad de Madrid un $82,7 \%$ respecto al total de las especies conocidas en la Península. Las nuevas citas para la Península Ibérica figuran con el símbolo (*) en el listado de especies precedente.

Teniendo en cuenta los datos disponibles de su distribución, la gran mayoría de las especies del presente catálogo (89\%) son de distribución paleártica; de ellas, 11 especies son elementos de la subregión mediterránea y 4 son conocidas tan sólo en la Península Ibérica; un 6\% se corresponde con especies holárticas y el 5\% restante estaría constituido por especies cosmopolitas.

Si consideramos su biología, podemos asignar las distintas especies encontradas a un grupo trófico determinado, teniendo en cuenta la clasificación de los insectos parasitoides en gremios, propuesta por Garbarczyk y Sawoniewicz (1984), así, si exceptuamos las especies de biología desconocida que por tanto no podemos asignar a ningún grupo trófico y que constituyen el $40 \%$ del total, el porcentaje mayoritario lo constituyen las especies parasitoides de insectos gallícolas, minadores $\mathrm{y}$ enrolladores de hojas con un 52\% seguidas de las especies parasitoides de fitófagos externos y por las especies parasitoides de parásitos de fitófagos (hiperparásitas). En menor proporción aparecen las especies parasitoides de xilófagos, de frugívoros y seminívoros, de fitosaprófagos, de fitófagos taladradores o picadores, especies predadoras de huevos, especies parasitoides de rizófagos, parasitoides de predadores, y especies parasitoides de ectoparasitoides de vertebrados.

Este catálogo obviamente no puede considerarse definitivo dada, por un lado la enorme diversidad de la familia estudiada y por otro, la gran amplitud territorial y heterogeneidad ambiental de la Comunidad de Madrid, teniendo en cuenta que, además, los muestreos no han pretendido ser exhaustivos.

Hay que resaltar el alto número de especies (82) que no han podido ser plenamente identificadas $\mathrm{y}$ 
no se incluyen, por tanto, en el presente catálogo, pero que, de hacerlo, incrementarían el listado muy significativamente. Con los datos de la presente memoria y otros datos disponibles, podríamos estimar la cifra real del catálogo de pteromálidos de la CAM en al menos 450 especies.

\section{CLEONYMINAE CLEONYMINI}

Cleonymus Latreille, 1809

Diversidad y distribución.- Cuenta con cuatro especies paleárticas, de las que tres están distribuidas por toda Europa (Boucek y Rasplus, 1991).

Referencias taxonómicas._- Boucek (1972); Hedqvist (1983).

Biología.- Probablemente todas las especies del género son parásitas de coleópteros xilófagos (Cerambycidae, Scolytidae, etc.) (Boucek y Rasplus, 1991).

\section{Cleonymus laticornis Walker, 1837}

Distribución.- Especie ampliamente distribuida en Europa (Graham, 1969). En España citada sólo de Mallorca (Askew, 1973).

Citas en la Comunidad de Madrid.- Se encontró en la colección Mercet un ejemplar procedente de Madrid; se colectaron además varios ejemplares en El Ventorrillo con trampa Malaise, principalmente durante primavera y verano.

Biología.- Parásita de coleópteros xilófagos, se conoce como hospedador Molorchus minor L. (Col., Cerambycidae), además, se pudo observar algunas hembras buscando sus hospedadores sobre troncos y ramas de árboles viejos, especialmente Salix L. (Salicaceae) y Corylus L. (Corylaceae) atacados por coleópteros (Graham, 1969).

\section{Cleonymus obscurus Walker, 1837}

Distribución.- Especie paleártica, conocida de Inglaterra, Francia, Suecia y Checoslovaquia (Graham, 1969). En la Península Ibérica se encontró en Cantabria (Garrido y Nieves-Aldrey, 1992b).

Citas en la Comunidad de Madrid.- Según nuestros datos, esta especie sería menos abundante que la anterior, tan sólo se obtuvo un ejemplar en El Pardo mediante el empleo de trampas Malaise, mientras que en El Ventorrillo los escasos ejemplares se recogieron, además, mediante barrido sobre la vegetación, al igual que en el caso anterior, a lo largo de la primavera y verano.

Biología.- Parásita de coleópteros xilófagos; se han citado como hospedadores Scolytus scolytus F. e Hylesinus toranio Ber. (Col., Scolytidae) (Graham, 1969).

Notanisus Walker, 1837

Diversidad y distribución.—Género principalmente distribuido en la subregión mediterránea (Boucek, 1988), en Europa se han descrito cuatro especies (Boucek y Rasplus, 1991).

Referencias taxonómicas.- Graham (1969).

Biología.- Tres de las especies europeas, son parásitas de Tetramesa Walker (Hym., Eurytomidae) sobre tallos de herbáceas, la cuarta especie es parásita de pequeños coleópteros xilófagos en ramas de árboles. (Boucek y Rasplus, 1991).

\section{Notanisus versicolor Walker, 1837}

Distribución.-Especie de distribución mediterránea, se conoce de Argelia, Checoslovaquia, España, Francia, Georgia, Italia y Yugoslavia (Graham, 1969). Citas en la Comunidad de Madrid.- Se recogieron algunos ejemplares en El Pardo y El Ventorillo con trampa Malaise en los meses de agosto y septiembre. Biología. - Ha sido encontrada en agallas de al menos dos especies de Tetramesa (Hym., Eurytomidae) (Graham, 1969).

\section{Notanisus sexramosus (Erdös, 1946)}

Distribución.- Especie paleártica. Se conoce en Austria, Bulgaria, Checoslovaquia, Francia, Hungría y antigua URSS (Graham, 1969). Es la primera cita en la Península Ibérica.

Citas en la Comunidad de Madrid.- Al parecer se trata de una especie poco frecuente ya que sólo se colectaron tres ejemplares en El Ventorrillo con trampa Malaise, durante el mes de julio.

Biología.- Parásita de especies de Tetramesa (Hym., Eurytomidae) sobre tallos de gramíneas; se ha citado como hospedador Tetramesa calamagrostidis (Hed.) sobre tallos de Calamagrostis Adanson (Graminaceae) (Graham, 1969).

\section{HEYDENIINI \\ Heydenia Förster, 1856}

Diversidad y distribución.- Género cosmopolita, aunque no se ha encontrado en la región neotropi- 
cal. Se conocen al menos cinco especies, pero sólo una de ellas es de distribución europea (Boucek, 1988). El género se cita por primera vez en la Península Ibérica.

Referencias taxonómicas.- Graham (1969);

Boucek y Rasplus (1991).

Biología.- Los hospedadores incluyen varios coleópteros escolítidos (Scolytidae). Los adultos de Heydenia se pueden encontrar sobre los troncos y ramas de árboles secos atacados por dichos coleópteros (Boucek, 1988).

\section{Heydenia pretiosa (Förster, 1856)}

Distribución.- Ampliamente distribuida en Europa, se conoce en Alemania, Checoslovaquia, Finlandia, Francia, Hungría, Italia, Suecia y antigua URSS (Graham, 1969). Es la primera cita para la Península Ibérica.

Citas en la Comunidad de Madrid.- - Tan sólo se encontró en El Ventorrillo, donde se colectó un ejemplar con trampa Malaise en junio.

Biología.- Parásita de varios Ipidae y Scolytidae (Coleoptera), se conocen como hospedadores Myelophilus minor Htg, Ips acuminatus Gyll., Ips typographus L., Scolytus ratzeburgi Jans., Phloeotribus scarabaeoides Bern, Lepperesinus fraxini (Pz.) e Hylesinus toranio (Bern.) (Graham, 1969).

\section{CEINAE}

Cea Walker, 1837

Diversidad y distribución.—Género monoespecífico, ampliamente distribuido desde Suecia hasta Argelia (Boucek y Rasplus, 1991).

Referencias taxonómicas.— Graham (1969); Boucek y Rasplus (1991).

Biología.- Se han recogido ejemplares parasitando Phytomiza pauliloewi Hend. (Dipt. Agromyziidae) sobre umbelíferas (Boucek y Rasplus, 1991).

\section{Cea pulicaris Walker, 1837}

Distribución.- En la Península Ibérica se encontró en Cantabria (Garrido y Nieves-Aldrey, 1992b). Citas en la Comunidad de Madrid.- Especie poco abundante; tan sólo se colectaron algunos ejemplares en El Pardo durante el mes de marzo con trampa Malaise y en El Ventorrillo utilizando, además, bandejas amarillas durante los meses de junio y julio.
Spalangiopelta Masi, 1922

Diversidad y distribución.- Cuenta con cuatro especies, se trata de un género raro pero ampliamente distribuido en Europa (Boucek y Rasplus, 1991).

Referencias taxonómicas.- Graham (1969); Darling (1991).

Biología.- Sólo se conoce como hospedador: Scaptomyza flaveola Meigen (Dipt., Drosophilidae) sobre Cakile maritima (Cruciferae) (Boucek, y Rasplus, 1991).

\section{Spalangiopelta dudichi Erdös, 1955}

Distribución.- Conocida en Hungría, República de Moldavia y Suecia (Darling, 1995).

Citas en la Comunidad de Madrid.- Los dos únicos ejemplares colectados con trampa Malaise en El Ventorrillo fueron descritos por Darling (1995) como los machos de esta especie, hasta ahora desconocidos.

Biología.-Desconocida.

\section{Spalangiopelta procera Graham, 1966}

Distribución.- Especie conocida en Inglaterra, Irlanda y Suecia (Graham, 1969); constituye ésta, la primera cita para Península Ibérica.

Citas en la Comunidad de Madrid.- Los dos únicos ejemplares encontrados fueron colectados con trampa Malaise en El Ventorrillo.

Biología.- Se desconoce el hospedador.

\section{SPALANGIINAE \\ Spalangia Latreille, 1805}

Diversidad y distribución.- Género de distribución cosmopolita, comprende al menos 50 especies (Boucek, 1988). En Europa, el género cuenta con 12 especies (Boucek y Rasplus, 1991). Es la primera cita para la Península Ibérica.

Referencias taxonómicas.— Boucek (1963); Graham (1969).

Biología.- Se trata de un género parásito primario de Diptera, algunas especies atacan moscas sinantrópicas e hipobóscidos (Hippoboscidae) por lo que han sido utilizadas en algunas ocasiones en el control biológico de tales dípteros. Entre los hospedadores se incluyen Stomoxys calcitrans, Musca domestica, Sarcophaga, Pycnosoma y Chrysomyia sp. (Boucek, 1988). 


\section{Spalangia fuscipes Nees, 1834}

Distribución.- Ampliamente distribuida en Europa; Asia menor y norte de África (Graham, 1969). Se cita por primera vez para la Península Ibérica.

Citas en la Comunidad de Madrid.- El único ejemplar encontrado fue recogido en El Ventorrillo con trampa Malaise en julio.

Biología.- El único hospedador conocido es Oscinella frit (L.) (Dipt., Chloropidae) (Boucek, 1963; Graham, 1969).

\section{Spalangia subpunctata Förster, 1850}

Distribución.- Ampliamente distribuida en Europa, Asia Central y norte de África (Graham, 1969). Se cita por primera vez para la Península Ibérica.

Citas en la Comunidad de Madrid.- Se colectó mediante red de barrido en Navacerrada y El Piul, durante los meses de marzo y junio respectivamente y utilizando bandejas amarillas en El Ventorrillo en el mes de junio; aunque en todos los casos se capturó un pequeño número de ejemplares.

Biología.- Boucek (1963) señala como hospedadores Syritta pipiens L. (Dipt., Syrphidae) en la región caucásica y Physiphora demandata F. (Dipt., Ulidiidae) en Uzbekistán; añade, además, que la mayor parte de los ejemplares de Checoslovaquia, fueron encontrados asociados con excrementos de ganado en pastizales (Graham, 1969).

\section{DIPARINAE DIPARINI}

Dipara Walker, 1883

Diversidad y distribución.- Se encuentra distribuído en América del Norte (tres especies), sur de Asia (al menos tres especies), Australia (cuatro especies). En Europa sólo se conoce una especie con una amplia distribución por todo el continente (Boucek, 1988).

Referencias taxonómicas.— Graham (1969);

Boucek y Rasplus (1991)

Biología.-Desconocida.

\section{Dipara petiolata Walker, 1833}

Distribución.- Ampliamente distribuida por toda Europa, también se conoce de América del Norte. En la Península Ibérica, ha sido citada en Cantabria
(Garrido y Nieves-Aldrey, 1992b); España (Graham, 1969; Hedqvist, 1969).

Citas en la Comunidad de Madrid.- Se trata de una especie citada con anterioridad en la Pedriza de Manzanares (Mercet, 1927; Ceballos, 1941-43). Nosotros obtuvimos numerosos ejemplares en El Ventorrillo utilizando diversos métodos de captura: Trampa Malaise, bandejas amarillas y barrido; siendo una especie particularmente abundante durante los meses de verano.

Biología.- Desconocida, pero probablemente es parásita de algunos coleópteros curculiónidos (Col., Curculionidae) sobre raíces de plantas (Boucek y Rasplus, 1991).

\section{NEODIPARINAE \\ Neodipara Erdös, 1995}

Diversidad y distribución.- Cuenta con tres especies aparentemente raras (Boucek y Rasplus, 1991). Referencias taxonómicas. - Hedqvist (1971).

Biología.- Se desconocen sus hospedadores; se encuentran sobre todo en zonas pantanosas aunque Neodipara hispanica Hedqvist, 1971 se ha obtenido en playas arenosas (Boucek y Rasplus, 1991).

\section{Neodipara hispanica Hedqvist, 1971}

Distribución.- Únicamente conocida de la Península Ibérica, ha sido citada en Málaga (Hedqvist, 1971); España (Askew, 1975a).

Citas en la Comunidad de Madrid.- Se conoce un único ejemplar de la colección Mercet, colectado en El Pardo.

Biología.-Desconocida.

\section{EUNOTINAE \\ EUNOTINI}

Eunotus Walker, 1834

Diversidad y distribución.- Género holártico, con al menos 10 especies (Boucek y Rasplus, 1991).

Referencias taxonómicas.- Boucek (1972) (Especies europeas).

Biología.- Se desarrolla como predador de huevos de numerosas especies de cócidos (Hom., Coccoidea) sobre herbáceas (Boucek y Rasplus, 1991).

Eunotus acutus Kurdjumov, 1912

Distribución.- Checoslovaquia, Polonia, Ucrania (Boucek, 1972). Se cita por primera vez para la Península Ibérica. 
Citas en la Comunidad de Madrid.- Encontrada únicamente en El Ventorrillo, donde los ejemplares se capturaron con trampa Malaise.

Biología.- Parásito de cócidos (Hom., Coccoidea), se han encontrado como hospedadores Acanthococcus greeni (Newstead), Rhizococcus agropry Borchsenius y Greenisca placida (Green). Está asociado a herbáceas principalmente a especies de Agropyrum (Graminaceae) en hábitats xerotérmicos (Boucek, 1972).

\section{Eunotus areolatus (Ratzeburg, 1848)}

Distribución.- Se conoce en Alemania, Checoslovaquia, Dinamarca, Hungría y Suecia (Boucek, 1972). Es la primera cita en la Península Ibérica.

Citas en la Comunidad de Madrid.- Únicamente se colectaron ejemplares en El Ventorrillo, donde a lo largo de todo un ciclo anual sólo se recogieron tres ejemplares; todos ellos con trampa Malaise y durante el mes de junio.

Biología.- La especie parece estar asociada con cócidos (Hom., Coccoidea) sobre árboles o matorrales (Boucek, 1972).

Eunotus cretaceus Walker, 1834

Distribución.- Ampliamente distribuida en Europa, desde Inglaterra y Suecia hasta el sur de Italia, Moldavia y Georgia (Boucek, 1972). Citada por primera vez para la Península Ibérica.

Citas en la Comunidad de Madrid.- Se ha colectado en El Pardo; Vaciamadrid y El Ventorrillo. Tres ejemplares de las dos primeras localidades proceden de la colección de Mercet, mientras que los ejemplares de El Ventorrillo fueron capturados con trampas Malaise y bandejas amarillas a lo largo del mes de julio.

Biología.- La especie se desarrolla como predadora de huevos de los siguientes cócidos (Hom., Coccoidea) sobre herbáceas: Eriopeltis festucae (Fonscolombe), Eriopeltis agropry Borchsenius, Eriopeltis? strelkovi Borchsenius, Eriopeltis sp. y Scythia festuceti (Sulc) (Boucek, 1972).

\section{Eunotus nigriclavis (Förster, 1856)}

Distribución.- En Europa se conoce de Alemania, Checoslovaquia y Yugoslavia (Boucek, 1972). Se cita por primera vez para la Península Ibérica.

Citas en la Comunidad de Madrid.- Tan sólo se encontró en El Pardo; un total de seis ejemplares colectados con trampa Malaise durante los meses de agosto y septiembre.

Biología.- No se conoce el hospedador (Boucek, 1972).

\section{Eunotus obscurus Masi, 1931}

Distribución.- Amplia distribución Europea, se conoce de Alemania, Checoslovaquia, Dinamarca, Francia, Italia, Moldavia y Uzbekistán (Boucek, 1972). En la Península Ibérica se ha citado en: España (Graham, 1969; Boucek, 1972).

Citas en la Comunidad de Madrid.- Esta especie ya era conocida en la Comunidad; se había encontrado en Madrid (Masi, 1931). Adicionalmente se obtuvieron dos ejemplares con trampa Malaise en El Ventorrillo durante el mes de junio.

Biología.- Ataca a cócidos (Hom., Coccoidea) sobre matorrales y árboles, principalmente Pulvinaria vitis (L.). También se ha citado como hospedador Parthenolecanium persicae (F.) sobre Robinia pseudoacacia L. (Fabaceae) (Boucek, 1972).

\section{Scutellista Motschulsky, 1859}

Diversidad y distribución.- Género distribuido principalmente en países cálidos de la subregión mediterránea (cuatro o cinco especies), sur de Asia (al menos cinco especies) y África (dos especies). Una especie $(S$. coerulea) está muy distribuida en países tropicales, subtropicales y zonas templadas, incluida Australia (Boucek, 1988).

Referencias taxonómicas. - Graham (1969).

Biología.- Las larvas de este género se alimentan de huevos y larvas jóvenes de cócidos y pseudocócidos (Hom., Coccoidea) bajo el cuerpo de las hembras (Boucek y Rasplus, 1991).

Scutellista caerulea (Fonscolombe, 1832)

Distribución.- Especie cosmopolita, se conoce de norte y sur de África, Australia, Ceilán, China, Francia, Grecia, Hawai, Italia, Japón, Palestina, Perú, Estados Unidos (Graham, 1969). En la Península Ibérica ha sido citada de ESPAÑA en: Alicante (Mercet, 1910), Castellón (Limón de la Oliva y Blasco Pascual, 1973), Córdoba (Fernández et al., 1979), Granada (Morillo, 1974; Briales y Campos, 1985), Logroño (Alfaro Moreno, 1965), Sevilla (Morillo, 1974), Valencia (Morillo, 1974; Panis et al., 1977), Zaragoza (Mercet, 1910, 1916; Dusmet, 1944; Alfaro Moreno, 1956), 
España (Masi, 1931; Mercet, 1932; Yasumatsu, 1956; Panis, 1977) y de PORTUGAL en: Cadafais, Carregado, Elvas, (De Freitas, 1972), Extremadura (De Freitas, 1977), Santarem (De Freitas, 1972). Citas en la Comunidad de Madrid.- Recogida con anterioridad por Smith y Compere (1928) en Madrid. Ampliamos la cita con un ejemplar procedente de Cercedilla perteneciente a la colección de Mercet.

Biología.- Parásita de varios géneros y especies de Coccoidea (Homoptera). Ha sido citada como parásito de Saissetia oleae (Bern.) (Hom., Coccoidea) sobre cítricos (Graham, 1969).

\section{Scutellista nigra Mercet, 1910}

Distribución.- España y Argelia (Graham, 1969). En la Península Ibérica, ha sido citada en: Castellón, Valencia (Panis et al., 1977), Zaragoza (Mercet,1910). España (Masi, 1931; Mercet, 1932; Ceballos, 1941-43; Graham, 1969; Morillo, 1974). Citas en la Comunidad de Madrid. - Se ha estudiado un ejemplar en la colección Mercet procedente de Chamartín; además, se colectaron algunos ejemplares en El Ventorrillo con trampa Malaise a final de verano.

Biología.- Colectada parasitando a Lecanium oleae ( Hom., Coccoidea) sobre ramas de olivo, en Zaragoza (Mercet, 1910). Masi (1931), señala que en España, se ha obtenido de Lecanodiaspis sardoa Targ. (Hom., Coccoidea) sobre Cistus ladanifer L. (Cistaceae).

\section{Scutellista obscura (Förster, 1878)}

Distribución.- Ampliamente distribuida en Europa, conocida en Alemania, Checoslovaquia, Francia, Italia y antigua URSS (Graham, 1969). Se cita por primera vez para la Península Ibérica.

Citas en la Comunidad de Madrid.- Se identificó en la colección Mercet, un ejemplar de esta especie procedente de Madrid. Adicionalmente se colectó material de la especie en El Pardo y El Ventorrillo, mediante trampas Malaise, durante los meses de verano.

Biología.- Masi (1931) recoge como hospedadores de esta especie, a ciertos cócidos (Hom., Coccoidea) no identificados, sobre Pistacia (Anacardiaceae), pero sugiere que se trata de una especie polífaga. Kryger (1943), obtuvo en Dinamarca, un macho y una hembra sobre Salix repens L. (Salicaeae) infestado por cócidos (Hom., Coccoidea) (Graham, 1969).

\section{ASAPHINAE}

Asaphes Walker, 1834.

Diversidad y distribución. - El género cuenta con dos especies de distribución cosmopolita (Boucek, 1988). Referencias taxonómicas.—Graham (1969).

Biología.- Hiperparásito de áfidos (Hom., Aphidoidea) a través de Aphidiinae (Hym., Braconidae (Boucek y Rasplus, 1991).

\section{Asaphes suspensus (Nees, 1834)}

Distribución.- Ampliamente distribuido en Europa, se conoce de Alemania, Europa Central y Suecia (Graham, 1969). Aparentemente es una especie menos común que la otra especie del género. En la Península Ibérica, ha sido citada en Portugal (De Goveia e Araujo, 1985).

Citas en la Comunidad de Madrid.- Se estudió un ejemplar de la colección Mercet procedente de Alcalá. Adicionalmente se colectaron numerosos ejemplares en El Ventorrillo con red de barrido y empleando trampas Malaise, siendo especialmente abundante a finales de primavera y durante el verano. Biología.- Se ha encontrado parasitando áfidos (Hom., Aphidoidea) sobre distintas especies vegetales (Graham, 1969).

\section{Asaphes vulgaris Walker, 1834}

Distribución.- Especie muy común ampliamente distribuida; en Europa aparece probablemente por todo el continente, también se ha citado de Islandia, Groenlandia, Canadá, Estados Unidos y Argentina (Graham, 1969). En la Península Ibérica se han recogido las siguientes citas en ESPAÑA: Mallorca (Askew, 1973), España (Mercet, 1932) y en PORTUGAL: (De Goveia e Araujo, 1985).

Citas en la Comunidad de Madrid.- Son muy numerosas las localidades madrileñas en las que se ha colectado la especie; en algunos casos, los ejemplares fueron capturados mediante barrido sobre la vegetación, otros proceden de la colección de Mercet y la mayoría de los ejemplares capturados en El Ventorrillo y El Pardo, lo fueron mediante el empleo de trampas Malaise y bandejas amarillas. Su fenología parece ser más amplia que en la especie anterior, ya que además de primavera y verano, muchos de los ejemplares se capturaron durante los primeros meses del otoño.

Biología.- Hiperparásito de áfidos (Hom., Aphidoidea) a través de varios Aphidiinae (Hym., Braconidae) (Graham, 1969). 


\section{MISCOGASTERINAE \\ Halticoptera Spinola, 1811}

Diversidad y distribución.- Género cosmopolita con aproximadamente 20 especies en el paleártico occidental y ampliamente distribuido en Europa (Boucek y Rasplus, 1991).

Referencias taxonómicas.- Askew (1972);

Hedqvist (1975).

Biología.- Parásito de dípteros minadores (Agromyzidae, Tephritidae, Drosophilidae) asociados con plantas herbáceas o helechos (Boucek y Rasplus, 1991).

\section{Halticoptera aenea (Walker, 1833)}

Distribución.- Ampliamente distribuida en Europa. En la Península Ibérica ha sido citada de Mallorca (Askew, 1973).

Citas en la Comunidad de Madrid.- Se trata de una especie bastante común encontrada en Fuentidueña de Tajo, Loeches, Monte el Robledal, El Pardo y El Ventorrillo. Los ejemplares procedentes de El Ventorrillo se capturaron con trampa Malaise y bandejas amarillas; todos los del Pardo, excepto uno procedente de la colección de Mercet, se obtuvieron igualmente mediante el empleo de trampa Malaise, el resto de los ejemplares fueron capturados mediante barrido sobre la vegetación. En todas las localidades, los ejemplares se recogieron principalmente durante la primavera, sobre todo durante el mes de mayo. A tenor del tipo de comunidad vegetal donde se realizaron la mayor parte de las capturas, esta especie parece mostrar preferencia por los encinares manchegos.

Biología.- Se conoce como parásito de Agromyzidae (Diptera) sobre Laburnum (Fabaceae) (Askew, 1968; 1972). Graham (1969) cita como hospedador Phytomyza plantaginis R.D. (Dipt., Agromyzidae) sobre Plantago (Plantaginae) y Scaptomyza graminum (Fallén) (Dipt., Agromyzidae) sobre Spergularia (Cariopyllaceae) (Askew, 1972).

Halticoptera circulus (Walker, 1833)

Distribución.- Ampliamente distribuida en Europa. Se conoce también en Canadá y Estados Unidos (Graham, 1969). Constituye la primera cita para la Península Ibérica.

Citas en la Comunidad de Madrid.- Es una especie más abundante que la anterior. Se ha colectado en Alameda del Valle, Carretera Villamanrique a
Colmenar, Oteruelo del Valle, El Pardo, El Paular, El Piul, El Porcal, Rivas-Vaciamadrid y El Ventorrillo. Como en el caso anterior la mayoría de los ejemplares de El Ventorrillo y el Pardo se obtuvieron mediante el empleo de trampas Malaise y bandejas amarillas y en el resto de las localidades mediante barrido. Los ejemplares se capturaron preferentemente durante la primavera y el verano siendo una especie particularmente abundante en melojares y en matorrales nitrófilos.

Biología.- Ha sido obtenida en Europa y América como un parásito de Oscinella frit (L.) (Dipt., Chloropidae), también se ha citado en Inglaterra parasitando especies de Phytomyza (Dipt., Agromyzidae) sobre Mentha (Lamiaceae) y Sonchus (Asteraceae) (Graham, 1969; Askew, 1972).

\section{Rhicnocoelia Graham, 1956}

Diversidad y distribución.- El género cuenta con cinco especies, cuatro de ellas europeas con una amplia distribución; la quinta ha sido citada en Australia (Boucek, 1988; Boucek y Rasplus, 1991). Referencias taxonómicas.- Graham (1969); Heydon (1989b) (Especies neárticas).

Biología.- No se conoce, pero probablemente es parásito de dípteros (Boucek, 1988; Boucek y Rasplus, 1991).

\section{Rhicnocoelia constans (Walker, 1836)}

Distribución. - Europa occidental. Se conoce de Inglaterra, Irlanda, Suecia. En la Península Ibérica, ha sido citada en la provincia de Castellón (Verdú 1991).

Citas en la Comunidad de Madrid.- - Su presencia consta por un ejemplar de El Ventorrillo.

Biología.- Desconocida, aunque se ha obtenido de minadores indeterminados sobre alfalfa (Verdú, 1991).

\section{Rhicnocoelia impar (Walker, 1836)}

Distribución.- Se trata de una especie menos frecuente que la anterior, conocida en Inglaterra e Irlanda (Graham, 1969). Se cita por primera vez en la Península Ibérica.

Citas en la comunidad de Madrid.- - A pesar de que se trata de una especie aparentemente poco frecuente, se han capturado ejemplares, mediante red de barrido, en Alameda del Valle, Arganda, Fuentiueña de Tajo, Monte el Robledal y Valle de 
Bustarviejo, y empleando trampas Malaise en El Ventorrillo, siendo su aparición más frecuente en la comunidad fitoclimática del encinar manchego. Biología.- Desconocida.

\section{Seladerma}

Diversidad y distribución.- Aproximadamente existen treinta especies en Europa donde se encuentra ampliamente distribuido (Boucek y Rasplus, 1991). Se cita por primera vez en la Península Ibérica. Referencias taxonómicas._- Graham (1969). Biología.- La mayor parte de las especies del género, son parásitas de Agromyzidae (Diptera) pero algunas especies atacan Scatophagidae (Diptera) o Stigmellidae (Lepidoptera).

\section{Seladerma diffine (Walker, 1833)}

Distribución.- Especie muy común (Graham, 1969). Se cita por primera vez para la Península Ibérica.

Citas en la comunidad de Madrid.- Todos los ejemplares fueron capturados con trampa Malaise en El Ventorrillo a principios de otoño.

Biología.- Se ha obtenido de Phytomyza conyzae Hendel (Dipt. Agromyzidae) sobre Inula conyza DC. (Asteraceae) (Graham, 1969).

\section{Seladerma geniculatum (Zetterstedt, 1838)}

Distribución.- Ampliamente distribuida en Europa, se conocía en Alemania, Inglaterra, Irlanda, Islandia y Suecia (Graham, 1969). Es la primera vez que se cita en la Península Ibérica.

Citas en la Comunidad de Madrid.- Al igual que en el caso anterior, los ejemplares se capturaron con trampa Malaise en El Ventorrillo a principios de otoño.

Biología.- Se han colectado ejemplares procedentes de una pupa de Phytomyza veripes Macq. (Dipt., Agromyzidae) en semillas de Rhinanthus (Scrophulariaceae) (Graham, 1969).

\section{Seladerma laetum Walker, 1834}

Distribución.- Especie con una amplia distribución en Europa; citada en Alemania, Inglaterra, Irlanda, Moldavia y Suecia (Graham, 1969). Es la primera referencia en la Península Ibérica.

Citas en la Comunidad de Madrid.- Un único ejemplar procedente de El Pardo donde se capturó con trampa Malaise durante el mes de mayo.
Biología.- Se ha obtenido como parásito de Amaurosoma armillatum (Zett.) y Amaurosoma flavipes (Fln.) (Dipt., Scatophagidae) (Graham, 1969).

\section{Sphaeripalpus Förster, 1841}

Diversidad y distribución. - El género comprende seis especies con una amplia distribución europea (Boucek y Rasplus, 1991).

Referencias taxonómicas.- Graham (1969).

Biología.- Principalmente parásito de Agromyzidae (Diptera) (Boucek y Rasplus, 1991).

\section{Spheripalpus fuscipes (Walker, 1833)}

Distribución.- Ampliamente distribuida en Europa, citada en Inglaterra y Suecia (Graham, 1969). En la Península Ibérica, se conoce de Cantabria (Garrido y Nieves-Aldrey, 1992b).

Citas en la Comunidad de Madrid. - Se ha colectado únicamente mediante el empleo de trampas Malaise en El Pardo y en El Ventorrillo.

Biología.- Probablemente parásito de agromízidos (Dipt., Agromyzidae), se ha obtenido de Agromyza rufipes Mg. (Dipt., Agromyzidae) sobre Echium vulgare (L.) (Boraginaceae).

\section{Miscogaster Walker, 1833}

Diversidad y distribución.- Comprende cinco especies ampliamente distribuidas en Europa (Boucek y Rasplus, 1991).

Referencias taxonómicas.- Graham (1969).

Biología.- Parásito de Agromyzidae (Diptera) sobre plantas herbáceas (Boucek y Rasplus, 1991).

\section{Miscogaster hortensis Walker, 1833}

Distribución. - Especie ampliamente distribuida en Europa, se conoce en Inglaterra y Suecia (Graham, 1969). Primera cita para la Península Ibérica.

Citas en la Comunidad de Madrid.- Todos los ejemplares estudiados se colectaron mediante barrido de plantas del encinar manchego en Arganda, Carretera Estremera a Brea y Monte el Robledal, principalmente durante la primavera y principios de otoño.

Biología.- Se conoce como hospedador, Agromyza genistae Hendel (Graham, 1969).

\section{Miscogaster maculata Walker, 1833}

Distribución.- Especie de amplia distribución europea, citada de Inglaterra y Suecia (Graham, 
1969). En la Península Ibérica, se conoce de Mallorca (Askew, 1973).

Citas en la Comunidad de Madrid.- Se capturó en El Pardo con trampa Malaise durante los meses de diciembre, y de febrero a mayo.

Biología.- Se ha obtenido de diferentes agromízidos (Dipt., Agromyzidae) sobre una gran variedad de plantas principalmente Scrophulariaceae. Se han citado como hospedadores Phytomyza ranunculi (Shr.) (Dipt., Agromyzidae) sobre Ranunculus acris L. (Ranunculaceae); Phytomyza pethoi (Dipt., Agromyzidae) Her. sobre Mentha (Lamiaceae); Phytomyza symphyti Hend. (Dipt., Agromyzidae) sobre Myosotis (Boraginaceae); Phytomyza fallaciosa Br.(Dipt., Agromyzidae); Napomyza glechomae (Kalt.) (Dipt., Agromyzidae) sobre Glechoma hederaceae L. (Lamiaceae); Phytobia labiatarum Hend. (Dipt. Agromyzidae) sobre Stachys palustris L. (Lamiaceae) y sobre Lamium album L. (Lamiaceae) (Graham, 1969).

\section{Miscogaster rufipes Walker, 1833}

Distribución. - Ampliamente distribuida en Europa, se conoce de Inglaterra, Alemania, Irlanda y Suecia (Graham, 1969). Es la primera vez que se cita en la Península Ibérica.

Citas en la Comunidad de Madrid.- Capturada mediante trampas Malaise en El Pardo y en El Ventorrillo durante la primavera, siendo más elevado el número de ejemplares capturados en la primera de las localidades.

Biología. - Se han citado como hospedadores de esta especie Agromyza reptans Fln. (Dipt., Agromyzidae) sobre Urtica dioica L. (Urticaceae), Agromyza rufipes Mg. (Dipt., Agromyzidae) sobre Boraginaceae (Echium vulgare L.; Borago officinalis L. Cynoglossum officinale L. Anchusa arvensis (L.) y Myosotis sp.) y Phytomyza symphyti Hend (Dipt., Agromyzidae) sobre Shymphytum officinale L. (Boraginaceae) (Graham, 1969).

\section{Lamprotatus Westwood, 1833}

Diversidad y distribución.-Cuenta al menos con 19 especies ampliamente distribuidas en Europa (Boucek y Rasplus, 1991). Se cita por primera vez en la Península Ibérica.

Referencias taxonómicas._- Graham (1969).

Biología.- Parásito de varios Diptera (Agromyzidae, Muscidae, Anthomyiidae).

\section{Lamprotatus annularis Walker, 1833}

Distribución.- Ampliamente distribuido en Europa donde se conocía en Inglaterra, Irlanda y Suecia (Graham, 1969). Se trata de la primera referencia para la Península Ibérica.

Citas en la Comunidad de Madrid.- Sólo se ha estudiado un ejemplar de El Escorial, procedente de la colección Mercet.

Biología. - Se ha encontrado como parásito de distintas especies de dípteros (Diptera) sobre Stellaria media (L.) (Cariophyllaceae) (Graham, 1969).

Lamprotatus truncatus (Fonscolombe, 1832)

Distribución. - Especie conocida de Inglaterra y Suecia. Se cita por primera vez para la Península Ibérica (Graham, 1969).

Citas en la Comunidad de Madrid. - Se capturó un ejemplar mediante barrido en Chinchón-Titulcia y con trampa Malaise y bandejas amarillas en El Ventorrillo; la mayoría de los ejemplares se obtuvieron durante la primavera.

Biología. - En Inglaterra, se obtuvo una hembra, de un hospedador no identificado sobre Rumex acetosa L. (Polygonaceae) (Graham, 1969).

Ammeia Delucchi, 1962

Diversidad y distribución.-Género monoespecífico distribuido por los países mediterráneos de Europa y África, también se ha citado en el sureste asiático y en Australia (Boucek, 1988). Se cita por primera vez en la Península Ibérica.

Referencias taxonómicas.— Delucchi (1962); Graham (1969); Boucek y Rasplus (1991).

Biología.- Desconocida, pero probablemente se trate de un género parásito de dípteros (Agromyzidae o Drosophilidae) (Boucek, 1988).

\section{Ammeia pulchella Delucchi, 1962}

Citas en la Comunidad de Madrid. - Se capturó mediante barrido una hembra en el mes de octubre en Arganda.

\section{Micradelus Walker, 1834}

Diversidad y distribución.- El género cuenta con tres especies en Europa, de las que sólo han sido descritas dos (Boucek y Rasplus, 1991). Se cita por primera vez para la Península Ibérica.

Referencias taxonómicas._- Graham (1969); 
Boucek y Rasplus (1991).

Biología.-Desconocida.

Micradelus acutus Graham, 1969

Distribución.- Sólo conocida en Inglaterra (Graham, 1969). Es la primera referencia para la Península Ibérica.

Citas en la Comunidad de Madrid.- Todos los ejemplares proceden de El Ventorrillo donde la mayor parte de ellos se capturaron con bandejas amarillas durante la primavera, con excepción de un ejemplar capturado con trampa Malaise en el mes de agosto.

Biología.-Desconocida.

\section{ORMOCERINAE}

ORMOCERINI

Ormocerus Walker, 1834

Diversidad y distribución.- Sólo cuenta con dos especies que presentan una amplia distribución europea (Boucek y Rasplus, 1991).

Referencias taxonómicas.- Askew (1961c); Nieves-Aldrey (1982a).

Biología.- Género parásito de insectos gallícolas principalmente Cynipoidea (Hymenoptera) sobre Quercus sp. (Askew, 1961b; Nieves-Aldrey, 1982a; Boucek y Rasplus, 1991).

\section{Ormocerus latus Walker, 1834}

Distribución.- Ampliamente distribuida en toda Europa (Graham, 1969). En la Península Ibérica se ha citado en Cataluña (Pujade, 1991) y Salamanca (Nieves-Aldrey, 1982a).

Citas en la Comunidad de Madrid.- Se colectaron algunos ejemplares mediante barrido sobre la vegetación en la Carretera Villamanrique a Colmenar de Oreja y con trampas Malaise en El Pardo y en El Ventorrillo, en todos los casos durante la primavera. También se obtuvieron ejemplares procedentes de agallas de cinípidos (Hym., Cynipidae), concretamente a partir de agallas de Plagiotrochus razeti Barbotin, 1985 sobre Quercus ilex L y de Andricus quercusramuli (L., 1761) sobre Quercus faginea Lam.

Biología.- Askew (1961c), obtuvo esta especie de agallas de Neuroterus albipes (Schenck, 1863) (Hym., Cynipidae); Graham (1969) la capturó sobre follaje de Betula (Betulaceae). NievesAldrey (1982a) y Pujade (1991) citan como hospedadores distintas especies de Andricus Hartig (Hym., Cynipidae) sobre Quercus L. sp. (Fagaceae) y Plagiotrochus amenti Tav., 1926 (Hym., Cynipidae) sobre Quercus suber L. (Fagaceae).

Ormocerus vernalis Walker, 1834

Distribución.- Ampliamente distribuida en Europa (Graham, 1969). En la Península Ibérica se ha citado en Salamanca (Nieves-Aldrey, 1982a).

Citas en la Comunidad de Madrid.-Confirmando las referencias anteriores, algunos ejemplares emergieron de agallas de Andricus niger Tav., 1916 (Hym., Cynipidae) sobre Quercus suber L. en Torrelaguna-El Berrueco, además, algunos se obtuvieron como parásitos de agallas de Andricus pseudoinflator Tav., 1901 (Hym., Cynipidae) sobre Quercus faginea Lam. Un ejemplar fue capturado con trampa Malaise en El Pardo.

Biología.-Especie parásita en agallas de cinípidos (Hym., Cynipidae) sobre Quercus (Fagaceae). Ha sido citada en España como parásito de Andricus quercusramuli (L., 1761) sobre Quercus faginea Lam.; Andricus burgundus Gir., 1859 sobre $Q$. suber L., Andricus niger Tav., 1916 sobre $Q$. suber L. y Cynips divisa Hartig, 1840 sobre $Q$. pyrenaica Willd. (Nieves-Aldrey, 1982a; Pujade, 1991).

\section{Semiotellus Wetwood, 1839}

Diversidad y distribución.- Comprende cinco especies distribuidas por el norte y centro de Europa (Boucek y Rasplus, 1991).

Referencias taxonómicas.- Askew y Kennaugh (1992) (Especies de Inglaterra).

Biología.- Ejemplares de este género se han encontrado en pupas de Cecidomyiidae (Diptera).

\section{Semiotellus mundus (Walker, 1834)}

Distribución.- Especie no muy frecuente, conocida sólo en Inglaterra y Suecia. En la Península Ibérica sólo se ha citado en Cantabria (Garrido y Nieves-Aldrey, 1992b).

Citas en la Comunidad de Madrid.-El único ejemplar colectado procede de El Ventorrillo, donde se capturó con trampa Malaise en julio. Biología.-Desconocida.

\section{SYSTASINI}

Systasis Walker, 1834

Diversidad y distribución.- Comprende cinco especies algunas de ellas con amplia distribución europea (Boucek y Rasplus, 1991). 
Referencias taxonómicas.—Graham (1969).

Biología.- Aparentemente es un género parásito de larvas de Cecidómidos, (Dipt., Cecidomyiidae) en sus agallas, o quizás sea un género fitofago que se alimenta del tejido de la agalla o de semillas de herbáceas (Boucek y Rasplus, 1991).

\section{Systasis angustula Graham, 1969}

Distribución.- Se conoce sólo en Inglaterra (Graham, 1969). Es la primera cita en la Península Ibérica.

Citas en la Comunidad de Madrid.- Se capturó un ejemplar en Orusco, por barrido, en el mes de julio.

Biología.- Se han obtenido ejemplares procedentes de Kiefferia pimpinellae Hed. (Dipt., Cecidomyiidae) (Graham, 1969).

\section{Systasis encyrtoides Walker, 1834}

Distribución.—Especie muy común, ampliamente distribuida por toda Europa (Boucek, 1977). En la Península Ibérica se ha citado en Mallorca (Askew, 1973).

Citas en la Comunidad de Madrid.- Especie muy común en la Comunidad ya que se colectó en numerosas localidades. La mayor parte de los ejemplares fueron capturados mediante barrido, excepto los procedentes de El Escorial, Loeches y Madrid que pertenecen a la colección de Mercet y los de El Pardo y El Ventorrillo que se recogieron con trampas Malaise, estas capturas se realizaron principalmente durante la primavera y verano.

Biología.- Se ha encontrado en agallas de Dasyneura epilobii (F. Loew) (Dipt., Cecidomyiidae) sobre Epilobium angustifolium (L.) (Onagraceae). También se ha obtenido de Phytomyza isais Her. (Dipt., Agromyzidae) en semillas de Odontites verna (Bell.) (Solanaceae) y de Contarinia medicaginis (Dipt., Cecidomyiidae) (Graham, 1969).

\section{Systasis parvula Thomson, 1876}

Distribución.- Especie conocida en Checoslovaquia, Irlanda y Suecia (Graham, 1969). Se cita por primera vez para la Península Ibérica. Citas en la Comunidad de Madrid.- Colectada únicamente en El Pardo y El Ventorrillo.

Biología.- Desconocida, aunque Graham (1969) obtuvo ejemplares sobre plantas herbáceas situadas en los bordes de campos cultivados.

\section{Systasis tenuicornis Walker, 1834}

Distribución.- Especie poco común, sólo se conoce en Inglaterra (Graham, 1969). Se cita por primera vez para la Península Ibérica.

Citas en la Comunidad de Madrid.- Estudiado un único ejemplar de El Ventorrillo, capturado con bandejas amarillas al final de la primavera.

Biología.-Desconocida.

\section{PIRENINAE}

Gastrancistrus Westwood, 1833

Diversidad y distribución.- En el conjunto de Eurasia y América cuenta con más de 100 especies, mientras que en Australia y Nueva Zelanda, así como en África se conocen unas 30 especies (Boucek, 1988).

Referencias taxonómicas. - Graham (1969).

Biología.- En su mayoría, las especies de este género, se desarrollan como parásitas en agallas de Cecidomyiidae (Diptera) sobre diversas especies vegetales (Boucek y Rasplus, 1991).

\section{Gastrancistrus acontes Walker, 1840}

Distribución.- Especie poco común, sólo conocida de Inglaterra y Suecia (Graham, 1969). Se cita por primera vez para la Península Ibérica.

Citas en la Comunidad de Madrid.- Se colectó en Camporreal y Cerros del Porcal mediante barrido en la primavera y En El Pardo y en El Ventorrillo, empleando trampas Malaise y bandejas amarillas. Biología.-Desconocida.

\section{Gastrancistrus acutus Walker, 1834}

Distribución.- Poco común, sólo conocida de Inglaterra y Suecia (Graham, 1969). Es la primera cita para la Península Ibérica.

Citas para la Comunidad de Madrid.- Los únicos ejemplares fueron capturados en primavera en El Ventorrillo con trampa Malaise.

Biología.-Desconocida.

\section{Gastrancistrus autumnalis (Walker, 1834)}

Distribución.- Conocida sólo en Checoslovaquia, Inglaterra e Irlanda (Graham, 1969). Constituye la primera cita en la Península Ibérica.

Citas en la Comunidad de Madrid.-Colectada en primavera en El Pardo y en El Ventorrillo.

Biología.- El hospedador se desconoce, aunque 
parece tratarse de algunos cecidómidos (Dipt., Cecidomyiidae) asociados con Fagus L. sp. (Fagaceae) (Graham, 1969).

\section{Gastrancistrus crassus Walker, 1834}

Distribución.- Especie poco común, conocida en Inglaterra e Irlanda (Graham, 1969). Se cita por primera vez para la Península Ibérica.

Citas para la Comunidad de Madrid.- Numerosos ejemplares de El Ventorrillo, capturados con trampa Malaise sobre todo durante el verano.

Biología.-Desconocida.

\section{Gastrancistrus glabellus (Nees, 1834)}

Distribución.- Poco común, citada en Alemania, Inglaterra y Suecia (Graham, 1969). Es la primera cita en la Península Ibérica.

Citas en la Comunidad de Madrid.- Sólo encontrados tres ejemplares en El Ventorrillo en primavera utilizando trampas Malaise.

Biología.-Desconocida.

\section{Gastrancistrus hamillus Walker, 1848}

Distribución.- Se conoce solamente en Inglaterra y Suecia (Graham, 1969). Se cita por primera vez para la Península Ibérica.

Citas en la Comunidad de Madrid.- Un ejemplar de El Pardo capturado con trampa Malaise en mayo. Biología.- Desconocida, aunque aparentemente se trata de una especie frecuente en el follaje de las especies de Salix L. (Salicaceae) y de Betula (Betulaceae) (Graham, 1969).

\section{Gastrancistrus indivisus Graham, 1969}

Distribución.- Conocida únicamente en Inglaterra (Graham, 1969). Se cita por primera vez en la Península Ibérica.

Citas en la Comunidad de Madrid.- Como en el caso anterior los dos únicos ejemplares se encontraron en El Pardo empleando el mismo método de captura y durante el mismo mes.

Biología.-Desconocida.

\section{Gastrancistrus laticornis Walker, 1834}

Distribución.- Especie bastante común, probablemente de amplia distribución Europea (Graham, 1969). Se cita por primera vez para la Península Ibérica.
Citas en la Comunidad de Madrid.- A diferencia de lo apuntado por Graham (1969), no parece ser una especie común en nuestra zona de estudio ya que sólo hemos encontrado un ejemplar en El Ventorrillo, colectado con trampa Malaise en el mes de mayo.

Biología.-Desconocida.

Gastrancistrus latifrons (Thomson, 1876)

Distribución.- Poco común, conocida en Inglaterra y Suecia (Graham, 1969). Se cita por primera vez en la Península Ibérica.

Citas en la Comunidad de Madrid.- Los ejemplares estudiados proceden de El Ventorrillo donde se capturaron con trampa Malaise en el mes de julio. Biología.-Desconocida.

\section{Gastrancistrus oporinus Graham, 1969}

Distribución.- Sólo se conoce en Inglaterra (Graham, 1969). Es la primera cita en la Península Ibérica.

Citas en la Comunidad de Madrid.- En la colección Mercet, se encontraron siete ejemplares procedentes de Madrid, todos ellos capturados en el mes de abril, por otro lado se pudo capturar mediante barrido un ejemplar en El Porcal en el mes de mayo y otro en El Ventorrillo empleando bandejas amarillas durante el mes de abril.

Biología.-Desconocida.

\section{Gastrancistrus praecox Graham, 1969}

Distribución.- Conocida en Inglaterra (Graham, 1969). Se cita por primera vez en la Península Ibérica.

Citas en la Comunidad de Madrid.- Se ha encontrado un único ejemplar, capturado con trampa Malaise en El Pardo, en el mes de abril.

Biología.-Desconocida.

\section{Gastrancistrus salicis (Nees, 1834)}

Distribución.- Ampliamente distribuida en Europa. Se ha citado de Alemania, Checoslovaquia, Inglaterra, Irlanda y Suecia (Graham, 1969). Primera cita para la Península Ibérica.

Citas en la Comunidad de Madrid.- A pesar de que se trata de una especie con amplia distribución europea, sólo se ha colectado un ejemplar en El Ventorrillo con trampa Malaise.

Biología.- Se ha obtenido como parásito de 
Rabdophaga salicis (Schr.) (Dipt., Cecidomyidae) en agallas de Salix L. (Salicaceae) (Graham, 1969).

Gastrancistrus vagans Westwood, 1833

Distribución.- Aparentemente rara, citada en Inglaterra (Graham, 1969). En la Península Ibérica se conocía de Mallorca (Askew, 1973).

Citas en la Comunidad de Madrid.- Algunos ejemplares capturados con trampa Malaise en El Pardo durante la primavera.

Biología.-Desconocida.

Gastrancistrus viridis Walker, 1834

Distribución.- Conocida sólo en Francia, Inglaterra y Suecia (Graham, 1969). En la Península Ibérica ha sido citada en Cantabria (Garrido y Nieves-Aldrey, 1992b).

Citas en la Comunidad de Madrid.- Se ha colectado un buen número de ejemplares en El Pardo utilizando trampas Malaise. Todas las capturas tuvieron lugar durante la primavera. Otro ejemplar de esta especie fue colectado por Dusmet en la Sierra de Guadarrama.

Biología.- No se conoce, aunque se ha recogido sobre plantas herbáceas y en ocasiones sobre flores de Crataegus (Rosaceae) (Graham, 1969).

\section{Macroglenes Westwood, 1832}

Diversidad y distribución.- Cuenta con 11 especies europeas, aunque también se distribuye por América del Norte (dos especies), este de Asia (como mínimo dos especies) y Australia (aproximadamente 12 especies) (Boucek, 1988). Se cita por primera vez para la Península Ibérica.

Referencias taxonómicas: Graham (1969).

Biología.- Las especies europeas son parásitas de cecidómidos (Dipt., Cecidomyiidae) asociados con Gramineae (Boucek, 1988).

\section{Macroglenes chalibeus (Haliday, 1833)}

Distribución.- Ampliamente distribuida en Europa donde es bien conocida de Inglaterra, Irlanda, Alemania, Suecia y Suiza (Graham, 1969). Se cita por primera vez para la Península Ibérica.

Citas en la Comunidad de Madrid.- Un único ejemplar capturado con trampa Malaise en El Ventorrillo durante el mes de octubre.

Biología.- Parásito de Contarinia pisi (Winn.) y Contarinia tritici (Kirby) (Dipt., Cecidomyiidae), también se han obtenido ejemplares de Dasyneura viciae (Kieffer) (Dipt., Cecidomyiidae) sobre Vicia tetrasperma (L.) Schreb (Fabaceae) (Graham, 1969).

\section{Macroglenes varicornis (Haliday, 1833)}

Distribución. - Ampliamente distribuida en Europa (Graham, 1969). Se cita por primera vez para la Península Ibérica.

Citas en la Comunidad de Madrid.- En El Ventorrillo se encontraron bastantes ejemplares con trampa Malaise, principalmente durante el verano. Biología.- Se han obtenido ejemplares que parasitaban agallas de Contarinia tritici (Kirby) (Dipt., Cecidomyiidae) (Graham, 1969).

\section{PTEROMALINAE TRIGONODERINI Plutothrix Förster, 1856}

Diversidad y distribución. - Cuenta con al menos siete especies. Está ampliamente distribuido en Europa (Boucek y Rasplus, 1991).

Referencias taxonómicas.-Graham (1993).

Biología.- Las especies de este género son parásitas de coleópteros que viven sobre madera muerta (Ciidae, Scolytidae, Cerambycidae, Anobiidae) o de dípteros.

\section{Plutothrix acuminata (Thomson, 1878)}

Distribución.- Especie citada en Canadá, Inglaterra y Suecia (Graham, 1969). En la Península Ibérica se conoce de Cantabria (Garrido y Nieves-Aldrey, 1992b).

Citas en la Comunidad de Madrid.- Mucho menos abundante que la especie anterior, sólo se capturó un ejemplar en El Ventorrillo con trampa Malaise durante el mes de agosto.

Biología.- Probablemente parásito de Cis boleli (Scop.) (Col., Ciidae) (Graham, 1969).

Plutothrix bicolorata (Spinola, 1808).

Distribución.-Ampliamente distribuida en Europa donde ha sido citada de Finlandia, Checoslovaquia, República de Moldavia, Inglaterra, Irlanda y Suecia (Graham, 1969; Boucek, 1977). En la Península Ibérica, se ha citado en Cantabria (Garrido y Nieves-Aldrey, 1992b).

Citas en la Comunidad de Madrid.- Especie frecuente en El Ventorrillo donde se colectaron ejem- 
plares con trampa Malaise sobre todo en los meses de verano.

Biología.- Se ha encontrado junto con Anobium puctatum DeG. (Col., Anobiidae) en tallos de Ulex (Fabaceae) (Graham, 1969).

\section{Plutothrix trifasciata (Thomson, 1878)}

Distribución. - Especie conocida en Checoslovaquia, Dinamarca, Inglaterra, República de Moldavia y Suecia (Graham, 1969). En la Península Ibérica se ha citado en Cantabria (Garrido y Nieves-Aldrey, 1992b).

Citas en la Comunidad de Madrid.- Como en el caso anterior, el único ejemplar estudiado procede de El Ventorrillo donde se colectó con trampa Malaise en primavera.

Biología.- Desconocida.

\section{Jansoniella Kerrich, 1957}

Diversidad y distribución.—El género cuenta con tres especies que, aunque son poco comunes están ampliamente distribuidas en el norte y centro de Europa (Boucek y Rasplus, 1991). Se cita por primera vez para la Península Ibérica.

Referencias taxonómicas. - Graham (1969).

Biología. - Problablemente se trata de un género parásito de coleópteros que viven en Polyporus (Fungi, Poliporaceae) (Boucek y Rasplus, 1991).

\section{Jansoniella ambigua Graham, 1969}

Distribución.- Se conoce sólo en Inglaterra (Graham, 1969). Es la primera cita en la Península Ibérica.

Citas en la Comunidad de Madrid.- Colectado un ejemplar mediante barrido en los Cerros del Porcal en el mes de abril.

Biología.- Desconocida.

\section{Platygerrhus Thomson, 1878}

Diversidad y distribución. - En Europa cuenta con nueve especies distribuidas por todo el continente (Boucek y Rasplus, 1991). Se cita por primera vez en la Península Ibérica.

Referencias taxonómicas.—Graham (1969).

Biología.- Parásito de pequeños coleópteros sobre madera muerta (Anobiidae, Cucujidae, Scolytidae) (Boucek y Rasplus, 1991).
Platygerrhus dolosus (Walker, 1836)

Distribución. - Se conoce de Checoslovaquia, Inglaterra y Suecia (Graham, 1969). Es la primera cita en la Península Ibérica.

Citas en la Comunidad de Madrid. - Los ejemplares estudiados fueron colectados en El Pardo y en El Ventorrillo con trampa Malaise en los meses de junio y julio respectivamente.

Biología. - Se ha encontrado como ectoparásito de Laemophloeus ater (Oliv.) (Col., Cucujidae), y como predador de Phloeothorus rhododactylus (Marsh.) (Col., Scolytidae) sobre Cytisus scoparius (L.) (Graham, 1969).

Platygerrhus maculatus Erdös, 1957

Distribución.- Sólo se conoce en Checoslovaquia y Hungría (Graham, 1969). Es la primera cita en la Península Ibérica.

Citas en la Comunidad de Madrid.- Un único ejemplar colectado en El Ventorrillo durante el mes de julio utilizando trampa Malaise.

Biología.-Desconocida.

\section{Gastracanthus Westwood, 1833}

Diversidad y distribución.- Género monoespecífico ampliamente distribuido por los bosques europeos (Boucek y Rasplus, 1991). Se cita por primera vez para la Península Ibérica.

Referencias taxonómicas._- Graham (1969).

Biología. - Probablemente es parásito de coleópteros xilófagos (Boucek y Rasplus, 1991).

Gastracanthus pulcherrimus Westwood, 1833

Citas en la Comunidad de Madrid.- Se capturaron dos ejemplares durante los meses de invierno en El Pardo por medio de trampa Malaise.

PTEROMALINI

Sphegigaster Spinola, 1811

Diversidad y distribución.- Género cosmopolita que cuenta con al menos 14 especies ampliamente distribuidas por Europa (Boucek, 1988; Boucek y Rasplus, 1991).

Referencias taxonómicas.- Graham (1969); Heydon y Laberge (1988) (especies neárticas).

Biología.- Parásito de dípteros minadores, principalmente agromícidos (Dipt., Agromyzidae) (Boucek y Rasplus, 1991). 
Sphegigaster brevicornis (Walker, 1833)

Distribución.- Especie conocida sólo en Inglaterra (Graham, 1969). Se cita por primera vez para la Península Ibérica.

Citas en la Comunidad de Madrid.- Con red de barrido se colectó un ejemplar en El Pardo.

Biología.-Desconocida.

\section{Sphegigaster nigricornis (Nees, 1834)}

Distribución.- Citada en Inglaterra y Alemania (Graham, 1969). En la Península Ibérica se conoce en Mallorca (Askew, 1973); provincia de Barcelona (Verdú, 1991) y Cantabria (Garrido y NievesAldrey, 1992b).

Citas en la Comunidad de Madrid.- Aparentemente no se trata de una especie infrecuente; colectamos ejemplares mediante barrido en Canencia, Oteruelo del Valle y El Ventorrillo, donde también se capturaron con trampa Malaise, todos ellos durante el verano. Biología.- Se han encontrado como hospedadores Melannagromyza dettmeri (Graham) y Melanagromyza sativae Spencer (Dipt., Agromyzidae) (Graham, 1969). También se obtuvo como parásito de algunos dípteros minadores no identificados sobre col (Verdú, 1991).

Sphegigaster pallicornis (Spinola, 1808)

Distribución.- Ampliamente distribuida en Europa, se conoce de Inglaterra, Irlanda y Suecia (Graham, 1969). Es la primera cita para la Península Ibérica.

Citas en la Comunidad de Madrid.- Parece tratarse de una especie con una amplia distribución en la comunidad ya que se han colectado ejemplares mediante barrido sobre la vegetación en: Carretera Villamanrique a Colmenar de Oreja, Soto del Real, Valle de Bustarviejo y El Ventorrillo donde, además, se colectaron ejemplares con trampas Malaise. La mayoría de los ejemplares se capturaron durante la primavera y el verano. La especie aparece con frecuencia ligada a los Encinares Carpetanos del norte de la Comunidad.

Biología.- Parásito común de Phytomyza ilicis Curt. (Dipt., Agromyzidae) sobre Ilex aquifolium L. (Aquifoliaceae) (Graham, 1969).

\section{Syntomopus Walker, 1833}

Diversidad y Distribución.- Género cosmopolita que cuenta con cinco especies paleárticas, amplia- mente distribuidas en Europa (Boucek, 1988; Boucek y Rasplus, 1991). Se cita por primera vez para la Península Ibérica.

Referencias taxonómicas.- Hedqvist (1972); Heydon (1993) (Especies neárticas).

Biología.- Parásito de Agromyzidae (Diptera), principalmente del género Melanagromyza, minadores de tallos de herbáceas (Boucek y Rasplus, 1991).

\section{Syntomopus incisus Thomson, 1878}

Distribución.- Especie bastante común conocida en Inglaterra, Italia y Suecia (Hedqvist, 1972). Es la primera cita en la Península Ibérica.

Citas en la Comunidad de Madrid.- Estudiado un ejemplar de El Pardo procedente de la colección Mercet y varios ejemplares de El Ventorrillo, colectados a lo largo de varios años con trampas Malaise, centrándose la mayoría de las capturas en los meses de verano.

Biología.- Se han citado como hospedadores Melanagromyza lappae (Lw.); Melanagromyza dettmeri Her. y Melanagromyza aeneiventris (Fln.) (Dipt., Agromyzidae) (Hedqvist, 1972).

Notoglyptus Masi, 1917

Diversidad y distribución. - Género cosmopolita con una única especie europea (Boucek y Rasplus, 1991).

Referencias taxonómicas.- Heydon (1989c).

Biología.- No se conoce, pero problemente se trata de un género parásito de algunos dípteros asociados con plantas herbáceas (Boucek y Rasplus, 1991).

\section{Notoglyptus scutellaris (Dodd y Girault, 1915)}

Distribución. - En la Península Ibérica se ha citado en Cantabria y Burgos (Garrido y NievesAldrey, 1992b).

Citas en la Comunidad de Madrid.- Colectada en dos únicas localidades, mediante barrido en Madarcos y con trampas Malaise en El Ventorrillo. En todos los casos, las capturas se realizaron durante el mes de agosto.

\section{Cyrtogaster Walker, 1833}

Diversidad y distribución.- Género con cuatro especies europeas ampliamente distribuidas (Boucek y Rasplus, 1991). 
Referencias taxonómicas.- Askew (1965) (Machos europeos); Heydon (1989a) (Especies neárticas.)

Biología.- Parásito dentro de las pupas de dípteros minadores (Boucek y Rasplus, 1991).

\section{Cyrtogaster clavicornis Walker, 1853}

Distribución.- Especie cómun, ampliamente distribuida en Europa donde ha sido citada en Checolosvaquia, Dinamarca, Inglaterra, Irlanda, República de Moldavia, Rumania y Suecia, (Graham, 1969). En la Península Ibérica se conoce de Cantabria (Garrido y Nieves-Aldrey, 1992b). Citas en la Comunidad de Madrid.- Todos los ejemplares fueron colectados mediante trampas Malaise en El Ventorrillo siendo especialmente abundantes al comienzo del verano.

Biología.- Se ha obtenido de pupas de Hydropota griseola (Fln.) y de Hydropota nasturtii (Collin) (Dipt., Ephydridae). También se han citado como hospedadores Lonchoptera (Dipt., Lonchopteridae), Agromyza sp. (Dipt., Agromyzidae) y Pegomya hyoscyani (Dipt., Muscidae) (Askew, 1965).

\section{Cyrtogaster vulgaris Walker, 1833}

Distribución.- Especie ampliamente distribuida, muy común en Europa (Graham, 1969). En la Península Ibérica se ha citado en Cantabria (Garrido y Nieves, 1992b) y en Valladolid (Archimowitsh, 1952).

Citas en la Comunidad de Madrid.- Especie frecuente en la Comunidad. Se han encontrado ejemplares en Canencia, Cercedilla, Fuentidueña de Tajo, Monte el Robledal, El Pardo, Puerto de Canencia y El Ventorrillo donde, además de ser capturados con red, se colectaron con trampas Malaise y bandejas amarillas, obteniéndose un elevado número de ejemplares, sobre todo durante la primavera y principio de verano.

Biología.- Se ha encontrado como parásito primario de la pupa de Phytomyza ilicis Curtis (Dip., Agromyzidae). También se han citado como hospedadores Phytomyza atricornis Meigen sobre Chrysanthemun, Gazania y Aster (Asteraceae); Phytomyza nigra Meigen; Phytomyza crassiseta Zett. sobre Veronica officinalis L (Scrophulariaceae). Phytomyza sonderupi Hering sobre Carex (Cyperaceae), y algunos hopedadores no identificados sobre Senecio jacobea L. (Asteraceae) y Primula vulgaris (Primulaceae). Se han obtenido ejemplares de Cyrtogaster vulgaris de Opomyza florum (F.)
(Dipt., Opomyzidae) y de hospedadores desconocidos sobre Brassica sp. (Cruciferae) y Papaver sp. (Papaveraceae). También se ha mencionado como hospedador Oscinella frit (L.) (Dipt., Chloropidae), aunque este último dato necesita confirmación (Askew; 1965).

\section{Toxeuma Walker, 1833}

Diversidad y distribución.— Género con al menos seis especies, ampliamente distribuidas por Europa (Boucek y Rasplus, 1991). Se cita por primera vez en la Península Ibérica.

Referencias taxonómicas.- Graham (1969); Heydon y Grissell (1988) (Especies neárticas).

Biología.- Parásito de agromízidos (Dipt., Agromyzidae) que se desarrollan en semillas de herbáceas (Boucek y Rasplus, 1991).

\section{Toxeuma fuscicorne Walker, 1833}

Distribución.- Conocida en Alemania, Inglaterra, Irlanda, Hungría, Suecia y Suiza (Graham, 1969). Es la primera cita en la Península Ibérica.

Citas en la Comunidad de Madrid.-El Ventorrillo; un único ejemplar capturado con trampa Malaise en julio.

Biología.- Se ha encontrado en semillas de Avena elatior (L.) Avena pubescens (Huds.) y Avena pratensis (L.) (Graham, 1969).

\section{Dinotiscus Ghesquière, 1946}

Diversidad y distribución. - Agrupa cuatro especies europeas de las que tres tienen una amplia distribución (Boucek y Rasplus, 1991).

Referencias taxonómicas.- Grissell (1983) (especies holárticas).

Biología.- Es un género parásito de coleópteros escolítidos (Col., Scolytidae) (Boucek y Rasplus, 1991).

\section{Dinotiscus eupterus (Walker, 1836)}

Distribución.- Especie holártica; en la región neártica su distribución incluye Nueva Escocia y Quebec; sur de Virginia y desde el norte de los Estados Unidos hasta Oregón y California. Las citas paleárticas incluyen Alemania, Inglatera, Suecia, Europa Central y Japón (Grissell, 1983). Es primera cita para la Península Ibérica.

Citas en la Comunidad de Madrid.- El Ventorrillo; cinco ejemplares colectados durante la primavera y comienzo del verano. 
Biología.- En la región neártica se han citado como hospedadores Dendroctomus ponderosae Hopkins y Polygraphus rufipennis (Kirby) (Col., Scolytidae). Los hospedadores paleárticos son distintas especies de escolítidos (Col., Scolytidae) de los géneros Polygraphus Erich., Phthorophloeus Rey, Cryphalus Erich., Pithyophthorus Eichh., Pytiogenes Bed., Dryocoetes Eichh. e Ips De Geer (Grissell, 1983).

\section{Rhopalicus Förster, 1856}

Diversidad y distribución.- Género holártico que cuenta con al menos cuatro especies (Boucek y Rasplus, 1991). En la Península Ibérica se conocía una especie de Los Monegros (Askew, 1994).

Referencias taxonómicas._- Grissell (1983) (Especies holárticas).

Biología.- Sus especies atacan principalmente coleópteros escolítidos (Col., Scolytidae) sobre coníferas (Boucek y Rasplus, 1991) pero recientemente Skuhravá (1995) cita a Rhopalicus nudicoxalis Askew, 1994, junto a Thureonella punctata Gijswijt, 1990 como parásitos en agallas de Etsuhoa thuriferae Skuhravá (Diptera, Cecidomyiidae) en Los Monegros (España).

\section{Rhopalicus guttatus (Ratzeburg, 1844)}

Distribución.- Citada en Alemania, Checoslovaquia, Inglaterra y Suecia y conocida también de Yugoslavia y Turquía (por ejemplares existentes en el Museo Británico) (Grissell, 1983). En la Península Ibérica se ha citado en Portugal (Grissell, 1983).

Citas en la Comunidad de Madrid.- Especie infrecuente, sólo se ha encontrado dos ejemplares en El Ventorrillo utilizando trampas Malaise.

Biología.- Se conocen como hospedadores algunas especies de Pissodes Germar (Col., Curculionidae) especies de Ips De Geer (Col., Scolytidae) (Grissell, 1983).

\section{Rhopalicus quadratus (Ratzeburg, 1844)}

Distribución. - Se conoce principalmente en el noroeste de Europa, incluida Inglaterra (Grissell, 1983). Es la primera cita en la Península Ibérica.

Citas en la Comunidad de Madrid. - Como en el caso anterior, parece tratarse de una especie rara en la comunidad, sólo se ha capturado un ejemplar en El Ventorrillo con trampa Malaise.

Biología.- Todos sus hospedadores conocidos son coleópteros escolítidos (Col., Scolitidae) de los géne- ros Tomicus Latr., Carphoborus Eichh., Hylurgops Lec., Ips De Geer, Orthotomicus Ferr., Phloeosinus Chap. y Pytiogenes Bed. (Grissell, 1983).

\section{Rophalicus tutela (Walker, 1836)}

Distribución. - Especie holártica con una amplia distribución europea. Se ha citado también en Japón, en los Estados Unidos y Canadá (Grissell, 1983). Es la primera referencia para la Península Ibérica.

Citas en la Comunidad de Madrid.- Unicamente se han encontrado dos ejemplares en El Piul y El Ventorrillo respectivamente.

Biología.- Es un parásito común de un gran número de géneros y especies de escolítidos (Col., Scolytidae), también se ha citado como parásito de especies del género Pissodes (Col., Curculionidae) (Graham, 1969).

\section{Acrocormus Förster, 1856}

Diversidad y distribución.- Género monoespecífico con una amplia distribución europea (Graham, 1969; Boucek y Rasplus, 1991). Se cita por primera vez para la Península Ibérica.

Referencias taxonómicas.- Graham (1969). Biología.- Parásito de curculiónidos (Col., Curculionidae) y escolítidos (Col., Scolytidae) sobre ramas de árboles, sobre todo Ulmus L. (Ulmaceae) y Fraxinus (Oleaceae) (Boucek y Rasplus, 1991). Se han citado como hospedadores Scolitus intricatus Ratz., Magdalis armigera (Geoffr.) en tallos de Ulmus L. (Ulmaceae), Hylesinus toranio Danth sobre Fraxinus L. (Oleacea). Se encontraron ejemplares sobre Ulmus L. infestados por Acrantus vittatus (F.) (Col., Scolytidae) (Graham, 1969).

\section{Acrocormus semifasciatus Thomson, 1878}

Citas en la Comunidad de Madrid.Aparentemente rara, sólo se colectó un único ejemplar en El Ventorrillo utilizando trampas Malaise.

\section{Cheiropachus Westwood, 1828}

Diversidad y distribución.- Género holártico con una sola especie (Boucek y Rasplus, 1991) de amplia distribución europea. En la Península Ibérica se ha citado en Asturias, Cantabria (Garrido y NievesAldrey, 1992b) y Granada (Gonzalez y Campos, 1990a, 1990b, 1991; Campos y Lozano 1994). 
Referencias taxonómicas.—Graham (1969).

Biología.- Parásito común de pequeños coleópteros xilófagos especialmente sobre árboles de hoja caduca (Boucek y Rasplus, 1991). Gonzalez y Campos (1990a, 1990b, 1991) citan como hospedador a Phloeotribus scarabaeoides Bern., (Hym., Scolytidae), Campos y Lozano (1994), mencionan además como hospedador a Hylesinus varius Bed., (Col., Scolytidae).

\section{Cheiropachus quadrum (Fabricius, 1787)}

Citas en la Comunidad de Madrid.- Esta especie había sido citada anteriormente en Madrid por (Mercet, 1926-1928). Se amplía ahora esta cita con las siguientes localidades: El Escorial, Madrid, Montarco, El Pardo, El Ventorrillo. En las dos últimas localidades, los ejemplares fueron capturados por nosotros utilizando trampas Malaise, mientras que en las demás se trata de material perteneciente a la colección Mercet. En cualquier caso, se trata de una especie bastante común, más frecuente durante primavera y verano.

\section{Rhaphitelus Walker, 1834}

Diversidad y distribución.- Género con dos especies, una de ellas muy común con una amplia distribución y la otra aparentemente rara (Boucek y Rasplus, 1991).

Referencias taxonómicas. - Graham (1969).

Biología.- Parásito principalmente de pequeños coleópteros (Scolytidae, Curculionidae) que se desarrollan sobre ramas de árboles (distintas especies de coníferas), Fagus L. (Fagaceae), Carpinus L. (Corylaceae), Sorbus L. (Rosaceae) (Boucek y Rasplus, 1991).

Rhaphitelus maculatus Walker, 1834

Distribución.- Es la especie más común del género. Ampliamente distribuida por toda Europa, también citada en Estados Unidos y Argentina. En la Península Ibérica se conoce en Granada (Gonzalez y Campos, 1990a, 1990b, 1991; Campos y Lozano 1994) y Cantabria (Garrido y Nieves-Aldrey, 1992b).

Citas en la Comunidad de Madrid.- Se han obtenido algunos ejemplares en El Ventorrillo utilizando trampas Malaise principalmente durante los meses de julio y agosto.

Biología.- Parásito de varios escolítidos (Col., Scolytidae) especialmente de las especies de los géneros Scolytus Oliv., Hylesinus F. y Phloeotribus Latr.; en Norteamérica además, se ha obtenido como parásito de algunos curculiónidos (Col. Curculionidae) principalmente de los géneros Magdalis Germar y Pissodes Germar (Graham, 1969). Gonzalez y Campos (1990a, 1990b, 1991) y Campos y Gonzalez (1990) citan como hospedador a Phloeotribus scarabaeoides Bern., (Hym., Scolytidae).

\section{Roptrocerus Ratzeburg, 1844}

Diversidad y distribución.- Cuenta con tres o cuatro especies europeas (Boucek y Rasplus, 1991), también ha sido citada una especie común con Europa en América del Norte, América Central e India (Boucek, 1988).

Referencias taxonómicas. - Graham (1969).

Biología.- Ectoparásito de larvas de coleópteros escolítidos (Col., Scolytidae) sobre coníferas, especialmente de los géneros Pinus y Picea (Pinaceae) (Boucek, 1988).

\section{Roptrocerus xylophagorum (Ratzeburg, 1844)}

Distribución.- Ampliamente distribuida por toda Europa, conocida también en Estados Unidos, Guatemala y Japón (Graham, 1969). En la Península Ibérica se ha citado en Ávila, Huesca (Mercet, 1926-28); España (Chararas, 1959; Hedqvist, 1963).

Citas en la Comunidad de Madrid.- - A pesar de ser una especie con una amplia distribución europea sólo se ha encontrado un ejemplar de Collado Mediano procedente de la colección Mercet.

Biología.- Parásito de escolítidos (Col., Scolytidae) (Graham, 1969).

\section{Habritys Thomson, 1878}

Diversidad y distribución.- Género hólartico, monoespecífico, ampliamente distribuido en Europa (Boucek y Rasplus, 1991). En la Península Ibérica se ha citado en Cantabria (Garrido y Nieves Aldrey, 1992b).

Referencias taxonómicas.—-Graham (1969).

Biología.- Parásito de crabróninos (Hym., Sphecidae) que anidan en madera muerta (Boucek y Rasplus, 1991). Se han citado como hospedadores Crossocerus megacephalus (Rossi) y Crossocerus annulipes (Lep. \& Brullé) (Graham, 1969). 
Habritys brevicornis (Ratzeburg, 1844)

Citas en la Comunidad de Madrid.- Mediante trampas Malaise, se colectaron varios ejemplares en El Pardo y en El Ventorrillo durante la primavera y el otoño.

\section{Caenocrepis Thomson, 1878}

Diversidad y distribución.- Dos especies ampliamente distribuidas en Europa (Boucek y Rasplus, 1991). Se cita por primera vez para la Península Ibérica.

Referencias taxonómicas.—Graham (1969).

Biología.- Parásitos de huevos de gorgojos (Col., Curculinidae) que atacan plantas herbáceas en condiciones áridas (Boucek y Rasplus, 1991).

\section{Caenocrepis arenicola Thomson, 1878}

Distribución.- Ampliamente distribuida en Europa, se conocía en Austria, Checoslovaquia, Francia, Hungría, Suecia y antigua URSS (Graham, 1969). Es la primera vez que se cita en la Península Ibérica.

Citas en la Comunidad de Madrid.- Especie poco frecuente en la Comunidad; colectado un ejemplar mediante barrido en El Pardo.

Biología.-Desconocida.

\section{Cyrtoptyx Delucchi, 1956}

Diversidad y distribución.- Género con tres especies ampliamente distribuidas en los países mediterráneos (Boucek y Rasplus, 1991).

Biología.- Presenta una gran variedad de hospedadores que incluyen especies de Dacus (Dipt., Tephrytidae), algunos curculiónidos (Col., Curculionidae) y cinípidos gallícolas (Hym., Cynipidae). (Boucek y Rasplus, 1991).

Referencias taxonómicas.- Delucchi (1956); Graham (1969); Boucek (1974).

\section{Cyrtoptyx latipes (Rondani, 1877)}

Distribución.— Especie de distribución mediterránea (Boucek, 1974). Se cita por primera vez en la Península Ibérica.

Citas en la Comunidad de Madrid.- Estudiados varios ejemplares de El Pardo y El Ventorrillo, la mayoría colectados con trampas Malaise, excepto un ejemplar de la colección Mercet.

Biología.- Se conocen como hospedadores Dacus oleae Gmel (Dipt., Tephrytidae) y algunas especies de curculiónidos (Col., Curculionidae) (Boucek, 1974).

Cyrtoptyx robustus (Masi, 1907)

Distribución.- Especie mediterránea (Boucek, 1974). En la Península Ibérica se conocía de Burgos (Garrido y Nieves-Aldrey, 1992b), Cataluña (Pujade, 1991) y Salamanca (Nieves-Aldrey, 1982b).

Citas en la Comunidad de Madrid.- La mayoría de los ejemplares estudiados se obtuvieron a partir de agallas de cinípidos (Hym., Cynipidae) colectadas sobre Quercus faginea L. y Quercus ilex L en distintas localidades También se colectó la especie en Madarcos y El Pardo mediante red de barrido y en El Ventorrillo con trampa Malaise.

Biología.- Parásito de cinípidos (Hym., Cynipidae). Delucchi (1956) la cita como obtenida a partir de agallas de Cynips (=Andricus kollari) y C. polycera Giraud. Graham (1969) recoge las citas de Masi a partir de Cynips (=Andricus) coriaria y Cynips argentea (= Andricus quercustozae (Bosc, 1792)). En Salamanca, los ejemplares de esta especie se han obtenido principalmente a partir de las agallas de Andricus kollari (Hartig, 1843) (NievesAldrey, 1982b).

Oxysychus Delucchi, 1956

Diversidad y distribución.- Género que cuenta con cuatro especies circunmediterráneas, aparentemente poco comunes (Boucek y Rasplus, 1991). Se cita por primera vez en la Península Ibérica.

Referencias taxonómicas.— Delucchi (1956); Graham (1969).

Biología.- Se ha encontrado en tallos o ramas atacados por coleópteros xilófagos como escolítidos (Col., Scolytidae) o pequeños cerambícidos (Col., Cerambycidae) (Boucek y Rasplus, 1991).

\section{Oxysychus sp. nr. regnieri}

Citas en la Comunidad de Madrid.- Los ejemplares capturados aunque tienen algunos caracteres comunes con esta especie, no pueden ser asimilados a ella; se colectaron en Chinchón-Titulcia y Cotos de Monterrey mediante barrido y en El Pardo con trampa Malaise.

\section{Dinarmus Thomson, 1878}

Diversidad y distribución.- Género con al menos 10 especies, distribuidas en zonas templadas, sub- 
tropicales y tropicales (Boucek, 1988); de ellas, dos, son de distribución mediterránea (Boucek y Rasplus, 1991).

Referencias taxonómicas.- Graham (1969); Rasplus (1989) (Especies africanas).

Biología.- Probablemente todas las especies atacan brúquidos (Col., Bruchidae) en las cápsulas de Papilionaceae (Boucek, 1988).

Dinarmus acutus Thomson, 1878

Distribución.- Se ha citado en la región paleártica en: Argelia, Austria, Bulgaria, Checoslovaquia, España, Francia, Grecia, Hungría, Inglaterra, Israel, Suiza, Malta, Marruecos, Turquía, antigua URSS y Yugoslavia. En la región neártica se ha citado en Canada y Estados Unidos: En la región afrotropical en Costa de Marfil, Gambia y Senegal y en la región oriental en la India (Rasplus, 1989). En la Península Ibérica se conoce en ESPAÑA: Cantabria (Garrido y Nieves-Aldrey, 1992b) y PORTUGAL: Porto de Lisboa (Diniz, 1960).

Citas en la Comunidad de Madrid.- Muy frecuente en la comunidad; se ha encontrado en: Alcalá, Arganda, Canencia, Carretera Estremera-Brea de Tajo, Cerceda, El Escorial, Oteruelo del Valle, El Pardo, El Ventorrillo y Sierra de Guadarrama. Se trata de una especie muy abundante especialmente durante los meses de verano.

Biología.- En la región holártica parece parasitar únicamente los brúquidos de los géneros Bruchus y Bruchidius (Col., Bruchidae) que atacan leguminosas herbáceas (Vicia sp., Lathyrus sp. etc). Para las poblacionses asiáticas o Áfricanas se desconocen todavía los hospedadores (Rasplus, 1989).

Dinarmoides Masi, 1924

Diversidad y distribución.- Género monoespecífico de distribución principalmente mediterránea (Boucek y Rasplus, 1991). Se cita por primera vez en la Península Ibérica.

Referencias taxonómicas. - Graham, 1969.

Biología.- No se conoce el hospedador (Boucek y Rasplus, 1991).

\section{Dinarmoides spilopterus Masi, 1924}

Citas en la Comunidad de Madrid.- Con trampa Malaise se colectaron en El Pardo ocho ejemplares a lo largo de los meses de verano.
Stenoselma Delucchi, 1956

Diversidad y distribución. - Cuenta con al menos tres especies de distribución mediterránea (Boucek y Rasplus, 1991).

Referencias taxonómicas.—Delucchi (1956).

Biología.- Parásito de bupréstidos (Col. Buprestidae) o de mariposas (Lepidoptera) (Boucek y Rasplus, 1991).

\section{Stenoselma nigrum Delucchi, 1956}

Distribución. - Ampliamente distribuida por las regiones mediterráneas y centroeuropeas (Graham, 1969; Boucek, 1977). En la Península Ibérica se ha citado en Burgos (Garrido y Nieves-Aldrey, 1992b). Citas en la Comunidad de Madrid.- Especie muy frecuente en la comunidad. Colectados ejemplares en: Alameda del Valle, Arganda, Brea de Tajo, Carretera Brea de Tajo a Orusco, Carretera Colmenar viejo a San Agustín de Guadalix, Carretera Estremera a Brea de Tajo, Carretera Villamanrique a Colmenar, Cerceda, Cercedilla, Cerros de Morata, Chinchón, Madarcos, Madrid (Chamartín), Madrid, Montarco, Oteruelo del Valle, El Pardo, El Piul, El Porcal, El Ventorrillo y Villaviciosa de Odón. En el caso de El Ventorrillo y el Pardo, la mayoría de los ejemplares se colectó con trampas Malaise durante los meses de agosto y septiembre.

Biología.- Especie parásita de larvas de coleópteros bupréstidos, principalmente del género Anthaxia (Col., Buprestidae), o de mariposas del género Bembecia (Lep., Sessidae) sobre tallos de arbustos (Boucek y Rasplus, 1991).

Norbanus Walker, 1843

Diversidad y distribución.- Género que al menos cuenta con 20 o 25 especies distribuidas en casi todos los continentes, aunque probablemente estén ausentes en Suramérica (Boucek, 1988). De estas, al menos 10 aparecen distribuidas por la región mediterránea (Boucek y Rasplus, 1991).

Referencias taxonómicas.- Graham (1969).

Biología.- Es un género parásito de larvas de Diptera e Hymenoptera y menos frecuentemente de otros insectos que se desarrollan en tallos de plantas herbáceas (Boucek y Rasplus, 1991).

Norbanus cerasiops (Masi, 1922)

Distribución.- Ampliamente distribuida en los países mediterráneos (Graham, 1969). Es la prime- 
ra cita para la Península Ibérica.

Citas en la Comunidad de Madrid.- Se estudiaron algunos ejemplares de Aranjuez y El Escorial de la colección Mercet. Adicionalmente colectada mediante red de barrido en Chinchón-Titulcia y con trampa Malaise en El Pardo.

Biología.- Menozzi (1930) señala que esta especie se obtuvo como parásita de Lixus junci Boh. (Col., Curculionidae) y que probablemente sería un parásito endófago de la larva de este coleóptero, aunque admitía la posibilidad que se tratara de un hiperparásito a través de Bracon intercessor (Nees) (Hym., Braconidae) o Eurytoma sp. (Hym., Eurytomidae), ambos parásitos primarios de Lixus (Graham, 1969).

\section{Norbanus meridionalis (Masi, 1919)}

Distribución.- Se conoce en Checoslovaquia, Italia y Hungría (Graham, 1969). Primera cita en la Península Ibérica.

Citas en la Comunidad de Madrid.- El Pardo; un ejemplar colectado en julio con trampa Malaise. Biología.-Desconocida.

\section{Norbanus obscurus (Masi, 1922)}

Distribución.- Sólo conocida de Italia y Turquia (Graham, 1969). Se cita por primera vez para la Península Ibérica.

Citas en la Comunidad de Madrid.- El Ventorrillo; un ejemplar colectado en julio con trampa Malaise

Biología.- Nikol'skaya (1952) señala que esta especie parasita una especie de tentredínido (Hym., Tenthredinidae) (Graham, 1969).

\section{Norbanus scabriculus (Nees, 1834)}

Distribución.- Citado en Alemania, Italia, Suecia y antigua URSS (Graham, 1969). En la Península Ibérica se conocía en Mallorca (Askew, 1973).

Citas en la Comunidad de Madrid.- Esta especie ya había sido citada anteriormente en la Comunidad en Madrid (Ceballos, 1941-43). Parece ser mucho más común que las demás especies del género; estudiados ejemplares de la colección Mercet, colectados en Alcalá y Aranjuez. Capturados mediante red de barrido ejemplares en Arganda, Camporreal, Cerros de Morata, Monte el Robledal, El Piul y El Porcal y con las trampas Malaise en El Pardo y El Ventorrillo. La mayoría de las capturas se realizó durante la primavera y el verano.
Biología.- Se ha obtenido como parásito de Cephus pygmaeus L. y Trachelus tabidus F. (Hym., Tenthredinoidea) sobre cereales en la antigua URSS y como parásito de Lixus junci Boh. (Col., Curculionidae) en caña de azucar en Italia (Graham, 1969).

\section{Norbanus (Picroscytoides) sp. ind.}

Citas en la Comunidad de Madrid.- bajo esta denominación se incluyen una serie de ejemplares que no han podido ser identificados hasta especie por tratarse de machos, para los cuales no existen claves de identificación. Algunos de estos ejemplares proceden de la colección Mercet y fueron colectados en Alcalá y Aranjuez, el resto proceden de El Ventorrillo donde se recogieron con trampa Malaise

\section{Merisus Walker, 1835}

Diversidad y distribución.- Dos especies holárticas (Boucek y Rasplus, 1991). Es un género nuevo para la Península Ibérica.

Referencias taxonómicas.- Graham (1969).

Biología.- Su principal especie es parásita de calcídidos euritómidos (Hym., Eurytomidae) sobre tallos de gramíneas (Gramineae) (Boucek y Rasplus, 1991).

\section{Merisus splendidus Walker, 1835}

Distribución. - Ampliamente distribuida por Europa donde se ha citado en Alemania, Checoslovaquia, Francia, Hungría, Inglaterra, Italia, República de Moldavia y Suecia; también se conoce en el norte de África (Graham, 1969). Se trata de la primera cita para la Península Ibérica.

Citas en la Comunidad de Madrid.- Es una especie muy frecuente en la Comunidad; se han estudiado ejemplares de la colección Mercet procedentes de Collado Mediano, Galapagar, El Pardo (Chamartín), Somosierra y Villaviciosa de Odón. Otros ejemplares se capturaron mediante barrido en Brea de Tajo, Canencia, Carretera Estremera a Brea de Tajo, Morata de Tajuña, Oteruelo del Valle y con trampas Malaise en El Ventorrillo. Todas las capturas se concentran a finales de primavera y durante los meses de verano.

Biología.- Algunos ejemplares se obtuvieron de un grupo de agallas producidas por Tetramesa brevicornis (Walker) (Hym., Eurytomidae) sobre tallos de Festuca rubra L. var. arenaria (Osb.) (Gramineae) (Graham, 1969). 


\section{Homoporus Thomson, 1878}

Diversidad y distribución.- Género ampliamente distribuido, con un gran número de especies: América del Norte (12); paleártico occidental (al menos 28); África (al menos 2); sur y este de Asia (2); Australia (1) (Boucek, 1988).

Referencias taxonómicas.- - Graham (1969).

Biología. - La mayor parte de las especies paleárticas presentan hospedadores que se desarrolllan sobre tallos de plantas herbáceas, más raramente, aparecen asociados con insectos que viven sobre tallos de arbustos (Boucek y Rasplus, 1991).

\section{Homoporus apharetus (Walker, 1839)}

Distribución.- Especie común, ampliamente distribuida en Europa (Graham, 1969). Se cita por primera vez en la Península Ibérica.

Citas en la Comunidad de Madrid.- No es una especie rara en la Comunidad. Se han estudiado ejemplares de la colección Mercet, colectados en El Escorial, El Pardo, Vaciamadrid y Villaviciosa de Odón. Adicionalmente colectada por los autores en Collado Mediano mediante barrido y en El Pardo y El Ventorrillo con trampas Malaise.

Biología.-Desconocida.

\section{Homoporus arestor (Walker, 1848)}

Distribución.- Aparentemente se trata de una especie poco común, citada en Inglaterra, Suecia y Europa Central (Graham, 1969). En la Península Ibérica ha sido citada en Burgos (Garrido y NievesAldrey, 1992b).

Citas en la Comunidad de Madrid.- Estudiados dos únicos ejemplares capturados en El Pardo y El Ventorrillo con trampas Malaise. Biología.-Desconocida.

\section{Homoporus destructor (Say, 1817)}

Distribución.- Holártica (Graham, 1969). Se cita por primera vez para la Península Ibérica.

Citas en la Comunidad de Madrid.- Es una especie muy frecuente en la Comunidad; se han recogido ejemplares mediante barrido en Arganda, Carretera Estremera a Brea de Tajo, Cerros de Morata, El Pardo, El Porcal y Valle de Bustarviejo. Otros ejemplares estudiados, pertenecientes a la Colección Mercet, proceden de Collado Mediano, El Escorial (Zarzalejo), Loeches, Paracuellos del Jarama, El Pardo (Chamartín), Vaciamadrid y
Villaviciosa de Odón. Además, con las trampas Malaise se colectaron ejemplares en El Pardo y en El Ventorrillo, realizándose estas capturas principalmente durante la primavera y el verano.

Biología.-Especie de gran importancia en la lucha biológica contra plagas por ser uno de los principales parásitos de Mayetiola destructor (Say) (Dipt., Cecidomyiidae), causante de graves daños en los cereales. Normalmente es un ectoparásito primario, solitario, pero ocasionalmente puede ser un parásito secundario a través de Platygaster hiemalis Forbes o Platygaster zosina Walker (Hym., Platygastridae). También se han citado como hospedadores Mayetiola avenae Marsh. (Dipt., Cecidomyiidae), Oscinella frit (L.) (Dipt., Chloropidae) y Elachiptera cornuta (Fln) (Graham, 1969).

\section{Homoporus febriculosus (Girault, 1917)}

Distribución.- Especie holártica (Graham, 1969). Se cita por primera vez en la Península Ibérica.

Citas en la Comunidad de Madrid.- Especie relativamente frecuente en la CAM. Capturados mediante barrido numerosos ejemplares en Arganda, Brea de Tajo, Carretera Estremera a Brea de Tajo, Carretera Villamanrique a Colmenar, Monte el Robledal y El Paular. En la colección Mercet, se encontraron ejemplares de El Pardo, Vaciamadrid y Villaviciosa de Odón. Utilizando trampas Malaise se recogió un único ejemplar en el Pardo y un número más elevado en El Ventorrillo. Ligada a comunidades vegetales de encinares manchegos en el sur de la CAM.

Biología.- Peck (1963) recoge una lista de hospedadores entre los que se encuentran Hymenoptera de las familias Cephidae, Braconidae, Eupelmidae, Eurytomidae (Tetramesa sp.) y Platygastridae y también Mayetiola destructor (Say) (Dipt., Cecidomyiidae). Se trata de una especie solitaria y normalmente es un ectoparásito primario (Graham, 1969).

\section{Homoporus sp. nr. febriculosus}

Citas en la Comunidad de Madrid.- Mediante barrido en la Carretera de Arganda a Morata y con la trampa Malaise en El Ventorrillo, se recogieron algunos ejemplares que, si bien comparten muchos caracteres con esta especie, no pueden ser totalmente asimilados con ella.

\section{Homoporus fulviventris (Walker, 1835)}

Distribución.- Ampliamente distribuida en Europa (Graham, 1969). En la Península Ibérica se 
conocía de Guadalajara y Madrid (Nieves-Aldrey y Martín Chicote, 1986).

Citas en la Comunidad de Madrid.- Esta especie ya se conocía en la Comunidad donde se encontró en agallas de Timaspis cichorii Kieffer, 1909 (Hym., Cynipidae) sobre Cichorium intybus en Arganda (Nieves-Aldrey y Martín Chicote, 1986). Colectada con red de barrido en Alameda del Valle, Arganda, Brea de Tajo, Carretera Estremera a Brea de Tajo, Monte el Robledal, Oteruelo del Valle y El Ventorrillo. También, en la colección Mercet, aparecen ejemplares de El Escorial; El Pardo y Vaciamadrid. Utilizando trampas Malaise se colectó en El Pardo y en El Ventorrillo. La mayor parte de las capturas se concentró durante los meses de verano, aunque algunos ejemplares se recogieron en la primavera e incluso a principios de otoño.

Biología.- Está ligada a agallas de cinípidos producidas en plantas de la familia Asteraceae, principalmente del género Centaurea L. Se han obtenido ejemplares de agallas de Phanacis centaureae (Foerst.) (Hym., Cynipidae) sobre tallos de Centaurea aspera L., y sobre Centaurea scabiosa L. y de agallas de Timaspis cichorii Kieffer, 1909 (Hym., Cynipidae) sobre tallos de Cichorium intybus L. (Nieves-Aldrey y Martín Chicote, 1986).

\section{Homoporus gibbiscuta Thomson, 1878}

Distribución.- La especie se conocía en Inglaterra, Suecia, Alemania y norte de África (Graham, 1969). Constituye la primera cita para la Península Ibérica.

Citas en la Comunidad de Madrid.- Mucho menos frecuente que las anteriores, sólo se han colectado dos ejemplares, uno de ellos perteneciente a la colección Mercet, de Paracuellos del Jarama y otro colectado con trampa Malaise en El Ventorrillo.

Biología.- Desconocida.

\section{Homoporus luniger (Nees, 1834)}

Distribución.- Se trata de una de las especies más comunes del género, ampliamente distribuida en Europa (Graham, 1969). En la Península Ibérica se conoce de Burgos y Cantabria (Garrido y NievesAldrey, 1992b).

Citas en la Comunidad de Madrid.- Colectada en Arganda, Camporreal, Carretera Estremera a Brea de Tajo, Cerros de Morata, Cotos de Monterrey y El Ventorrillo. Aunque el número de ejemplares es menor que algunas otras especies del género, pare- ce tratarse de una especie común, mucho más frecuente durante los meses de verano.

Biología.- Se han obtenido ejemplares de Tetramesa calamagrostidis (Hed.) (Hym., Eurytomidae). Delucchi (1957) señala que es un parásito probable de Mayetiola spp. (Dipt., Cecidomyiidae) pero esta afirmación necesita ser comprobada según Graham, (1969).

\section{Homoporus nubilipennis Garrido y Nieves- Aldrey, 1996}

Distribución. - Sólo conocida en la Península Ibérica donde se ha colectado en la Comunidad de Madrid y en Galicia.

Citas en la Comunidad.- Se trata de una especie descrita a partir del material colectado por Mercet en Somosierra, quien a pesar de haberla rotulado como nueva, nunca la describió.

Biología.-Desconocida.

\section{Homoporus nypsius (Walker, 1839)}

Distribución. - Especie no muy común, pero ampliamente distribuida por Europa; también se ha citado en norte de África (Marruecos) y Estados Unidos (Graham, 1969). En la Península Ibérica se conoce de Cantabria (Garrido y Nieves-Aldrey, 1992b).

Citas en la Comunidad de Madrid.- Estudiados dos ejemplares de la colección Mercet de Guadarrama y Vaciamadrid; un tercer ejemplar fue capturado en El Ventorrillo con trampa Malaise.

Biología.- Peck (1963) cita como hospedadores Phytophaga destructor Say (Dipt., Cecidomyiidae), varias especies de euritómidos (Eurytoma y Tetramesa sp.) (Hym., Euytomidae) que viven sobre plantas herbáceas y Ditropinotus aureoviridis Crawf. (Hym., Torymidae) (Graham, 1969).

\section{Homoporus pulchripes Erdös, 1953}

Distribución.- Conocida en Hungría, República de Moldavia y Suiza (Graham, 1969). Se cita por primera vez para la Península Ibérica.

Citas en la Comunidad de Madrid.- La mayor parte de los ejemplares se colectaron con red de barrido en: Cerros de Morata, Collado Mediano, El Piul y El Porcal. De la colección Mercet se estudiaron algunos ejemplares de Vaciamadrid y se colectó uno con trampa Malaise en El Ventorrillo. Especie frecuente en el sur de la Comunidad, donde aparece ligada a comunidades vegetales de matorrales halófilos y coscojares. 
Biología.-En Hungría se han obtenido ejemplares parásitos de Tetramesa aciculata v. Schlecht. (Hym., Eurytomidae) sobre tallos de Stipa capillata L. (Gramineae) (Graham, 1969).

\section{Homoporus semiluteus (Walker, 1872)}

Distribución.- Amplia distribución europea (Graham, 1969). Se cita por primera vez para la Península Ibérica.

Citas en la Comunidad de Madrid.- Los únicos ejemplares estudiados se colectaron en agosto en El Ventorrillo con trampa Malaise.

Biología.-Desconocida.

\section{Homoporus subniger (Walker, 1835)}

Distribución.- Especie común, citada en Checoslovaquia, Inglaterra y República de Moldavia (Graham, 1969). En la Península Ibérica se conoce de Barcelona, Guadalajara, León, Madrid y Valladolid (Nieves-Aldrey y Martín Chicote, 1986). Citas para la Comunidad de Madrid.- L La especie se conocía ya en la comunidad donde se encontró como parásito de agallas de Timaspis phoenixopodos Mayr, 1882 sobre Lactuca viminea Link en El Escorial y de agallas de Timaspis cichorii Kieffer, 1909 sobre Cichorium intybus L. en Perales de Tajuña (Nieves-Aldrey y Martín Chicote, 1986); se han recogido nuevos ejemplares parásitos de Phanacis centaureae Foerster, 1860 Förster sobre Centaurea sp. en Alpedrete y en agallas de Timaspis phoenixopodos Mayr, 1882 sobre Lactuca viminea Link. en El Escorial, lo que concuerda con los hospedadores antes citados. Además, se colectaron ejemplares mediante barrido en Arganda, Carretera Estremera a Brea de Tajo y Cerros de Morata; pertenecientes a la colección Mercet en Chamartín y Paracuellos del Jarama y con trampas Malaise en El Pardo y El Ventorrillo. Especie ligada a comunidades vegetales de encinar manchego. Biología.- Se han obtenido ejemplares de tallos de Centaurea scabiosa L. (Asteraceae). El hospedador no se conoce con certeza pero probablemente se trate de Phanacis centaureae Foerster, 1869 (Hym., Cynipidae). Szelényi (1956) lo cita como parásito primario de Timaspis papaveris (Thomson) (Hym., Cynipidae) sobre tallos de Papaver somniferum L. (Papaveraceae) y de agallas de Phanacis centaureae Foerster, 1860 (Hym., Cynipidae) en tallos de Centaurea Sadleriana Janka (Asteraceae) (Graham, 1969). Nieves-Aldrey y Martín Chicote (1986) citan como hospedadores Aulacidea
Tragopogonis (Thomson) (Hym., Cynipidae) sobre Tragopogon sp. Phanacis centaureae Foerster, 1860 sobre tallos de Centaurea aspera L. y de Centaurea scabiosa L., Timaspis cichorii Kieffer, 1909 sobre tallos de Cichorium intybus L., Phanacis hypochoeridis (Kieffer, 1887) sobre Hypochoeris radicata L. Phanacis caulicola (Hedicke, 1939) sobre Picris echioides L. y sobre agallas de Phanacis phoenixopodos (Mayr, 1882) sobre Lactuca viminea Link., confirmando de esta manera el parasitismo de esta especie en agallas de cinípidos (Hym., Cinipidae) sobre Asteraceae.

\section{Callitula Spinola, 1811}

Diversidad y distribución.- Ampliamente distribuido por todo el mundo, desde el norte y sur de la zona templada donde existen aproximadamente 10 especies, hasta los trópicos donde se trata de un género poco conocido con sólo cinco especies descritas. En Europa se conocen cinco especies (Boucek, 1988; Boucek y Rasplus, 1991). Referencias taxonómicas. - Graham (1969).

Biología.- Parásito de pequeños dípteros, especialmente agromícidos (Dipt., Agromyzidae). Los hospedadores preferidos parecen ser especies cuyas larvas perforan tallos $\mathrm{u}$ otras partes de plantas herbáceas (Boucek, 1988).

\section{Callitula bicolor Spinola, 1811}

Distribución.- Holártica; muy común, distribuida ampliamente en Europa (Graham, 1969; Boucek, 1977). En la Península Ibérica se ha citado en Cantabria (Garrido y Nieves-Aldrey, 1992b).

Citas en la Comunidad de Madrid.- Aunque sólo se ha colectado en El Pardo y El Ventorrillo mediante barrido o con trampas Malaise, se trata de una especie muy abundante, sobre todo en la última localidad, donde se colectó un número muy elevado de ejemplares durante la primavera, verano y principios de otoño.

Biología.- Es un parásito primario o secundario de pequeños dípteros sobre tallos de gramineas. En Europa y Norteamérica se ha encontrado como parásito de Mayetiola destructor (Say) (Dipt., Cecidomyiidae), y de los siguientes Chloropidae: Chlorops taeniopus $\mathrm{Mg}$, Lasiosina cinctipes $\mathrm{Mg}$; Meromyza americana Fitch, Meromyza saltatrix (L.); Oscinella frit (L.), Oscinella minor (Adams) y probablemente también Oscinella carbonaria (Löw) y Oscinella soror (Macq.). También se ha citado como hiperparásito atacando a Proctotrupoidea 
(Platygastridae) que son parásitos primarios de los dípteros antes citados (Graham, 1969).

\section{Psilocera Walker, 1833}

Diversidad y distribución.- Comprende siete especies europeas (Graham, 1992a), también se encuentra distribuido por Norteamérica hasta el sur de Brasil (tres especies), África (al menos una especie), Asia (al menos tres especies), Nueva Guinea y Australia (dos o tres especies) (Boucek, 1988).

Referencias taxonómicas.- Graham (1992a) (Especies europeas).

Biología.- No se conocen los hospedadores, pero se piensa que se tratan de coleópteros que habitan en el suelo o cuyas pupas se desarrollan en él (Boucek, 1988).

\section{Psilocera confusa Graham, 1992}

Distribución.- Se ha citado en Checoslovaquia, Francia y Portugal (Graham, 1992a). Constituye la primera referencia para la Península Ibérica.

Citas en la Comunidad de Madrid.- - Es una especie frecuente en la CAM. En la colección de Mercet existen ejemplares recogidos en Aranjuez, El Pardo, Rivas y Vaciamadrid. Adicionalmente se ha colectado con red en Canencia, Carretera Estremera a Brea de Tajo, Madarcos, Morata de Tajuña, El Piul y El Ventorrillo y con trampas Malaise en El Pardo y El Ventorrillo.

Biología.- Se desconoce el hospedador; Graham, (1992a) obtiene ejemplares sobre Erica scoparia L. (Ericaceae).

\section{Psilocera crassispina (Thomson, 1878)}

Distribución.- Conocida en Checoslovaquia, Francia, Italia, Inglaterra y Suecia (Graham, 1992a). Es primera cita en la Península Ibérica.

Citas en la Comunidad de Madrid.-Colectada en: Carretera Villamanrique a Colmenar, ChinchónTitulcia, Madarco y El Ventorrillo. De la colección Mercet se estudió un ejemplar de El Pardo. El mayor número de ejemplares fue recogido en $\mathrm{El}$ Ventorrillo con trampas Malaise. En todos los casos, las capturas corresponden a finales de primavera o los meses de verano.

Biología.-Desconocida.

\section{Psilocera obscura Walker, 1833}

Distribución.- Se conoce en Checoslovaquia,
Inglaterra y Yugoslavia (Graham, 1992a). Es la primera cita en la Península Ibérica.

Citas en la Comunidad de Madrid.- Mucho menos frecuente que las anteriores especies del género, sólo se ha colectado con red de barrido en Canencia y Orusco en los meses de agosto y mayo respectivamente.

Biología.-Desconocida.

Psilocera seiugata Graham, 1992

Distribución.- Citada en Francia y España (Graham, 1992a).

Citas en la Comunidad de Madrid.- Esta especie fue descrita por Graham (1992a) a partir de ejemplares colectados en El Pardo durante el mes de octubre. Sin embargo, no ha aparecido en nuestros muestreos. Biología.- Desconocida.

\section{Catolaccus Thomson, 1878}

Diversidad y distribución.- Cuenta con dos especies ampliamente distribuidas en Europa (Boucek, y Rasplus, 1991). Se cita por primera vez en la Península Ibérica.

Referencias taxonómicas. - Dzhanokmen (1980) (Especies de la antigua URSS).

Biología.- Probablemente se trata de un género hiperparásito via Apanteles sp. (Hym., Braconidae) (Boucek y Rasplus, 1991).

\section{Catolaccus crassiceps (Masi, 1911)}

Distribución.-Europa central y meridional (Boucek, 1977). Es la primera cita en la Península Ibérica.

Citas en la Comunidad de Madrid.- Especie muy frecuente en la CAM. Recogida mediante barrido en las siguientes localidades: Canencia, Carretera Estremera a Brea de Tajo, Cerceda, Monte el Robledal, El Piul, Rivas Vaciamadrid y El Ventorrillo. En la Colección Mercet existen ejemplares de Cercedilla, El Escorial, Montarco, El Pardo y Vaciamadrid. Además se capturaron bastantes ejemplares con trampas Malaise en el Pardo y El Ventorrillo. La mayor parte de ellos durante el verano. Biología.- Hiperparásito de varios insectos a través de Braconidae e Ichneumonidae (Hymenoptera) (Boucek, 1977).

Psychophagus Mayr, 1904

Diversidad y distribución.- Género monoespecífico muy común, con una amplia distribución euro- 
pea (Boucek y Rasplus, 1991). Se cita por primera vez en la Península Ibérica.

Referencias taxonómicas.- Graham (1969); Boucek y Rasplus (1991).

Biología.- Parásito gregario de algunos lepidópteros (Lepidoptera) y de algunas especies de Tenthredinoidea (Hymenoptera); en ocasiones hiperparásito vía Ichneumonidae, Braconidae, etc (Hymenoptera) (Boucek y Rasplus, 1991).

\section{Psychophagus omnivorus (Walker, 1835)}

Citas en la Comunidad de Madrid.- Sólo se ha encontrado esta especie en El Ventorrillo; algunos ejemplares colectados con trampa Malaise y uno con trampas bandeja coloreadas.

\section{Stenetra Masi, 1931}

Diversidad y distribución.- Comprende tres especies distribuidas en el centro y sur de Europa (Boucek y Rasplus, 1991). Se cita por primera vez para la Península Ibérica.

Referencias taxonómicas.- Boucek y Rasplus (1991). Biología.- Se desconocen sus hospedadores.

\section{Stenetra hungarica (Szelényi, 1982)}

Distribución.- Especie conocida en Francia y Hungría (Boucek y Rasplus, 1991). Se cita por primera vez en la Península Ibérica.

Citas en la Comunidad de Madrid.- Especie poco común; capturado un único ejemplar en El Ventorrillo con trampa Malaise en agosto.

Biología.-Desconocida.

\section{Stenetra ligustica Masi, 1931}

Distribución.- Especie rara aunque ampliamente distribuida en el centro y sur de Europa (Boucek y Rasplus, 1991). Es la primera cita para la Península Ibérica.

Citas en la Comunidad de Madrid.- Especie menos rara que la anterior en la Comunidad, aunque sólo se han capturado ejemplares en El Pardo y El Ventorrillo utilizando trampas Malaise y durante los meses de verano.

Biología.-Desconocida.

\section{Spilomalus Graham. 1956}

Diversidad y distribución.- Cuenta con cuatro especies poco conocidas en Europa y en norte de
África (dos especies), Canarias (una especie) y Madeira (una especie) (Boucek y Rasplus, 1991).

Referencias taxonómicas.- Gijswijt y Graham (1986).

Biología.- No se conocen los hospedadores, si bien se cree que sean algunas especies de coleópteros (Boucek y Rasplus, 1991).

Spilomalus dolichogaster Gijswijt y Graham, 1986

Distribución.- Se ha citado en Francia y en la Península Ibérica de Barcelona y Murcia (Gijswijt y Graham, 1986).

Citas en la Comunidad de Madrid.- Citada previamente en la CAM a partir de ejemplares recogidos en El Escorial (Gijswijt y Graham, 1986). Adicionalmente se han colectado dos ejemplares en El Ventorrillo con bandejas amarillas en el mes de mayo. Biología.-Desconocida.

\section{Spilomalus quadrinota (Walker, 1835)}

Distribución.- Aparentemente es una especie rara, citada en Holanda, Inglaterra (Graham, 1969), Italia y Yugoslavia (Gijswijt y Graham, 1986). En la Península Ibérica se conoce de Asturias (Garrido y Nieves-Aldrey, 1992b), Barcelona (Gijswijt y Graham, 1986), Cantabria (Garrido y Nieves-Aldrey, 1992b) y Castellón (Gijswijt y Graham, 1986).

Citas en la Comunidad de Madrid.- Estudiados ejemplares de la colección Mercet procedentes de El Escorial y Somosierra. Colectada también en El Pardo y El Ventorrillo con trampas Malaise durante el verano.

Biología.-Algunos ejemplares se han obtenido de Auletobius politus Ser. (Col., Curculionidae) (Graham, 1969).

\section{Spintherus Thomson, 1878}

Diversidad y distribución.- Cuenta con una sola especie de distribución holártica (Boucek y Rasplus, 1991).

Referencias taxonómicas.— Graham (1969); Boucek y Rasplus (1991).

Biología.- Parásito de Apionidae (Coleoptera) en inflorescencias de Trifolium L. (Leguminoseae) (Boucek y Rasplus, 1991).

\section{Spintherus dubius (Nees, 1834)}

Distribución.- Especie holártica, ampliamente distribuida por toda Europa (Graham, 1969; 
Boucek, 1977). En la Península Ibérica ha sido citada en Asturias y Cantabria (Garrido y NievesAldrey, 1992b).

Citas en la Comunidad de Madrid.- Es una especie muy frecuente en la Comunidad; se colectó mediante barrido en Brea de Tajo, Canencia, Carretera Colmenar Viejo-San Agustín, Navacerrada, Oteruelo del Valle, El Pardo y El Ventorrillo. En la Colección Mercet se estudiaron ejemplares procedentes de Collado Mediano, Chamartín, El Escorial, El Pardo y Villaviciosa de Odón. A estos ejemplares hay que añadir los capturados con trampas Malaise en El Pardo y El Ventorrillo donde también los recogimos con bandejas amarillas. En todos los casos la especie parece ser más abundante durante el verano y principios de otoño.

Biología.- Parásita de Apion sp. (Col., Apionidae) sobre Trifolium sp (Boucek y Rasplus, 1991).

\section{Sceptrothelys Graham, 1956}

Diversidad y distribución.- Siete especies distribuidas regionalmente en Europa y América del Norte (Boucek y Rasplus, 1991). Se cita por primera vez para la Península Ibérica.

Referencias taxonómicas.—Graham (1969).

Biología.- Algunas especies se han obtenido como parásitas de Coleophora spp. (Lep., Coleophoridae) y de Phytonomus nigrirostris F. (Col., Curculionidae) (Boucek y Rasplus 1991).

\section{Sceptrothelys grandiclava (Walker, 1835)}

Distribución.-Citada en Alemania Checoslovaquia, Inglatera, Suecia, (Graham, 1969). Es la primera referencia para la Península Ibérica.

Citas en la Comunidad de Madrid.- Un único ejemplar de El Ventorrillo colectado con trampa Malaise en julio.

Biología.-Desconocida.

Pteromalus Swederus, 1795

Diversidad y distribución.- Género cosmopolita con aproximadamente 100 especies descritas (Boucek y Rasplus, 1991).

Referencias taxonómicas.- Graham (1969).

Biología.- La mayoría de las especies del género son parásitas de pupas de Lepidoptera, Coleoptera, Hymenoptera y de agallas de tefrítidos (Dipt. Tephrytidae) (Boucek y Rasplus, 1991).
Pteromalus albipennis Walker, 1835

Distribución.- Especie conocida en Alemania. Checoslovaquia, Inglaterra, Irlanda y Suecia (Graham, 1969). En la Península Ibérica se ha citado en Cantabria (Garrido y Nieves-Aldrey, 1992b).

Citas en la Comunidad de Madrid. - Los escasos ejemplares encontrados proceden de El Ventorrillo, colectados con red de barrido y trampas Malaise en los meses de julio y septiembre.

Biología.- Parásita de Chaestomella cylindrica R.-D y Chaetoriella jacaceae (R.-D) (Dipt., Tephrytidae) en cabezuelas de Centaurea memoralis Jord. (Asteraceae). También se han identificado los siguientes hospedadores Tephritis bardanae Schr (Dipt., Tephrytidae) y Trypeta tussilaginis F. (Dipt., Tephrytidae) en Arctium lappa L. (Asteraceae) y Trypeta winthemi Mg (Dipt. Tephrytidae) en Carduus crispus L. (Asteraceae) (Graham, 1969), Askew (1970). encontró ejemplares en cabezuelas de Actium lappa L. y Centaruea scabiosa L.

Pteromalus altus (Walker, 1834)

Distribución.- Se conoce en Checoslovaquia (Graham, 1969), Francia (Graham, 1984), Inglaterra y República de Moldavia (Graham, 1969). Es la primera cita en la Península Ibérica.

Citas en la Comunidad de Madrid.- Encontrados tres ejemplares en El Ventorrillo, colectados con trampa Malaise a finales de septiembre y principios de octubre.

Biología.- Desconocida. Graham (1984) obtuvo ejemplares sobre flores de Euphorbia amygaloides L. (Euphorbiaceae).

\section{Pteromalus apum (Retzius, 1783)}

Distribución.- Ampliamente distribuida en Europa (Boucek, 1977). Se cita por primera vez para la Península Ibérica.

Citas en la Comunidad de Madrid.- Estudiados algunos ejemplares de la colección Mercet, procedentes de Alcalá. Adicionalmente se colectó mediante red de barrido en El Piul y con trampas Malaise en El Pardo y El Ventorrillo. Los datos de captura indican que es más abundante a finales de primavera y durante el verano.

Biología.- Parásito de Megachile spp. (Hym., Apoidea) (Graham, 1969; Boucek, 1977). 
Pteromalus bedeguaris (Thomson, 1878)

Distribución.- Amplia distribución Europea (Graham, 1969). En la Península Ibérica se conoce en: Barcelona (Pujade, 1992), Córdoba (Díaz, 1923), Lleida (Pujade, 1992), Salamanca (NievesAldrey, 1980, 1983a) y Tarragona (Pujade, 1992). Citas en la Comunidad de Madrid. - Citada anteriormente en la Comunidad de Madrid (Díaz, 1923; Nieves-Aldrey,1983). Confirmando los datos de las citas anteriores se encontraron numerosos ejemplares en agallas de Diplolepis mayri (Schl., 1877) y Diplolepis rosae (L., 1758) sobre Rosa sp. en distintas localidades de la Comunidad. En El Ventorrillo se capturaron algunos ejemplares con trampas Malaise y bandejas amarillas.

Biología. - Aparece de modo constante en agallas de Diplolepis rosae (L., 1758) y Diplolepis mayri (Schl., 1877) (Hym., Cynipidae). Según Nordlander (1973) parasitaría predominantemente a Orthopelma mediator (Rhum.) (Hym., Ichneumonidae); en ocasiones a Diplolepis rosae (L., 1758) y excepcionalmente a Periclistus brandii (Hym., Cynipidae) (Nieves-Aldrey, 1983a; Pujade, 1992).

\section{Pteromalus sp. nr. bedeguaris}

Citas en la Comunidad de Madrid.- De agallas de Diplolepis eglanteriae (Hartig, 1840) sobre Rosa sp recogidas en El Ventorrillo, emergieron ejemplares con similitudes con la especie anterior, pero que no pueden ser totalmente asimilados con ella.

\section{Pteromalus sp. nr. berylli}

Citas en la Comunidad de Madrid.- Se colectó en El Ventorrillo con trampa Malaise un ejemplar que muestra algunas características similares con esta especie, pero que no puede serle asignada con toda seguridad.

\section{Pteromalus bifoveolatus Förter, 1861}

Distribución.- Se encuentra principalmente en el centro y sur de Europa y norte de África (Boucek, 1977). Es la primera cita en la Península Ibérica. Citas en la Comunidad de Madrid.-Se estudiaron dos ejemplares de la Colección Mercet recogidos en El Pardo. Además, la especie se colectó mediante barrido, con trampa Malaise y bandejas amarillas en El Ventorrillo, principalmente durante el verano. Biología.- Parásito de Lepidoptera (Lasiocampidae, Notodontidae y Saturnidae). Se han citado como hospedadores Philudoria potatoria (L.), Saturnia pyri Schiff (Saturnidae), Malacosoma neustria L. y Cerura vinula (L.) (Notodontidae) (Graham, 1969).

\section{Pteromalus brachygaster (Graham, 1969)}

Distribución.- Citado en Inglaterra (Graham, 1969), y más recientemente en Francia (Gijswijt, 1994). Es la primera vez que se cita en la Península Ibérica.

Citas en la Comunidad de Madrid.- Sólo encontrado un ejemplar en El Ventorrillo, capturado en julio con trampa Malaise.

Biología.- Desconocida. Gijswijt (1994) obtuvo ejemplares sobre cabezuelas de Artemisia absinthium L. (Asteraceae).

\section{Pteromalus cioni (Thomson, 1878)}

Distribución.- Se conoce de Alemania, Inglaterra y Suecia (Graham, 1969). Es la primera cita para la Península Ibérica.

Citas en la Comunidad de Madrid. - Encontrada únicamente en Rivas Vaciamadrid y El Ventorrillo. Biología.- Se ha obtenido de Cionus sp. (Col., Curculionidae) sobre Scrophularia sp (Scrophulariaceae) (Graham, 1969).

\section{Pteromalus cionobius (Erdös, 1953)}

Distribución.- Especie con una amplia distribución europea (Boucek, 1977). Se cita por primera vez para la Península Ibérica.

Citas en la Comunidad de Madrid. - Es una especie frecuente en la Comunidad; se han recogido ejemplares mediante barrido en Canencia, Carretera Estremera a Brea, Cotos de Monterrey, Oteruelo del Valle, El Piul y El Ventorrillo; y en esta última localidad se colectó en abundancia con trampas Malaise, sobre todo durante el verano. Especie frecuente en fresnedas del norte de la Comunidad.

Biología.- Se ha obtenido de capullos de Cionus thapsi (F.) (Col., Curculionidae) en frutos de Verbascum phlomoides L. (Scrophulariaceae) (Graham, 1969).

\section{Pteromalus sp. nr. cionobius}

Citas en la comunidad de Madrid.- Estudiado un ejemplar de El Ventorrillo que, aunque comparte algunos de los caracteres de la especie, presenta 
algunas diferencias que impiden que sea asimilado totalmente con ella.

\section{Pteromalus dispar (Curtis, 1827)}

Distribución.- Ampliamente distribuida en Europa; conocida también en Pakistan (Graham, 1969). Es la primera cita para la Península Ibérica. Citas en la Comunidad de Madrid.- A tenor del material colectado es una especie frecuente; se dispone de ejemplares colectados en Carretera Brea de Tajo a Orusco, Carretera Villamanrique a Colmenar, Monte el Robledal, Orusco, Puerto de Canencia y Rivas Vaciamadrid. De la Colección Mercet existen ejemplares de El Escorial, Madrid, Móstoles, Vaciamadrid y Zarzalejo, mientras que en El Ventorrillo se colectó con trampa Malaise. Las capturas fueron más abundantes al final de primavera y durante el verano, pero también se recogieron ejemplares a comienzos de otoño e incluso en el mes de enero.

Biología.- Se han obtenido ejemplares procedentes de Macrocentrus linearis (Nees) (Hym., Braconidae), también se han recogido de capullos de Apanteles glomeratus (Hym., Braconidae) en Pieris brassicae L. (Lep. Pieridae) y de larvas de Notarcha ruralis Scop. (Lep. Pyralidae) sobre Urtica dioica L. (Urticaceae) (Graham, 1969).

Pteromalus dolichurus (Thomson, 1878)

Distribución.- Especie aparentemente común, citada en Alemania, Inglaterra y Suecia (Graham, 1969). En la Península Ibérica se conoce de Salamanca (Nieves-Aldrey y Martín Chicote, 1986).

Citas en la Comunidad de Madrid.- El Ventorrillo; algunos ejemplares capturados con red de barrido y trampa Malaise en verano.

Biología.- Parásito común de Pontania sp. (Hym., Tenthredinidae) sobre Salix L. sp (Salicaceae) (Graham, 1969; Nieves-Aldrey y Martín Chicote, 1986).

\section{Pteromalus elevatus (Walker, 1834)}

Distribución.- Probablemente se encuentra distribuida por toda Europa (Boucek, 1977). En la Península Ibérica se ha citado en Cuenca y Huesca (Nieves-Aldrey y Martín Chicote, 1986).

Citas en la Comunidad de Madrid.- Recogidos con red de barrido tres ejemplares en Carretera Estremera a Brea de Tajo durante los meses de mayo y julio; otros tantos en El Ventorrillo con trampa Malaise en junio y julio.
Biología.- Es un parásito común de tripétidos (Dipt., Tephrytidae) sobre Asteraceae (Graham, 1969). Nieves-Aldrey y Martin Chicote (1986) obtuvieron ejemplares procedentes de capítulos de Centaurea scabiosa L (Asteraceae) con agallas de Urophora sp. (Dipt., Tephrytidae).

\section{Pteromalus sp. nr. elevatus}

Citas en la Comunidad de Madrid.- En El Ventorrillo, mediante trampas Malaise, recogimos algunos ejemplares que presentan algunas diferencias con la especie por lo cual no han sido incluidos plenamente en la misma.

\section{Pteromalus fasciatus (Thomson, 1878)}

Distribución.- Conocida sólo de Suecia (Graham, 1969). Constituye la primera cita para la Península Ibérica.

Citas en la Comunidad de Madrid. - Encontrado un ejemplar de Madrid en la colección Mercet. Mediante barrido se colectó otro ejemplar en julio en el Puerto de Canencia, pero ha sido con trampas Malaise en El Ventorrillo donde se colectaran numerosos ejemplares, todos ellos durante los meses de julio y agosto.

Biología.-Desconocida.

\section{Pteromalus hieracii (Thomson, 1878)}

Distribución: Ampliamente distribuida en Europa (Graham, 1969). En la Península Ibérica se ha citado en León (Nieves-Aldrey y Martín Chicote, 1986).

Citas en la Comunidad de Madrid.- Estudiado un ejemplar de Madrid de la colección Mercet. Además se han colectado ejemplares en el Monte el Robledal, en comunidades vegetales de encinar manchego, mediante red de barrido y en El Ventorrillo con trampa Malaise. Todas las capturas se realizaron durante los meses de junio y agosto.

Biología.- En Inglaterra se ha obtenido de Phanacis centaureae Foerster, 1860 sobre Centaurea scabiosa L. (Asteraceae). En Suecia se ha obtenido de Aulacidea hieracii (Bouché, 1834) y Aulacidea tragopogonis (Thomson, 1877) (Hym., Cynipidae) (Graham, 1969). Nieves-Aldrey y Martin Chicote (1986) la obtuvieron de agallas de Aulacidea tragopogonis (Thomson, 1877) sobre Tragopogon sp. (Asteraceae). 


\section{Pteromalus intermedius (Walker, 1834)}

Distribución.- Se ha citado en Francia (Gijswijt, 1994), Inglaterra y Suecia (Graham, 1969). En la Península Ibérica se conoce en Asturias y Cantabria (Garrido y Nieves-Aldrey, 1992b).

Citas en la Comunidad de Madrid.- Es una de las especies de este género más frecuentes y abundantes en la Comunidad. Se ha recogido mediante barrido en Arganda, Canencia, Carretera Arganda a Morata, Carretera Brea de Tajo a Orusco, Carretera Estremera a Brea de Tajo, Carretera Morata a Chinchón, Cerceda, Fuentidueña de Tajo, Monte el Robledal, Orusco, Oteruelo del Valle y El Ventorrillo donde además se colectó con trampa Malaise. De la colección Mercet se estudiaron ejemplares de Chamartín, El Escorial, Madrid y Somosierra. Por otra parte, se obtuvieron ejemplares a partir de agallas de Tephrytidae (Diptera) sobre Tragopogon (Asteraceae) en El Escorial. Las capturas fueron más frecuentes durante la primavera y el verano, aunque algunos ejemplares se recogieron durante el otoño.

Biología.- Obtenido de tallos de Artemisia vulgaris L (Asteraceae) quizás como parásito de Oxyna nebulosa (Wied.) (Dipt., Tephritidae) (Graham, 1969). Gijswijt (1994) obtuvo ejemplares sobre cabezuelas de Artemisa absinthium L (Asteraceae).

\section{Pteromalus isarchus Walker, 1839}

Distribución.- Conocida en Inglaterra y Suecia (Graham, 1969). En la Península Ibérica se ha citado en Salamanca (Nieves-Aldrey y Martín Chicote, 1986).

Citas en la Comunidad de Madrid.- De acuerdo con las referencias antes citadas, se obtuvieron ejemplares en agallas de Xestophanes potentillae (Redz. in DeGeer, 1873) sobre Potentilla reptans L. En la colección Mercet se estudiaron ejemplares colectados en Paracuellos del Jarama y Vaciamadrid. Adicionalmente se ha colectado con red de barrido y trampas Malaise en El Pardo y en El Ventorrillo.

Biología.- Parásito de Xestophanes potentillae (Retz. in DeGeer, 1873) (Hym., Cynipidae) sobre Potentilla reptans L. (Rosaceae) (Graham, 1969; Nieves-Aldrey y Martín Chicote, 1986).

\section{Pteromalus musaeus Walker, 1844}

Distribución.- Ampliamente distribuida en Europa, citada en Inglaterra y Suecia (Graham, 1969). En la Península Ibérica se conoce en
Asturias (Garrido y Nieves-Aldrey, 1992b) y Mallorca (Askew, 1973).

Citas en la Comunidad de Madrid. - Colectada en Arganda; Brea de Tajo, Carretera Estremera a Brea de Tajo, Carretera Villamanrique a Colmenar y, en El Ventorrillo, con trampa Malaise durante el mes de agosto; en el resto de las localidades, las capturas se realizaron durante los meses de mayo y octubre.

Biología.- Se han obtenido ejemplares de Cirsium vulgare (Savi) y Carduus nutans L. (Asteraceae) infectados por Terellia serratulae (L.) (Dipt., Tephritidae) (Graham, 1969).

\section{Pteromalus platyphilus (Walker, 1836)}

Distribución.- Especie paleártica (Graham, 1969). Es la primera cita para la Península Ibérica. Citas en la comunidad de Madrid.- Relativamente frecuente, se han encontrado ejemplares en Cerceda, El Escorial, Monte el Robledal, El Piul y El Ventorrillo. Todos ellos fueron colectados durante los meses de verano.

Biología.- Se han obtenido ejemplares procedentes de la puesta de Dictyna arundinacea (L) (Aracnida, Dictynidae) (Graham, 1969).

\section{Pteromalus puparum (Linnaeus, 1758)}

Distribución.- Especie cosmopolita (Graham, 1969). En la Península Ibérica se había citado en Portugal (Figueiredo y Araujo, 1985).

Citas en la Comunidad de Madrid. - Es bastante frecuente en la Comunidad, sobre todo durante el verano, que es la época a que se refieren la mayoría de las citas. Procedentes de la colección Mercet se han examinado ejemplares de Alcalá, Cercedilla, El Escorial, Loeches, Madrid, Montarco y Villaviciosa de Odón. Además se han colectado ejemplares en Fuentidueña de Tajo mediante barrido y en El Ventorrillo con trampa Malaise y bandejas amarillas.

Biología.- Parásito de pupas de lepidópteros especialmente Rhopalocera; en Europa sus hospedadores más comunes son Pieris spp (Lep., Pieridae), Nymphalis spp. (Lep., Nymphalidae), Papilio machaon L. (Lep., Papilionidae), Aglais urticae (L.), Vanessa cardui (L.), Vanesa atalanta (L.) (Lep., Nymphalidae). Peck en Muesbeck et al (1951) y Peck (1963) recoge como hospedadores otras especies pertenecientes a otras familias de Lepidoptera, Ichneumonidae, Braconidae, Vespidae y Sphecidae (Hymenoptera), incluso cita como hospedador Dibrachys cavus (Walker) 
(Hym., Pteromalidae) tratándose en este caso de hiperparasitismo (Graham, 1969).

\section{Pteromalus semotus (Walker, 1834)}

Distribución.- Especie cosmopolita (Boucek, 1977). En la Península Ibérica se ha citado en Mallorca (Askew, 1973), España: (Mercet, 1929, 1932; Romanyk y Ruperez, 1960).

Citas en la Comunidad de Madrid.- Es una de las especies del género más frecuentes y abundantes, sobre todo a finales de primavera, durante el verano e incluso a comienzo de otoño. Se ha colectado mediante barrido en Alameda del Valle, La Cabrera, Canencia, Carretera Villamanrique a Colmenar, Fuentidueña de Tajo, Madrid (Alto los Leones), Monte el Robledal, Navacerrada, Orusco, Oteruelo del Valle, Puerto de Cotos y El Ventorrillo donde, además, se recogieron un elevado número de ejemplares con trampas Malaise y bandejas coloreadas. También se estudiaron ejemplares de la colección Mercet de El Escorial, Madrid y El Pardo.

Biología.- Esta especie es un parásito primario o un hiperparásito de varios lepidópteros, también se ha recogido asociada con ciertos coleópteros, pero en estos casos no se sabe si se trata de un parásito primario o secundario. Se ha obtenido de larvas maduras de Coleophora frischella L. (Lep. Coleophoridae) como un parásito solitario y ocasionalmente gregario. En algunos casos, las larvas de Pteromalus semotus (Walk.) se encontraron como hiperparásitas de Coleophora a través de Bracon osculator Nees (Hym., Braconidae) y de Pieris brassicae L. (Lep. Pieridae) a través de Apanteles glomeratus L. (Hym., Braconidae). (Graham, 1969).

\section{Pteromalus sequester Walker, 1835}

Distribución.- Ampliamente distribuida por toda Europa (Boucek, 1977). En la Península Ibérica, se ha citado en Asturias, Cantabria (Garrido y NievesAldrey 1992b) y Mallorca (Askew, 1973).

Citas en la Comunidad de Madrid.- Se trata de una especie ya citada en la Sierra de Guadarrama (Sanz Benito, 1994). Es la especie más abundante de todas las del género en la Comunidad habiendo sido colectada en Alcalá, Arganda, Canencia, Carretera Estremera a Brea de Tajo, Cerceda, Cercedilla, El Escorial, Fuentidueña de Tajo, Madrid (Alto de los Leones), Monte el Robledal, Orusco, Oteruelo del Valle, El Pardo, El Paular, El Piul, El Porcal, Puerto de Cotos, Somosierra, Sierra de Guadarrama, Vaciamadrid, El Ventorrillo,
Villaviciosa de Odón y Zarzalejo. El mayor número de ejemplares ha sido colectado en El Ventorrillo y El Pardo con trampas Malaise; el resto fue recogido mediante barrido o bien eran ejemplares procedentes de la colección Mercet, concentrándose la mayoría de las capturas durante los meses de verano.

Biología.- Se ha obtenido como parásito de agallas de Asphondylia mayeri Lieb. (Dipt., Cecidomyiidae) sobre Cytisus scoparius (L.) (Leguminoseae); de Oedaule italica Masi en vainas de Calycotome spinosa Link (Leguminoseae). También se han encontrado ejemplares procedentes de larvas de Exapion fuscirostre (F.) (Col., Apionidae) en semillas de Cytisus (Graham, 1969). Ha sido citado como un parásito común de Exapion spp. (Sanz Benito, 1994).

\section{Pteromalus sp. nr. sequester}

Citas en la Comunidad de Madrid.- En El Ventorrillo, empleando trampas Malaise, fueron colectados durante los meses de julio y agosto, un cierto número de ejemplares, que si bien presentan la mayor parte de los caracteres de la especie, cuentan también con algunos aspectos diferenciales, por lo que no se han identificado formalmente con la misma.

\section{Pteromalus smaragdus Graham, 1969}

Distribución.- Tan sólo citada de Suecia (Graham, 1969). Es la primera cita para la Península Ibérica. Citas en la Comunidad de Madrid.- Únicamente recogidos tres ejemplares en El Ventorrillo con trampa Malaise a lo largo de junio, julio y agosto. Biología.-Desconocida.

\section{Pteromalus temporalis (Graham, 1969)}

Distribución.-Se conoce sólo de Suecia (Graham, 1969). Es la primera cita para la Península Ibérica. Citas en la Comunidad de Madrid. - Todos los ejemplares colectados proceden de El Ventorrillo donde parece ser una especie relativamente frecuente a lo largo del verano. Todos se colectaron con trampa Malaise.

Biología.-Desconocida.

Pteromalus tripolii (Graham, 1969)

Distribución.- Conocida en Inglaterra e Irlanda (Graham, 1969). Es la primera cita en la Península Ibérica. 
Citas en la Comunidad de Madrid.- Se han estudiado escasos ejemplares de El Ventorrillo donde se colectaron con trampa Malaise.

Biología.- Encontrado como parásito de Paroxyna plantaginis (Hal.) en cabezuelas de Aster tripolium L. (Asteraceae) (Graham, 1969).

\section{Pteromalus sp. nr. tripolii}

Citas en la Comunidad de Madrid.- En el Ventorillo, con trampas Malaise y mediante barrido, se recogieron algunos ejemplares que no pueden ser totalmente asignados a esta especie.

\section{Pteromalus varians (Spinola, 1808)}

Distribución.- Ampliamente distribuida en Europa (Boucek, 1977); se conocía en Alemania, Checoslovaquia, Francia, Inglaterra, República de Moldavia, Suecia y antigua URSS (Graham. 1969). Es la primera cita para la Península Ibérica.

Citas en la Comunidad de Madrid.- Se ha colectado con red de barrido en Madrid (Puerto de los Leones), Puerto de Canencia, Soto del Real y El Ventorrillo. Procedentes de Collado Mediano se han estudiado dos ejemplares de la colección Mercet y otros dos se han colectado con trampa Malaise en El Ventorrillo durante el mes de agosto. Especie que con frecuencia aparece en abedulares en el norte de la Comunidad.

Biología.- Parásito de Anthonomus sp. (Col., Curculionidae) (Boucek, 1977).

\section{Pteromalus vibulennus (Walker, 1839)}

Distribución.- Citada en Inglaterra, Irlanda, Alemania y Checoslovquia (Graham, 1969). Se cita por primera vez para la Península Ibérica.

Citas en la Comunidad de Madrid.- Poco frecuente; tan sólo se ha encontrado un ejemplar en Arganda mediante barrido en el mes de abril y tres más en El Ventorrillo, con trampa Malaise y bandejas amarillas, durante mayo y julio.

Biología.- Hiperparásito de Pieris brassicae (L.) (Lep., Pieridae) a través de Apanteles glomeratus (L.) (Hym., Braconidae). También se han obtenido ejemplares procedentes de Salebria obductella F. R. Kent. (Lep.) obtenidos en cabezuelas de Centaurea nemoralis Jord. (Asteraceae) (Graham, 1969).

\section{Phaenocytus Graham, 1969}

Diversidad y distribución.- Género monoespecífico ampliamente distribuido, pero local (Boucek y Rasplus, 1991).

Referencias taxonómicas.— Graham (1969); Boucek y Rasplus (1991).

Biología: Parásito de agallas de cinípidos (Hym., Cynipidae) (Boucek y Rasplus, 1991).

\section{Phaenocytus glechomae (Förster, 1841)}

Distribución.- En la Península Ibérica han sido encontrados algunos ejemplares en Cantabria que no se han podido asimilar totalmente a esta especie (Garrido y Nieves-Aldrey, 1992b).

Citas en la Comunidad de Madrid.- Poco frecuente, sólo recogido un ejemplar en El Ventorrillo con trampa Malaise en agosto.

Biología.- Obtenido de agallas de Aulax glechomae (L.) (Hym., Cynipidae) sobre Glechoma hederacea (Lamiaceae) (Boucek y Rasplus, 1991).

\section{Cecidostiba Thomson, 1878}

Diversidad y distribución.- Cuenta con al menos siete especies, la mayor parte de ellas distribuidas por los países mediterráneos (Boucek y Rasplus, 1991).

Referencias taxonómicas.- Nieves-Aldrey y Askew (1988).

Biología.- Género cuyas especies están asociadas con agallas de cinípidos (Hym., Cynipidae) sobre Quercus spp. (Fagaceae) (Nieves-Aldrey y Askew, 1988; Boucek y Rasplus, 1991).

\section{Cecidostiba adana Askew, 1961}

Distribución.- Citada en Francia (Askew, 1961a; Graham, 1969) y en la Península Ibérica en Cataluña (Pujade, 1991) Salamanca (NievesAldrey, 1982b; Nieves-Aldrey y Askew, 1988).

Citas en la Comunidad de Madrid.- Se ha encontrado parasitando agallas de Andricus quercustozae (Bosc, 1792) sobre Quercus pyrenaica Willd. en El Escorial. Adicionalmente se colectó en El Ventorrillo con trampa Malaise.

Biología.- Está asociada con agallas de especies de Andricus Hartig y Cynips L. (Hym., Cynipidae) sobre Quercus spp. (Fagaceae) (Graham, 1969; Nieves-Aldrey, 1982b). 
Cecidostiba atra Askew, 1975

Distribución.- Citada en Francia (Askew, 1975b) y en la Península Ibérica en Barcelona (Pujade, 1985). España (Nieves-Aldrey y Askew, 1988).

Citas en la Comunidad de Madrid.- La mayoría de los ejemplares se obtuvieron como parásitos en agallas de Plagiotrochus australis (Mayr, 1882) sobre Quercus ilex L. en Cerceda, Navalquejigo y Los Rancajales. Un ejemplar fue recogido en El Ventorrillo con trampa Malaise.

Biología.- Asociada con agallas de Plagiotrochus australis (Mayr, 1882) (Askew, 1975b) y Plagiotrochus panteli Pujade, 1985 (Hym., Cynipidae) (Pujade, 1985) sobre Quercus ilex L. y Quercus coccifera L. (Nieves-Aldrey y Askew, 1988).

\section{Cecidostiba geganius (Walker, 1848)}

Distribución.- Especie citada en Bulgaria, Checoslovaquia, Francia, Hungría, Inglaterra, República de Moldavia y Yugoslavia (Graham, 1969). En la Península Ibérica se ha citado en Cataluña (Pujade, 1991), Salamanca (Nieves-Aldrey, 1982b); España (Nieves-Aldrey y Askew, 1988).

Citas en la Comunidad de Madrid.-Confirmando citas anteriores, todos los ejemplares estudiados proceden de agallas de Andricus quercusradicis (F., 1798) sobre Quercus pyrenaica Willd., colectadas en la Casa de Campo y El Escorial y sobre Quercus faginea Lam. en la Dehesa de Arganda y San Agustín de Guadalix.

Biología.- Se trata de un parásito específico en las agallas de Andricus quercusradicis (F., 1798) (Hym., Cynipidae) (Askew, 1961a, 1975b; NievesAldrey, 1982b; Nieves-Aldrey y Askew, 1988).

\section{Cecidostiba fungosa (Geoffroy, 1785)}

Distribución.- Ampliamente distribuida por toda Europa (Graham, 1969). En la Península Ibérica se ha citado en Cataluña (Pujade, 1991) y Salamanca (Nieves-Aldrey, 1982b).

Citas en la Comunidad de Madrid.- Todos los ejemplares estudiados de esta especie se han obtenido a partir de las siguientes agallas de cinípidos (Hym., Cynipidae): Andricus quercusradicis (F., 1798), Andricus quercusramuli (L., 1761) y Biorhiza pallida (Oliv., 1791), colectadas sobre Quercus pyrenaica Willd., y Quercus faginea en Casa de Campo, El Escorial, Guadalix de la Sierra, Miraflores y Soto del Real.
Biología.- Esta especie está considerada como parásita específica en las agallas de Biorhiza pallida (Oliv., 1791) (Hym., Cynipidae), aunque se han obtenido ejemplares a partir de agallas de Andricus quercusradicis (F., 1798) y en menor medida de Andricus quercusramuli (L., 1761) (Hym., Cynipidae) (Nieves-Aldrey, 1982b; Nieves-Aldrey y Askew, 1988).

Cecidostiba ilicina (Nieves-Aldrey y Askew, 1988)

Distribución.-Especie únicamente conocida en la Península Ibérica. Se ha citado en Cataluña (Pujade, 1991) y Salamanca (Nieves-Aldrey y Askew, 1988).

Citas en la Comunidad de Madrid.- NievesAldrey y Askew (1988), obtuvieron ejemplares a partir de agallas de Plagiotrochus quercusilicis (F., 1798) sobre Quercus ilex L. en Las Rozas de Puerto Real. Se ha estudiado maerial adicional de este mismo hospedador en Cadalso de los Vidrios; Robledo de Chavela y Rozas de Puerto Real; en agallas de Plagiotrochus australis (Mayr, 1882) sobre Quercus ilex L. en Hoyo de Manzanares y en agallas de Plagiotrochus fusifex Mayr, 1882 sobre Quercus coccifera L. en Valdemorillo. En El Ventorrillo se colectó, además, un ejemplar con trampa Malaise.

Biología.- Obtenida de agallas de Plagiotrochus quercusilicis (F., 1798) (Hym., Cynipidae) sobre Quercus ilex L. (Fagaceae) (Nieves-Aldrey y Askew, 1988).

\section{Cecidostiba semifascia (Walker, 1835)}

Distribución.- Ampliamente distribuida en Europa (Graham, 1969).

Citas en la Comunidad de Madrid. - Todos los ejemplares se obtuvieron de agallas de Biorhiza pallida (Oliv., 1791) sobre Quercus faginea Lam. en Cotos de Monterrey; Guadalix de la Sierra y Valgallego y sobre Q. pyrenaica Willd. en El Escorial.

Biología.- Parásito específico en agallas de Biorhiza pallida (Oliv., 1791) (Hym., Cynipidae) (Graham, 1969).

Hobbya Delucchi, 1957

Diversidad y distribución.- Género monoespecífico ampliamente distribuido en la región paleártica (Boucek y Rasplus, 1991).

Referencias taxonómicas.- Graham (1969); Boucek y Rasplus (1991). 
Biología.- Parásito de agallas de cinípidos (Hym., Cynipidae) sobre Quercus spp. (Fagaceae) (Boucek y Rasplus, 1991).

\section{Hobbya stenonota (Ratzeburg, 1848)}

Distribución.- Ampliamente distribuida por toda Europa (Boucek, 1977). En la Península Ibérica se ha citado en Cataluña (Pujade, 1991) y Salamanca (Nieves-Aldrey, 1982b).

Citas en la Comunidad de Madrid.- Aunque con trampas Malaise, se han colectado dos ejemplares en El Ventorrillo, la mayoría del material se ha obtenido a partir de agallas de cinípidos (Hym, Cynipidae), confirmando y ampliando citas previas de hospedadores conocidos; así se recogieron ejemplares en la Casa de Campo de Andricus quercusradicis (F., 1798) sobre Quercus pyrenaica Willd., en El Escorial de Andricus coriarius (Hartig, 1843), Andricus quercusramuli (L., 1761), Andricus quercustozae (Bosc, 1792) y Biorhiza pallida (Oliv., 1791) sobre Quercus pyrenaica Willd.; en Guadalix de la Sierra y Miraflores, de Andricus quercusramuli (L., 1761) sobre Quercus faginea Lam.; de Biorhiza pallida (Oliv., 1791) sobre Quercus faginea Lam. en Navalquejigo y en Torrelaguna-El Berrueco a partir Andricus kollari (Hartig, 1843) y Andricus quercustozae (Bosc, 1792) sobre Quercus faginea Lam.

Biología. - Las referencias bibliográficas de esta especie señalan que es un parásito cómun en las agallas de Biorhiza pallida (Oliv., 1791) y ocasionalmente de las de Andricus kollari (Hartig, 1843) (Hym., Cynipidae) (Askew, 1961a; Graham, 1969). Se han obtenido también ejemplares en otras agallas del género Andricus Hartig especialmente en las de Andricus coriarius (Hartig, 1843) (Hym., Cynipidae) donde es muy común (Nieves-Aldrey, 1982b).

Caenacis Förster, 1859

Diversidad y distribución.- Género con dos especies ampliamente distribuidas en el paleártico (Boucek y Rasplus, 1991).

Referencias taxonómicas.- Graham (1969).

Biología.- Sus especies están asociadas con agallas de cinípidos (Hym., Cynipidae) sobre Quercus spp. (Fagaceae) o Rosa spp (Rosaceae) (Boucek y Rasplus, 1991).

\section{Caenacis inflexa (Ratzeburg, 1848)}

Distribución.- Ampliamente distribuida por toda Europa (Boucek, 1977). En la Península Ibérica se ha citado en Cataluña (Pujade, 1991) y Salamanca (Nieves-Aldrey, 1983a).

Citas en la Comunidad de Madrid.- Se conocían anteriormente ejemplares procedentes de agallas de Diplolepis mayri (Schl., 1877) en Cercedilla (Nieves-Aldrey, 1983a). Se ha estudiado material adicional obtenido de agallas de este mismo hospedador sobre Rosa sp. en Cotos de Monterrey, Oteruelo del Valle y Soto del Real.

Biología.- Parásito específico de las larvas de Periclistus brandtii (Ratz., 1832). (Hym., Cynipidae) inquilino de agallas de Diplolepis spp. (Hym., Cynipidae) (Callan, 1944); (Askew, 1961a; Nordlander, 1973; Nieves-Aldrey, 1983b).

\section{Caenacis lauta (Walker, 1835)}

Distribución.- Ampliamente distribuida en Europa (Boucek, 1977). En la Península Ibérica se ha citado en Cataluña (Pujade, 1991) y Salamanca (Nieves-Aldrey, 1982b).

Citas en la Comunidad de Madrid.- - Recogido un ejemplar con trampa Malaise en El Ventorrillo; el resto se obtuvo a partir de agallas de Andricus kollari (Hartig, 1843) (Hym., Cynipidae) sobre Quercus faginea Lam. en Torrelaguna-El Berrueco.

Biología.- Asociada a las agallas de algunas especies de Andricus Hartig y Cynips L. (Hym., Cynipidae) (Askew, 1961a; Nieves-Aldrey, 1982b).

Ablaxia Delucchi, 1957

Diversidad y distribución.- Género que cuenta con unas 10 especies europeas, por lo general poco comunes (Boucek y Rasplus, 1991). Se cita por primera vez en la Península Ibérica.

Referencias taxonómicas. - Graham (1969).

Biología.- Algunas especies se desarrollan en tallos atacados por coleópteros xilófagos (Col., Scolytidae) (Boucek y Rasplus, 1991).

\section{Ablaxia megachlora (Walker, 1835)}

Distribución.- Tan sólo conocida en Inglaterra (Graham, 1969). Es la primera cita en la Península Ibérica.

Citas en la Comunidad de Madrid.- El único ejemplar estudiado se capturó en El Ventorrillo en mayo con bandejas amarillas.

Biología.-Desconocida. 
Apelioma Delucchi, 1956

Diversidad y distribución.- Dos especies conocidas en Europa (Boucek y Rasplus, 1991). Es la primera cita en la Península Ibérica.

Referencias taxonómicas.—-Graham (1969).

Biología.- Se asocia a zonas boscosas. Parásita de bupréstidos (Col., Buprestidae) y otros coleópteros sobre ramas muertas (Boucek y Rasplus, 1991).

\section{Apelioma restrictum Graham, 1961}

Distribución.- Sólo se conoce en Inglaterra y Suecia (Graham, 1969). Es la primera cita para la Península Ibérica.

Citas en la Comunidad de Madrid.- Dos ejemplares colectados en El Ventorrillo, con trampa Malaise, en el mes de julio.

Biología.-Desconocida. Las especies aparecen asociadas con Pinus spp. (Pinaceae) (Graham, 1969).

Holcaeus Thomson, 1878

Holcaeus subg. Holcaeus Thomson, 1878

Diversidad y distribución.- Comprende de 8 a 10 especies europeas (Boucek y Rasplus, 1991). Es la primera cita para la Península Ibérica.

Referencias taxonómicas.- Graham (1969).

Biología.- No se conoce, aunque probablemente sea parásito de dípteros que se desarrollan sobre madera en putrefacción (Boucek y Rasplus, 1991).

Holcaeus compresus (Walker, 1836)

Distribución.- Ampliamente distribuida en Europa (Boucek, 1977). Se cita por primera vez en la Península Ibérica.

Citas en la Comunidad de Madrid.- Tan sólo colectada en El Ventorrillo con bandejas amarillas, en junio. Biología.- No se conoce el hospedador.

\section{Holcaeus gorgasus (Walker, 1839)}

Distribución.- Especie muy común, ampliamente distribuida en Europa (Graham, 1969). Es la primera cita en la Península Ibérica.

Citas en la Comunidad de Madrid.- A pesar de tratarse de una especie común, sólo encontrada en El Pardo y El Ventorrillo utilizando en ambos casos trampas Malaise, concentrándose las capturas a finales de la primavera y durante el verano. Biología.- Desconocida.
Holcaeus varro (Walker, 1839)

Distribución.- Únicamente se conoce en Inglaterra (Graham, 1969). Es la primera cita para la Península Ibérica.

Citas en la Comunidad de Madrid.- Tan sólo recogido un ejemplar mediante barrido en El Ventorrillo en el mes de julio.

Biología.-Desconocida.

\section{Holcaeus subg. Cricellius Thomson, 1878}

Diversidad y distribución.- Cuenta con cuatro especies distribuidas por los bosque de hoja caduca, principalmente de norte y centro Europa (Boucek y Rasplus, 1991). Es la primera cita para la Península Ibérica.

Referencias taxonómicas.- Graham (1969).

Biología.- No se conoce, aunque algunas especies son parásitas de pequeños coleópteros (Coleoptera) (Boucek y Rasplus, 1991).

\section{Holcaeus (Cricellius) gracilentus Boucek, 1954}

Distribución.- Sólo se ha citado en Checoslovaquia (Graham, 1969). Es la primera referencia en la Península Ibérica.

Citas en la Comunidad de Madrid.- Se ha estudiado un ejemplar de la colección Mercet, colectado en Villaviciosa de Odón.

Biología.-Desconocida.

Kaleva Graham, 1957

Diversidad y distribución.- Comprende dos especies europeas (Boucek y Rasplus, 1991). Se cita por primera vez en la Península Ibérica.

Referencias taxonómicas.—Graham (1969).

Biología.- Es un género parásito de esfécidos (Hym., Sphecidae) sobre madera muerta (Boucek y Rasplus, 1991).

\section{Kaleva corynocera Graham, 1957}

Distribución.- Especie encontrada en Azerbaiján, Bulgaria, Checoslovaquia, Inglaterra, Suecia y Yugoslavia (Graham, 1969; Boucek, 1977). Es la primera cita para la Península Ibérica.

Citas en la Comunidad de Madrid.- Únicamente recogida en El Ventorrillo, en los meses de julio y septiembre, utilizando trampas Malaise.

Biología.- Se han obtenido ejemplares junto con Spilomena troglodytes (v.d.L.) (Hym., Sphecidae) 
sobre ramas podridas de Quercus robur L. (Fagaceae) (Graham, 1969).

\section{Stenomalina Ghesquière, 1946}

Diversidad y distribución.- Al menos cuenta con 15 especies en el Paleártico occidental (Boucek y Rasplus, 1991).

Referencias taxonómicas.—Graham (1969).

Biología.- Probablemente todas las especies de este género están asociadas con plantas herbáceas, donde parasitan diversos Diptera, principalmente Agromyzidae, Cecidomyiidae y Chloropidae (Boucek y Rasplus, 1991).

\section{Stenomalina communis (Nees, 1834)}

Distribución.—Probablemente de amplia distribución europea (Boucek, 1977). Es la primera cita en la Península Ibérica.

Citas para la Comunidad de Madrid.- Se ha colectado en Canencia y El Pardo en octubre con red de barrido.

Biología.- Se obtuvieron ejemplares de Chlorops pumilionis (Bjerk.) (Dipt. Chloropidae) (Graham, 1969).

\section{Stenomalina epistena (Walker, 1835)}

Distribución.- Aparentemente poco común; se ha citado en Inglaterra, Irlanda, República de Moldavia y Suecia (Graham, 1969). En la Península Ibérica se encontró en Asturias (Garrido y Nieves-Aldrey, 1992b).

Citas en la Comunidad de Madrid.- Estudiados algunos ejemplares de la colección Mercet, procedentes de Alcalá y El Escorial. También colectada en Canencia con barrido y en El Pardo y El Ventorrillo sobre todo con trampas Malaise. Los datos de captura indican que es una especie más frecuente durante la primavera y el otoño.

Biología.-Desconocida.

\section{Stenomalina fervida Graham, 1965}

Distribución.- Especie tan sólo encontrada en Checoslovaquia e Inglaterra (Graham, 1969). Es la primera cita en la Península Ibérica.

Citas en la Comunidad de Madrid.- Estudiado un único ejemplar de la colección Mercet, colectado en Villaviciosa de Odón.

Biología.- Se desconoce.
Stenomalina gracilis (Walker, 1834)

Distribución.— Especie muy común ampliamente distribuida por toda Europa (Boucek, 1977). En la Península Ibérica se ha citado en Valladolid (Archimowitsch, 1952); España (Graham, 1969; Graham y Claridge, 1965).

Citas en la Comunidad de Madrid.- Es la especie más común y frecuente de todas las del género en la Comunidad. Se ha colectado en Canencia, Colmenar de Oreja, Dehesa de Somosierra, El Escorial, El Pardo, El Paular, Puerto de Canencia, Somosierra, El Ventorrillo y Zarzalejo. El mayor número de ejemplares se recogió en El Ventorrillo, sobre todo con trampa Malaise durante la primavera y el verano.

Biología. - Se han encontrado como hospedadores: Melanagromyza symphyti Griff., Agromyza apfelbecki Strobl., Napomyza lateralis (Fln.), Phytomyza cineracea Hend., Phytomyza rufipes Ng., Phytomyza ramosa Hd. (Dipt., Agromyzidae), Chlorops pumilionis (Bjerk.) (Dipt., Chloropidae) (Graham, 1969).

\section{Stenomalina illudens (Walker, 1836)}

Distribución.- Ampliamente distribuida por toda Europa (Graham, 1969). En la Península Ibérica se ha encontrado en Burgos (Garrido y Nieves-Aldrey, 1992b).

Citas en la Comunidad de Madrid.- La mayoría de los ejemplares estudiados pertenecen a la colección Mercet y proceden de El Pardo, Torrejón de Ardoz y Zarzalejo. Adicionalmente se colectaron algunos ejemplares más en el Pardo y El Ventorrillo empleando trampas Malaise.

Biología.- Se han obtenido ejemplares de renuevos de cebada (Graham, 1969).

\section{Stenomalina laticeps (Walker, 1848)}

Distribución.-Aparentemente se trata de una especie rara, citada de Alemania e Inglaterra (Graham, 1969). Es la primera cita en la Península Ibérica.

Citas en la Comunidad de Madrid.- Colectada con red de barrido en Chinchón-Titulcia.

Biología.-Desconocida.

\section{Stenomalina liparae (Giraud, 1863)}

Distribución.- Ampliamente distribuida en Europa, se conoce en Alemania, Checoslovaquia, Dinamarca, Finlandia, Francia, Inglaterra y Suecia, 
(Graham, 1969). Es la primera cita para la Península Ibérica.

Citas en la Comunidad de Madrid._ En la Carretera Brea de Tajo a Orusco se colectó con barrido en el mes de junio; también se colectó en El Ventorrillo con trampa Malaise en el mes de julio. Biología.- Se ha obtenido como un ectoparásito primario de la larva de Lipara lucens Mg. (Dipt., Chloropidae) (Graham, 1969).

\section{Chlorocytus Graham, 1956}

Diversidad y distribución.- Se extiende desde Europa, donde cuenta con al menos 20 especies, al este de África y Asia (probablemente 10 especies) hasta Australia (Boucek, 1988).

Referencias taxonómicas._- Graham (1969).

Biología. - Las especies paleárticas son parásitas de larvas de insectos que perforan tallos de gramíneas, principalmente de Diptera, Hymenoptera y Coleoptera (Boucek, 1988).

\section{Chlorocytus deschampsiae Graham, 1965}

Distribución. - Tan sólo conocida en Inglaterra (Graham, 1969). Es la primera cita en la Península Ibérica.

Citas en la Comunidad de Madrid. - Encontrada en dos localidades: Puerto de Canencia y El Ventorrillo, en esta última localidad parece tratarse de una especie frecuente dado el elevado número de ejemplares colectado, sobre todo durante la primavera y el verano.

Biología. - Parásita de algunas especies de euritómidos, especialmente Tetramesa petiolata (Walker) (Hym., Eurytomidae) cuyas larvas viven en tallos de Deschampsia caespitosa (L.) (Gramineae) (Graham, 1969).

\section{Chlorocytus diversus (Walker, 1836)}

Distribución.- Únicamente conocida en Inglaterra, Irlanda y Suecia (Graham, 1969). Es la primera cita para la Península Ibérica.

Citas en la Comunidad de Madrid. - Colectada en El Ventorrillo con red de barrido, trampas Malaise y trampas bandeja coloreadas de amarillo; en todos los casos durante el mes de julio.

Biología. - Es un parásito común de Phanacis centaureae Foerster, 1860 (Hym., Cynipidae) en tallos de Centaurea Spp. (Asteraceae). Algunos ejemplares se han obtenido de los primeros estadíos larvarios de Hartigia xanthostoma (Eversm.) (Hym., Cephidae) (Graham, 1969).
Chlorocytus harmolitae Boucek, 1957

Distribución.- Se conoce en Checoslovaquia, Francia e Inglaterra (Graham, 1969). Es la primera cita para la Península Ibérica.

Citas en la Comunidad de Madrid. - Colectado un ejemplar durante el mes de julio en El Ventorrillo con trampa Malaise.

Biología.- Parásito de Tetramesa eximia (Giraud) (Hym., Eurytomidae) en tallos de Calamagrostis spp. (Gramineae) (Graham, 1969).

\section{Chlorocytus pilosus Graham, 1965}

Distribución. - Sólo se ha encontrado en Inglaterra (Graham, 1969). Es la primera cita en la Península Ibérica.

Citas en la Comunidad de Madrid.-Al igual que el caso anterior, especie rara de la que se ha colectado un único ejemplar. Fue colectado en el mes de julio en El Ventorrillo con bandejas amarillas.

Biología. - Desconocida.

\section{Chlorocytus planus (Walker, 1834)}

Distribución. - Tan sólo conocido en Inglaterra (Graham, 1969). Se cita por primera vez en la Península Ibérica.

Citas en la Comunidad de Madrid.- Sólo encontrada en El Ventorrillo, capturada con trampa Malaise a lo largo de los meses de verano.

Biología. - Parásito de euritómidos, principalmente Tetramesa angustipennis (Hym., Eurytomidae) sobre tallos de Alopecurus pratensis L. y Alopecurus geniculatus L. (Gramineae) (Graham, 1969).

\section{Chlorocytus spenceri Graham, 1965}

Distribución.- Conocida sólo en España y Yugoslavia (Boucek, 1977). Se ha citado en Barcelona (Graham y Claridge, 1965; Graham, 1969); España (Boucek, 1977).

Citas en la Comunidad de Madrid. - De la colección Mercet se estudió un ejemplar de esta especie proveniente de El Pardo; además, se ha colectado en El Porcal mediante barrido y en El Ventorrillo con trampa Malaise.

Biología. - Se han encontrado como hospedadores Melanagromyza angelicae (Frost) (Dipt., Agromyzidae), sobre tallos de Angelica sylvestris L. (Umbeliferae) y Melanagromyza cirsii (Dipt., Agromyzidae) sobre tallos de Senecio jacobea L. (Asteraceae) (Boucek, 1977). 
Chlorocytus spicatus (Walker, 1835)

Distribución.- Ampliamente distribuida, sobre todo en el norte y centro de Europa (Boucek, 1977). En la Península Ibérica se ha citado en Mallorca (Askew, 1973).

Citas en la Comunidad de Madrid. - Sin duda es la especie más frecuente del género en la Comunidad; se ha encontrado en El Pardo, Puerto de Canencia, Torrejón, El Ventorrillo y Villaviciosa de Odón. El mayor número de ejemplares se recogió en El Ventorrillo utilizando trampas Malaise, sobre todo durante la primavera y el verano.

Biología.- Se han obtenido ejemplares procedentes de larvas de Melanagromyza angelicae (Frost.) (Dipt., Agromyzidae) sobre tallos de Angelica sylvestris L. (Umbeliferae) y de Melanagromyza lappae Loew (Dipt., Agromyzidae) (Graham, 1969).

\section{Eumacepolus Graham, 1957}

Diversidad y distribución.- Comprende tres especies europeas (Boucek y Rasplus, 1991).

Referencias taxonómicas. - Graham (1969).

Biología.- Todas las especies son parásitas de agallas de cecidómidos (Dipt., Cecidomyiidae) sobre Fagus L. (Fagaceae) (Boucek y Rasplus, 1991) o de cinípidos sobre Quercus (Nieves-Aldrey y Askew, 1988).

\section{Eumacepolus obscurior Graham, 1961}

Distribución.- Citado en Inglaterra e Irlanda (Graham, 1969). En la Península Ibérica se conocía en Guadalajara (Nieves-Aldrey y Askew, 1988). Citas en la Comunidad de Madrid.- Se han estudiado ejemplares obtenidos de agallas de Andricus kollari (Hartig, 1843) (Hym., Cynipidae) sobre Quercus faginea Lam. en Torrelaguna-El Berrueco.

Biología.- Nieves-Aldrey y Askew (1988) la han obtenido de ramillas de Quercus faginea Lam. con agallas de cinípidos (Hym., Cynipidae).

\section{Eumacepolus pulcher Graham, 1961}

Distribución. - Sólo se conoce en Alemania e Irlanda (Graham, 1969). Es la primera cita en la Península Ibérica.

Citas en la Comunidad de Madrid. - Colectada tan sólo mediante barrido en El Pardo, en octubre. Biología.-Desconocida.
Mesopolobus Westwood, 1833

Diversidad y distribución.- Género cosmopolita que cuenta con al menos 40 especies en el paleártico occidental (Boucek, 1988; Boucek y Rasplus, 1991).

Referencias taxonómicas. - Rosen (1960, 1962); Graham (1969); Pujade (1994b) (Especies asociadas con cinípidos).

Biología.- Este género presenta una gran cantidad de hospedadores. Los insectos atacados por Mesopolobus incluyen varios dípteros, principalmente cecidómidos (Dipt., Cecidomyiidae), himenópteros y coleópteros gallícolas y larvas que se desarrollan en semillas y tallos de plantas herbáceas (Boucek, 1988).

\section{Mesopolobus aequus (Walker, 1834)}

Distribución.- Ampliamente distribuido en el paleártico occidental; se conoce también en Madeira y Estados Unidos (Boucek, 1977). Es la primera cita en la Península Ibérica.

Citas en la Comunidad de Madrid.- Su presencia consta por los ejemplares colectados en verano con trampa Malaise en El Ventorrillo.

Biología.- Predador en herbáceas donde se alimenta de huevos y larvas de otros insectos. Se ha encontrado en Achillea millefolium L. (Asteraceae) y Medicago sativa L. (Fabaceae) (Graham, 1969).

Mesopolobus amaenus (Walker, 1834)

Distribución.- Ampliamente distribuida por toda Europa (Boucek, 1977). En la Península Ibérica se ha citado en la provincia de Barcelona (Pujade,1994b) y en Salamanca (Nieves-Aldrey, 1983b).

Citas en la Comunidad de Madrid.- Confirmando datos previos de biología abajo reseñados se obtuvieron ejemplares de agallas de Andricus coriarius (Hartig, 1843) sobre Quercus pyrenaica Willd., en El Escorial, y de Andricus pseudoinflator Tav., 1901 sobre Quercus faginea Lam. en el Embalse del Vellón. También fue colectada en El Ventorrillo con trampa Malaise.

Biología.- Parásita de varias especies de cinípidos (Hym., Cynipidae). En Inglaterra es muy frecuente de Biorhiza pallida (Oliv., 1791), aunque también se ha obtenido de agallas de Andricus curvator (Hartig, 1840) y Andricus solitarius (Fosc., 1832) (Askew, 1961c). Los datos aportados por NievesAldrey (1983b) y Pujade (1994b) indican que, en el 
caso de la Península Ibérica, no se ha obtenido de Biorhiza pallida (Oliv.,1791) y sin embargo sí aparece en agallas de Andricus curvator (Hartig, 1840) y Andricus pseudoinflator Tav. 1901 (Hym., Cynipidae) sobre Quercus faginea Lam. (Fagaceae), y en agallas de Andricus coriarius (Hartig, 1843) (Hym., Cynipidae) sobre Quercus pyrenaica Willd.

\section{Mesopololus sp. nr. amaenus}

Citas en la comunidad de Madrid.- Con red de barrido, en la Carretera de Colmenar de Oreja a Villamanrique, se han colectado cinco hembras que no pueden ser asimiladas con toda certeza a esta especie.

\section{Mesopolobus aspilus (Walker, 1835)}

Distribución.- Citada en Inglaterra y Suecia (Graham, 1969). En la Península Ibérica se encontró en Cantabria (Garrido y Nieves-Aldrey, 1992b). Citas en la Comunidad de Madrid.- Especie poco frecuente, sólo encontrada en El Ventorrillo utilizando trampas Malaise.

Biología.- Se han obtenido ejemplares procedentes de agallas de Oligotrophus juniperinus (L.) (Dipt., Cecidomyiidae) sobre ramas de Juniperus (Cupressaceae), de Taxomia taxi (Inchb.) (Dipt., Cecidomyiidae) sobre Taxus baccata L. (Taxaceae) y Euneura amerinae (L.) (Hym., Tenthredinidae) (Rosen, 1959; Graham, 1969).

\section{Mesopolobus diffinis (Walker, 1834)}

Distribución.- Ampliamente distribuido en Europa (Boucek, 1977). En la Península Ibérica se ha encontrado en Asturias (Garrido y NievesAldrey, 1992b).

Citas en la Comunidad de Madrid.- Especie relativamente frecuente colectada en las siguientes localidades: Loeches, Móstoles, Navafría, El Pardo, Puerto de Canencia, El Ventorrillo y Zarzalejo. El mayor número de ejemplares es de El Ventorrillo, colectados con trampa Malaise y bandejas amarillas principalmente durante la primavera y el verano.

Biología.- Se conoce como parásito de varias especies de cecidómidos gallícolas (Dipt., Cecidomyiidae) sobre Artemisia o Chrysanthemum (Asteraceae) (Boucek, 1977). Se han obtenido ejemplares procedentes de agallas de Misopatha tubifex (Bouché) (Dipt., Cecidomyiidae) sobre
Artemisia campestris L. (Asteraceae) y de agallas de Diarthonomyia chrysanthemi Ahlberg (Dipt., Cecidomyiidae) (Graham, 1969).

\section{Mesopolobus dubius (Walker, 1834)}

Distribución.- Ampliamente distribuida en Europa (Boucek, 1977). En la Península Ibérica, se ha citado en Barcelona (Pujade, 1985, 1994b), Gerona (Pujade, 1994b), Mallorca (Marchall, 1900) y Salamanca (Nieves-Aldrey, 1983b).

Citas en la Comunidad de Madrid. - Se ha colectado en abundancia en Carretera Villamanrique a Colmenar, Fuentidueña de Tajo, Monte el Robledal, El Paular, El Piul y Puerto de Canencia. También capturada en El Pardo y El Ventorrillo con trampa Malaise, y en esta última localidad con bandejas amarillas, sobre todo durante la primavera y el verano. Adicionalmente se ha obtenido de agallas de Biorhiza pallida (Oliv., 1791) sobre Quercus faginea Lam. en Cotos de Monterrey y de Trigonaspis mendesi Tav., 1901 tambén sobre $Q$. faginea en San Agustín de Guadalix.

Biología.- Parásito de cinípidos gallícolas (Hym., Cynipidae) principalmente de Andricus spp. Neuroterus spp. y Biorhiza spp. sobre Quercus spp. (Fagaceae) (Askew, 1961c; Nieves-Aldrey, 1983b; Pujade, 1994b).

\section{Mesopolobus fasciiventris Westwood, 1833}

Distribución.- Ampliamente distribuida por toda Europa (Graham, 1969). En la Península Ibérica se ha citado en Barcelona (Pujade, 1994b), Salamanca (Nieves-Aldrey, 1983b), Tarragona (Pujade, 1994b), España. (Kieffer, 1899).

Citas para la Comunidad de Madrid.- Especie bastante frecuente. Se ha obtenido a partir de agallas de Andricus curvator (Hartig, 1840) sobre Quercus faginea Lam. en Cotos de Monterrey y en Los Rancajales en agallas de Andricus curvator (Hartig, 1840) sobre Quercus pyrenaica Willd. En la colección Mercet, se han estudiado ejemplares de El Escorial y Zarzalejo. Además se ha colectado en El Pardo con trampa Malaise; El Paular y Puerto de Canencia mediante barrido y en El Ventorrillo con trampa Malaise y bandejas amarillas.

Biología.- Parásito de cinípidos gallícolas principalmente agallas foliares de especies de Andricus Hartig, Cynips L., Neuroterus Hartig y Trigonaspis Hartig (Hym., Cynipidae) (Askew, 1961c; NievesAldrey, 1983b; Pujade, 1994). 
Mesopolobus fuscipes (Walker, 1834)

Distribución.- Ampliamente distribuida por toda Europa (Graham, 1969). Se cita por primera vez para la Península Ibérica.

Citas en la Comunidad de Madrid.- Obtenida de agallas de Neuroterus aprilinus (Giraud, 1859) sobre Quercus pyrenaica Willd. en El Escorial. También se colectaron dos ejemplares en El Ventorrillo con trampa Malaise en julio.

Biología.- Parásito de agallas de cinípidos (Hym., Cynipidae), principalmente de Neuroterus spp., Andricus spp. y Cynips spp. (Askew, 1961c; Graham, 1969).

\section{Mesopolobus graminum (Hard, 1950).}

Distribución.- Conocida en Dinamarca, Finlandia, Inglaterra, Suecia y antigua URSS (Graham, 1969). Se cita por primera vez en la Península Ibérica.

Citas en la comunidad de Madrid.- Tan sólo colectada en El Ventorrillo con trampa Malaise en mayo.

Biología.- Se ha encontrado como predador de huevos de Calligpona pellucida (F.) (Hemipt., Delphacidae) sobre tallos de herbáceas, también se ha obtenido parasitando larvas de Eurytoma suecica Rosen y Tetramesa angustipennis (Walker) (Hym., Eurytomidae) y a sus parásitos Pediobius eubius (Walker) (Hym., Eulophidae) y Chlorocytus pulchripes (Walker) (Hym., Pteromalidae). Se ha citado también como parásito en agallas de Trigonaspis synaspis (Hartig, 1841) (Hym., Cynipidae) (Graham, 1969).

\section{Mesopolobus incultus (Walker, 1834)}

Distribución.- Ampliamente distribuida por toda Europa. Se conoce también en Madeira y Estados Unidos (Graham, 1969). Es la primera cita para la Península Ibérica.

Citas en la Comunidad de Madrid.- - Es la especie más frecuente del género en la Comunidad, sobre todo durante la primavera y el verano. Encontrada en numerosas localidades ampliamente repartidas de la Comunidad.

Biología.-Es un hiperparásito (en ocasiones parásito primario) de Apion spp. (Col., Apionidae) sobre Trifolium repens $\mathrm{L}$ (Fabaceae). También se ha obtenido de un curculiónido (Col., Curculionidae) en semillas de Plantago (Plantaginaceae) (Graham, 1969).

\section{Mesopolobus juniperinus Rosen, 1858}

Distribución.- Especie tan sólo conocida en el este de Europa, Dinamarca y Suecia (Graham, 1969). Es la primera cita para la Península Ibérica. Citas en la Comunidad de Madrid. - Colectada en El Pardo y El Ventorrillo, en ambos casos con trampa Malaise, siendo especialmente abundante en El Ventorrillo al final de la primavera y comienzo del verano.

Biología.- Se ha encontrado en agallas de Oligotrophus juniperinus (L.) (Dipt., Cecidomyiidae) sobre Juniperus (Cupressaceae) (Graham, 1969).

\section{Mesopolobus laticornis (Walker, 1834)}

Distribución.- Sólo se conoce de Suecia (Rosen, 1966). Es la primera cita en la Península Ibérica.

Citas en la Comunidad de Madrid.- Especie relativamente frecuente; se ha encontrado en Carretera Estremera a Brea de Tajo, Orusco, Oteruelo del Valle, El Pardo, El Piul, El Porcal, Puerto de Canencia y El Ventorrillo.

Biología.- Rosen (1966) cita como hospedador Oscinella frit (Dipt., Chloropidae) sobre Avena elatior (Gramineae).

\section{Mesopolobus lichtensteini (Mayr, 1903).}

Distribución.- Circunmediterránea, se conoce en Argelia, España, Francia e Italia. (Pujade, 1994b). En la Península Ibérica se ha citado en las provincias de Barcelona y Tarragona (Pujade, 1994b).

Citas en la Comunidad de Madrid.- Fue citada por primera vez en Madrid por Templado (1957) sobre Quercus coccifera L.. Se ha obtenido ahora a partir de agallas de distintas especies de Plagiotrochus Mayr y de Andricus burgundus Gir., 1859 y Andricus grossulariae Gir., 1849 sobre Quercus ilex L., Quercus coccifera L. y Quercus suber L.; en distintas localidades madrileñas. Adicionalmente, se ha colectado también mediante barrido en Carretera Villamanrique a Colmenar y Puerto de Canencia y en El Ventorrillo con trampa Malaise.

Biología.- Se han obtenido ejemplares a partir de agallas producidas por Dryomyia lichtensteini F. Löw (Dipt., Cecidomyiidae) y de agallas de distintas especies de Plagiotrochus Mayr (Hym., Cynipidae) sobre Quercus de hoja perenne. (Pujade, 1994b). 
Mesopolobus longicollis Graham, 1969

Distribución. - Tan sólo conocida en Escocia (Graham, 1969). Es la primera cita para la Península Ibérica.

Citas en la comunidad de Madrid.- En la colección Mercet, se encontraron ejemplares de esta especie provenientes de Villamanta y Zarzalejo; se ha capturado también en El Pardo y El Ventorrillo con trampas Malaise.

Biología.- Se desconocen los hospedadores, aunque se obtuvieron ejemplares procedentes de Betula (Betulaceae) o Salix spp. (Salicaceae) (Graham, 1969).

\section{Mesopolobus maculicornis (Girault, 1863)}

Distribución.-Ampliamente distribuida por el sur y oeste de Europa (Graham, 1969). Es la primera cita en la Península Ibérica.

Citas en la Comunidad de Madrid.- Sólo encontrada El Ventorrillo, donde unicamente recogimos un ejemplar con trampa Malaise en agosto.

Biología.- Se conoce como hospedador Craneiobia corni (Giraud) (Dipt., Cecidomyiidae) (Graham, 1969).

\section{Mesopolobus maculipennis (Mercet, 1923)}

Distribución.- Conocida sólo de la Península Ibérica. Ha sido citada en España (Graham, 1969; Rosen, 1958) y en Los Monegros (Zaragoza) con el nombre de Mesopolobus blascoi Askew, 1994, sinonimizada con M. maculipennis por Garrido y Nieves-Aldrey (1996).

Citas en la Comunidad de Madrid.- Está especie fue descrita por Mercet $(1923 ; 1924)$ a partir de ejemplares colectados sobre Olea europaea en Vaciamadrid. Posteriormente se han colectado numerosos ejemplares en esta misma localidad y en la vecina del Piul. Se trata de una especie muy frecuente en esta zona de la Comunidad donde aparece ligada a comunidades vegetales de matorrales nitrófilos y a coscojares.

Biología.- Se han obtenido ejemplares a partir de agallas de Stephaniola salsolae (Tavares) (Dipt., Cecidomyiidae) sobre Salsola vermiculata L. (Askew, 1994).

\section{Mesopolobus mediterraneus (Mayr, 1903)}

Distribución. - Europa y Turquía (Pujade, 1994b). En la Península Ibérica se ha citado en Badajoz (Díaz,
1923, 1925; Mercet, 1923), Barcelona (Pujade, 1994b), Cáceres (Mercet,1923), Cantabria (Garrido y Nieves-Aldrey, 1992b), Madrid (Templado, 1957), Mallorca (Askew, 1973), Salamanca (Nieves-Aldrey, 1983a), Tarragona (Pujade, 1994b).

Citas en la Comunidad de Madrid.- Había sido citada con anterioridad en Madrid (Templado, 1957). Ahora se han estudiado numerosos ejemplares procedentes de agallas de cinípidos (Hym., Cynipidae) principalmente de los géneros Andricus Hartig y Plagiotrochus Mayr sobre Quercus ilex L. y Quercus coccifera L. en Arganda, Cadalso de los Vidrios, Casa de Campo, Cotos de Monterrey, en Torrelaguna-El Berrueco y Valdemorillo. Además se han estudiado numerosos ejemplares procedentes de la colección Mercet o colectados mediante barrido, trampa Malaise o bandejas amarillas, en diferentes puntos de la Comunidad.

Biología.- Especie hiperparásita muy polífaga. Puede atacar larvas de dípteros cecidómidos y de varias familias de lepidópteros e himenópteros. Tambíen se ha obtenido como parásita de agallas de cinípidos de los robles principalmente de los géneros Cynips L., Andricus Hartig, Neuroterus Hartig (Hym., Cynipidae) sobre Quercus sp (Fagaceae) (Nieves-Aldrey, 1983b; Pujade, 1994b).

\section{Mesopolobus meridionalis Garrido y Nieves- Aldrey, 1996}

Distribución.-Conocida sólo de la Comunidad de Madrid.

Citas en la Comunidad.- - Descrita por Garrido y Nieves-Aldrey (1996) a partir de material colectado por Mercet en el Escorial que aparecía rotulado como especie nueva por dicho autor, pero que nunca fue descrita.

Biología.-Desconocida.

\section{Mesopolobus morys (Walker, 1848)}

Distribución.- Ampliamente distribuida por toda Europa (Boucek, 1977). Es la primera cita para la Península Ibérica.

Citas en la Comunidad de Madrid.- Sólo se han encontrado algunos ejemplares en El Ventorrillo, capturados con red de barrido y trampas Malaise en el mes de julio.

Biología.- Parásito de Ceuthorrhyncus assimilis Payk. (Col., Curculionidae); también se ha citado como parásito de Dasyneura brassicae (Winn.) (Dipt., Cecidomyiidae) (Graham, 1969). 
Mesopolobus nobilis (Walker, 1834)

Distribución.- Ampliamente distribuida por Europa (Graham, 1969). Se cita por primera vez para la Península Ibérica.

Citas en la Comunidad de Madrid.- Especie bastante común. Se han obtenido ejemplares en distintas localidades, en ocasiones pertenecientes a la colección de Mercet o colectados mediante barrido o con Trampas Malaise en: Canencia, Carretera Estremera a Brea de Tajo, Fuentidueña de Tajo, Monte el Robledal, Oteruelo del Valle, El Pardo, Puerto de Canencia, El Ventorrillo y Zarzalejo. En El Ventorrillo es una especie muy frecuente, sobre todo durante julio, mes en que se produjeron la mayoría de las capturas.

Biología.- Rosen (1962), señala que vive en semillas de plantas herbáceas e indica haber encontrado ejemplares procedentes de semillas de Avena elatior Beauv. y Bromus inermis Lindm. (Gramineae) (Graham, 1969).

\section{Mesopolobus prasinus (Walker, 1834)}

Distribución.- Conocida en Austria, Inglaterra y Suecia (Graham, 1969). Es la primera cita para la Península Ibérica.

Citas en la Comunidad de Madrid.- En la Colección Mercet encontramos un ejemplar de El Escorial; la hemos recogido, además, en El Pardo y El Ventorrillo con trampa Malaise, en el mes de junio en ambos casos.

Biología.- El único dato conocido es que se ha colectado sobre Elymus repens (L.) (Graminaeae) (Graham, 1969).

\section{Mesopolobus sericeus (Forster, 1770)}

Distribución.- Ampliamente distribuida por Europa también conocida en Israel (Boucek, 1977). En la Península Ibérica se ha citado en Barcelona (Pujade, 1994b) y Salamanca (Nieves-Aldrey, 1983b).

Citas en la Comunidad de Madrid.- Obtenida a partir de agallas de Andricus mayri Kieffer, 1990 sobre Quercus faginea Lam. en Torrelaguna-El Berrueco. También fue colectada en El Ventorrillo mediante barrido en junio.

Biología.- Parásita de cinípidos gallícolas, principalmente especies del género Andricus Hartig sobre Quercus spp. (Nieves-Aldrey, 1983b; Pujade, 1994b) y Neuroterus spp (Hym., Cynipidae) (Pujade, 1994b).
Mesopolobus subfumatus (Ratzeburg, 1852)

Distribución.- Ampliamente distribuida en toda Europa (Graham, 1969). Es la primera cita para la Península Ibérica.

Citas en la Comunidad de Madrid.- Se ha colectado tan sólo un ejemplar en El Ventorrillo con trampa Malaise en julio.

Biología.- Parásito primario de Diprion spp. (Hym., Diprionidae), ocasionalmente es hiperparásito a traves de Ichneumonidae o Braconidae (Hymenoptera) (Graham, 1969).

Mesopolobus szelenyii Boucek, 1974

Distribución.- Sólo conocido en la República de Ucrania y República de Azerbaiján (Boucek, 1974). En la Península Ibérica se ha citado en la provincia de Zaragoza (Askew, 1994).

Citas en la Comunidad de Madrid.- Aparece en las mismas localidades que Mesopolobus maculipennis, El Piul y Rivas Vaciamadrid. Especie ligada a comunidades vegetales halófilas, en las zonas de yesos del sur de la provincia.

Biología.- Desconocida. Askew (1994), señala que obtuvo ejemplares de agallas de cecidómidos (Dipt., Cecidomyiidae) sobre Salsola (Chenopodiaceae) en Fuerteventura.

\section{Mesopolobus tarsatus (Nees, 1834)}

Distribución.- Se conocía en Checoslovaquia y Suecia (Graham, 1969). En la Península Ibérica se ha citado en Guadalajara (Nieves-Aldrey y Askew, 1988), Gerona, Lérida (Pujade, 1994b) y Salamanca (Nieves-Aldrey y Askew, 1988).

Citas en la Comunidad de Madrid.- Se ha obtenido de agallas de Andricus curvator (Hartig, 1840) sobre Quercus pyrenaica Willd. en El Escorial.

Biología.- Nieves-Aldrey y Askew (1988), obtienen ejemplares de agallas indeterminadas de Quercus ilex L.y Quercus faginea Lam. Pujade (1994b) obtiene ejemplares de esta especie de agallas de Andricus burgundus Gir., 1859 y Plagiotrochus quercusilicis (F., 1798) (Hym. Cynipidae) sobre Quercus ilex L. y Quercus suber L.

\section{Mesopolobus tibialis (Weswood, 1833)}

Distribución.- Ampliamente distribuida en Europa; también ha sido citada en Siria (Graham, 1969). En la Península Ibérica se conoce en la provincia de Barcelona (Pujade, 1994b), Salamanca 
(Nieves-Aldrey 1983b) y provincia de Tarragona (Pujade, 1994b).

Citas en la Comunidad de Madrid.- La mayoría de los ejemplares estudiados proceden de agallas de cinípidos (Hym., Cynipidae), de los géneros Andricus Hartig, Neuroterus Hartig y Plagiotrochus Mayr sobre distintas especies de Quercus, colectadas en Arganda, Casa de Campo, Cerro de los Angeles, Cotos de Monterrey, Dehesa de Arganda, Guadalix de la Sierra, Miraflores, El Pardo, Los Rancajales, Robledillo de la Jara, Soto del Real, Torrelaguna, Torrelaguna-El Berrueco, Torrelodones, Valdemorillo y Villar del Olmo. A estos ejemplares hay que añadir los encontrados en la colección Mercet o colectados con barrido, trampas Malaise o bandejas amarillas en Carretera Villamanrique a Colmenar; Loeches, El Paular, Puerto de Canencia, El Ventorrillo y Zarzalejo.

Biología.- Parásita de varias especies de cinípidos gallícolas, principalmente de los géneros Andricus Hartig, Neuroterus Hartig y Cynips L. sobre Quercus spp. (Fagaceae) (Askew, 1961c); (Boucek, 1977); (Nieves-Aldrey, 1983b); (Pujade, 1994b).

Mesopolobus typographi (Ruschka, 1924)

Distribución.- Se conoce del centro y norte Europa (Graham, 1969). Es la primera cita para la Península Ibérica.

Citas en la Comunidad de Madrid.- Tan sólo se ha encontrado en El Ventorrillo capturada mediante red de barrido y con trampas Malaise.

Biología.- Ectoparásito de Tomicobia seitneri (Ruschka) (Hym., Pteromalidae), e hiperparásito de Ips typographus L. y otras especies de Ips (Col., Scolytidae) (Graham, 1969).

\section{Mesopolobus xanthocerus (Thomson, 1878)}

Distribución.- Ampliamente distribuida en Europa (Graham, 1969). En la Península Ibérica se ha citado en la provincia de Barcelona, Gerona (Pujade, 1994b) y Salamanca (Nieves-Aldrey, 1983b).

Citas en la Comunidad de Madrid.- Se ha obtenido de agallas de cinípidos (Hym., Cynipidae) de los géneros Andricus Hartig, y Plagiotrochus Mayr sobre distintas especies de Quercus, concretamente en: Arganda de agallas de Plagiotrochus quercusilicis (F., 1798) sobre Quercus coccifera L.; Cadalso de los Vidrios en agallas de Andricus quercusramuli (L., 1761) sobre Quercus faginea Lam.; Casa de Campo de agallas de Plagiotrochus fusifex Mayr,
1882 sobre Quercus ilex L.; Cotos de Monterrey de agallas de Andricus quercusramuli (L., 1761) sobre Quercus faginea Lam.; Dehesa de Arganda de agallas de Andricus nudus Adler, 1881, Andricus anthracina (Curtis, 1838) Andricus pseudoinflator Tav., 1901 y Andricus quercusramuli (L., 1761) sobre Quercus faginea Lam.; en Guadalix de la Sierra de Andricus quercusramuli (L., 1761) sobre Quercus faginea Lam. en El Pardo de Plagiotrochus panteli Pujade, 1985 sobre Quercus coccifera L.; en San Agustín de Guadalix de Andricus quercusramuli (L., 1761) sobre Quercus faginea Lam., en Torrelaguna-El Berrueco de agallas de Andricus niger Tav., 1916 sobre Quercus suber L. y de Andricus nudus Adler, 1881 sobre Quercus faginea Lam. Otros ejemplares pertenecen a la colección de Mercet o fueron colectados con red de barrido y trampas Malaise en El Pardo, Puerto de Canencia y El Ventorrillo.

Biología.- Parásito de agallas de cinípidos (Hym., Cynipidae), principalmente de Andricus spp. sobre Quercus spp. (Askew, 1961c; Nieves-Aldrey, 1983b; Pujade, 1994b).

\section{Meraporus Walker, 1834}

Diversidad y distribución.- Dos especies en el paleártico occidental (Boucek y Rasplus, 1991). Referencias taxonómicas. - Graham (1969).

Biología.- Parásito principalmente de Cecidomyiidae (Boucek y Rasplus, 1991).

\section{Meraporus graminicola Walker, 1834}

Distribución.- Es una de las especies más comunes de pteromálidos. Ampliamente distribuida por Europa, también conocida en Islandia y norte de África (Boucek, 1977). En la Penísula Ibérica se ha citado en Mallorca (Askew, 1973).

Citas en la Comunidad de Madrid.- Es una especie muy frecuente en la zona. Se ha estudiado abundante material, en parte perteneciente a la colección de Mercet, pero la mayoría de los ejemplares fueron colectados por los autores mediante barrido o con bandejas amarillas y trampas Malaise en las siguientes localidades: Canencia, Carretera Brea de Tajo a Orusco, Cercedilla, Collado Mediano, Chamartín, Fuentidueña de Tajo, Galapagar, Madrid (Alto de los Leones), Monte el Robledal, El Pardo, El Paular, El Porcal, Puerto de Canencia, Puerto de Cotos, Vaciamadrid, El Ventorrillo, Villaviciosa de Odón y Zarzalejo. Es de destacar el gran número de ejemplares recogidos con trampas 
Malaise en El Ventorrillo donde la especie está presente desde la primavera hasta comienzos de otoño. Biología.- Parásito de Mayetiola spp. (Dipt., Cecidomyiidae) sobre Gramineae (Boucek y Rasplus, 1991).

\section{Lampoterma Graham, 1956}

Diversidad y distribución.- Cuenta con dos especies poco comunes en Europa (Boucek y Rasplus, 1991). Primera cita para la Península Ibérica. Referencias taxonómicas.- Graham (1969). Biología.- Se desconocen los hospedadores (Boucek y Rasplus, 1991).

\section{Lampoterma bianellatum Graham, 1956}

Distribución.- Tan sólo conocida en Inglaterra e Irlanda (Graham, 1969). Es la primera cita para la Península Ibérica.

Citas en la Comunidad de Madrid. - Encontrado ejemplares de esta especie en la Carretera Estremera a Brea de Tajo, Cerceda, Loeches, El Pardo y El Ventorrillo durante la primavera y el verano.

Biología.-Desconocida.

\section{Lampoterma sp. $n r$. bianellatum}

Citas en la Comunidad de Madrid.- Algunos ejemplares colectados en El Ventorrillo con trampa Malaise, aún presentando muchas similitudes con la especie anterior, no han podido ser totalmente asimilados a ella.

\section{Lampoterma viride (Thomson, 1875)}

Distribución.- En Europa se conoce en Inglaterra, República de Moldavia y Suecia (Graham, 1969). Es la primera cita en la Península Ibérica.

Citas en la Comunidad de Madrid.- Se encontraron en la colección Mercet ejemplares de esta especie procedentes de El Escorial, Madrid, Montarco, Vaciamadrid y Zarzalejo. Se capturaron además algunos ejemplares en Oteruelo del Valle y Puerto de Cotos con barrido y en El Ventorrillo con trampas Malaise.

Biología.-Desconocida.

\section{Lampoterma sp. nr. viride}

Citas para la Comunidad de Madrid.- Colectado en Cerceda un ejemplar que no ha podido ser asignado plenamente a la especie anterior.

\section{Stinoplus Thomson, 1878}

Diversidad y distribución.- Probablemente cuenta con cinco especies europeas (Boucek y Rasplus, 1991).

Referencias taxonómicas.- Graham (1969).

Biología.- Parásito de agallas de cinípidos (Hym., Cynipidae) sobre plantas herbáceas (Boucek, 1988).

\section{Stinoplus etearchus (Walker, 1848)}

Distribución.- Ampliamente distribuida en Europa; también se encuentra en Nueva Zelanda (Boucek, 1977). Es la primera cita en la Península Ibérica.

Citas en la Comunidad de Madrid.- El único ejemplar de esta especie en la Comunidad fue capturado en El Ventorrillo con trampa Malaise en junio.

Biología.- Se han obtenido ejemplares de Hypochoeris radicata L. (Asteraceae) junto con agallas de Phanacis hypochoeridis (Kieffer) (Hym., Cynipidae) que podrían ser sus hospedadores (Graham, 1969).

\section{Stinoplus sp. nr. etarchus}

Citas en la Comunidad de Madrid.- Se ha estudiado un ejemplar obtenido de agallas de Timaspis cichorii Kieffer, 1909 sobre Cichorium intybus L. (Asteraceae) procedente de El Porcal, que aunque muestra muchas similitudes con los ejemplares de esta especie, no puede ser totalmente asimilado a ella.

\section{Stinoplus lapsanae Graham, 1969}

Distribución. - Tan sólo citado en Francia (Graham, 1969). En la Península Ibérica se conoce de Cantabria y Asturias (Garrido y Nieves-Aldrey, 1992b).

Citas en la Comunidad de Madrid.- NievesAldrey y Martín Chicote (1986) citan esta especie de El Escorial donde la obtuvieron a partir de Timaspis lampsanae sobre Lapsana communis L. Los ejemplares colectados ahora proceden de El Ventorrillo, capturados con trampa Malaise y bandejas amarillas.

Biología.- Parásito de Timaspis lampsanae (Perris) (Hym., Cynipidae) sobre Lapsana communis L. (Asteraceae) (Graham, 1969; Nieves-Aldrey y Martín Chicote, 1986). 
Pseudocatolaccus Masi, 1908

Diversidad y distribución.- Género monoespecífico muy común y ampliamente distribuido por toda Europa (Boucek y Rasplus, 1991). Se cita por primera vez en la Península Ibérica.

Referencias taxonómicas.— Graham (1969); Boucek y Rasplus (1991).

Biología.- Parásito de agallas de cecidómidos (Dipt., Cecidomyiidae) sobre plantas herbáceas (Boucek y Rasplus, 1991).

\section{Pseudocatolaccus nitescens (Walker, 1834)}

Citas en la Comunidad de Madrid.- - Es una especie frecuente: se han capturado numerosos ejemplares; algunos coresponden a la colección Mercet, mientras que otros fueron capturados con red de barrido, trampas Malaise y bandejas amarillas en las siguientes localidades: Carretera Brea de Tajo a Orusco, Carretera Villamanrique a Colmenar, Cercedilla, Cerros de Morata, Cotos de Monterrey, Fuentidueña de Tajo, Monte el Robledal, Morata de Tajuña, Orusco, El Pardo, El Piul, El Porcal y El Ventorrillo.

\section{Rohatina Boucek, 1954}

Diversidad y distribución.- Tres especies en el paleártico occidental, poco comunes (Boucek y Rasplus, 1991).

Referencias taxonómicas.-Graham (1969).

Biología.- Desconocida.

\section{Rohatina monstrosa Boucek, 1954}

Distribución.- Es la especie más rara del género, sólo citada en Checoslovaquia (Boucek, 1977). En la Península Ibérica se ha citado en Cantabria (Garrido y Nieves-Aldrey, 1992b).

Citas en la Comunidad de Madrid.- Estudiado un único ejemplar, colectado en Oteruelo del Valle mediante barrido en el mes de agosto.

Biología.-Desconocida.

\section{Peridesmia Förster, 1856}

Diversidad y distribución.- Se conocen tres especies en Europa (Boucek y Rasplus, 1991). Es la primera cita para la Península Ibérica.

Referencias taxonómicas.—- Boucek (1973).

Biología.- Algunas especies son parásitas de curculiónidos (Col., Curculionidae) (Boucek y Rasplus, 1991).

\section{Peridesmia discus (Walker, 1835)}

Distribución.- Es la especie más común del género ampliamente distribuida por toda Europa; también se encuentra en Estados Unidos donde fue introducida procedente de Europa (Boucek, 1977). Se cita por primera vez en la Península Ibérica.

Citas en la Comunidad de Madrid. - Tan sólo colectamos ejemplares en El Ventorrillo con trampas Malaise y bandejas amarillas; parece ser una especie común en esta localidad.

Biología.- Parásita de los huevos de Phytonomus posticus (Gyllendal) (Col., Curculionidae) (Boucek y Rasplus, 1991).

\section{Trichomalus Thomson, 1878}

Diversidad y distribución.- Género muy amplio con, al menos, 40 especies en Europa (Boucek y Rasplus, 1991).

Referencias taxonómicas.- Graham (1969); Boucek y Rasplus (1991).

Biología.- Algunas de sus especies se desarrollan como parásitas de Diptera sobre tallos de Gramineae, pero la mayoría parasitan larvas de curculiónidos (Col., Curculionoidea) (Boucek y Rasplus, 1991).

Trichomalus alonsoi Nieves-Aldrey y Garrido, 1994

Distribución. - Citada sólo en Madrid.

Citas para la Comunidad de Madrid.- Especie recientemente descrita a partir de material colectado en Torrelodones (Nieves-Aldrey y Garrido, 1994).

Biología.- Obtenida de agallas de Pericartiellus durieui (Lucas) (Col., Apionidae) sobre Umbilicus rupestris (Salisb.) (Crassulaceae) (Nieves-Aldrey y Garrido, 1994).

\section{Trichomalus sp. nr. acuminatus}

Citas en la Comunidad de Madrid.- En El Ventorrillo, con trampas Malaise, se colectaron algunos ejemplares que no se ha podido asignar con toda seguridad a esta especie.

Trichomalus apertus (Walker, 1835)

Distribución.- Aparentemente se trata de una especie poco común citada en Hungría e Inglaterra (Graham, 1969). En la Península Ibérica se conoce en Asturias (Garrido y Nieves-Aldrey, 1992b). 
Citas para la Comunidad de Madrid.- - A pesar de que en la bibliografía se señala que es poco común, ha sido colectada en numerosas localidades de la Comunidad: Carretera Brea de Tajo a Orusco, Monte el Robledal, El Pardo, El Porcal, Puerto de Canencia, Puerto de Cotos y El Ventorrillo. En todas ellas, excepto en el Pardo y en El Ventorrillo en que además se utilizaron trampas Malaise y bandejas amarillas, los ejemplares se capturaron mediante red de barrido, concentrándose la mayor parte de las capturas durante la primavera y el verano.

Biología.- Desconocida.

\section{Trichomalus bracteatus (Walker, 1835)}

Distribución.- Especie común, ampliamente distribuida en Europa (Graham, 1969). En la Península Ibérica se ha citado en Cantabria (Nieves-Aldrey y Garrido, 1992b).

Citas en la Comunidad de Madrid.- Se ha colectado en Chinchón-Titulcia, La Hiruela, Madrid, El Piul y El Ventorrillo; en esta última localidad en gran número con trampas Malaise, siendo particularmente abundante durante la primavera. Es de destacar que en todos los casos los ejemplares encontrados han sido machos.

Biología.-Desconocida.

\section{Trichomalus campestris (Walker, 1834)}

Distribución.- Muy común; ampliamente distribuida en Europa. En la Península Ibérica se ha citado en Asturias (Garrido y Nieves-Aldrey, 1992b) y en Mallorca (Askew, 1973).

Citas en la Comunidad de Madrid.- Es la especie más frecuente del género en la Comunidad; la hemos encontrado en Canencia, Carretera Brea de TajoOrusco, Carretera Colmenar Viejo a San Agustín de Guadalix, Collado Mediano, El Escorial, Fuentidueña de Tajo, Madrid, Monte el Robledal, El Pardo, Puerto de Canencia, Vaciamadrid, El Ventorrillo y Zarzalejo. Como en el caso anterior, también en El Ventorrillo colectamos un gran número de ejemplares con trampas Malaise sobre todo durante la primavera. Biología.- Probablemente es parásito de Apion sp (Col., Apionidae) (Graham, 1969; Boucek y Rasplus, 1991).

\section{Trichomalus conifer (Walker, 1836)}

Distribución.- Tan sólo conocida en Alemania e Inglaterra (Graham, 1969). Se cita por primera vez en la Península Ibérica.
Citas en la Comunidad de Madrid.- Encontrada en Monte el Robledal, asociada con la comunidad botánica de encinar manchego, donde fue colectada mediante barrido y en El Ventorrillo donde, además, la capturamos con trampa Malaise.

Biología.-Desconocida.

\section{Trichomalus sp. nr. conifer}

Citas en la Comunidad de Madrid. - Recogidos numerosos ejemplares en El Ventorrillo con trampa Malaise que presentan similitudes con esta especie, pero no pueden ser asignados a ella con toda certeza.

\section{Trichomalus coryphe (Walker, 1839)}

Distribución.- Sólo se conoce de Inglaterra (Graham, 1969). Es la primera cita en la Península Ibérica.

Citas en la Comunidad de Madrid.- Únicamente se encontraron tres ejemplares en El Ventorrillo con trampa Malaise en julio y agosto.

Biología.-Desconocida.

Trichomalus elongatus Delucchi y Graham, 1956

Distribución.- Conocida sólo en Austria e Inglaterra (Graham, 1969). Es la primera cita para la Península Ibérica.

Citas en la Comunidad de Madrid.- Especie que no es infrecuente en la Comunidad; se ha encontrado en Carretera Brea de Tajo a Orusco, Madarcos, Madrid, El Pardo, Puerto de Canencia y El Ventorrillo. A tenor de los datos de la mayor parte de las capturas, es más abundante durante el verano.

Biología.- Se han obtenido ejemplares, junto con Eurytoma sp. (Hym., Eurytomidae) en tallos de Althaea rosea (L.) (Malvaceae) probablemente como parásitos de Apion radiolus Marsh. (Col., Apionidae) (Graham, 1969).

\section{Trichomalus flagellaris Graham, 1969}

Distribución.- Citada sólo en Inglaterra (Graham, 1969). En la Península Ibérica se ha encontrado en Asturias y Cantabria (Garrido y Nieves-Aldrey, 1992b).

Citas en la Comunidad de Madrid.- Especie poco frecuente; encontrada en El Pardo y El Ventorrillo en junio y agosto.

Biología.-Desconocida. 
Trichomalus fulvipes (Walker, 1836)

Distribución.- Especie citada en Alemania, Inglaterra y Suiza (Graham, 1969). En la Península Ibérica ha sido encontrada en Cantabria (Garrido y Nieves-Aldrey, 1992b).

Citas en la Comunidad de Madrid. - Colectada en Arganda, Monte el Robledal y Oteruelo del Valle mediante barrido y en El Pardo y El Ventorrillo con trampa Malaise.

Biología.-Desconocida.

Trichomalus gracilicornis (Zettersted, 1838)

Distribución.- Especie poco común, citada en Inglaterra y Suecia. En la Península Ibérica se conoce de Cantabria (Garrido y Nieves-Aldrey, 1992b).

Citas en la Comunidad de Madrid.- Tan sólo se ha colectado un ejemplar en El Ventorrillo con bandejas amarillas en julio.

Biología.-Desconocida.

Trichomalus gynetelus (Walker, 1835)

Distribución.- Común; probablemente con una amplia distribución Europea (Graham, 1969). Se cita por primera vez en la Península Ibérica.

Citas en la Comunidad de Madrid.- Recogida sólo en El Ventorrillo con red de barrido y con trampas Malaise.

Biología.-Desconocida.

Trichomalus helvipes (Walker, 1834)

Distribución.- Es una de las especies más frecuentes del género con una amplia distribución europea (Graham, 1969). En la Península Ibérica se ha citado en Cantabria (Garrido y Nieves-Aldrey, 1992b) y Mallorca (Askew, 1973).

Citas en la Comunidad de Madrid.- Especie muy común; se ha colectado mediante red de barrido en Arganda, Carretera Brea de Tajo a Orusco, Chinchón-Titulcia, Monte el Robledal, El Piul y Puerto de Canencia; con trampa Malaise en El Pardo y El Ventorrillo. En todos los casos, se capturaron mayor número de ejemplares durante la primavera y principios de verano.

Biología.- Parásito de Brachonys pineti Payk (Col., Curculionidae). Probablemente parasita especies de Apion (Col., Apionidae) (Graham, 1969).
Trichomalus lepidus (Förster, 1841)

Distribución.- Se conoce en Alemania, Inglaterra y Suecia (Graham, 1969). Es la primera cita para la Península Ibérica.

Citas en la Comunidad de Madrid.- Únicamente colectada en El Ventorrillo con trampa Malaise durante la primavera.

Biología.-Desconocida.

\section{Trichomalus lucidus (Walker, 1835)}

Distribución.- Bastante cómun; se conoce en Inglaterra, Irlanda, Suecia y Alemania (Graham, 1969). Primera cita en la Península Ibérica.

Citas en la Comunidad de Madrid.- Los únicos ejemplares encontrados fueron colectados con trampa Malaise en El Pardo y El Ventorrillo, donde, al igual que en el caso anterior se capturaron principalmente durante la primavera.

Biología.-Desconocida.

\section{Trichomalus nanus (Walker, 1836)}

Distribución.- Ampliamente distribuida en Europa (Graham, 1969). Es la primera cita en la Península Ibérica.

Citas en la Comunidad de Madrid.- Aparece únicamente en El Ventorrillo, donde ha sido colectada con red y trampas Malaise. La mayor abundancia se detecto a finales de primavera y durante el mes de julio.

Biología.- Posiblemente sea una especie parásita de Chloropidae (Diptera). (Graham, 1969).

\section{Trichomalus perfectus (Walker, 1835)}

Distribución.- Ampliamente distribuida en Europa, también se ha encontrado en Canadá (Graham, 1969). Es la primera cita en la Península Ibérica.

Citas en la Comunidad de Madrid.- Especie frecuente en la Comunidad. Se colectó en ChinchónTitulcia, El Escorial, Fuentidueña de Tajo, Móstoles, Orusco, El Porcal y El Ventorrillo. La mayor parte del material procede de esta última localidad donde se colectó principalmente con trampa Malaise, sobre todo durante la primavera y el verano.

Biología.- Se han citado como hospedadores Ceuthorrhynchus assimilis Payk y Ceuthorrhynchus pleurostigma Marsh. (Col., Curculionidae) (Graham, 1969). 
Trichomalus pexatus (Walker, 1835)

Distribución. - Citado en Alemania e Inglaterra (Graham, 1969). En la Península Ibérica se ha encontrado en Asturias (Garrido y Nieves-Aldrey, 1992b).

Citas en la Comunidad de Madrid.- Colectada en El Ventorrillo con trampa Malaise y bandejas amarillas durante la primavera.

Biología.-Desconocida.

\section{Trichomalus posticus (Walker, 1834)}

Distribución.- Se conoce en Alemania, Inglaterra, Irlanda, Suecia y antigua URSS (Graham, 1969). Es la primera cita en la Península Ibérica.

Citas en la Comunidad de Madrid.-Colectada en la Carretera Villamanrique a Colmenar mediante barrido y en El Ventorrillo con trampa Malaise, en ambas zonas durante los meses de junio y julio.

Biología.- Probablemente se trata de una especie parásita de Chloropidae (Diptera) (Graham, 1969).

Trichomalus robustus (Walker, 1835)

Distribución.- Tan sólo se conoce en Inglaterra y Suecia (Graham, 1969). Es la primera cita para la Península Ibérica.

Citas en la Comunidad de Madrid.- Únicamente se han encontrado ejemplares en el Monte el Robledal mediante barrido en junio y en El Ventorrillo con trampa Malaise en los meses de mayo y septiembre.

Biología.-Desconocida.

\section{Trichomalus rufinus (Walker, 1835)}

Distribución.— Especie bastante común, ampliamente distribuida en Europa (Boucek, 1977). Es la primera cita para la Península Ibérica.

Citas en la Comunidad de Madrid.- - Especie muy frecuente en la Comunidad. Se ha encontrado en Canencia, Carretera Brea de Tajo a Orusco, Cercedilla, Fuentidueña de Tajo, El Paular, Paracuellos del Jarama, El Piul, Puerto de Canencia, San Agustín de Guadalix y El Ventorrillo. Como en otros casos, el mayor número de ejemplares corresponde a los recogidos en El Ventorrillo con trampa Malaise, sobre todo en la primavera y comienzo de verano.

Biología.- Probablemente es parásito de Apion sp. (Col., Curculionidae) (Graham, 1969).
Trichomalus rugosus Delucchi y Graham, 1956

Distribución.- Aparentemente se trata de una especie rara, tan sólo conocida en Austria e Inglaterra (Graham, 1969). Se cita por primera vez en la Península Ibérica.

Citas en la Comunidad de Madrid.- A pesar de ser considerada como una especie rara, se ha encontrado, sobre todo durante el verano, en Monte el Robledal, El Pardo, Puerto de Canencia y El Ventorrillo. Los ejemplares proceden tanto de la colección Mercet como de capturas propias con red de barrido, trampas Malaise y bandejas amarillas. Biología.- No se conocen los hospedadores

\section{Trichomalus sp. nr. rugosus}

Citas en la Comunidad de Madrid.- En El Ventorrillo, con trampa Malaise, se colectó un ejemplar que, aunque presenta similitudes con la especie anterior, no es posible asignarlo totalmente a ella.

Trichomalus tenellus (Walker, 1834)

Distribución.- Especie poco común. Citada en Inglaterra (Graham, 1969). En la Península Ibérica se conocía en Cantabria (Garrido y Nieves-Aldrey, 1992b).

Citas en la Comunidad de Madrid.- - Los datos disponibles indican que es una especie muy frecuente en la Comunidad. Se ha encontrado en Camporreal, Carretera Brea de Tajo a Orusco, Carretera Villamanrique a Colmenar, Chamartín, Fuentidueña de Tajo, Monte el Robledal, Orusco, El Pardo, El Piul, Puerto de Canencia, Puerto de Cotos y El Ventorrillo. Como en otros casos, fue en esta última localidad donde se obtuvo un mayor número de ejemplares, principalmente durante primavera y verano, con trampa Malaise y bandejas amarillas.

Biología.- Los autores han comprobado la existencia en la colección de Pteromálidos del Museo de Historia Natural de Londres de ejemplares obtenidos a partir de agallas de Iraella luteipes (= Timaspis papaveris) (Thomson) sobre Papaver somniferum L.

\section{Trichomalus sp. nr. tenellus}

Citas en la Comunidad de Madrid.- Se han estudiado algunos ejemplares que emergieron de agallas de Iraella luteipes (Thomson) (Hym., Cynipidae) sobre Papaver somniferum, que no se 
han podido adscribir con toda seguridad a la especie anterior.

\section{Trichomalopsis Crawford, 1913}

Diversidad y distribución.- Comprende al menos 35 especies en Europa, algunas de ellas aún sin describir (Boucek y Rasplus, 1991).

Referencias taxonómicas.-Graham (1969).

Biología.- Parásitos de pupas, principalmente de Lepidoptera, Coleoptera, Diptera e Hymenoptera, algunas especies son hiperparásitas (Boucek y Rasplus, 1991).

Trichomalopsis acuminatus (Graham, 1969)

Distribución.- Tan sólo se conoce en Suecia e Irlanda (Graham, 1969). Es la primera cita para la Península Ibérica.

Citas en la Comunidad de Madrid.- Colectada mediante red de barrido en Canencia y Cerros de Morata y con trampa Malaise en El Ventorrillo. En todos los puntos, se capturó un único individuo en el mes de julio.

Biología.- Se encontró como hiperparásito de Pieris brassicae L. (Lep. Pieridae) a través de Apanteles glomeratus (L.) (Hym., Braconidae) (Graham, 1969).

Trichomalopsis albopilosus (Graham, 1969)

Distribución.- Conocido únicamente en Suecia (Graham, 1969). Primera cita en la Península Ibérica. Citas en la Comunidad de Madrid.-Colectado un ejemplar en El Ventorrillo con trampa Malaise en junio.

Biología. - Desconocida. Algunos ejemplares fueron capturados en el follaje de Salix cinerea L. (Salicaceae), otros, sobre plantas herbáceas (Graham, 1969).

Trichomalopsis caricicola (Graham, 1969)

Distribución.- Sólo se conoce de Inglaterra (Graham, 1969). Es la primera cita para la Península Ibérica.

Citas en la Comunidad de Madrid.- Como en el caso anterior, sólo se colectaron dos ejemplares en El Ventorrillo con trampa Malaise en junio.

Biología.-Desconocida.

Trichomalopsis exigua (Walker, 1834)

Distribución.- Citado en Inglaterra (Graham, 1969). En la Península Ibérica se ha encontrado en
Burgos y Cantabria (Garrido y Nieves-Aldrey, 1992b).

Citas en la Comunidad de Madrid.- Es la especie más cómun del género en nuestra zona de estudio. Encontrada en Carretera Villamanrique a Fuentidueña de Tajo, Collado Mediano, El Pardo y El Ventorrillo; en este último punto en gran abundancia, con trampas Malaise en primavera y verano. Biología.-Desconocida.

\section{Trichomalopsis hemiptera (Walker, 1836)}

Distribución.- Parece ser una de las especies más comunes del género; probablemente se encuentra ampliamente distribuida en toda Europa (Graham, 1969). Es la primera cita para la Península Ibérica. Citas en la Comunidad de Madrid.- A pesar de que en la bibliografía se señala como una especie muy común, sólo ha aparecido en El Ventorrillo, donde se colectó un ejemplar con trampa Malaise en julio. Biología.- Se han citado como hospedadores Mayetiola destructor (Say ) (Dipt., Cecidomyiidae) y Chlorops taeniopus Mg. (Dipt., Chloropidae) (Graham, 1969).

Trichomalopsis littoralis (Graham, 1969)

Distribución.- Especie conocida de Inglaterra e Irlanda (Graham, 1969). Primera cita en la Península Ibérica.

Citas en la Comunidad de Madrid.- Recogidos algunos ejemplares en El Ventorrillo con trampa Malaise, sobre todo durante el verano.

Biología.-Desconocida.

\section{Trichomalopsis sp. nr. pompicola}

Citas en la Comunidad de Madrid.- Estudiado un ejemplar de Cercedilla de la colección Mercet que, aunque muestra caracteres comunes con esta especie, no se ha podido determinar con toda seguridad.

Tomicobia Ashmead, 1899

Diversidad y distribución.- Comprende cuatro especies en Europa, algunas con una distribución amplia (Boucek y Rasplus, 1991). Es la primera cita en la Península Ibérica.

Referencias taxonómicas._- Graham, 1969.

Biología.- La mayoría de las especies son parásitas de coleópteros, principalmente Scolytidae, y Curculionidae (Boucek y Rasplus, 1991). 
Tomicobia seitneri (Ruschka, 1924)

Distribución.- Es la especie más conocida del género, ampliamente distribuida en Europa (Graham, 1969). Se cita por primera vez en la Península Ibérica.

Citas en la Comunidad de Madrid.- Encontrada únicamente en El Ventorrillo, usando bandejas amarillas en junio y con trampa Malaise en julio.

Biología.- Es una especie endoparásita de los imagos de Ips typographus L.; también se han citado como hospedadores Ips acuminatus Gyll., Ips duplicatus Sahlb. e Ips amitinus Eichh. (Col., Scolytidae) (Graham, 1969).

\section{Arthrolytus Thomson, 1878}

Diversidad y distribución.- Comprende al menos nueve especies europeas (Boucek y Rasplus, 1991). Referencias taxonómicas.- - Graham, 1969; Askew y Nieves-Aldrey, 1982.

Biología.- Algunas especies están asociadas con cecidómidos (Dipt., Cecidomyiidae) sobre Gramineae, otras parasitan agallas de cinípidos (Hym., Cynipidae) sobr Quercus spp. (Fagaceae) e incluso se ha citado alguna especie que ataca larvas de Curculio (Col., Curculionidae) (Askew y Nieves-Aldrey, 1982; Boucek y Rasplus, 1991).

\section{Arthrolytus discoideus (Nees, 1834)}

Distribución.- Ampliamente distribuida en Europa (Graham, 1969). Es la primera cita en la Península Ibérica.

Citas en la Comunidad de Madrid.- En la colección Mercet se ha estudiado material de El Escorial y Somosierra colectado en mayo y junio. Adicionalmente se ha colectado en El Ventorrillo con trampa Malaise en el mes de julio.

Biología.-Desconocida.

\section{Arthrolytus maculipennis (Walker, 1836)}

Distribución.- Ampliamente distribuida por toda Europa (Graham, 1969). Es la primera cita en la Península Ibérica.

Citas en la Comunidad de Madrid.- Aunque según los datos bibliográficos es una especie común, sólo se ha colectado en Carretera Villamanrique a Colmenar en el mes de junio y en El Pardo y en El Ventorrillo con trampa Malaise y bandejas amarillas. Especialmente significativas fueron las capturas de El Ventorrillo que indican la mayor abundancia de la especie a lo largo del verano.

Biología.- Parásito de Mayetiola destructor Say (Dipt., Cecidomyiidae) (Graham, 1969).

Arthrolytus nanus Askew y Nieves-Aldrey, 1982

Distribución. - Tan sólo se conoce de Francia y España donde se encontró en la provincia de Salamanca (Askew y Nieves-Aldrey, 1982).

Citas en la Comunidad de Madrid. - La mayor parte de los ejemplares estudiados emergieron de las agallas abajo citadas, colectadas sobre Quercus pyrenaica en Miraflores y Soto del Real. Adicionalmente se recogieron dos ejemplares con trampa Malaise en El Ventorrillo, durante el mes de septiembre.

Biología.- Parásito específico de las agallas subterráneas de Andricus quercusradicis (F.) (Hym., Cynipidae) sobre Quercus pyrenaica. (Askew y Nieves-Aldrey, 1982).

\section{Cyclogastrella Bubowski, 1938}

Diversidad y distribución.-Comprende tres especies que se distribuyen en toda Europa; también se conoce de Japón, Norteamérica y Australia (Boucek, 1988). Referencias taxonómicas.- Graham (1969).

Biología.- Las especies europeas son parásitas de pequeños lepidópteros, en particular tortrícidos (Lep., Tortricidae) (Boucek y Rasplus, 1991).

\section{Cyclogastrella clypealis Boucek, 1965}

Distribución.- Ampliamente distribuida por el centro y sur de Europa (Boucek, 1977). En la Península Ibérica se ha citado en Burgos (Garrido y Nieves-Aldrey, 1992b).

Citas en la Comunidad de Madrid.- Muy frecuente en toda la zona de estudio. Se ha encontrado en una amplia lista de localidades de la Comunidad. Se estudiaron algunos ejemplares en la colección Mercet pero, en su gran mayoría, el material procede de colectas propias con red de barrido y trampas Malaise. La especie fue particularmente abundante en las muestras de trampas Malaise de El Pardo. A tenor de los datos de captura, la especie vuela sobre todo durante el verano y el otoño.

Biología.-Desconocida.

\section{Cyclogastrella simplex (Walker, 1834)}

Distribución.- Ampliamente distribuida en Europa, también se conoce en el norte de África y 
California (Boucek, 1977). Es la primera cita en la Península Ibérica.

Citas en la Comunidad de Madrid.- Mucho menos frecuente que la especie anterior; tan sólo se ha encontrado en Villaviciosa de Odón, y en El Ventorrillo con trampa Malaise.

Biología.- Especie parásita de varios Tortricoidea (Lepidoptera) como Tortrix viridana L., Cacoecia sorbiana Hübn., y Semasia diniana Gmel. (Graham, 1969).

\section{Dibrachys Förster, 1856}

Diversidad y distribución.- Género cosmopolita, con al menos 12 especies, ocho de las cuales se conocen en Europa (Boucek, 1988; Boucek y Rasplus, 1991).

Referencias taxonómicas.- Doganlar (1987).

Biología.- La mayoría de las especies son parásitos secundarios en prepupas o pupas de pequeños Lepidoptera, incluidos los capullos de sus parásitos primarios. Algunas especies parecen preferir pupas de Diptera y se han encontrado a menudo en pupas de Tachinidae. Pueden ser parásitos primarios aunque no se debe descartar su tendencia al hiperparasitismo (Boucek, 1988).

\section{Dibrachys cavus (Walker, 1835)}

Distribución.- Especie holártica (Boucek, 1977). En la Península Ibérica se ha citado en ESPAÑA de Barcelona, (Pujade, 1983), Cantabria (Garrido y Nieves-Aldrey, 1992b) Córdoba, Valencia, (Coscolla, 1980, 1981); España, (Mercet, 1929, 1932; Romanyk y Rupérez, 1960), PORTUGAL: Estribeiro, Valado de Fredes, Vila Real, (Figo, 1983); Portugal (Diniz, 1960; Azevedo e Silva, 1962-1965).

Citas en la Comunidad de Madrid.- Había sido citada anteriormente en Madrid (Díaz, 1923). Se han estudiado ejemplares de la colección Mercet procedentes de Collado Mediano, Galapagar, Madrid y Zarzalejo. Colectada, además, mediante red de barrido en Rivas Vaciamadrid, y en El Pardo y El Ventorrillo con trampas Malaise, sobre todo a lo largo del verano.

Biología.- Es un parásito primario y secundario muy común en pupas o capullos de muchos Lepidoptera, algunos Diptera e Hymenoptera (Braconidae, Ichneumonidae) (Graham, 1969; Boucek, 1977; Doganlar, 1987).
Dibrachys fuscicornis (Walker, 1836)

Distribución.- Se conoce en Alemania, Inglatera y Estados Unidos (Doganlar, 1987). Es la primera cita en la Península Ibérica.

Citas en la Comunidad de Madrid.-El Ventorrillo; varios ejemplares con trampa Malaise al final de primavera y durante los meses de verano.

Biología.- Se han encontrado ejemplares procedentes de pupas de Cladius uncinatus Nort. en Alemania y de Cladius isomerus Nort. en Estados Unidos (Hym., Tenthredinidae) y en tallos de Stipa comata (Gramineae) en Estados Unidos. Graham (1969) señala que Dibrachys fuscicornis está asociado con hospedadores que se desarrollan sobre Salix L. (Salicaceae) (Doganlar, 1987).

Dibrachys hians Boucek, 1965

Distribución.- Tan sólo se conoce en Checoslovaquia, República de Moldavia e Italia (Boucek, 1977). Es la primera cita en la Península Ibérica.

Citas en la Comunidad de Madrid.- Poco frecuente, los escasos ejemplares que se han estudiado proceden de El Ventorrillo donde se capturaron con trampa Malaise y bandejas amarillas durante el mes de julio. Biología.-Desconocida.

Dibrachys lignicola Graham, 1969

Distribución.- Sólo se ha encontrado en Inglaterra e Irlanda (Doganlar, 1987). Es la primera cita en la Península Ibérica.

Citas en la Comunidad de Madrid.- Especie rara, de la que se ha estudiado un único ejemplar de El Ventorrillo, colectado con trampa Malaise en junio. Biología.-Desconocida.

Dibrachoides Kurdjumov, 1913

Diversidad y distribución.- Tres especies europeas (Boucek y Rasplus, 1991). Primera cita en la Península Ibérica.

Referencias taxonómicas. - Graham (1969).

Biología.- Parásito de larvas de curculionidos (Col., Curculionidae) (Boucek y Rasplus, 1991).

Dibrachoides dynastes (Förster, 1841)

Distribución.- Es la especie más común del género, ampliamente distribuida, se ha encontrado en Europa, norte de África y Estados Unidos (Boucek, 
1977). Es la primera vez que se cita en la Península Ibérica.

Citas en la Comunidad de Madrid.- No es una especie infrecuente en la Comunidad. Se han estudiado algunos ejemplares de la colección Mercet colectados en El Escorial y Zarzalejo. Adicionalmente se ha colectado con red de barrido en el Puerto de Canencia y con trampa Malaise en El Pardo y El Ventorrillo.

Biología.- Parásito de las larvas de Phytonomus posticus (Gyll.), también se han citado como hospedadores Phytonomus nigrirostris (F.) y Phytonomus rumicis (L.) (Col., Curculionidae) (Graham, 1969).

\section{Kranophorus Graham, 1956}

Diversidad y distribución.- Comprende cuatro especies europeas, aunque también se ha citado en Norteamérica (Askew, 1980; Boucek y Rasplus, 1991).

Referencias taxonómicas.- Askew (1980b).

Biología.- Principalmente parásito de algunas mariposas nocturnas (Lep., Tortricoidea, Noctuidea) (Boucek y Rasplus, 1991; Askew, 1980).

\section{Kranophorus extentus (Walker, 1835).}

Distribución.- Es la especie más común del género, ampliamente distribuida en Europa (Askew, 1980). En la Península Ibérica se encontrado en Burgos (Garrido y Nieves-Aldrey, 1992b).

Citas en la Comunidad de Madrid.- Estudiado un ejemplar de Zarzalejo en la colección Mercet; otro ejemplar fue recogido con red en Oteruelo del Valle. El mayor número de individuos ha sido colectado en El Ventorrillo, empleando trampas Malaise y bandejas amarillas.

Biología. - Citada como parásito de algunos Tortricidae (Lepidoptera), pero este dato ha sido puesto en duda por Boucek (1977). Se ha encontrado una serie de ejemplares procedentes de Tyria jacobaea (L.) (Lep., Arctiidae) colectados en Norfolk en 1928 (Askew, 1980).

\section{Conomorium Masi, 1924}

Diversidad y distribución.- Comprende tres especies europeas (Graham, 1992b).

Referencias taxonómicas.- Graham (1992b).

Biología.- Parásito en pupas de varios géneros de Lepidoptera como Thaumetopaea Hübner, Sesamia
Guenée, Hyphantria Harris (Boucek y Rasplus, 1991).

\section{Conomorium amplum (Walker, 1835)}

Distribución.- Es la especie más común y más ampliamente distribuida del género, probablemente se encuentra en todos los países europeos también en Madeira y oeste de Asia. Tradicionalmente ha sido citada como Conomorium patulum (Graham, 1992b). En la Península Ibérica se encontró en Burgos, Cantabria (Garrido y Nieves-Aldrey, 1992b) y Mallorca (Askew, 1973)

Citas en la Comunidad de Madrid.- Muy común $\mathrm{y}$ abundante en toda la zona de estudio. Se encuentra en Arganda, Canencia, Carretera Estremera a Brea de Tajo, Chamartín, El Escorial, Loeches, Madrid, Montarco, Oteruelo del Valle, El Pardo, San Agustín de Guadalix, El Ventorrillo y Zarzalejo. Especialmente llamativo es el caso de El Ventorrillo donde con trampa Malaise, a lo largo de 1989-1990, se colectaron más de mil ejemplares, concentrados en los meses de otoño.

Biología.- Parásito de varios géneros de Lepidoptera. Como hospedadores se han citado Hyphantria cunea Drury (Lep., Arctiidae) y Erannis bajaria (Schiff.) (Lep., Selidosemidae) (Graham, 1969).

Conomorium pithyocampae Graham, 1992

Distribución. - Circunmediterránea. Se conoce de Chipre, Francia, Turquía y Yugoslavia. En la Península Ibérica se ha citado en Cáceres y Granada (Graham, 1992b).

Citas en la Comunidad de Madrid.- Se ha estudiado un ejemplar colectado en Chamartín de la colección Mercet

Biología.- Parásito de Thaumetopaea pityocampa (Den. y Schiff.) y Thaumetopaea wilkinsoni Tams. (Lep., Thaumatopoeidae) (Graham, 1992).

Muscidifurax Girault y Sanders, 1910

Diversidad y distribución.- Comprende cinco especies americanas sólo una de ellas está representada en Europa (Boucek, 1988).

Referencias taxonómicas.- Graham (1969); Boucek y Rasplus (1991).

Biología.- Parásito de dípteros sinantrópicos principalmente especies de los géneros Phormia Rob-Desv. Chrysomya Rob-Desv. (Dipt., Calliphoridae) y especialmente Musca domestica L. (Dipt., Muscidae) (Boucek, 1988). 
Muscidifurax raptor Girault y Sanders, 1910

Distribución.- Cosmopolita; es la única especie del género representada en Europa (Boucek y Rasplus, 1991). En la Península Ibérica se ha citado en Burgos y Cantabria (Garrido y NievesAldrey, 1992b).

Citas en la Comunidad de Madrid.- Únicamente encontrada en El Paular y Rivas Vaciamadrid mediante red de barrido, y en El Ventorrillo con trampas Malaise; en todos los casos durante el verano.

Biología.- Parásito de Musca domestica L. (Dipt., Muscidae); Phormia regina (Mg.) y Chrysomyia macellaria Rob-Desv. (Dipt., Calliphoridae) (Graham, 1969).

\section{Hemitrichus Thomson, 1878}

Diversidad y distribución.- Comprende al menos dos especies europeas (Boucek y Rasplus, 1991). Referencias taxonómicas.— Graham (1969). Biología.- Principalmente parásito de coleópteros del género Ptinus (Col., Ptinidae) (Boucek y Rasplus, 1991).

\section{Hemitrichus oxygaster Boucek, 1965}

Distribución.- Sólo citado en Checoslovaquia y República de Moldavia (Graham, 1969). En la Península Ibérica se ha encontrado en Burgos y Cantabria (Garrido y Nieves-Aldrey, 1992b).

Citas en la Comunidad de Madrid.- Se recogieron ejemplares de esta especie en El Pardo y El Ventorrillo, principalmente con trampas Malaise, aunque en esta última localidad también con red de barrido y bandejas coloreadas de amarillo.

Biología.- Desconocida.

\section{Hemitrichus senilicus (Nees, 1834)}

Distribución.- Ampliamente distribuido por toda Europa, también se ha encontrado en Norteamérica (Boucek, 1977). Es la primera cita para la Península Ibérica.

Citas en la Comunidad de Madrid.- Estudiados dos ejemplares de la colección Mercet procedentes de Alcalá.

Biología.- Está asociada con productos almacenados. Sus hospedadores incluyen Lepidoptera, Coleoptera y Diptera, especialmente ha sido citada como hospedador Ptinus tectus Boield. (Col., Ptinidae) (Graham, 1969).
Metastenus Walker, 1834

Diversidad y distribución.- Comprende una sola especie europea (Boucek y Rasplus, 1991). Primera cita para la Península Ibérica.

Referencias taxonómicas.- Graham (1969); Boucek y Rasplus (1991).

Biología.- Parásito de coccinélidos (Col., Coccinelidae) predadores de cócidos y áfidos (Hom., Coccoidea, Aphidoidea) (Boucek, 1988).

\section{Metastenus concinnus Walker, 1834}

Citas en la Comunidad de Madrid.- Poco frecuente. Recogido un único ejemplar en El Ventorrillo con trampa Malaise en agosto.

Pachyneuron Walker, 1833

Diversidad y distribución.- Género cosmopolita que comprende unas 15-20 especies (Boucek, 1988), al menos 11 de distribución europea (Boucek y Rasplus, 1991).

Referencias taxonómicas.- Graham (1969); Doganlar (1986) (Clave parcial).

Biología.-Algunas especies atacan sírfidos afidófagos (Dipt., Syrphidae) probablemente como parásitos primarios; otras especies emergen de áfidos (Hom., Aphidoidea) parasitados; de cócidos (Hom., Coccoidea), psílidos (Dipt., Psyllidae), prepupas de coccinélidos (Col., Coccinelidae); éstas últimas probablemente hiperparásitas, siendo su hospedador primario Aphidiinae o Chamaemyiidae (Diptera) (Boucek, 1988).

\section{Pachyneuron aphidis (Bouché, 1834)}

Distribución.- Muy común y probablemente cosmopolita (Boucek, 1977). En la Península Ibérica se ha citado en Cataluña (Torras, 1978), Valladolid (Archimowitsh, 1952); España (Mercet, 1932).

Citas en la Comunidad de Madrid.- Se ha encontrado en Monte el Robledal, El Pardo y El Ventorrillo. Recogidos también ejemplares con barrido y trampas Malaise, especialmente durante la primavera y verano en El Ventorrillo.

Biología.- Parásito de áfidos (Hom., Aphidoidea) o de sus parásitos (Hym., Braconidae, Dipt., Aphidiinae) (Graham, 1969).

Pachyneuron formosum Walker, 1833

Distribución.- Citado en Inglaterra, Alemania, Francia e Italia (Graham, 1969). En la Península 
Ibérica se encontró en las provincias de Burgos y Cantabria (Garrido y Nieves-Aldrey, 1992b). Citas en la Comunidad de Madrid.- Es muy frecuente en la Comunidad, donde se ha encontrado en Alcalá, Chamartín, El Escorial, Fuentidueña de Tajo, Galapagar, La Hiruela, Madrid; Oteruelo del Valle, El Pardo, El Paular, Puerto de Canencia y El Ventorrillo. Algunos ejemplares procedían de la colección Mercet, pero la mayoría fueron colectados con red de barrido o con trampas Malaise. El mayor número de capturas se realizó en El Ventorrillo a lo largo de la primavera y el verano. Biología.- Se han citado como hospedadores Syrphus ribesii L., Xanthandrus comtus (Harr.) y Epistrophe balteata (DeG.) (Dipt., Syrphidae) (Graham, 1969).

\section{Pachyenuron grande Thomson, 1878}

Distribución.- Probablemente ampliamente distribuida en Europa (Graham, 1969). Es la primera cita en la Península Ibérica.

Citas en la Comunidad de Madrid.- Capturados dos ejemplares en El Ventorrillo con trampa Malaise en julio.

Biología.- Parásito de sírfidos (Dipt., Syrphidae) (Boucek, 1977); se han citado como hospedadores Syrphus arcuatus Fln. y Epistrophe balteata (DeG.) (Graham, 1969).

\section{Pachyneuron muscarum (Linnaeus, 1758)}

Distribución.—Especie holártica (Boucek, 1977). En la Península Ibérica se ha citado en Burgos (Garrido y Nieves-Aldrey, 1992b) y Granada (Campos, 1986).

Citas en la Comunidad de Madrid. - Encontrada en El Pardo y en El Ventorrillo; en ambos casos los ejemplares se colectaron con trampa Malaise siendo más abundantes a lo largo del verano.

Biología.- Se han citado un gran número de hospedadores pero muchas de estas citas necesitan comprobación, así se han citado como hospedadores Oscinella frit (L.) (Dipt., Chloropidae) en Checoslovaquia, Coccus hesperidium L. Chilochorus bipustulatus L., Ceroplastes floridensis Comst:, Pseudocccus citriculum Green y Saissetia oleae (Bern.) (Hemipt., Coccoideae) en Israel (Graham, 1969).

\section{Pachyneuron solitarium (Hartig, 1838)}

Distribución.- Conocida en Alemania, Checoslovaquia y República de Moldavia (Graham, 1969).
En la Península Ibérica se ha citado en Almería (Ruiz de Castro, 1941) y Huelva (Cadahia, 1984). Citas en la Comunidad de Madrid.- Sólo se han colectado cuatro ejemplares con trampa Malaise en El Ventorrillo.

Biología.- Se han obtenido ejemplares procedentes de huevos de Dendrolimus pini (L.) (Lep., Lasiocampidae) (Graham, 1969).

\section{Euneura Walker, 1844}

Diversidad y distribución. - Comprende tres especies holárticas de las cuales dos están ampliamente distribuidas en Europa (Boucek y Rasplus, 1991). Es la primera cita en la Península Ibérica.

Referencias taxonómicas.- Graham (1969); Doganlar (1986).

Biología.- Es un género hiperparásito de áfidos (Hom., Aphidoidea) (Boucek y Rasplus, 1991).

\section{Euneura sopolis (Walker, 1840)}

Distribución.-Ampliamente distribuida en Europa, también se ha encontrado en Japón (Boucek, 1977). Es la primera cita en la Península Ibérica.

Citas en la Comunidad de Madrid.- Un ejemplar colectado en El Ventorrillo en junio.

Biología. - Especie hiperparásita de varios áfidos (Hom., Aphidoidea) a través de sus parásitos primarios, principalmente Diptera Aphidiinae (Boucek, 1977).

\section{Sedma Boucek, 1991}

Distribución.- Género monoespecífico de distribución mediterránea solamente conocido en Francia y Grecia (Boucek y Rasplus, 1991). Es la primera cita en la Península Ibérica.

Referencias taxonómicas.- Boucek (1991).

Biología.-Desconocida.

\section{Sedma dispar Boucek, 1991}

Citas en la Comunidad de Madrid.- Los dos únicos ejemplares encontrados fueron colectados con trampa Malaise en El Ventorrillo en el mes de septiembre.

\section{COLOTRECHNINAE Colotrechnus Thomson, 1878}

Diversidad y distribución.- Comprende cuatro especies europeas aunque sólo se han descrito dos 
(Boucek y Rasplus, 1991). Es la primera cita en la Península Ibérica.

Referencias taxonómicas.- Graham (1969).

Biología.- Desconocida, aunque algunos ejemplares se han recogido en la India procedentes de Melanagromyza Hendel (Dipt., Agromyzidae). En Francia una especie se encontró en cápsulas de Glaucium flavum Crantz (Papaveraceae) (Boucek y Rasplus, 1991).

\section{Colotrechnus subcoeruleus Thomosn, 1878}

Distribución.- Ampliamente distribuida en Europa hasta Transcaucasia (Boucek, 1977). Es la primera cita en la Península Ibérica.

Citas en la Comunidad de Madrid.- Recogido un ejemplar en El Ventorrillo.

Biología.- El hospedador aún no se conoce aunque probablemente pueda tratarse de coleópteros (Boucek, 1977).

\section{Colotrechnus viridis (Masi, 1921)}

Distribución.- Ampliamente distribuida por los países circunmediterráneos hasta Checoslovaquia (Boucek, 1977). Se cita por primera vez en la Península Ibérica.

Biología.-Desconocida.

Citas en la Comunidad de Madrid.- - Al igual que la especie anterior es poco frecuente, sólo encontrada en Canencia y El Porcal en agosto y Mayo respectivamente; en ambos casos los ejemplares fueron colectados con red de barrido.

\section{AGRADECIMIENTOS}

Agadecemos al Patrimonio Nacional el permiso para la instalación de trampas Malaise en el Monte de El Pardo (zona del Goloso); en particular las gestiones de Santiago Soria y la colaboración y ayuda prestadas por el guarda Francisco. Bernardino Torres, fue también de gran ayuda en el mantenimiento de las trampas Malaise instaladas en la estación Biogeológica de El Ventorrillo. Numerosos colegas y personal de la sección de Entomología del MNCN colaboraron en la tarea de separación de muestras de las trampas. Mención especial merece Carmen Rey, cuyo trabajo fue especialmente relevante en el programa de muestreos con trampas Malaise y bandejas coloreadas y en la separación de muestras.

\section{REFERENCIAS}

Alfaro Moreno, A., 1965. Notas sobre limitados aspectos de cuatro plagas del olivo en la zona del Ebro medio. Boletín de Patología Vegetal y entomología Agrícola, 28: 59-66.
Archimowitsh, A. Von., 1952. Fauna de insectos en España que acuden a los "portagranos" de la remolacha. Boletín de la Sociedad Española de Historia Natural, 50. Serie biológica: 90-119.

Askew, R. R., 1961a. Some biological notes on the pteromalid (Hym., Chalcidoidea) genera Caenacis Förster, Cecidostiba Thomson and Hobbya Delucchi, with descriptions of two new species. Entomophaga, 6(1): 57-67.

Askew, R. R., 1961b. Ormocerus latus Walker, and $O$. vernalis Walker (Hym., Pteromalidae), parasites in cynipid oak galls. The Entomologist: 193-195.

Askew, R. R., 1961c. A study of the biology of species of the genus Mesopolobus Westwood (Hymenoptera, Pteromalidae) associated with cynipid galls on oak. The Transactions of the Royal Entomological Society of London, 113(8):155-173.

Askew, R. R., 1965. The Holartic species of Cyrtogaster Walker and Polycystus Westwood (Hym., Pteromalidae) including the description of a new species of Cyrtogaster from Britain. Entomophaga, 10: 179-195.

Askew, R. R., 1968. Hymenoptera 2. Chalcidoidea. Section (b). Handbooks for the identification of British Insects, 8(2)b: 1-39.

Askew, R. R., 1970. Observation on the hosts and host food plants of some Pteromalidae (Hym., Chalcidoidea). Entomophaga, 15(4): 379-385.

Askew, R. R., 1972. A revision of the British species of Halticoptera allied to $H$. circulus (Walker). Journal of Entomology (Serie B), 41(1): 45-52.

Askew, R. R., 1973. Some Chalcidoidea from Majorca, with descriptions of two new species. Eos, 49: 13-27.

Askew, R. R., 1975a. The male of Neodipara masnieri Boucek (Hym., Pteromalidae) a correction. Entomologist's Gazette, 20: 208-210.

Askew, R. R., 1975b. Description of a new genus and two new species of Pteromalidae (Hym., Chalcidoidea) reared from cynipid (Hymenoptera) galls, with notes on some other species. Bulletin $d u$ Muséum National d'Histoire Naturelle Paris, 292(202):405-412.

Askew, R. R., 1980. The European species of Coelopisthia (Hymenoptera, Pteromalidae). Systematic Entomology, 5(11): 1-6.

Askew, R. R., 1994. Some Pteromalidae (Hym., Chalcidoidea) from Monegros, with descriptions of four new species. Eos, 69(1993): 75-82.

Askew, R. R. y Blasco-Zumeta, J., 1997. Parasitic Hymenoptera inhabiting seeds of Ephedra nebrodensis in Spain, with descriptions of a phytophagous pteromalid and four other new species of Chalcidoidea. Journal of Natural History, 31(6): 965-982.

Askew, R. R. y Kennaugh, J. H., 1992. a review of the British species of Semiotellus Westwood (Hym., 
Pteromalidae). Entomologist's Monthly Magazine, 128: 215-218.

AsKew, R. R. y Nieves Aldrey, J. L., 1982. European species of Arthrolytus Thomson (Hymenoptera: Pteromalidae) reared from cynipid oak galls, with descriptions of two new species. Entomologica Scandinavica, 13: 414-418.

AzEvedo E Silva, F., 1962-1965. Luta biológica contra os insectos nocivos florestais em Portugal. Direcçao geral dos serviços florestais e aquicolas, 29-32: 103-113.

Boucek, Z., 1963. A taxonomic study in Spalangia Latr. (Hymenoptera, Chalcidoidea). Sbornik Entomologického Oddeleni Narodního Musea v Praze, 35:429-512.

BouceK, Z., 1972. On European Pteromalidae (Hymenoptera) a revision of Cleonymus, Eunotus and Spaniopus with descriptions of new genera and species. Bulletin of the British Museum (Natural History) Entomology, 27(5): 267-315.

BouCEK, Z., 1974. A new genus and three new species of European Pteromalidae (Hymenoptera). Folia Entomologica Hungarica, 27: 21-28.

BouceK, Z., 1977. A faunistic review of the Yugoslavian Chalcidoidea (Parasitic Hymenoptera). Acta Entomologica Jugoslavica, 13(Suppl.): 1-145.

BouceK, Z., 1988. Australasian Chalcidoidea (Hymenoptera)- A biosystematic revision of genera of fourteen families, with a reclassification of species. C.A.B. International. Wallinford, UK. 831 pp.

BouceK, Z. y RAsPlus, J. Y., 1991. Illustrated key to West-Paleartic Genera of Pteromalidae. INRA Editions. Paris. 140 pp.

Briales, M. J. y CAMPos, M., 1985. Contribución al estudio de la entomofauna parasitaria de Saissetia oleae Olivier, 1791 (Hom. Coccidae) en la zona de Iznalloz (Granada). Boletín de la Asociación Española de Entomología, 9: 55-62.

CADAHIA, D., 1984. El interés biológico del género Cryptochatum Rond. (Diptera, Cryptochaetidae) y descripción de una nueva especie. Boletín del Servicio contra plagas, 10(2): 159-184.

Callan, E. MC. C., 1944. Habrocytus bedeguaris Thomson and Habrocytus periclisti n. sp. (Hym., Pteromalidae) reared from galls of Rhodites rosae (L.) Proceedings of the Royal Entomological Society of London. (B.), 13: 90-93.

CAMPOS, M., 1986. Influencia del complejo parasitario sobre las poblaciones de Chrysoperla carnea (Neuroptera, Chrysopidae) en olivares del sur de España. Neuroptera International, 4(2): 97-105.

CAMPos, M. y GonzÁLEZ, R., 1990. Influence of breeding conditions on longevity and fecundity of Raphitelus maculatus (Hym: Pteromalidae) reared under standard laboratory conditions. Entomophaga, 35(3): 411-420.
Campos, M. y Lozano, C., 1994. Observations on the reproductive biology of two parasites of Hylesinus varius and Phloeotribus scarabaeoides (Col: Scolytidae): Cheiropachus quadrum (Hym: Pteromalidae) and Dendrosoter protuberans (Hym: Braconidae). Entomophaga, 30(1): 51-59.

Ceballos, G., 1941-1943. Las tribus de Himenópteros de España. Trabajos del Instituto español de Entomología. Madrid. 420 pp.

Chararas, C., 1959. Coléoptères Scolytidae, hôtes nouveaux de divers Hyménoptères parasites. Bulletin de la Société Entomologique de France, 6: 8-14.

Coscolla, R., 1980. Aproximación al estudio del parasitismo natural sobte Lobesia botrana Den. y Schiff. en las comarcas vitícolas valencianas. Boletín del Servicio contra Plagas, 6(1): 5-14.

Coscolla, R., 1981. Algunas consideraciones sobre la dinámica poblacional de Lobesia botrana Den y Schiff. en las comarcas vitícolas valencianas. Boletín del Servicio contra Plagas, 7(1-2): 57-63.

DARLING, C., 1991. Revision of the world species of Spalangiopelta (Hymenoptera: Chalcidoidea: Pteromalidae: Ceinae). Royal Ontario Museum Life Sciences contributions, 155: 1-43.

DARLING, C., 1995. New Paleartic species of Spalangiopelta (Hymenoptera: Chalcidoidea: Pteromalidae: Ceinae). The Canadian Entomologist, 127: 225-233.

DE FreitAs, A., 1972. A cochonilla nigra (Saissetia oleae (Oliv.)) en Oliveira. Bio-ecologia e influênça dos tratamentos antidacido. Agronomia Lusitanica, 33(1-4): 349-390.

De FreitAS, A., 1977. A cochonilla nigra (Saissetia oleae (Oliv.)) en Laranjeira. Bio-ecología (tratamento e reinfestaçao). Agronomia Lusitanica, 38(1): 5-40.

De Goveia, M. A. y Araujo, J., 1985. contribuçao para o conhecimento dos parasitos afideos dos cerais em Portugal (Hym., Aphididae, Homoptera, Aphidoidea). Actas do II Congresso ibérico de Entomología. Suplemento 1. Boletim da Sociedade Portuguesa de Entomologia, 4: 365-373.

Delucchi, V., 1956. Beirtrage zur kenntnis der Pteromaliden (Hym., Chalcidoidea). II. Zeitschrift fur Angewandte Entomologie, 39: 229-257.

Delucchi, V., 1957. Beiträge zur kenntnis der Pteromaliden (Hym., Chalcidoidea). III. Zeitschrift fur Angewandte Entomologie, 40: 400-421.

Delucchi, V., 1962. Hyménoptères Chalcidiens du Maroc II. Pteromalidae. Alwania, 2: 113-135.

DíAz, B., 1923. Parásitos de Lymantria dispar L., Apanteles vitripennis. Revista de Fitopatología, 1: 99.

Diniz, M. de A., 1960. Notas sobre los Himenópteros de Portugal I. Memorias e Estudos do Museu Zoologica da Universidade de Coimbra, 266: 1-37. 
Doganlar, M., 1986. Morphological studies of the hypopygium and its importance to the taxonomy of the genera Pachyneuron and Euneura (Hymenoptera; Pteromalidae), with description of a new specie of Pachyneuron from Turkey. Fen Bilimleri Enstitusu dergisi Ege universitesi, 4: 23-32.

Doganlar, M., 1987. Hypopygia of most Neartic and Paleartic species of Dibrachys Foërster, key to most species of the genus, and descriptions of three new species (Hymenoptera, Pteromalidae). Spixiana, 10: 191-206.

Dusmet, J. M., 1944. Recuerdos para contribuir a la historia de la entomología española. Discurso de recepción en la real Academia de Ciencias Exactas Físicas y Naturales.

FAlcó, J. V., Luna, F. y JimÉnez, R., 1990. Complejo parasitario de Lymantria dispar L. en Sierra Espadán, Castellón (Lepidoptera: Lymantriidae). Boletín de la Asociación española de Entomología, 14: 261-267.

Fernández, J. M., Mendivil, Z. y Almagro, F., 1979. Estudio de Saissetia oleae en Córdoba. Boletín del Servicio Contra Plagas, 5(2): 149-156.

Figo, M. L., 1983. Parásitos e predadores de Thaumatopoea pityiocampa Schiff. em Portugal, Actas del I congreso ibérico de Entomología de León, 1: 229-235.

Figueiredo, D. y Araujo, J., 1985. Variaçao da taxa de parasitismo de Pieris brassicae L. (Lepidoptera, Pieridae) no sul de Portugal. Actas do II Congresso ibérico de Entomología. Boletim da Sociedade Portuguesa de Entomología, 4: 297-305.

GARBARCZyK, H. y SAwONIEWICZ, J., 1984. Classification of parasitoids into guilds associated with different host groups. Ekologia Polska, 32(2): 261-270.

Garrido, A. M., 1996. Pteromálidos de la Comunidad de Madrid (Hymenoptera, Chalcidoidea, Pteromalidae). Tesis Doctoral. Universidad Autónoma de Madrid. 741 pp.

Garrido, A. M. y Nieves-Aldrey, J. L., 1990. Catálogo actualizado de los pteromálidos de la Península Ibérica e Islas Baleares (Hym., Chalcidoidea, Pteromalidae). Boletín de la Asociación española de Entomología, 14: 71-87.

Garrido, A. M. y Nieves-Aldrey, J. L., 1992a. Estructura y dinámica de una taxocenosis de Pteromalidae (Hym., Chalcidoidea) en el sector medio de la Sierra de Guadarrama. Eos, 68(1): 29-49.

Garrido, A. M. y Nieves-Aldrey, J. L., 1992b. Nuevas citas de Pteromalidae para España (Hymenoptera, Chalcidoidea) colectados con trampas "Malaise". Actas do $V$ Congresso Ibérico de Entomología. Boletim da Sociedade Portuguesa de Entomología, Suplemento 3: 501-512.

Garrido, A. M. y Nieves-Aldrey, J. L., 1996. Revisión de las especies de pteromálidos escritas por $\mathrm{R}$.
García Mercet. (Hymenoptera, Chalcidoidea, Pteromalidae). Boletín de la Asociación española de Entomología, 20(1-2): 221-235.

Gaston, K. J., 1993. Spatial patterns in the description and richness of the Hymenoptera. En: Hymenoptera and Biodiversity. LaSalle, J. y Gauld, I. (Eds.). C.A.B. International. Wallingford, UK: 277-293.

GAuld, I. D. y Bolton, B. (eds.), 1988. The Hymenoptera. British Museum (Natural History) \& Oxford University Press. London and Oxford. 332 pp.

GiJswist, M. J., 1990. Two new species of Chalcidoidea from Spain associated with spanish juniper (Hymenoptera). Entomologische Berichten Nederlandsche entomologische Vereeniging Amsterdam, 50(4): 42-45.

Gisswist, M. J., 1994. Chalcidoidea (Hymenoptera) in flower heads of Artemisia absinthium (Asteraceae). Entomologische Berichten Nederlandsche entomologische Vereeniging Amsterdam, 54(54): 109-112.

Gijswijt, M. J. y Graham, M. V. R. DE V., 1986. The genus Spilomalus Graham, 1956 (Hym., Chalcidoidea, Pteromalidae). Entomologische Berichten Deel, 46: 124-127.

GonzÁlez, R. y CAmpos, M., 1990a. Evaluation of natural enemies of the Phloeotribus scarabaeoides (Bern,) (Col., Scolytidae) in Granada olive groves. Acta Horticulturae, 286: 355-358.

GonzÁlez, R. y CAMPos, M., 1990b. Rearing of Cheiropachus quadrum (Hym., Pteromalidae) from the olive beetle Phloeotribus scarabaeoides (Col., Scolytidae) potential biological control agent. Redia, 73(2): 495-505.

GonzÁlez, R. y CAmpos, M., 1991. Relaciones entre la fenología de Phloeotribus scarabaoides (Col., Scolytidae) y sus parasitoides (Hym., Pteromalidae). Boletín de la Asociación española de Entomología, 15: 131-143.

Graham, M. W. R. DE V., 1969. The Pteromalidae of Northwestern Europe. Bulletin of the British Museum (Natural History) Entomology, Supplement 16: 1-908.

Graham, M. W. R. DE V., 1984. New Chalcidoidea (Insecta, Hymenoptera) mainly from France, including several species of Eurytoma and Pteromalus associated with Euphorbia. Journal of Natural History, 18(4): 495-525.

Graham, M. W. R. DE V., 1992a. Second revision of Western European Psilocera (Hym., Pteromalidae) with description of three new species. Entomologist's Monthly Magazine, 128(1532-1535): 15-21.

Graham, M. W. R. DE V., 1992b. The European species of the genus Conomorium Masi, 1924 (Hym., Pteromalidae) including one new to science. Entomologist's Monthly Magazine, 128: 197-202.

GrAHAM, M. W. R. DE V., 1993. Revision of European species to the genera Trigonoderus Westwood and 
Plutothrix Förster (Hym., Pteromalidae) Entomologist's Monthly Magazine, 129:107-118.

Graham, M. W. R. DE V. y Claridge, M., 1965. Studies on Stenomalina-group of Pteromalidae (Hym., Chalcidoidea). The Transations of the Royal Entomological Society of London, 117: 263-311.

Grissell, E. E., 1983. Boharticus n. gen. with a review of Rhopalicus Förster and Dinotiscus Ghesquière (Hym., Pteromalidae). Pan-Pacific Entomologist. 59(1-4): 78-102.

Haeselbarth, E., 1979. Zur Parasitierung de Puppen von Forleule (Pannolis flammea [Schiff.]), Kiefernspanner (Bupalus piniarius [L.]) und Heidelbeerspanner (Boarmia bistortana [Goez]) in bayerischen Kiefernwäldern. Zeitschrift für Angewnadte Entomolgie, 87: 186-202, 311-222.

HedQvist, K. J., 1963. Die Feindeder borkenkäfer in Schweden I. (Chalcidoidea). Studia forestalica Suecica, 11: 1-176.

HedQvist, K. J., 1969. New genera and species of Diparini with notes on the tribe (Hym., Chalcidoidea). Entomologisk Tidskrift, 90: 174-202.

HedQvist, K. J., 1971. Description of a new specie of Neodipara Erdös from Spain (Hym., Chalcidoidea, Pteromalidae. Entomologica Scandinavica, 2:119120.

Hedqvist, K. J., 1972. Notes on Chalcidoidea (Hym.) I. The genus Syntomopus Walk. (Pteromalidae, Miscogasterinae, Sphegigasterini). Entomologisk Tidskrift, 93(4): 210-215.

HedQvist, K. J., 1975. Notes on Chalcidoidea 7. A key to the swedish species of the genus Halticoptera Spin. and three related genera (Hym., Pteromalidae). Entomologica Scandinavica, 6(2): 167-181.

HEYdon, S. L., 1989a. Relationships among holartic genera in the Cyrtogaster species, with a revision of the species of North America North of Mexico (Hym., Pteromalidae). Journal of the New York Entomological Society, 97(2): 192-217.

HEYdon, S. L., 1989b. A review of Neartic Rhicnocoelia and Callimerismus with a discussion of their phylogenetic relationships (Hymenoptera: Pteromalidae). Journal of the New York Entomological Society, 97(3): 347-357.

Heydon, S. L., 1989c. A review of the world species of Notoglyptus Masi (Hymenoptera: Pteromalidae). Proceedings of the Entomological Society of Washington, 91(1): 112-123.

Heydon, S. L., 1993. Syntomopus Walker, the Neartic species with a review of known host associations (Hymenoptera: Pteromalidae). Journal of the Hymenoptera Research, 2(1): 107-116.

Heydon, S. L. y Grissell, E. E., 1988. A review of Neartic Merismus Walker and Toxeuma Walker (Hymenoptera: Chalcidoidea: Pteromalidae).
Proceedings of the Entomological Society of Washington, 90(3): 310-322.

Heydon, S. L. y Laberge. W. E., 1988. A review of North America species of Sphegigaster North of Mexico and the biology of their hosts. (Hymenoptera, Pteromalidae). Journal of the Kansas Entomological Society, 61(3): 258-277.

KIEFFER, J. J., 1899. Description de quelques Chalcidites nouveaux. Annales de la société Entomologique de France, 68: 368-378.

Kryger, J. P., 1943. The Chalcid subfamily Eunotinae. Entomologiske Meddelelser, 23: 66-81.

Limón de la Oliva, F. y Blasco Pascual, J., 1973. Iniciación al estudio de la lucha natural y de los medios a utilizar contra las plagas de los agrios en la zona norte de la región levantina, con vistas al establecimiento de un programa de lucha integrada. Boletín del Servicio de Defensa contra Plagas. Boletín informativo de Plagas, 109: 69-80.

Marchall, L., 1900. Notes biologiques sur les chalcidiens et Proctotrypides obtenus par voie d'élévage pendant les années 1896, 1897 et 1899. Annales de la Société Entomologique de France, 69: 102-112.

Masi, L., 1931. Contributo alla sistematica degli Eunotini (Hym. Chalc.). Eos, 7: 411-431.

Menozzi, C., 1930. Inseti dannosi alla barbabietola (Observazione ed appunti preliminari). Società Entomologica Italiana. Genova. 89 pp.

Mercet, R. G., 1910. Notas sobre un insecto, Scutellista cyanea benficioso para la agricultura. Revista de la Real Academia de Ciencias Exactas, Físicas y Naturales, 9: 185-190.

Mercet, R. G., 1916. Calcídidos de España. Boletín de la Real Sociedad Española de Historia Natural, 16: 112-117.

Mercet, R. G., 1923. Un parásito de Tortrix viridiana y una especie nueva de Eutelus. Revista de Fitopatología, 1:100-107.

Mercet, R. G., 1924. Los Pteromálidos de España (Hym. Chalc.) (Primera nota). Boletín de la Real Sociedad Española de Historia Natural, 24: 421-430.

Mercet, R. G., 1924-1925. Calcidoideos parásitos de Curculiónidos y Escolítidos. Revista de Fitopatología, 5: 40-47.

Mercet, R. G., 1926-1928. Calcidoideos parásitos de Curculiónidos y Escolítidos. Revista de Fitopatología, 6:1-4.

Mercet, R. G., 1927. Nota sobre Lelapinos (Hym. Chalc). Eos, 3: 46-63.

Mercet, R. G., 1929. Los insectos auxiliares. Asociación Española para el Progreso de las Ciencias. Congreso de Barcelona: 6.

Mercet, R. G., 1932. Los parásitos de los insectos perjudiciales. Biblioteca Agrícola Salvat. Salvat editorial, Barcelona. $153 \mathrm{pp}$ 
Morillo, C., 1974. Regulación de las poblaciones de Saissetia oleae (Olivier, 1791). Factores de mortalidad (Hom. Coccidae). Graellsia, 30: 221-231.

Nieves-Aldrey, J. L., 1980. Datos sobre Diplolepis rosae (L.) (Hym., Cynipidae) y sus himenópteros parásitos en Salamanca. Boletín de la Asociación española de Entomología, 4: 107-113.

Nieves-AldRey, J. L., 1982a. Nuevos datos sobre las especies europeas del género Ormocerus Walker, 1834 (Hym., Pteromalidae) con descripción del macho de Ormocerus vernalis Walker, 1834. Nouvelle Revue d'Entomologie, 12(2): 183-187.

NiEves-AldREy, J. L., 1982b. Nuevos datos sobre las especies de los géneros Cyrtoptyx Delucchi, Caenacis Förster, Cecidostiba Thomson y Hobbya Delucchi asociadas con agallas de cinípidos de los robles. Graellsia, 38: 35-42.

Nieves-Aldrey, J. L., 1983a. Contribución al conocimiento de la fauna de himenópteros inquilinos y parásitos en las agallas de Diplolepis mayri (Schlechtendal) y Diplolepis eglanteriae (Hartig) (Hym., Cynipidae). Graellsia, 39: 93-102.

Nieves-Aldrey, J. L., 1983b. Sobre las especies del género Mesopolobus (Hym., Pteromalidae) asociadas con agallas de cinípidos en Quercus spp. en Salamanca. Boletín de la Asociación española de Entomología, 7: 9-18.

Nieves-Aldrey, J. L. y Askew, R. R., 1988. A new species of Cecidostiba Thomson (Hym., Pteromalidae) a key to species of the genus and rearing records of other pteromalidae associated with oak gall wasp (Hym., Cynipidae). Entomologist's Monthly Magazine, 124: 1-6.

Nieves-Aldrey, J. L. y GARrido, A. M., 1994. A new species of Trichomalus from Spain (Hym., Pteromalidae). Entomologist's Monthly Magazine, 130: 191-194.

Nieves-Aldrey, J. L. y Martín Chicote, I., 1986. Nuevas citas de calcídidos parásitos de insectos gallícolas en España (Hym., Chalcidoidea). Boletín de la Asociación española de Entomología, 10: 209-213.

Nordlander, G., 1973. Parasitsteklar i galler au Diplolepis rosae (L.) och. D. mayri Schlecttd. (Hym., Cynipidae) (Hym., Ichneumonoidea, Chalcidoidea, Cynipoidea). Entomologisk Tidskrift, 94(3-4): 148-176.

Noyes, J. S., 1982. Collecting and preserving chalcid wasps (Hymenoptera: Chalcidoidea). Journal of Natural History, 16: 315-334.

PANIS, A., 1977. Contribución al conocimiento de la biología de la "cochinilla negra" de los agrios (Saissetia oleae (Olivier)). Boletín del Servicio contra Plagas, 3(1): 157-173.

Panis, A., Carrero, J. M. y Limón, F., 1977. Nota biológica sobre la entomofauna de los cítricos en España. Anales del I.N.I.A. Serie de protección Vegetal, 7: 139-143.
PECK, O., 1963. A catalogue of the Neartic Chalcidoidea (Insecta: Hymenoptera). The Canadian Entomologist (Suppl. 3): 1092 pp.

Peck, O., Boucek, Z. y Hoffer, G., 1964. Keys to the Chalcidoidea of Czechoslovakia (Insecta: Hymenoptera). Memoirs of the Entomological society of Canada, 34: 1-120.

PujAde, J., 1983. Estudi dels parasits i hiperparasits de la crisalide de Lymantria dispar (Lep., Lymantridae). Servei de protecció dels vegetals. Generalitat de Catalunya. Full d'informació tecnica. 28.

Pujade, J., 1985. Sobre Plagiotrochus panteli Pujade (Hym., Cynipidae) y sus parásitos (Hym., Chalcidoidea). Actas do II Congresso ibérico de entomología. Suplemento1. Boletim da Sociedade Portuguesa de Entomología, 2: 531-539.

Pujade, J., 1991. Contribució al coneixement dels cinipids cecidogenes dels Arbres i Arbust de Catalunya del cinips associats a aquest $i$ del seus parasits. Tesis doctoral. Universidad de Barcelona. 1128 pp.

Pujade, J., 1992. Especies asociadas (Hym., Ichneumonidea, Chalcidoidea) a agallas de distintas especies de Diplolepis Geoffroy (Hym., Cynipoidea) detectadas en el Nordeste Ibérico. Actas do V congreso Ibérico de Entomología. Boletim da Sociedade Portuguesa de Entomología, Suplemento 3: 127-136.

Pujade, J., 1994a. Sobre el complejo parasitario (Hym: Eurytomidae, Pteromalidae, Eulophidae y Eupelmidae) de Pediaspis aceris (Gmelin) (Hym., Cynipidae) en la Península Ibérica. Boletín de la Asociación Española de Entomología, 18(1-2): 2130.

Pujade, J., 1994b. Especies de Mesopolobus (Hym., Pteromalidae) asociadas a agallas de Cynipini (Hym., Cynipidae) del nordeste ibérico y notas sobre la validez de M. lichtensteini (Mayr, 1903). Eos (1993), 69: 63-73.

Rasplus, J. Y., 1989. Révision des espèces afrotropicales du genre Dinarmus Thomson (Hymenoptera: Pteromalidae). Annales de la Société Entomologique de France, 25: 135-162.

Romanyk, N. y Rupérez, A., 1960. Principales parásitos observados en los defoliadores de España con atención particular de Lymantria despar (L.) Entomophaga, 5(3): 229-235.

Rosen, H. Von, 1958. Zur Kennits der Europäichen arten des Pteromaliden-genus Mesopolobus Westwood, 1833. Opuscula Entomologica, 23: 203240.

Rosen, H. Von, 1959. Zur kennits des Pteromaliden. Genus Mesopolobus Westwood, 1833 (Hym., Chalcidoidea.) IV. Entomologisk Tidskrift, 80: 146162.

Rosen, H. Von, 1960. Zur kenntnis des Pteromaliden. Genus Mesopolobus Westwood, 1833 (Hym., Chalc.) VII. Entomologisk Tidskrift, 82: 1-48. 
Rosen, H. Von, 1962. Zur kennits des Pteromaliden. Genus Mesopolobus Westwood, 1833 (Hym., Chalc.) IX. K. Lantbrhögsk. Annlr, 28: 141-148.

Rosen, H. Von, 1966. Zur kennits des Pteromaliden. Genus Mesopolobus Westwood, 1833 (Hym., Chalcidoidea.) X. Entomologisk Tidskrift, 87(1-2): 76-84.

Ruiz de Castro, A., 1941. El Melazo (P. citri Risso) en los parrales de Almería. Boletín de Patología Vegetal y Entomología Agrícola, 10: 157.

Sanz Benito, M. J., 1994. Curculiónidos de la Sierra de Guadarrama. Tesis doctoral. Universidad Autónoma de Madrid. 807 pp.

SMITH, H. y COMPÈRE, M., 1928. A preliminary report on the insect parasites of the black scales, Saissetia oleae (Bernard). University of California. Publications in Entomology, 4: 231-334.

SKuHraVÁ, M., 1995. A new gall midge species, Etsuhoa thuriferae sp. N. (Diptera: Cecidomyiidae), from galls on Juniperus thurifera L. (Cupressaceae) in Spain. Zapateri, 5: 135-146.

SzelÉNYI, G. Von, 1956. Notes on the Merisini (Hym., Chalcidoidea) I. The subtribe Merisina. Annales Historico-Naturales Musei Nationalis Hungarici (ns): $167-180$.

Templado, J., 1957. Observaciones biológicas sobre Dryomyia lichtensteini (Löw.), cecidómido productor de agallas en las hojas de la encina. Boletín de la Real Sociedad española de Historia Natural (B) (1956): 145-155.

Torras, C., 1978. Contribución a la entomología del avellano. Boletín de la Asociación española de Entomología, 2: 77-86.
Verdú, M. J., 1991. Chalcidoidea (Hym. Apocrita, Terebrantia) en plantas hortícolas de la comunidad Valenciana. Boletín de la Asociación española de Entomología, 15: 245-255.

Yasumatsu, K., 1956. A revised list of the known hymenopterous parasites of the scales of the genus Ceroplastis. Bolletino Portici, 33: 708-717. 


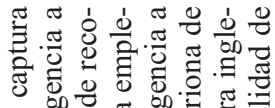

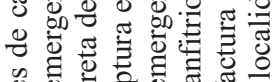

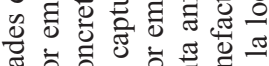

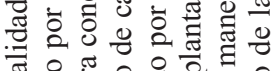

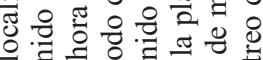

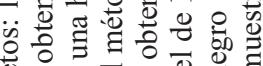

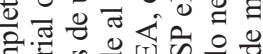

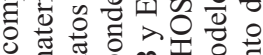

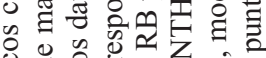

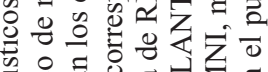

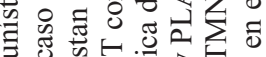

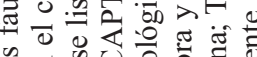

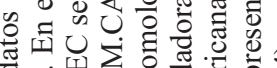

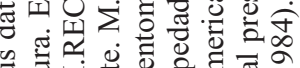

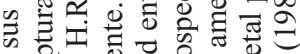

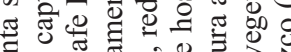
ఖ

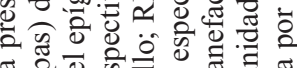

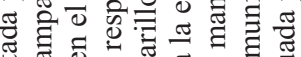

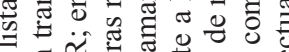

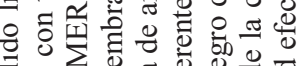

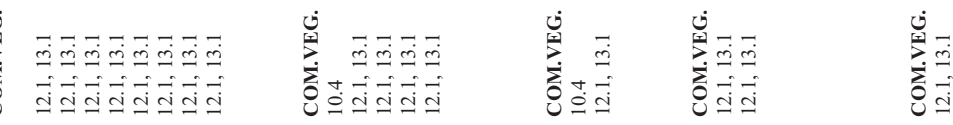

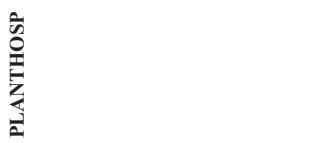<smiles>CCCCCCC</smiles>

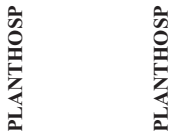<smiles>C=CC</smiles>

के

के

के के

के

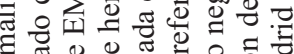

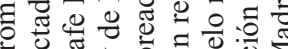
는 행 궁응 응 융

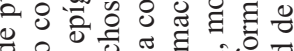

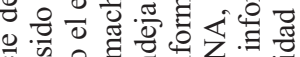

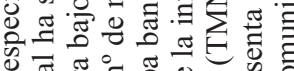
के 풀

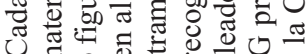

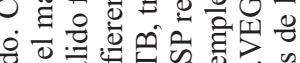

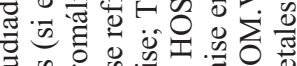
战

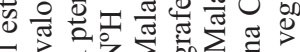

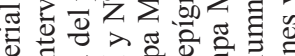
氜 \& ป

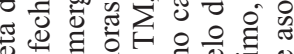

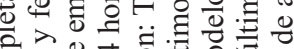

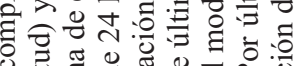

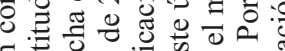
은

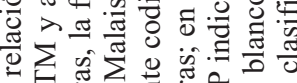

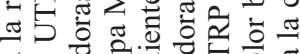

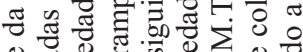
\& đ

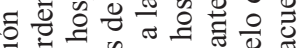

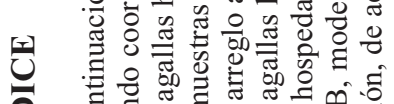

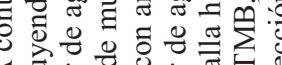

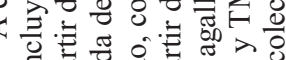

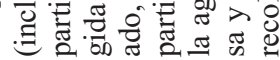

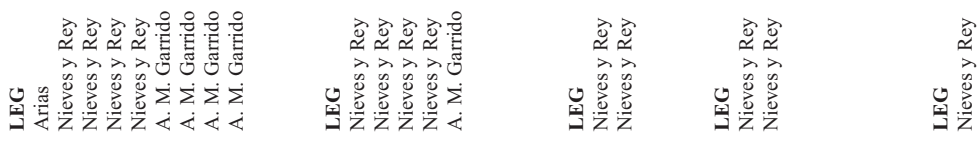

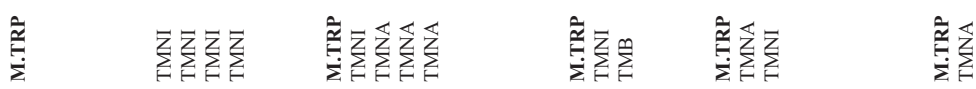

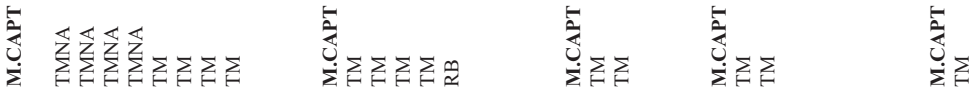

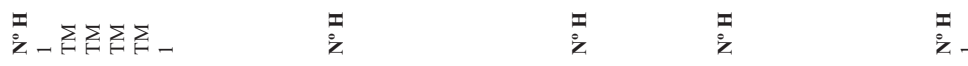

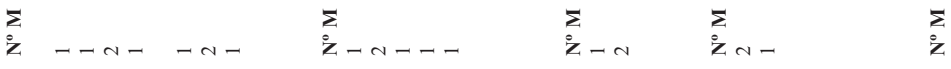
薯

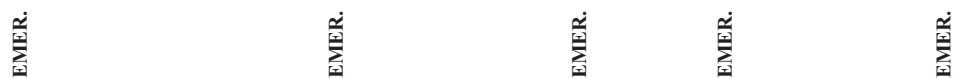

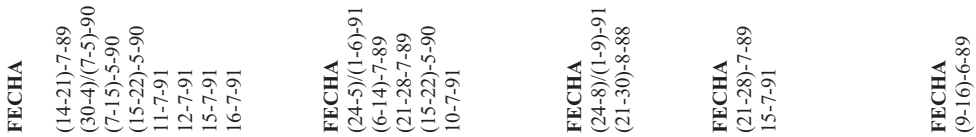

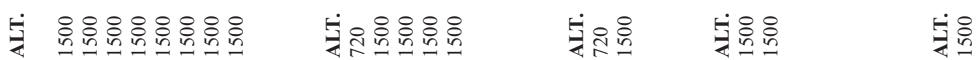

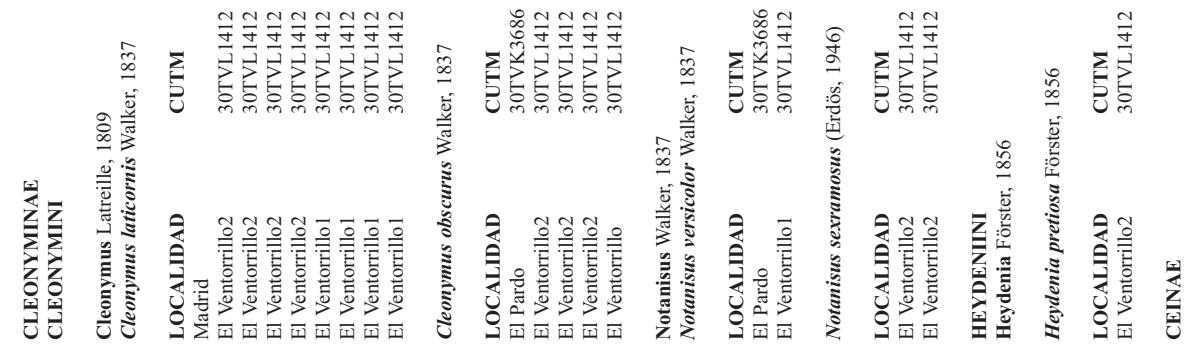




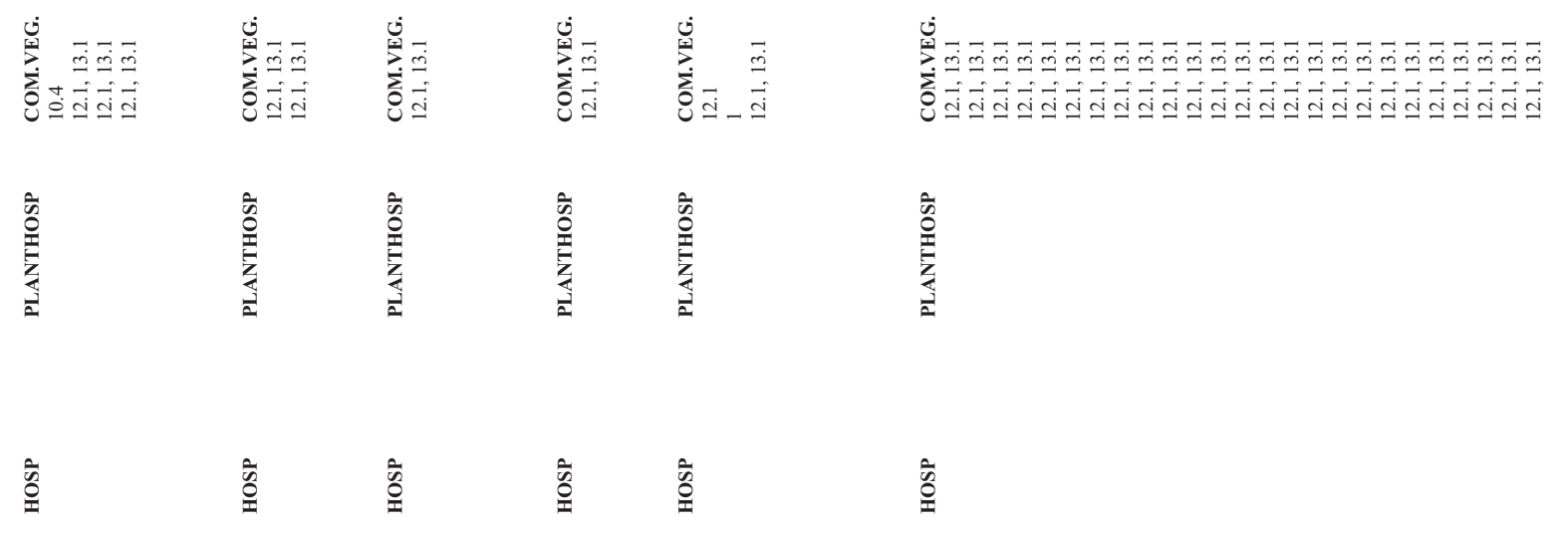

\begin{tabular}{|c|c|c|c|c|c|}
\hline 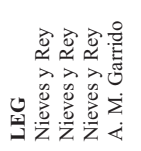 & 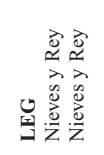 & 惫 & 离 & 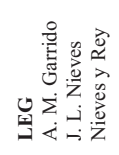 & 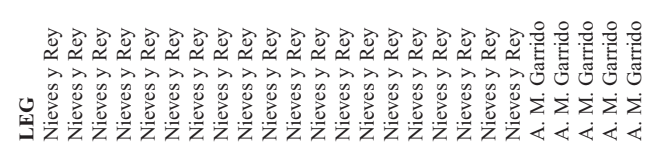 \\
\hline 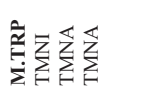 & 产至玄 & $\tilde{z} \bar{z}$ & $\stackrel{\tilde{\tilde{y}}}{\bar{z}} \bar{z}$ & $\stackrel{\tilde{\tilde{E}}}{\bar{z}}$ & 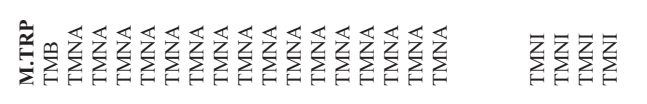 \\
\hline 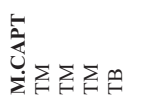 & 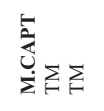 & 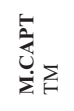 & 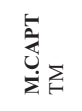 & 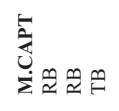 & 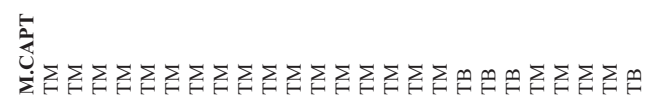 \\
\hline$\sum_{---}$ & $\frac{7}{2}$ & $\dot{z}_{n}^{2}$ & z & $\stackrel{m}{z}--$ & --- \\
\hline$\sum_{-}$ & $\sum_{i=-}$ & 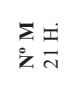 & $\sum_{i}$ & $\sum_{i}$ & 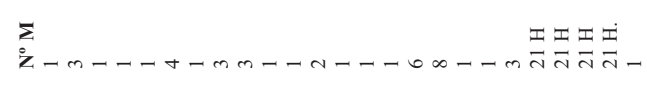 \\
\hline 幽 & 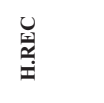 & 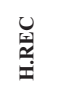 & 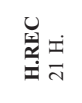 & 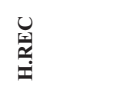 & 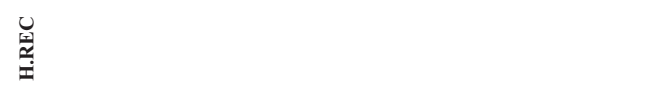 \\
\hline 曾 & 曾 & 兽 & 总 & $\dot{\ddot{x}}$ & 曾 \\
\hline
\end{tabular}
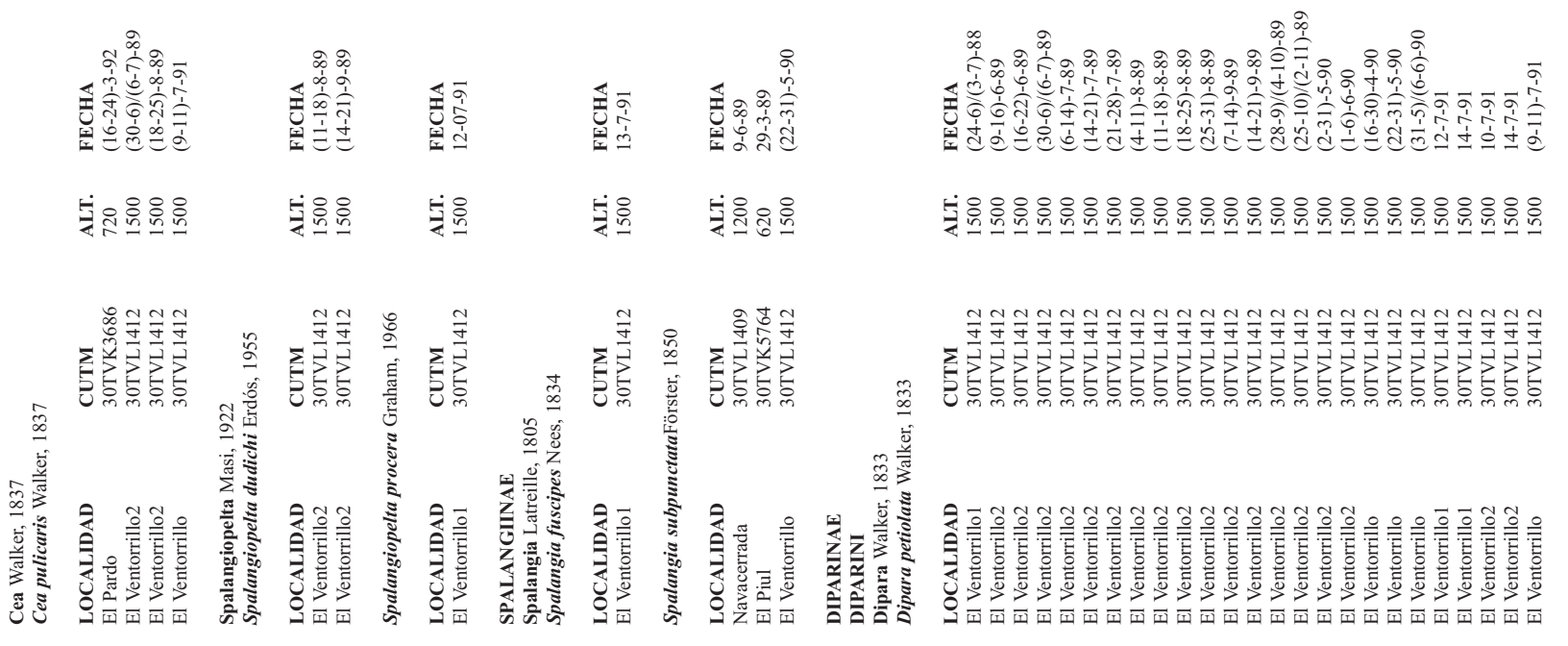


\begin{tabular}{|c|c|c|c|c|c|c|c|}
\hline 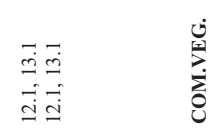 & 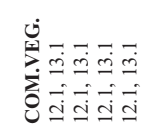 & 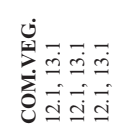 & ì & 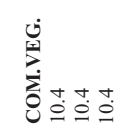 & 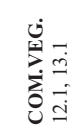 & 它 & 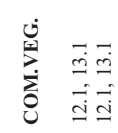 \\
\hline 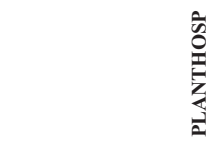 & 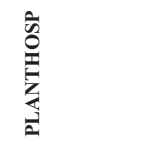 & 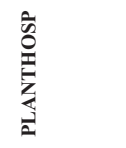 & 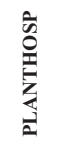 & 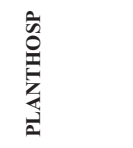 & 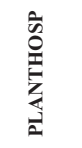 & 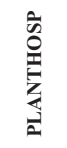 & 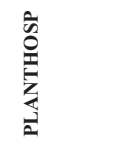 \\
\hline$\hat{\bar{s}}$ & $\begin{array}{l}\hat{\bar{े}} \\
\text { }\end{array}$ & के & 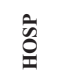 & 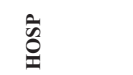 & के & 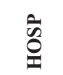 & $\hat{\bar{n}}$ \\
\hline
\end{tabular}

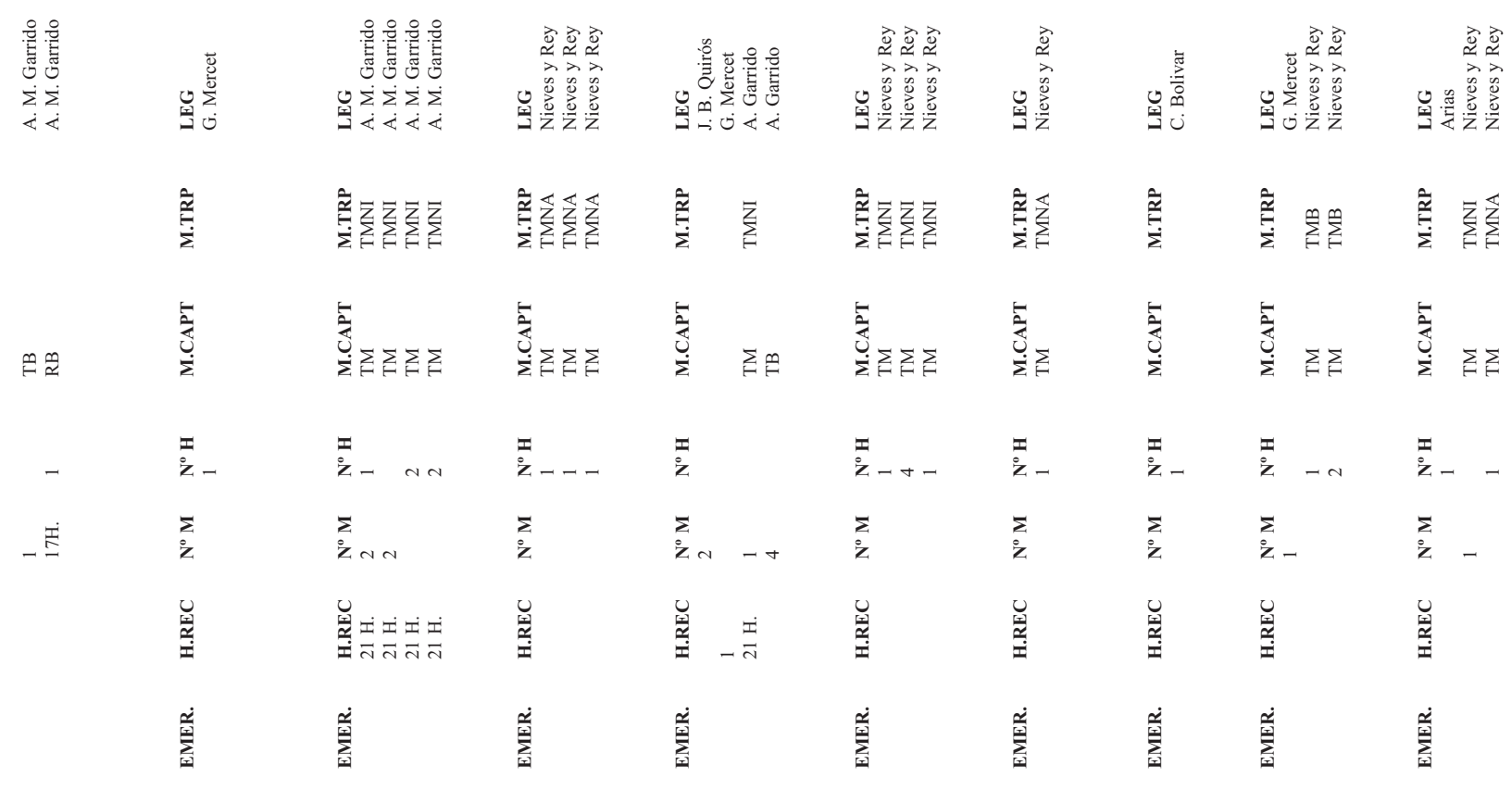

\begin{tabular}{|c|c|c|c|c|c|c|c|c|c|c|}
\hline 离 & 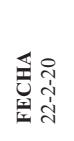 & 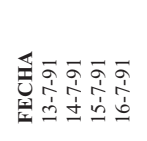 & 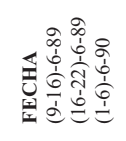 & 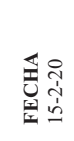 & 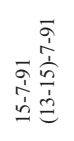 & 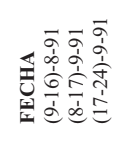 & 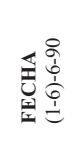 & 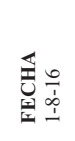 & 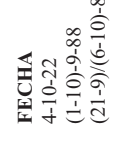 & 愿 \\
\hline 음음 & $\dot{y}$ & 분음음음음 & 家总总品 & 安 & & 분주윰주 & 湈足 & $\dot{s}$ & 安总店 & $\dot{3}$ \\
\hline
\end{tabular}

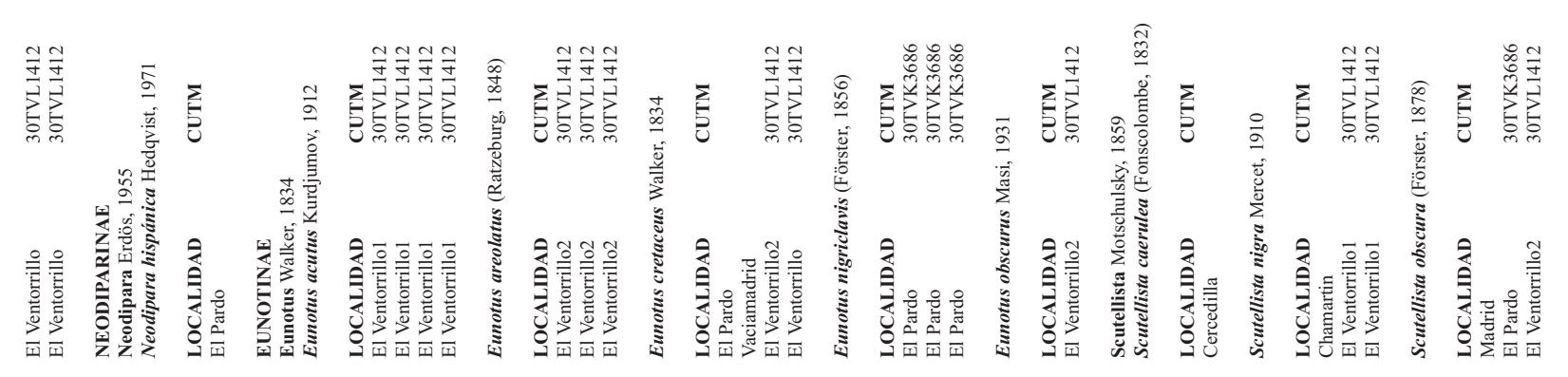




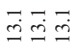

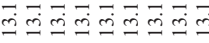

i்

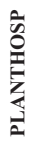

家

官

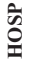

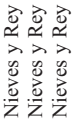

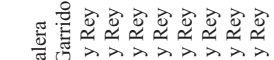

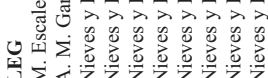

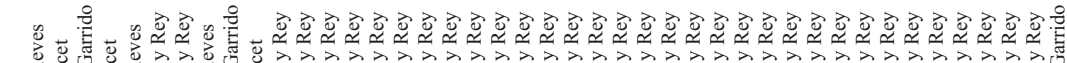

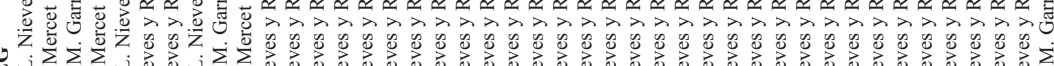

$\sum_{i=1}^{\mathbb{z}} \sum_{i}^{\mathbb{z}}$

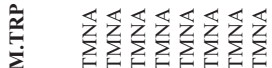

$\stackrel{\overline{\underline{z}}}{\mathrm{z}} \bar{z}$

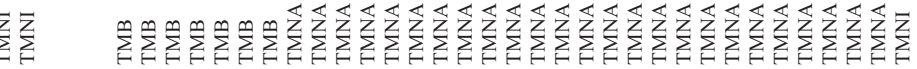

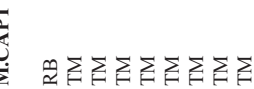

育

$\sum_{i} \sum$

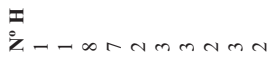

$\stackrel{7}{i}$

œ

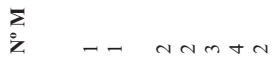

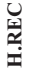

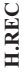

$\underset{i}{\dot{x}}$

$\dot{x}$

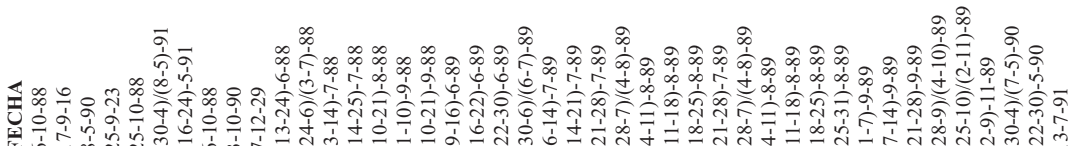

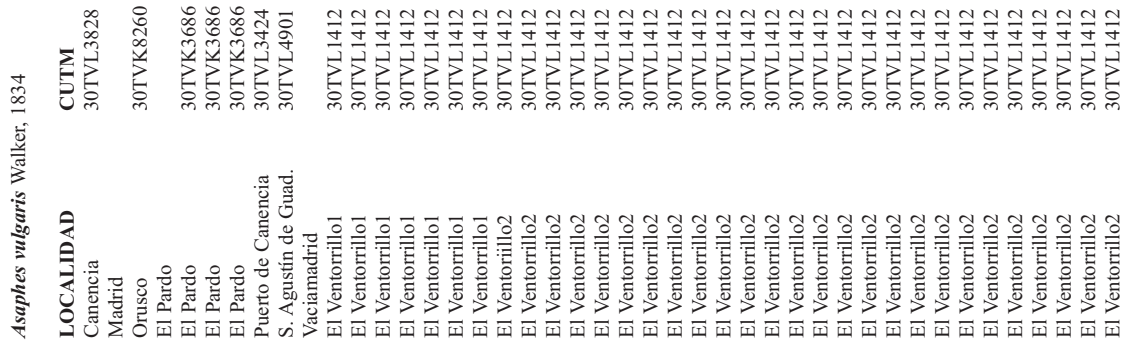




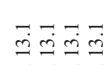

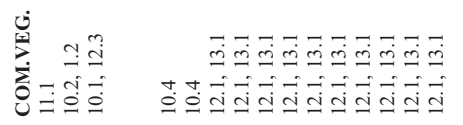

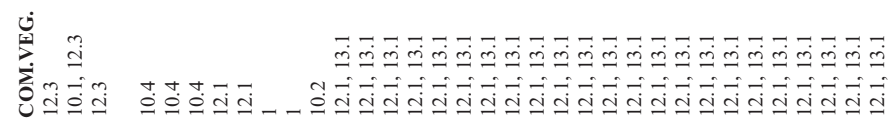

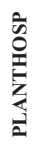

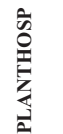

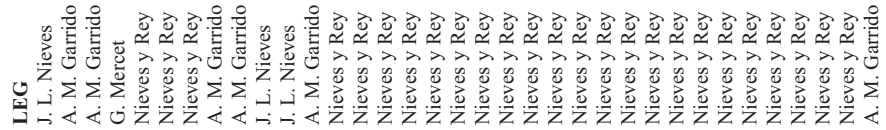

$\bar{b}$

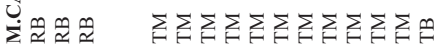

לे

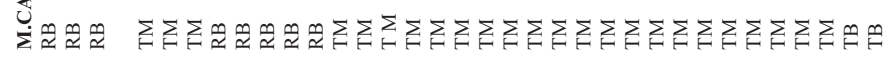
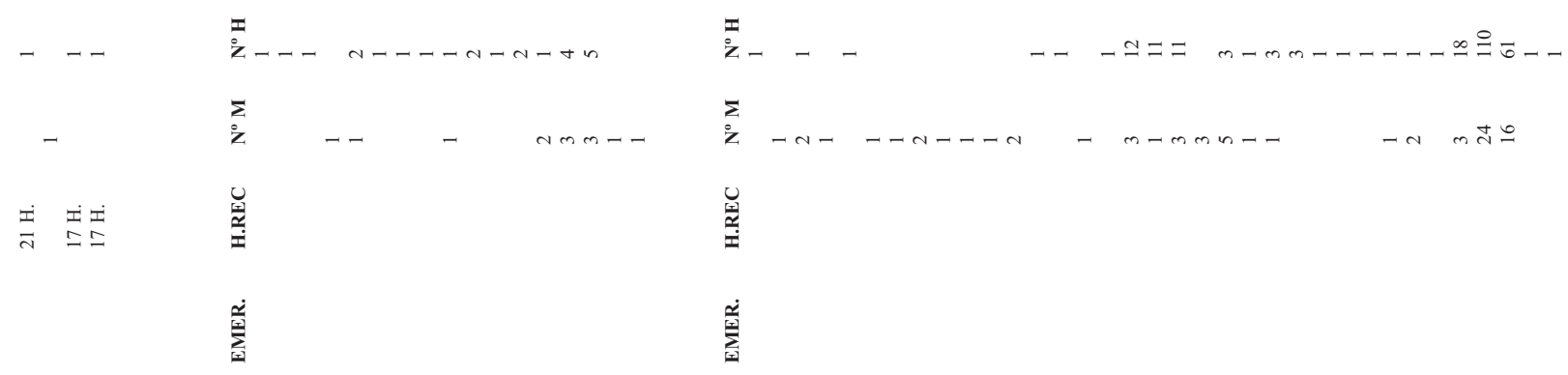

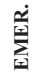

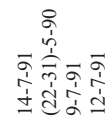

$\overline{\bar{T}} \bar{i} \infty \infty \infty$

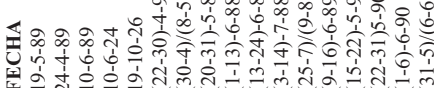

음음을욤

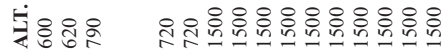

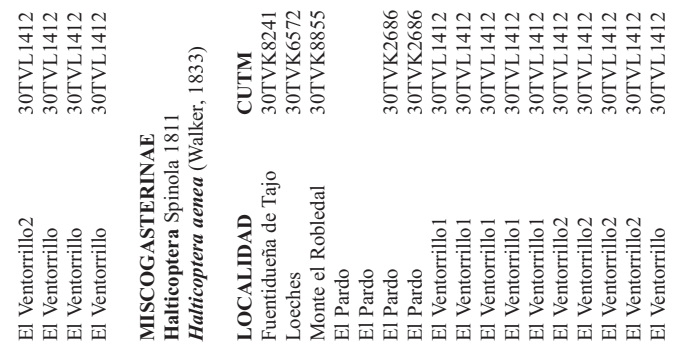

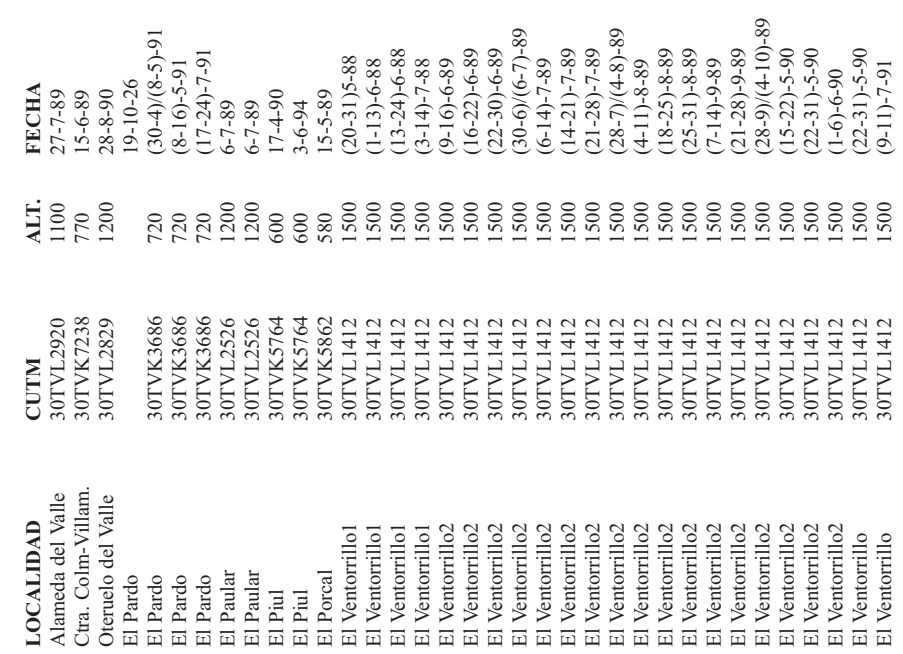




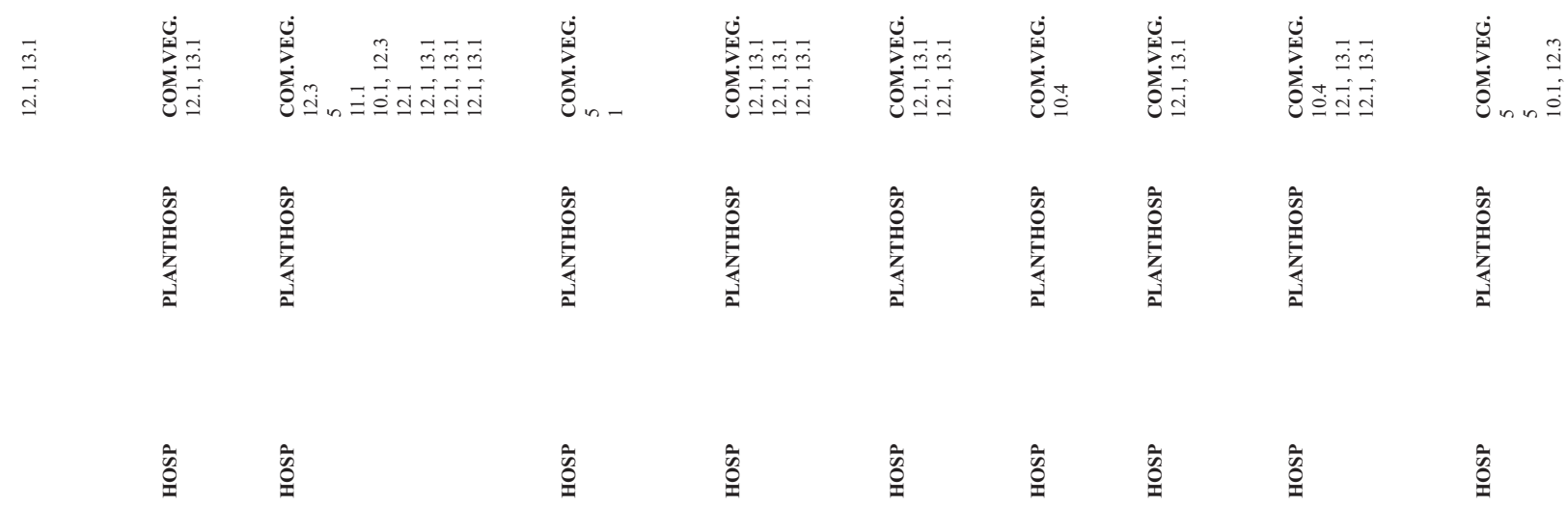

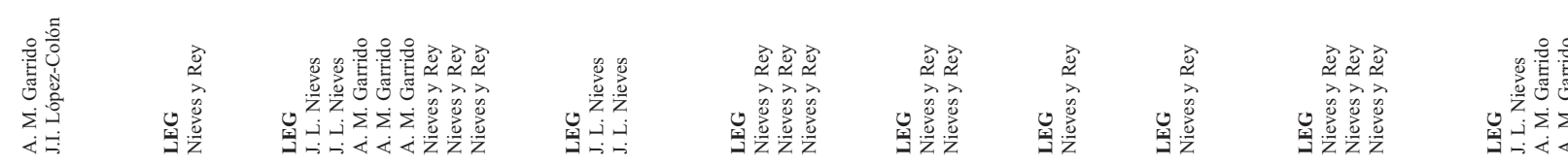

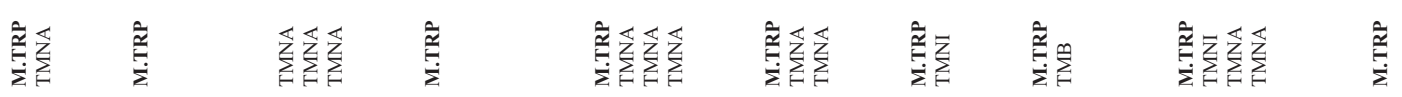

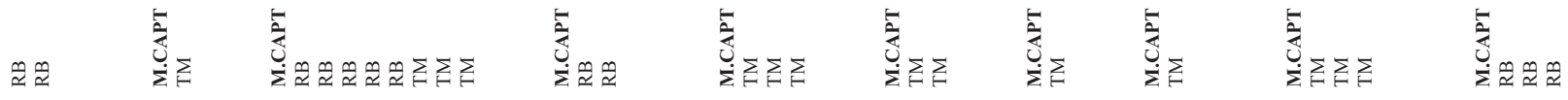

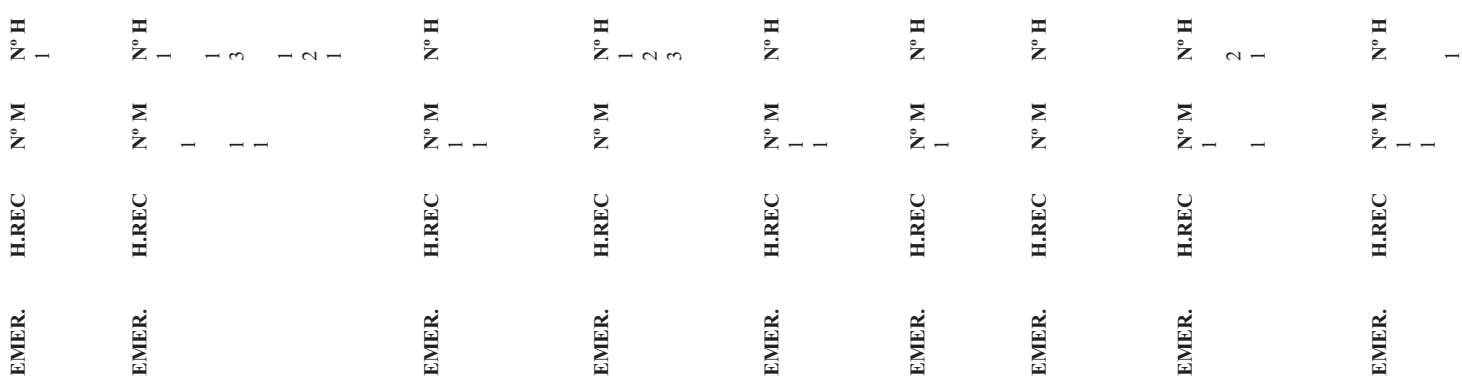

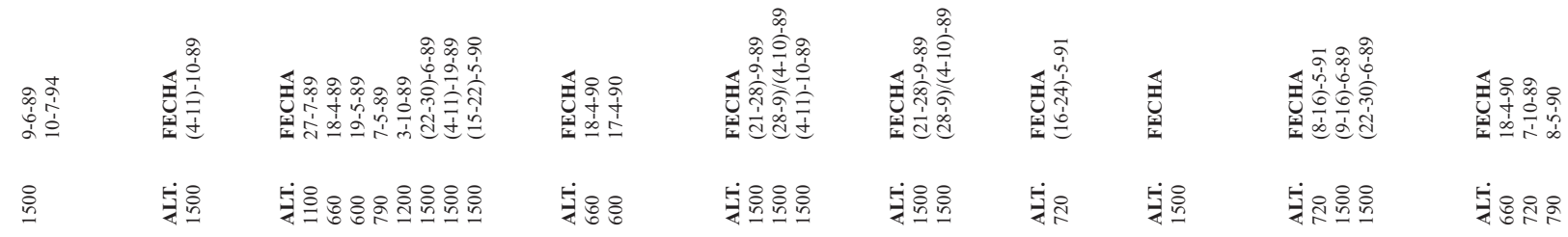

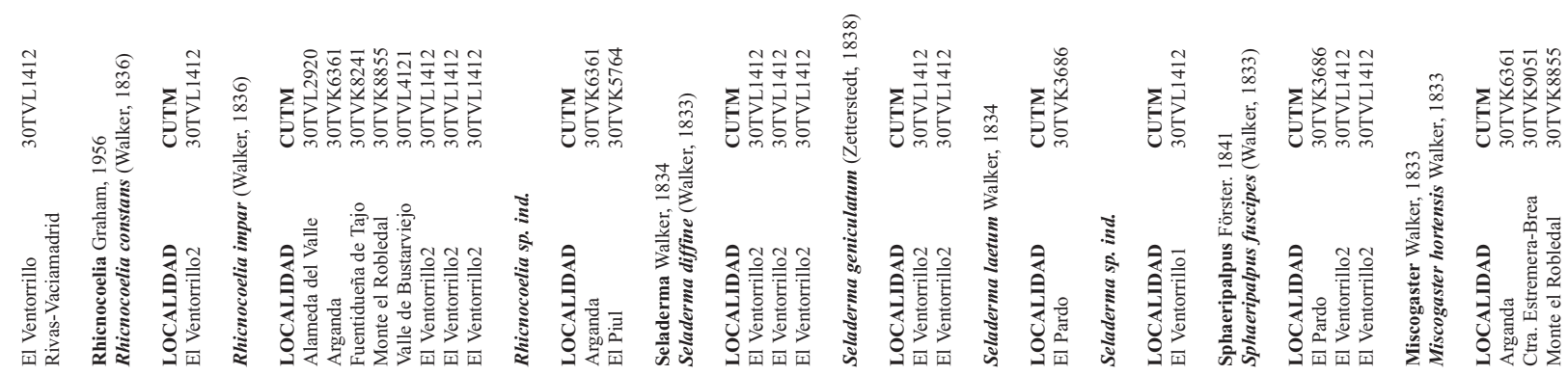




\begin{tabular}{|c|c|c|c|c|c|}
\hline 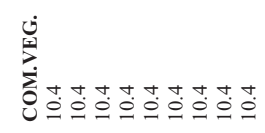 & 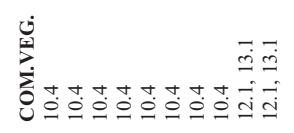 & 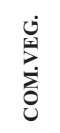 & 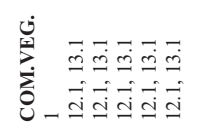 & 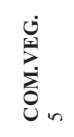 & 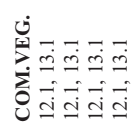 \\
\hline 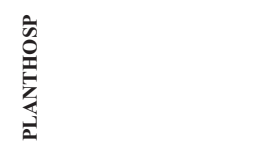 & 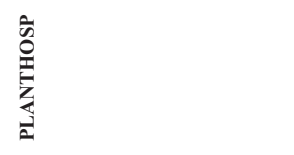 & 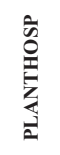 & 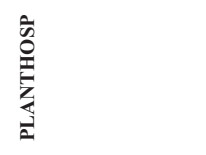 & 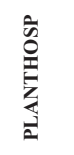 & 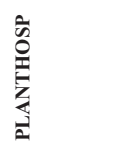 \\
\hline 容 & $\begin{array}{l}\tilde{\bar{o}} \\
\stackrel{\Xi}{1}\end{array}$ & 宮 & 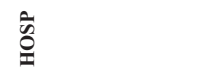 & 高 & के \\
\hline
\end{tabular}

\begin{tabular}{|c|c|c|c|c|c|}
\hline 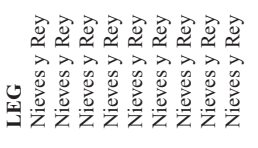 & 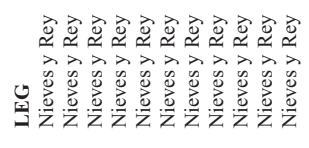 & 兽 & 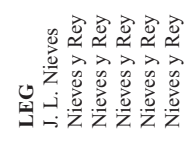 & 递蒿 & 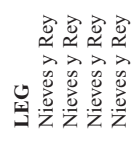 \\
\hline 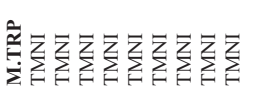 & 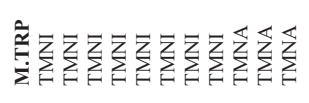 & 獄 & 言 & $\stackrel{\overline{\tilde{z}}}{\vec{z}}$ & 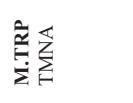 \\
\hline 矛 & 昰 & 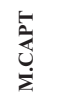 & 方 & 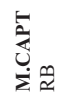 & 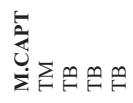 \\
\hline$\sum_{z}^{m}+-n m-n$ & $\sum_{z}^{z}-m--7 a n d a$ & $\frac{7}{2}$ & $\frac{\pi}{z}-m-n-$ & $\Sigma_{2}$ & $\frac{z}{z}$ \\
\hline$\sum_{i} \quad--$ & $\begin{array}{l}\sum_{0}^{2} \\
\dot{z}_{-}\end{array}$ & $\sum_{\bar{z}}$ & $\sum_{z}$ & $\sum_{\overline{2}}^{2}$ & $\stackrel{5}{z}_{n--}$ \\
\hline 岂 & 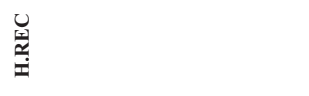 & 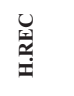 & 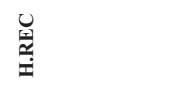 & 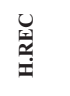 & 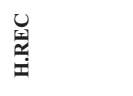 \\
\hline 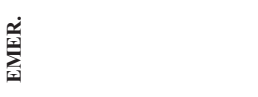 & 畄 & 兽 & 兽 & 首 & 檍 \\
\hline
\end{tabular}

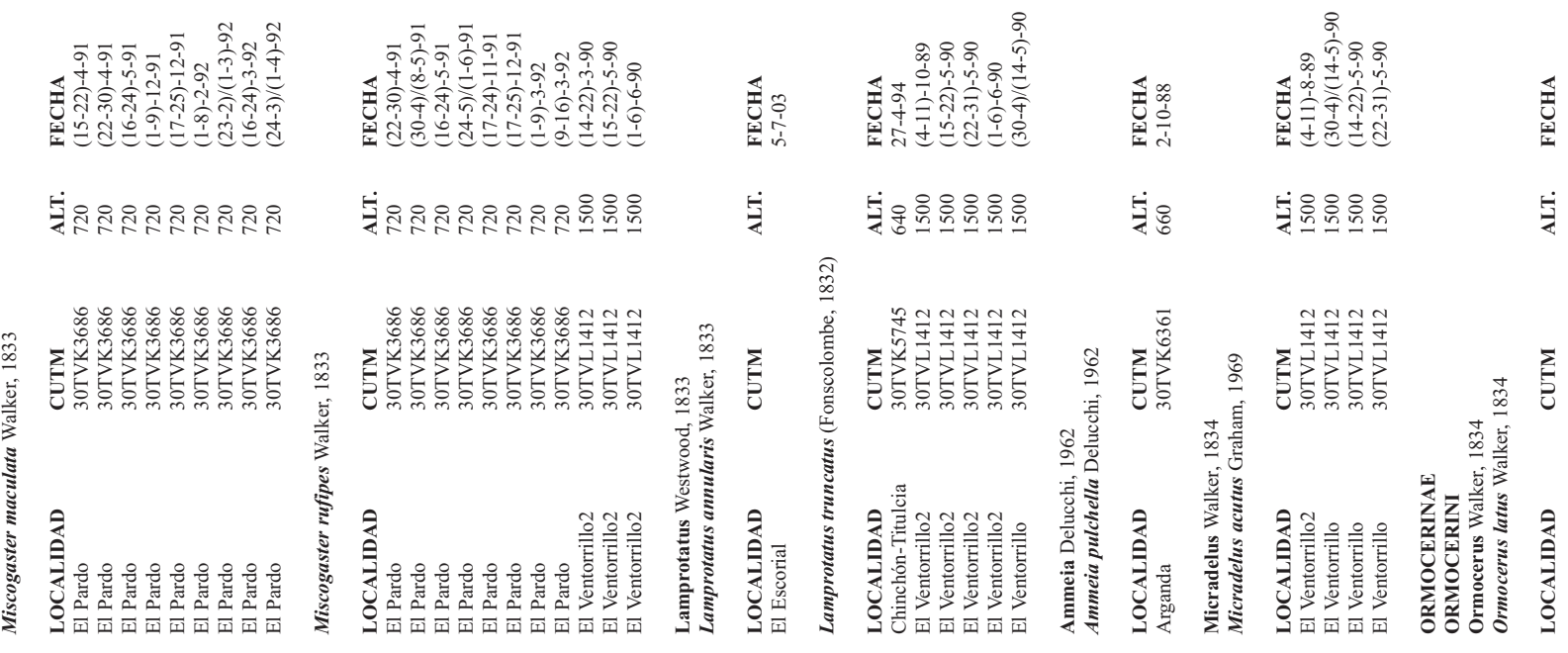




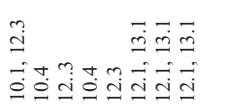
II

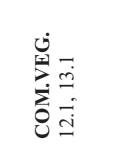

I.

章, and

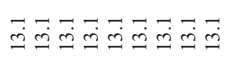

总泀离
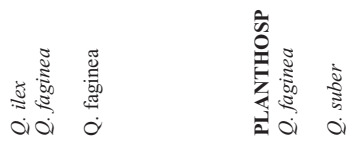

嚆

产

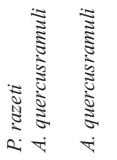

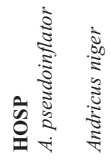

产

$\stackrel{\bar{s}}{\stackrel{x}{x}}$

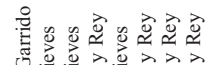

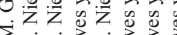

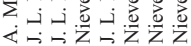

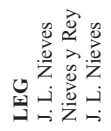

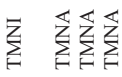

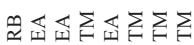

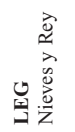

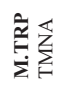

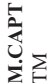

:

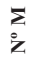

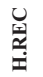

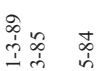

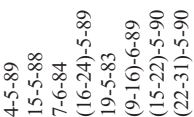

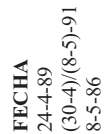

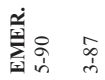

춫

:

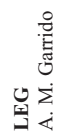

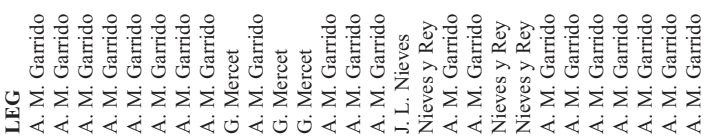

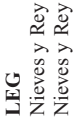

言

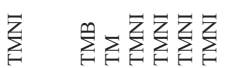

军玄芝

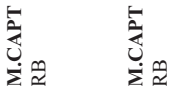

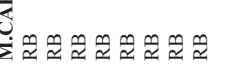

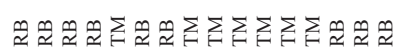

5

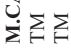

ฉ

ह

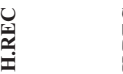

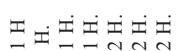

$\stackrel{\mathscr{2}}{=}$

奠舀

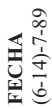

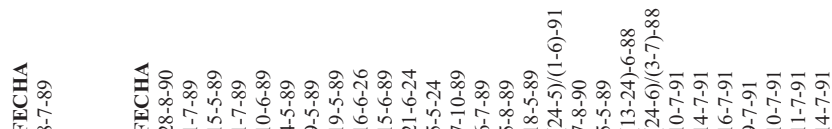

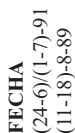

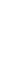

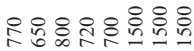

분웅ㅊํㅇํㅇ

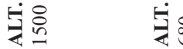

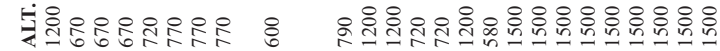

บั่ํํํำ

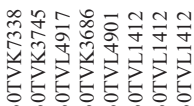

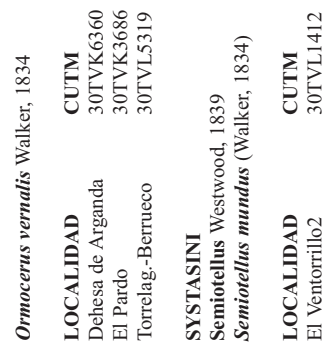

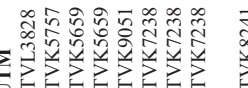

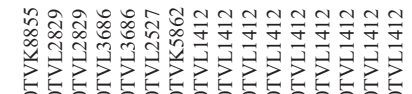




\begin{tabular}{|c|c|c|c|c|c|c|c|}
\hline 㦈 & 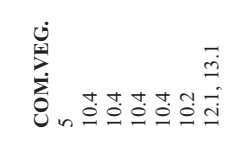 & 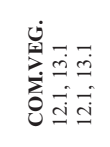 & 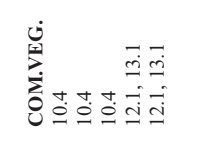 & 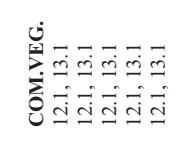 & 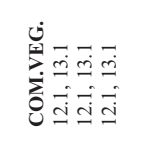 & 兽 & 要 \\
\hline 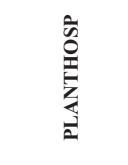 & 产 & 咅 & 咅 & 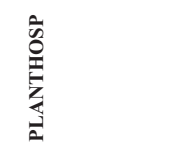 & 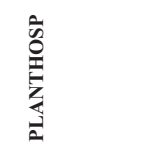 & 竞 & 竞 \\
\hline$\stackrel{\stackrel{े}{8}}{\rightleftarrows}$ & $\stackrel{\hat{0}}{\underline{\Xi}}$ & $\stackrel{\frac{\hbar}{0}}{\underline{x}}$ & $\stackrel{\overline{0}}{\underline{0}}$ & $\stackrel{\overline{0}}{\underline{x}}$ & $\stackrel{\overline{0}}{\underline{\Xi}}$ & $\stackrel{\bar{c}}{\underline{3}}$ & $\stackrel{\bar{c}}{\underline{3}}$ \\
\hline 谤产 & 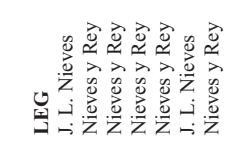 & 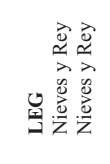 & 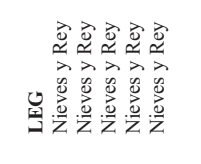 & 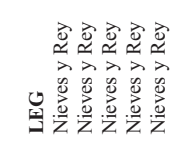 & 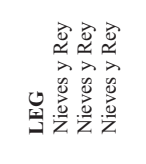 & 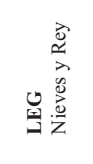 & 离 \\
\hline$\stackrel{\overline{\tilde{E}}}{\vec{z}}$ & 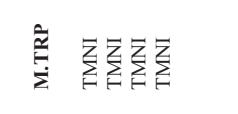 & 辣洂 & 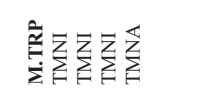 & 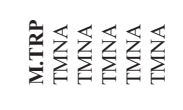 & 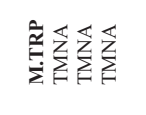 & 言表 & 产紊 \\
\hline 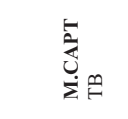 & 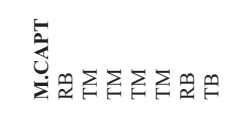 & 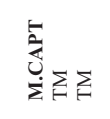 & 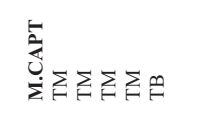 & 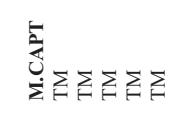 & 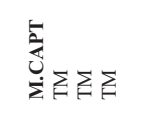 & $\underbrace{\grave{n}}_{\bar{u}}$ & 糹 \\
\hline 芠- & $\sum_{\dot{z}+}^{m} \quad a-$ & $\frac{z}{2}$ & $\frac{\pi}{z}-$ & $z_{z_{N-}}$ & $z_{2}^{z}$ & $\frac{\pi}{2}$ & $\frac{\pi}{2}$ \\
\hline $\bar{z}$ & $\bar{z}_{\bar{z}} \alpha-$ & $\frac{\bar{z}}{2}$ & $\sum_{\bar{z}}^{z-n}-4$ & $\bar{z}$ & 言 & $\bar{z}_{-}$ & $\sum_{2}$ \\
\hline$\stackrel{\mathscr{M}}{\dddot{M}}$ & $\stackrel{\mathscr{W}}{\ddot{M}}$ & $\stackrel{\mathscr{U}}{\ddot{x}}$ & $\stackrel{\mathscr{H}}{\ddot{H}}$ & $\stackrel{\mathscr{U}}{\ddot{x}}$ & $\stackrel{\underline{W}}{\ddot{E}}$ & 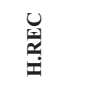 & $\stackrel{U}{\mathscr{W}}$ \\
\hline 罯 & 兽 & 善 & 檍 & 咅 & 曽 & 曽 & 曽 \\
\hline
\end{tabular}

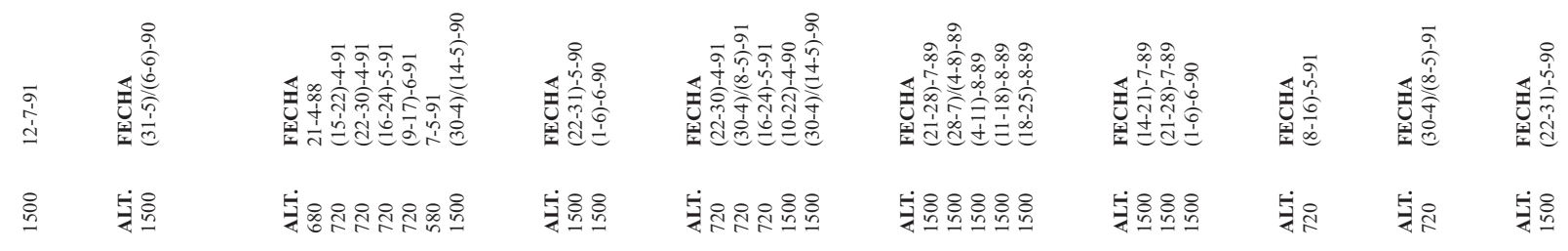

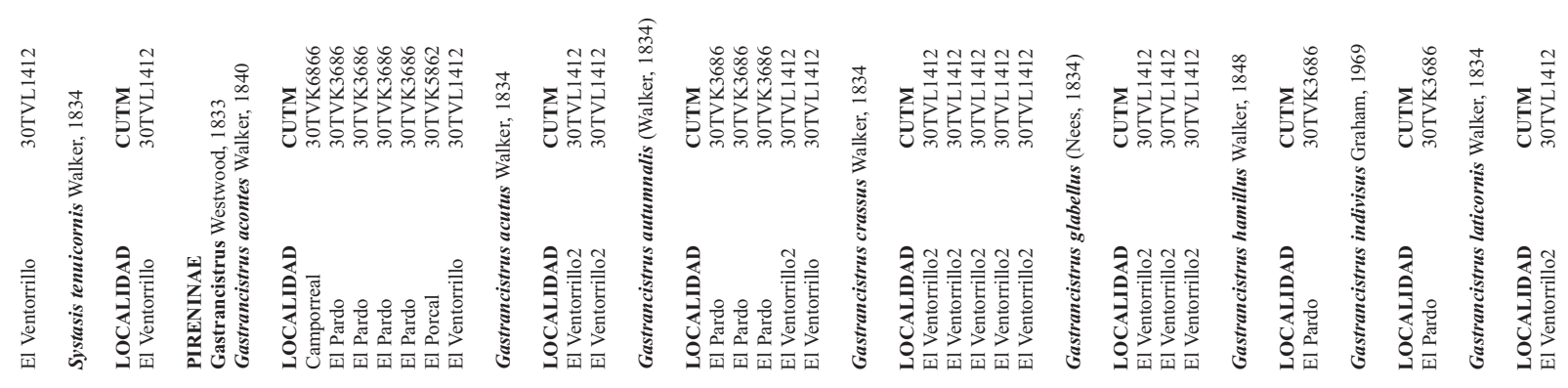




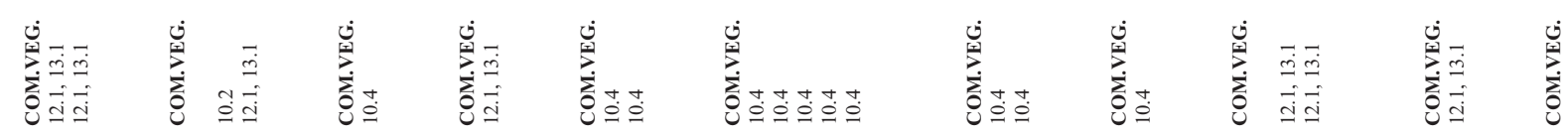

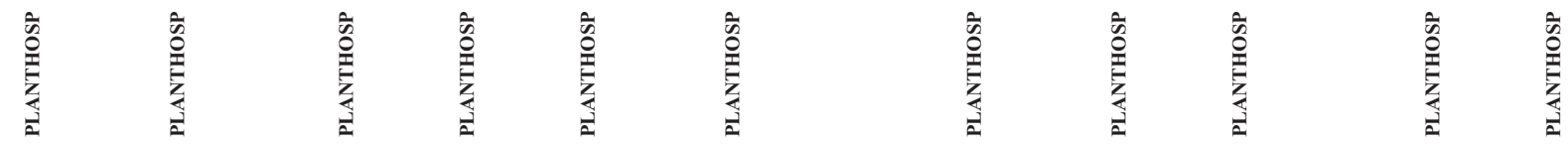

㐔 咅

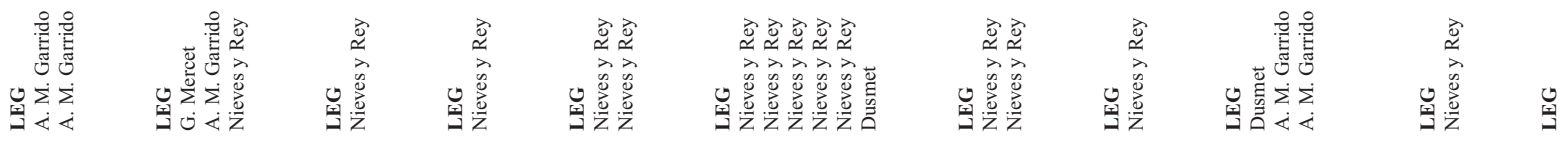

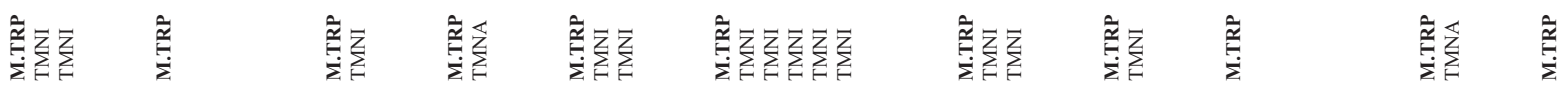

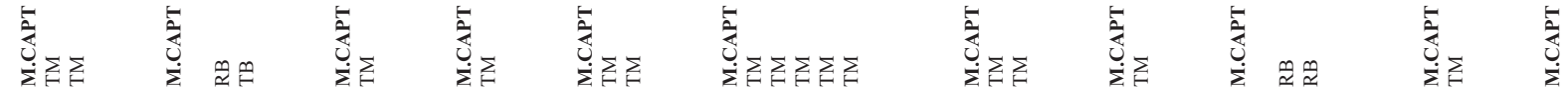

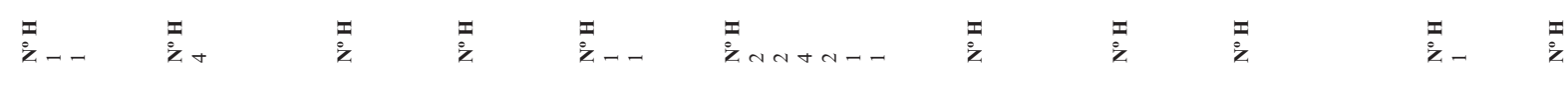

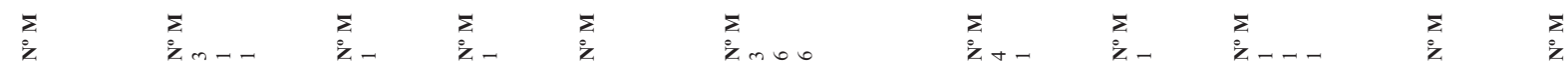

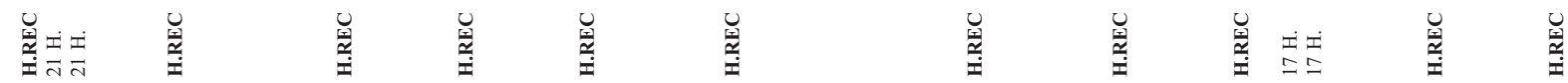

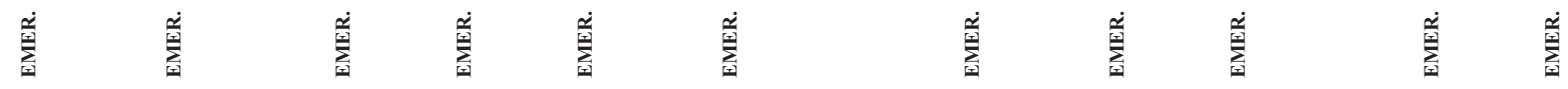

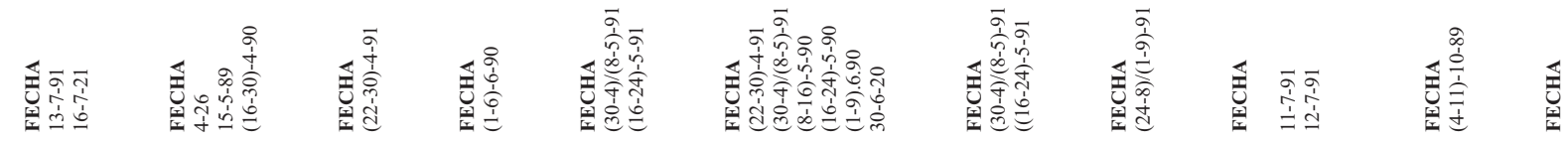

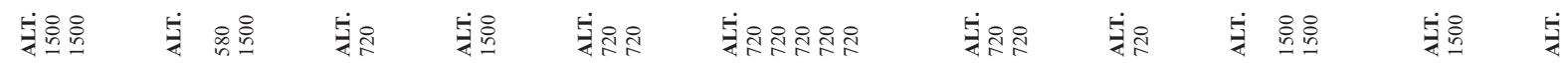

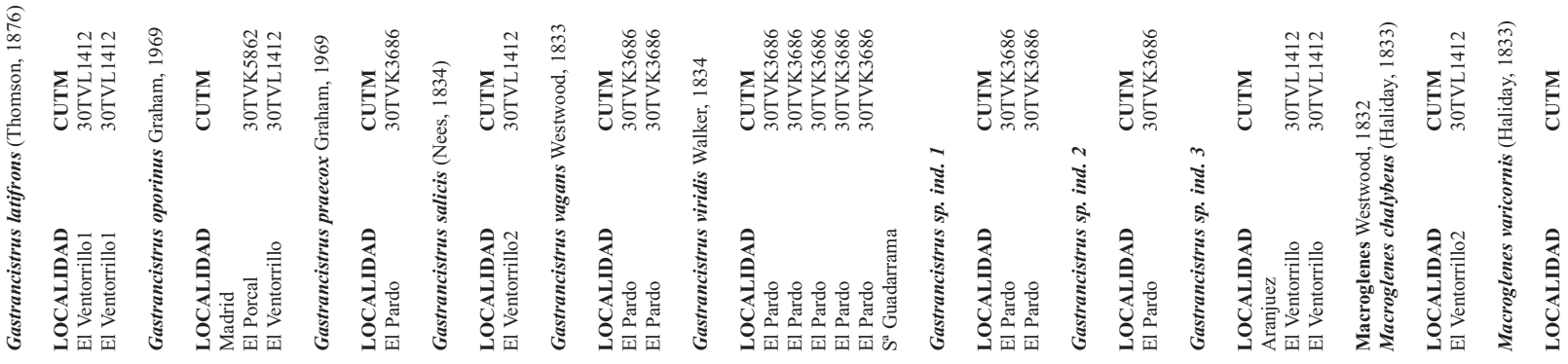




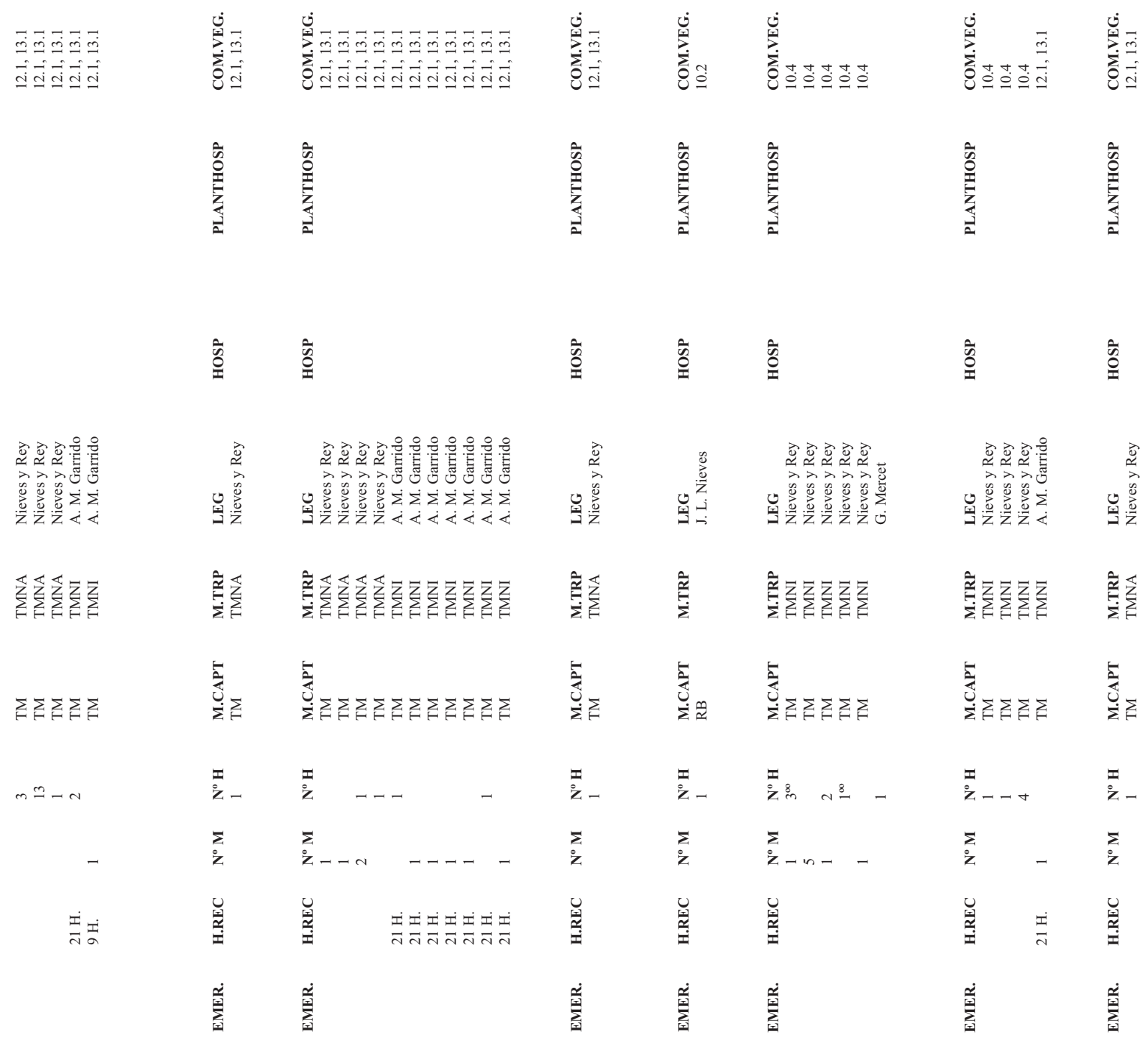

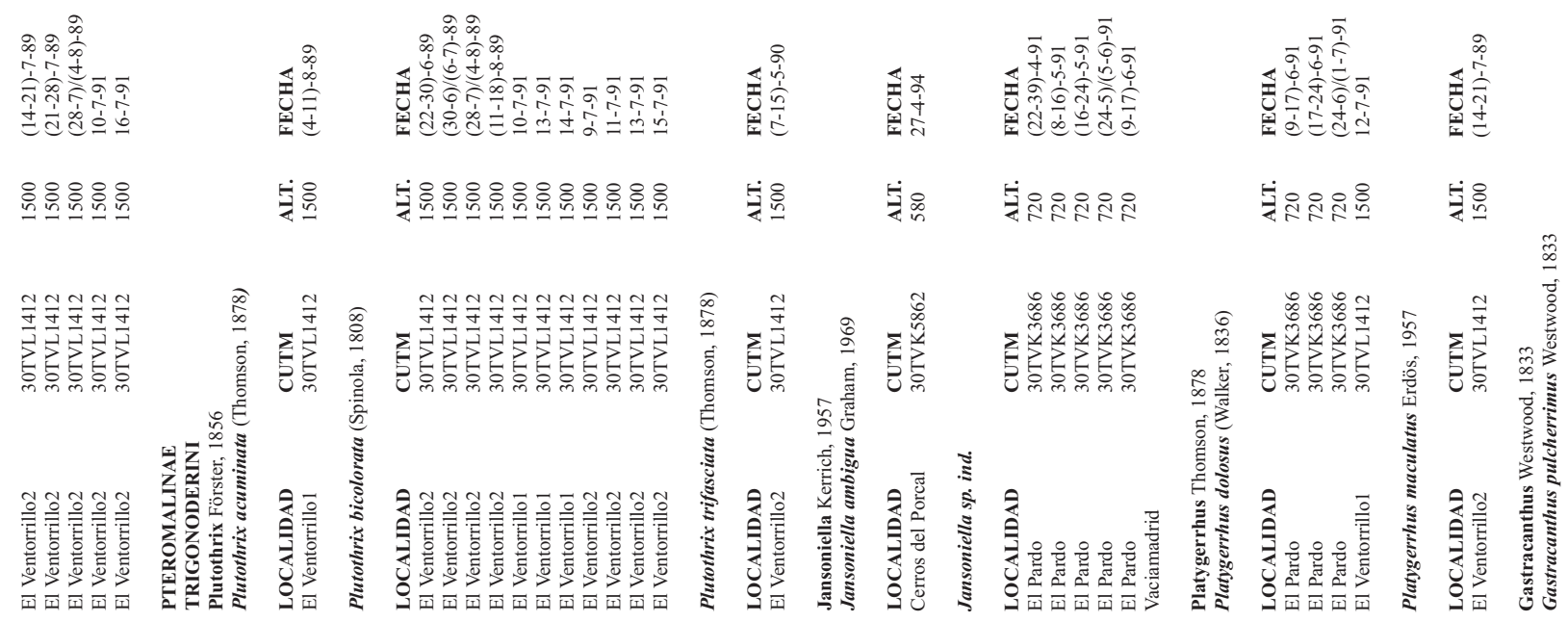




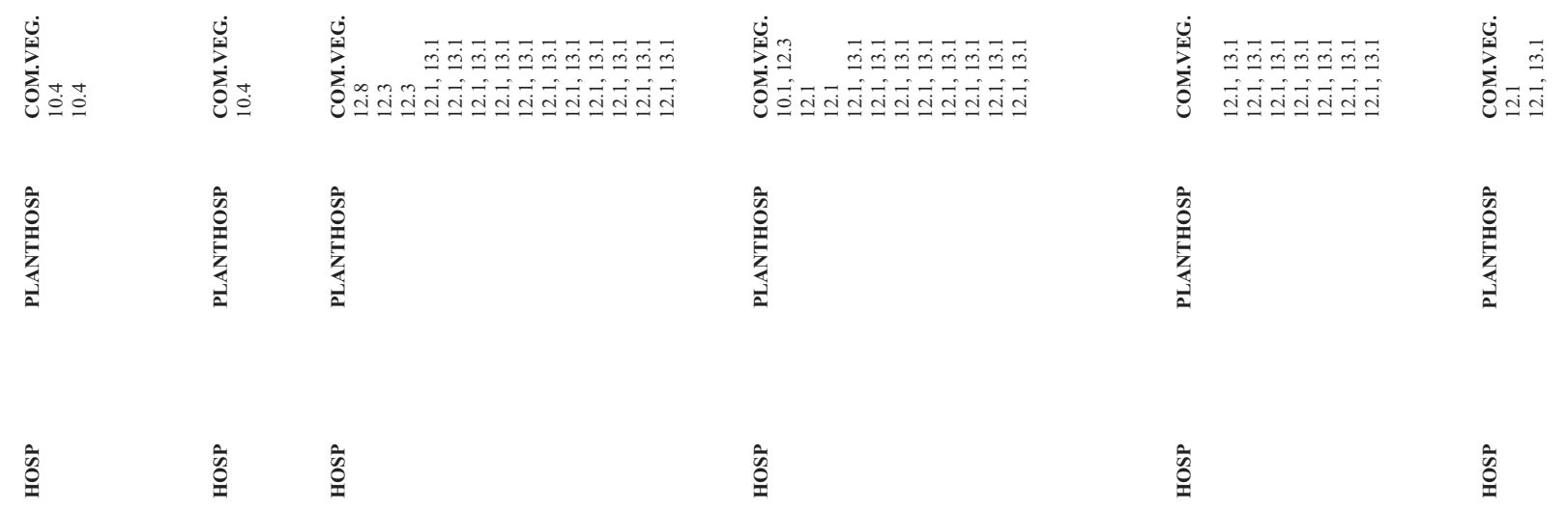

\begin{tabular}{|c|c|c|c|c|}
\hline 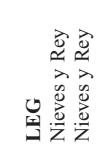 & 这 & 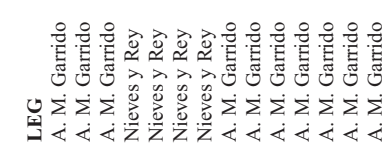 & 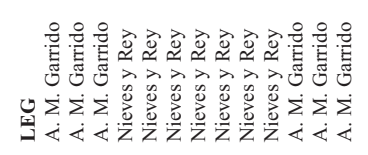 & 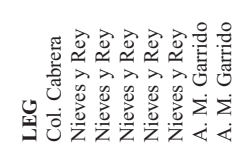 \\
\hline$\sum_{z}$ & $\stackrel{\overline{\underline{z}}}{\bar{z}}$ & 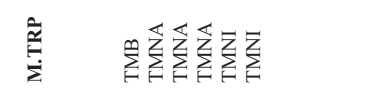 & 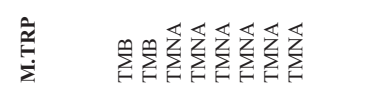 & 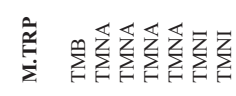 \\
\hline 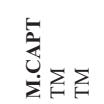 & 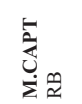 & 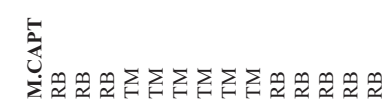 & 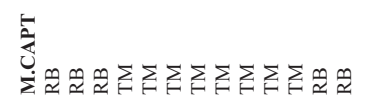 & 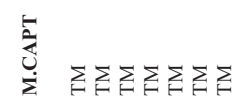 \\
\hline
\end{tabular}

\begin{tabular}{|c|c|c|c|c|c|c|c|}
\hline 范 & : & : &,$-\ldots-$ & 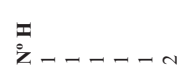 & $-\ldots-$ & $m_{-1}$ & ----- \\
\hline ż & $\sum_{\bar{z}}$ & $\bar{z}$ & $-\quad-$ & $\sum_{z}^{2}$ & - & $\sum_{\bar{z}}^{\Sigma}$ & - \\
\hline 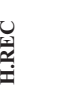 & 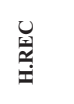 & 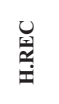 & 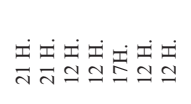 & 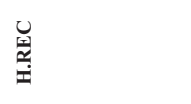 & 善黄垔 & 岂 & 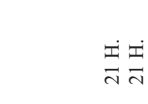 \\
\hline 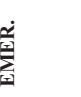 & 獣 & 兽 & & 道 & & 道 & \\
\hline
\end{tabular}

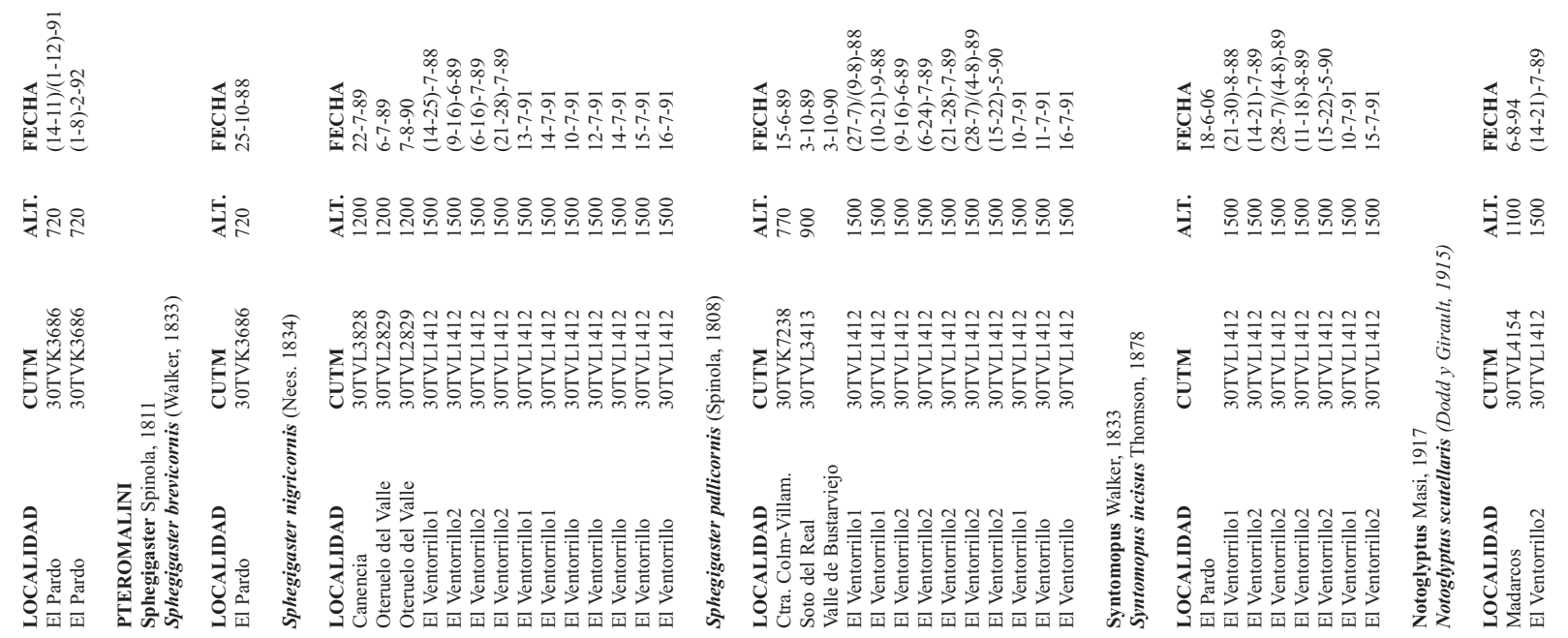




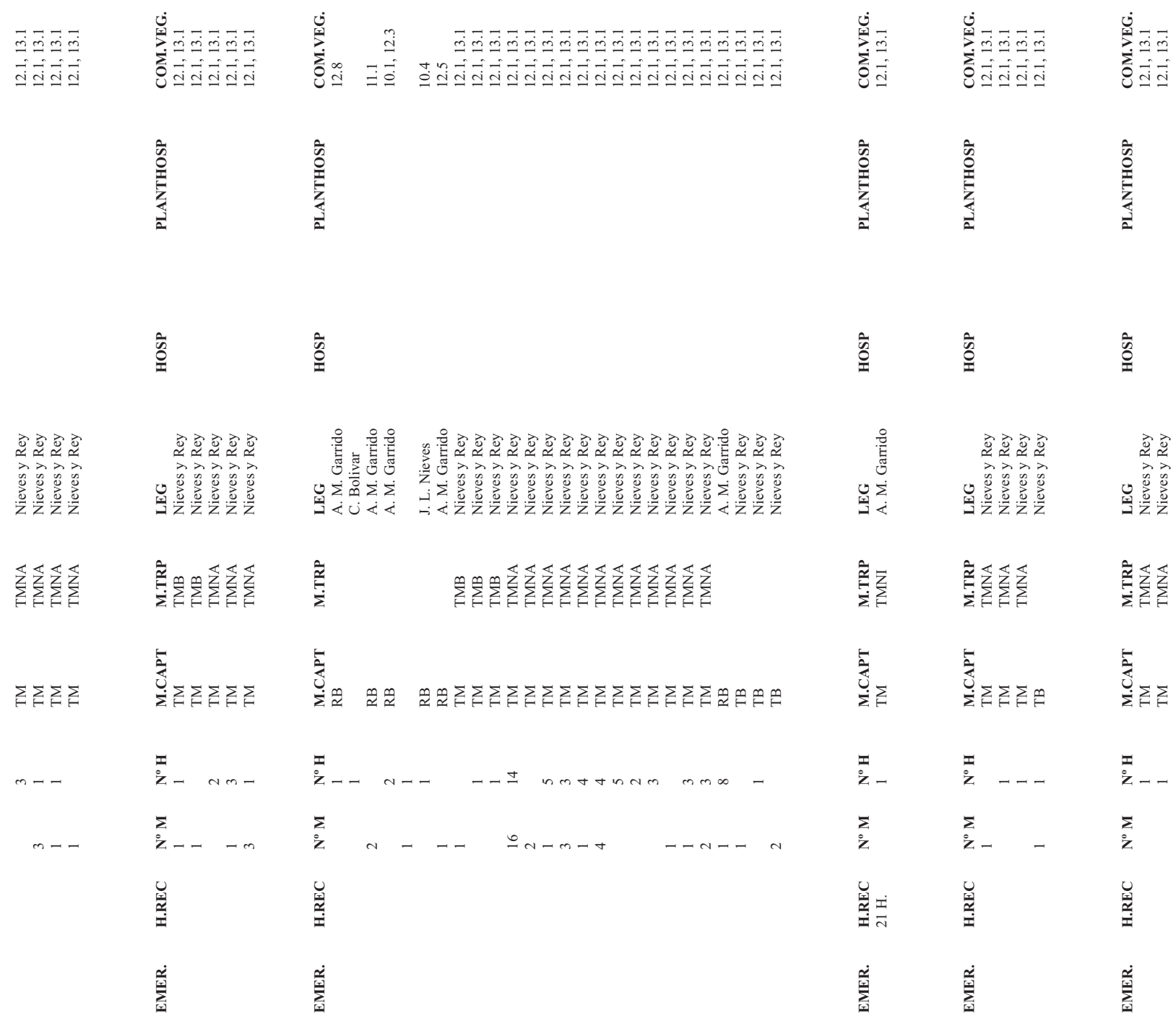

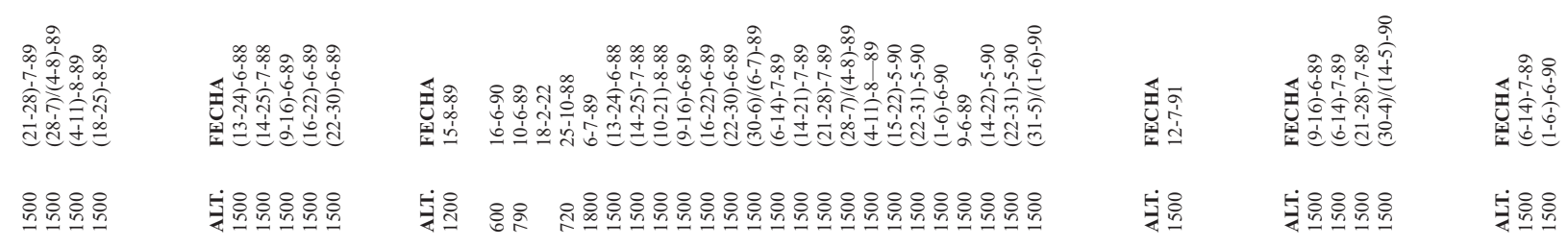

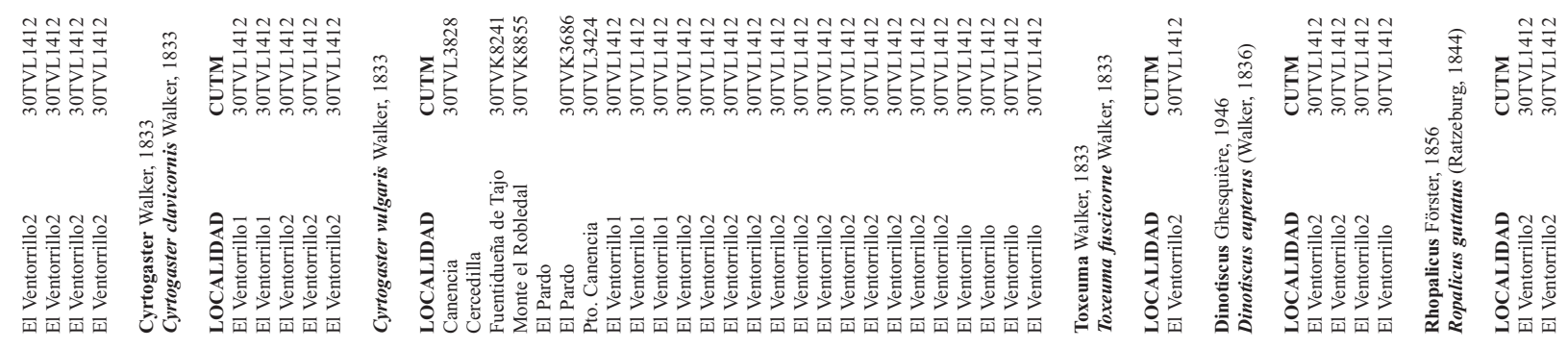




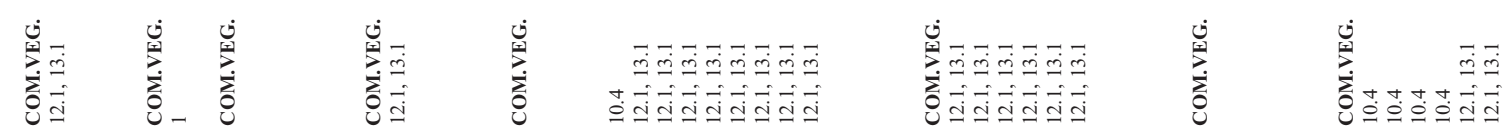

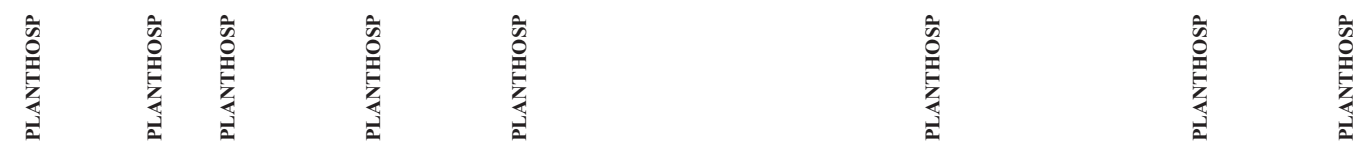

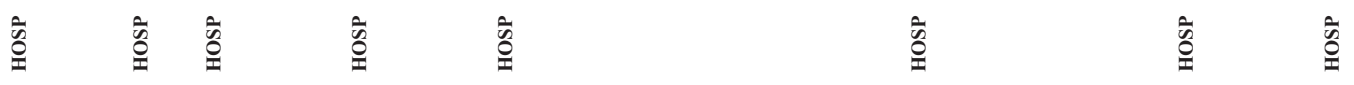

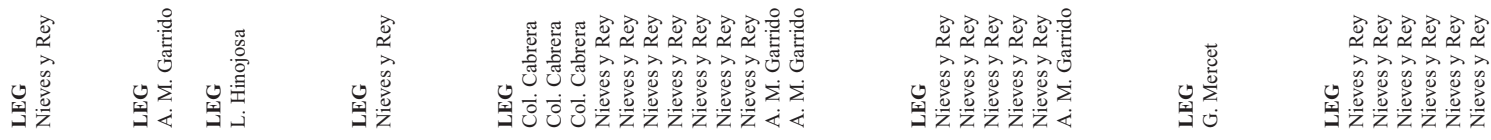

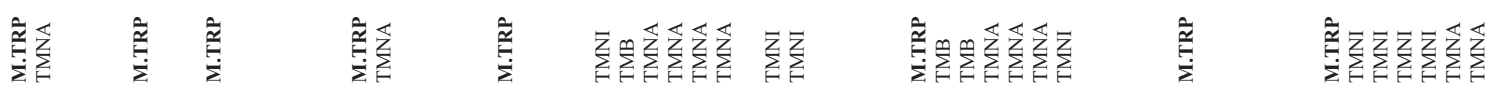

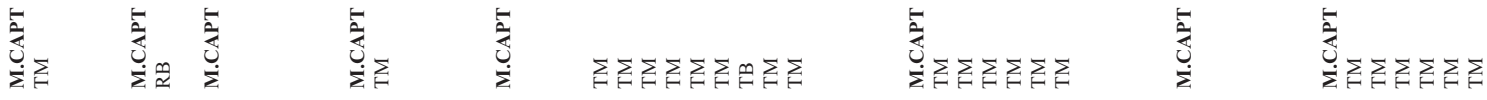

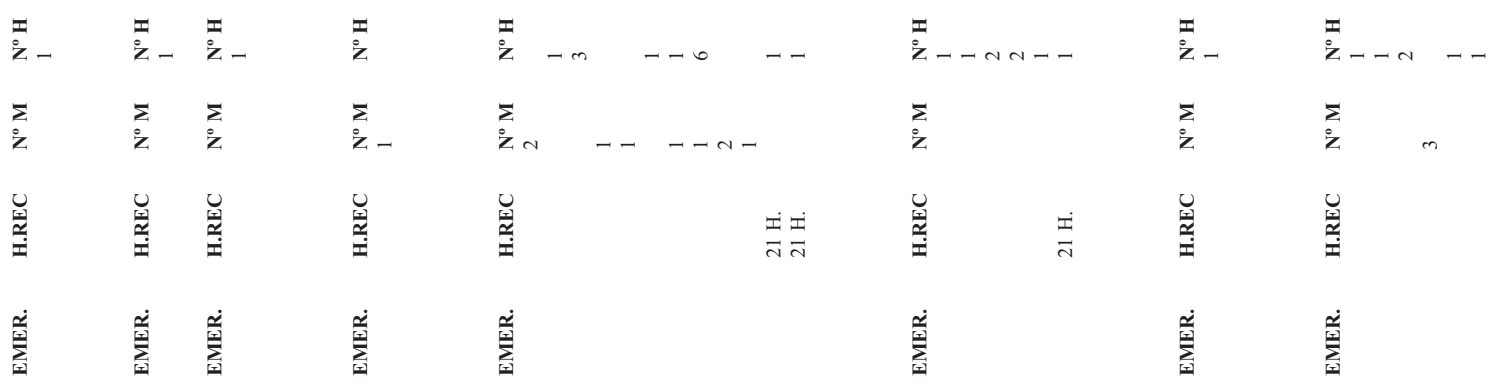

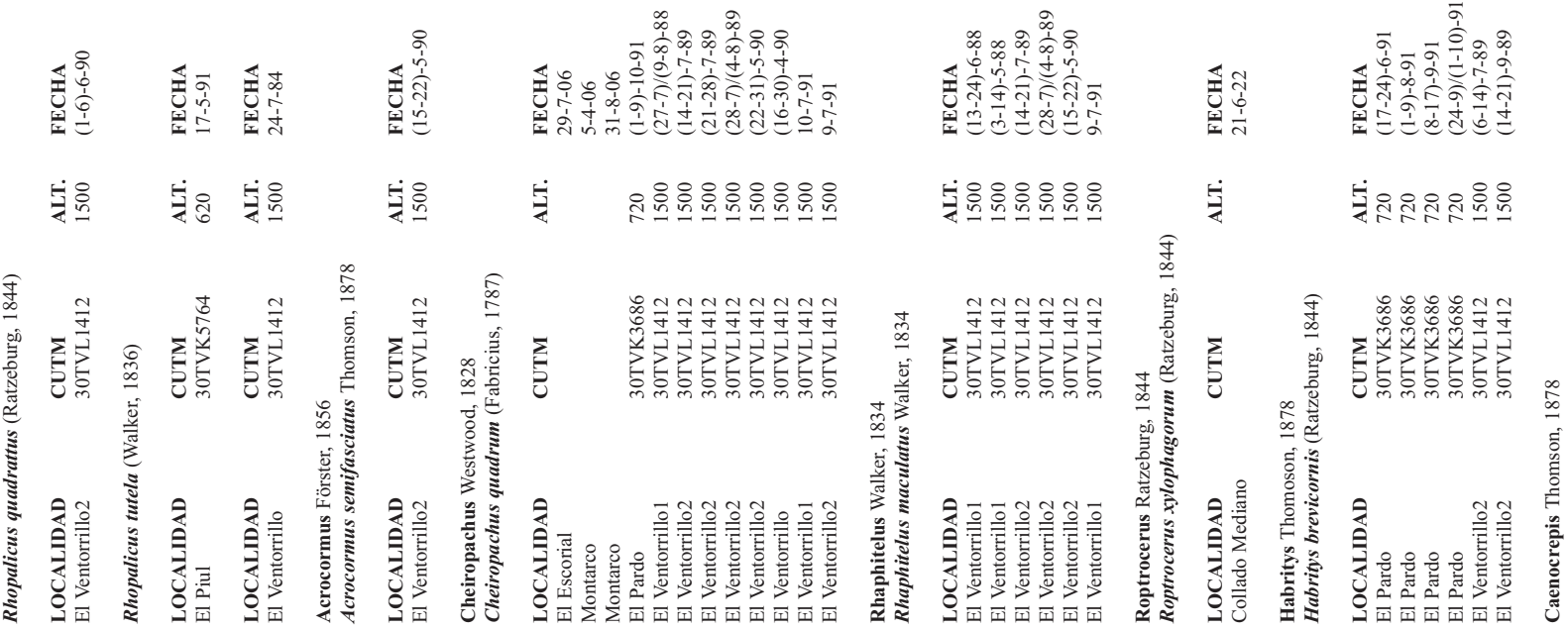




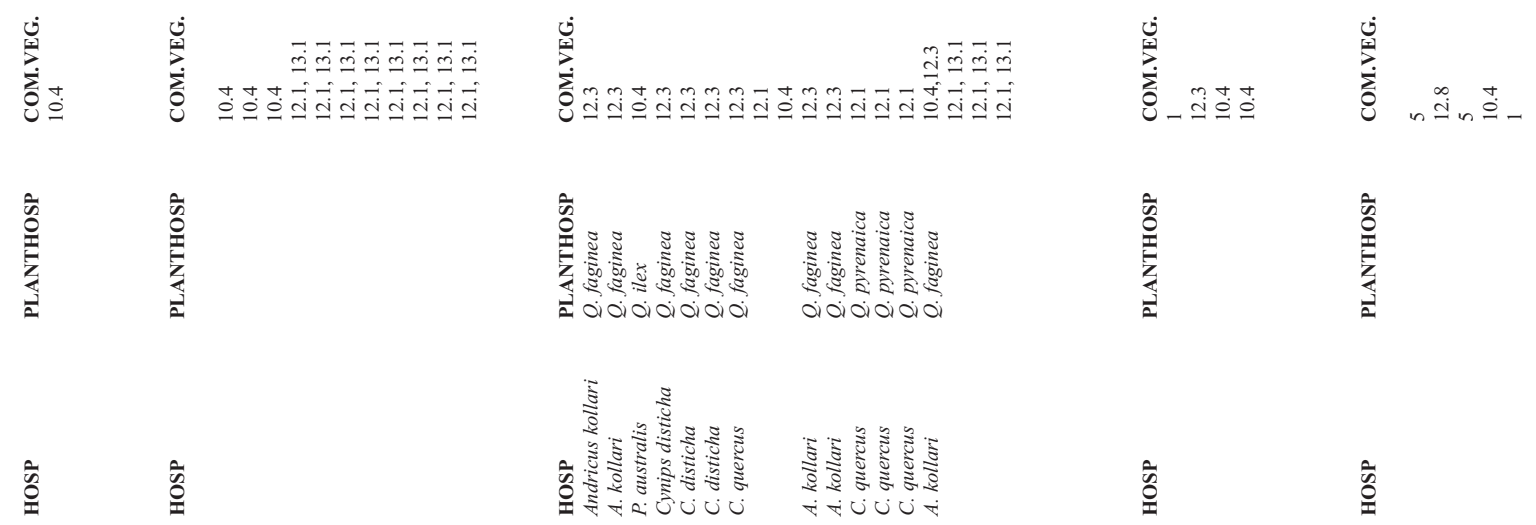

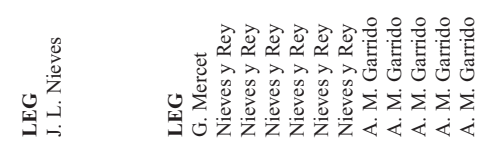
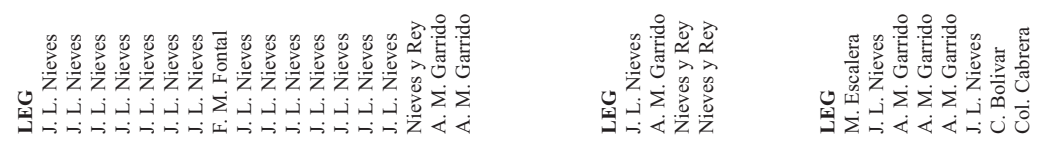

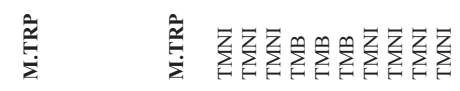

$\stackrel{\bar{\varkappa}}{\bar{z}}$

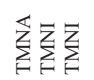

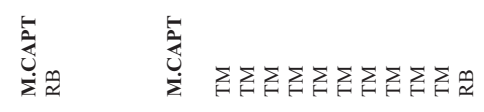

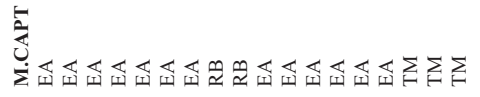

$\stackrel{\overline{\tilde{z}}}{\bar{z}} \quad \bar{z}$
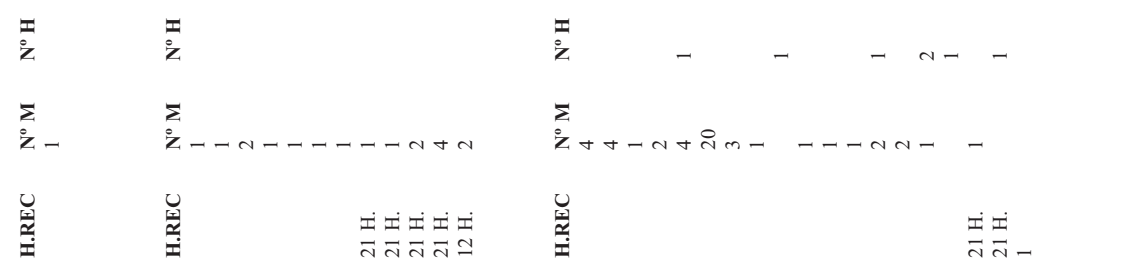

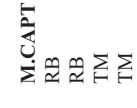

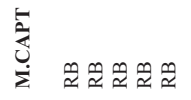

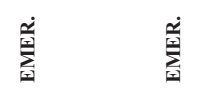

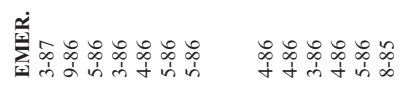
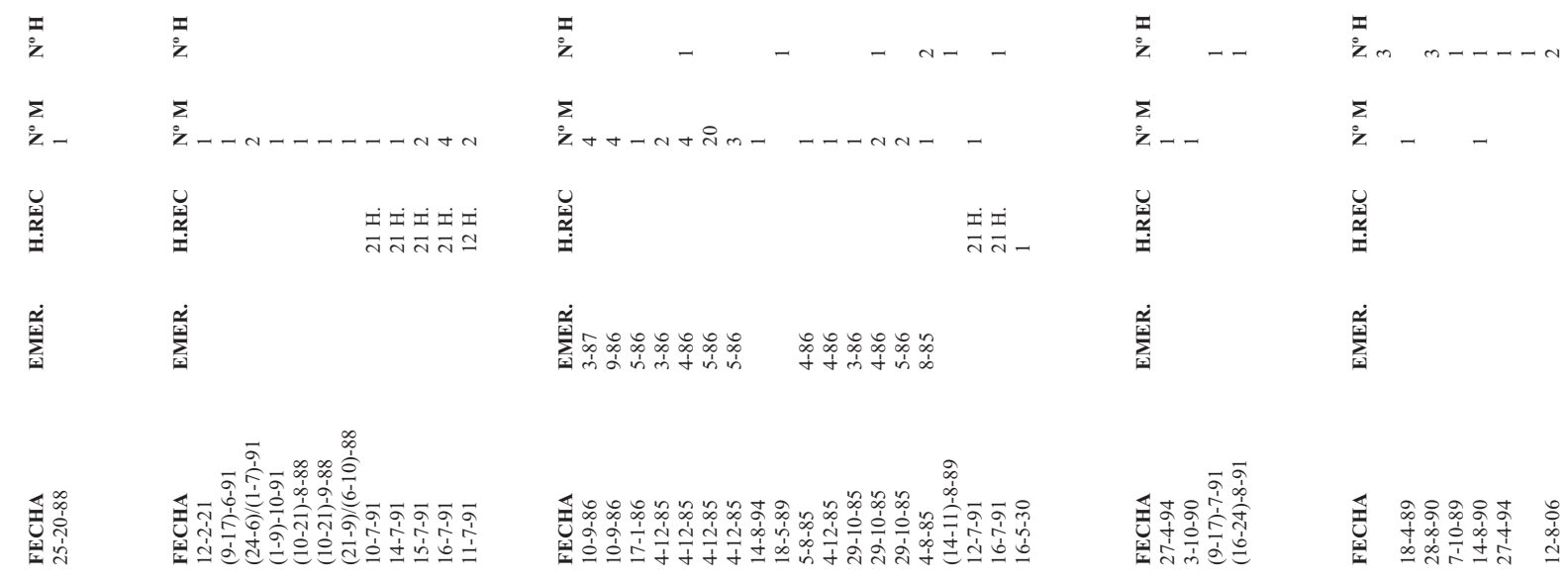

安오

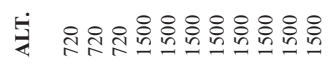

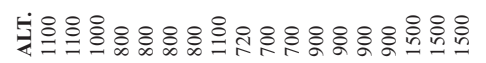

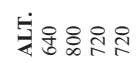

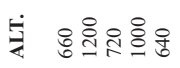
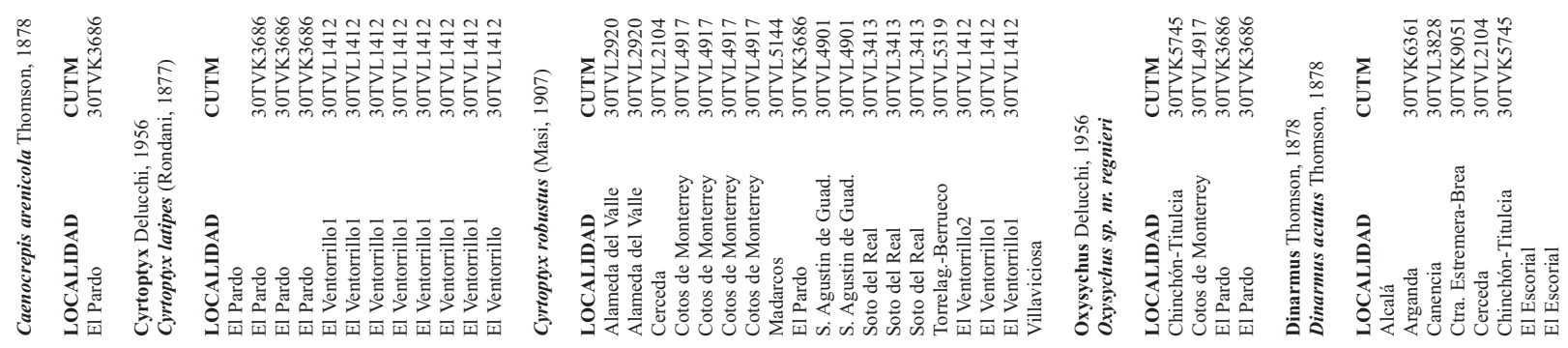


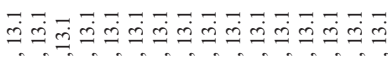

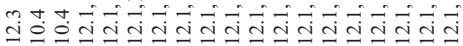

i.

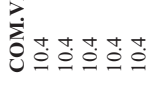

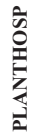

ڤे

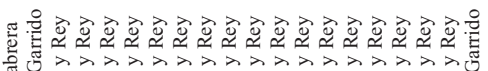

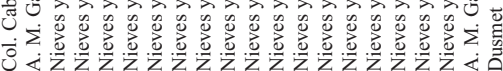

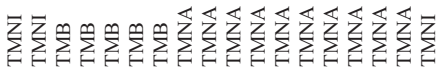

œ

$\stackrel{\text { त }}{\frac{1}{4}}$

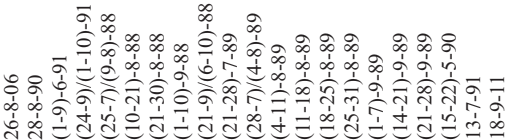

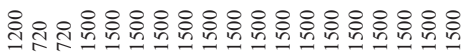

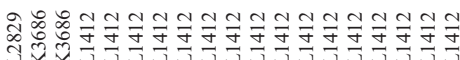

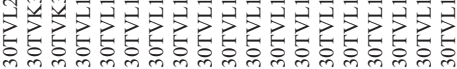

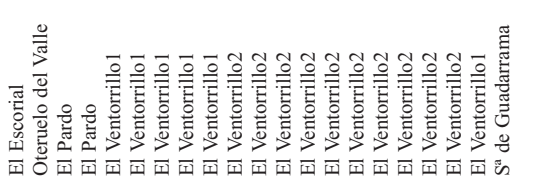

$\stackrel{\dot{*}}{\dot{x}}$

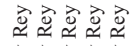

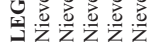

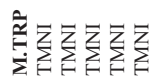

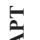
$\stackrel{U}{\dot{z}} \sum \sum \sum \sum$

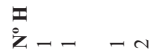

$\sum$

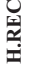

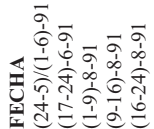

붒유ํํㅠํㅠำ

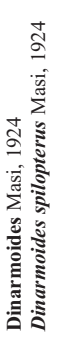
(1)

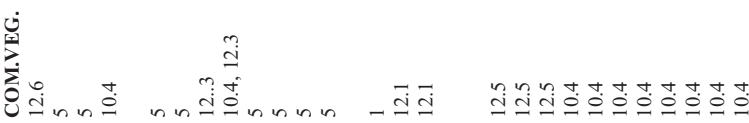<smiles>[CH]CCCC</smiles>

फे

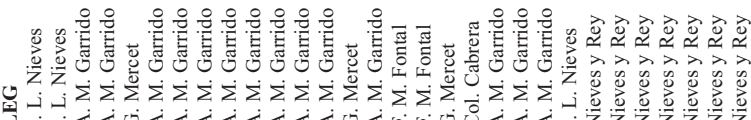

בิ

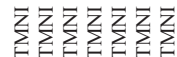

5

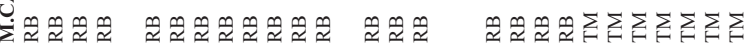

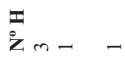

$\sum_{i}$

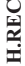

$\underset{x}{i}$

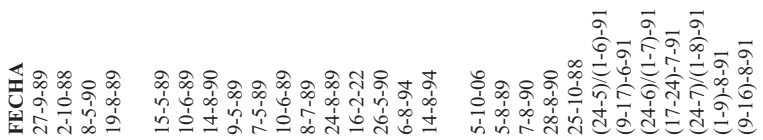

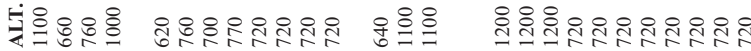

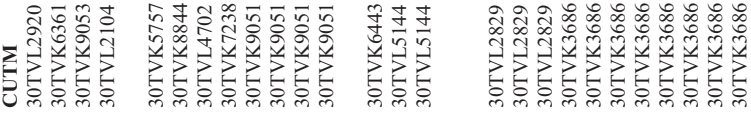

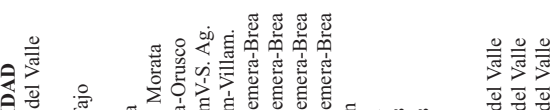

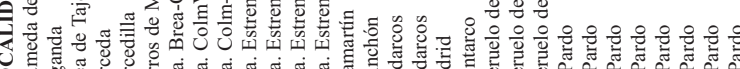




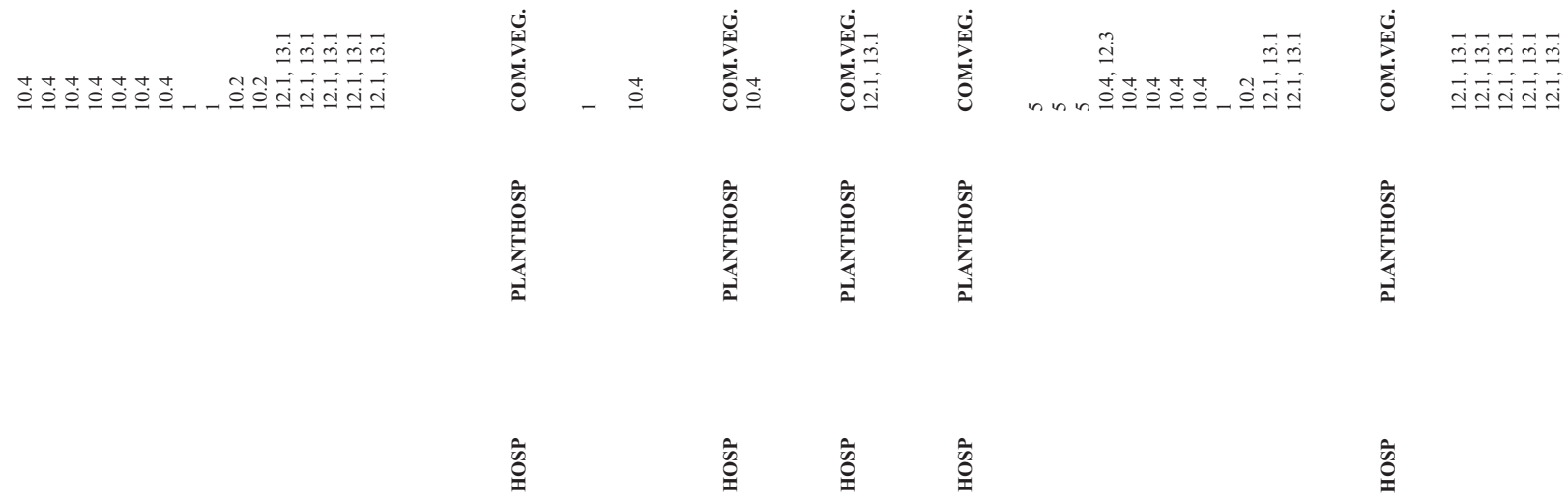

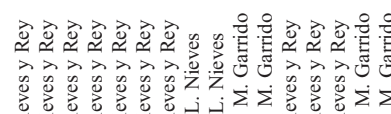

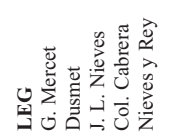

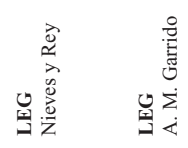

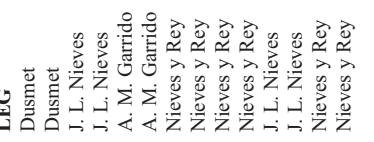

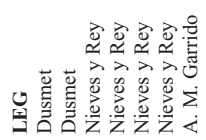

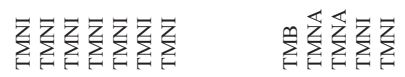

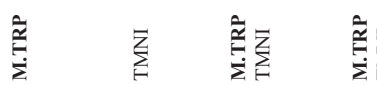

言玄

产 $\quad \sum_{i=1} \sum_{i=1} \sum_{i=1}^{\mathbb{Z}}$

产 $\quad \sum_{i}^{m} \sum_{i=1}^{m} \sum_{i=1}^{\infty}$

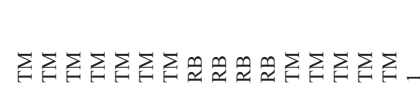

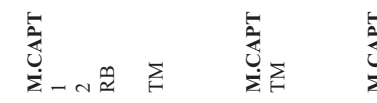

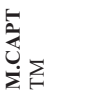

产

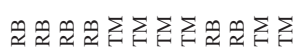

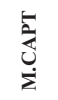

そミミミミ

\begin{tabular}{|c|c|c|c|}
\hline- & $\stackrel{z}{\frac{\pi}{2}}$ & $\stackrel{\pi}{z}_{n}$ & 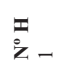 \\
\hline - & $\frac{\bar{z}}{2}$ & $\stackrel{\Sigma}{z}$ & 文 \\
\hline & 惫 & 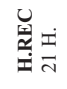 & 岂 \\
\hline & 兽 & 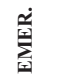 & 递 \\
\hline
\end{tabular}

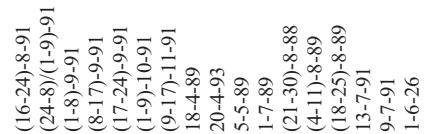

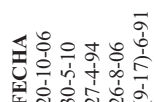

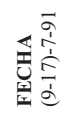

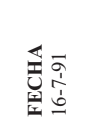

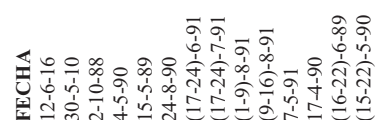

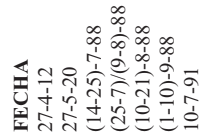

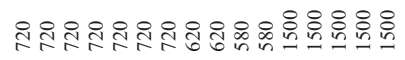

붕

迆迹

实怘

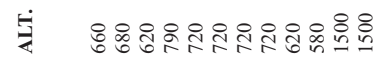

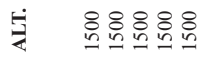
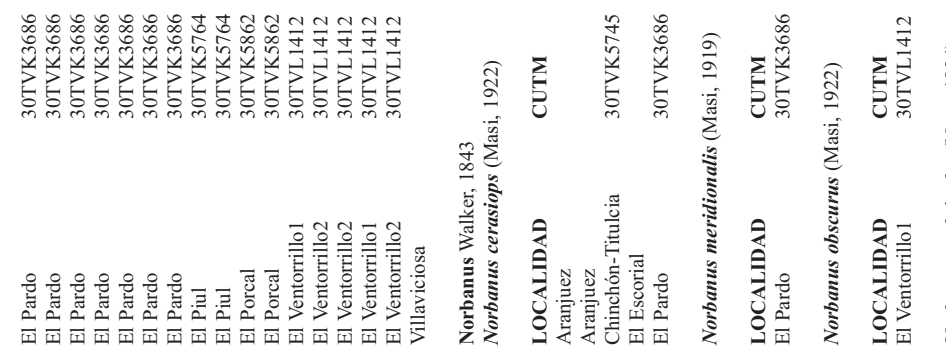

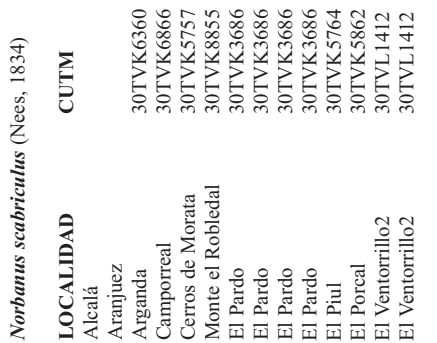

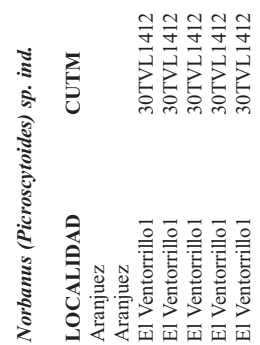




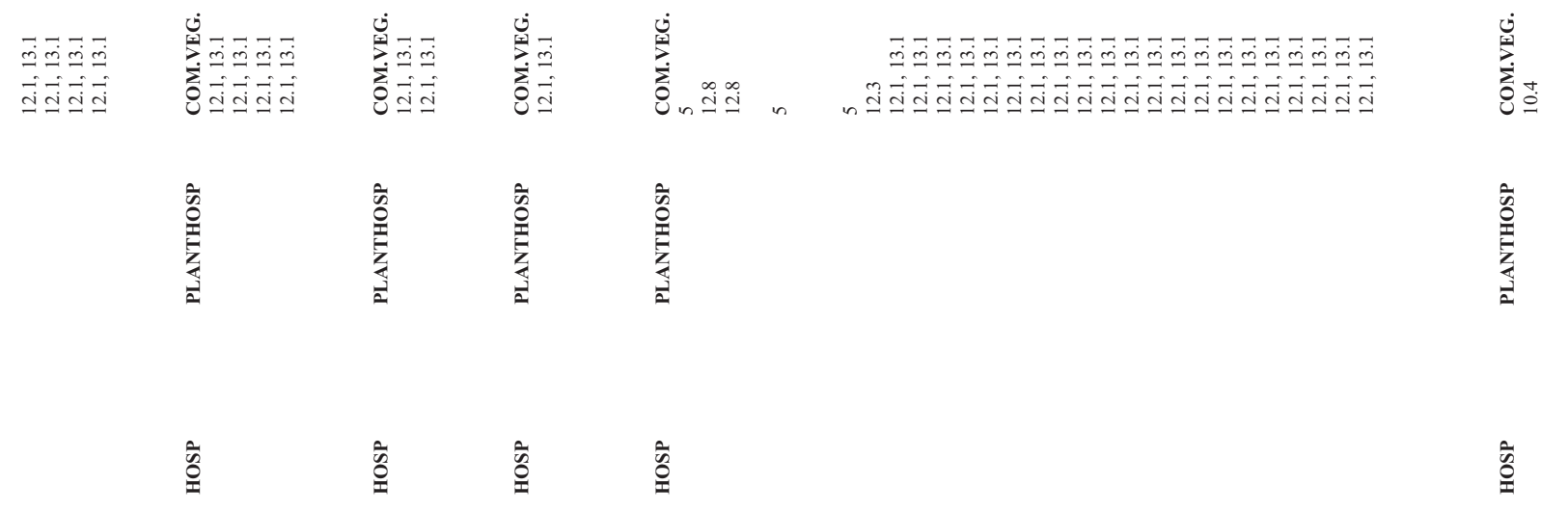

\begin{tabular}{|c|c|c|c|c|c|}
\hline 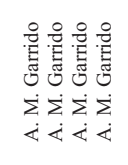 & 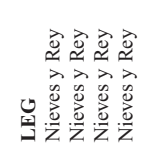 & 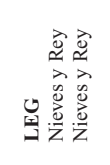 & 离 & 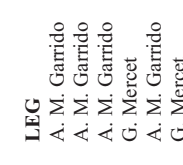 & 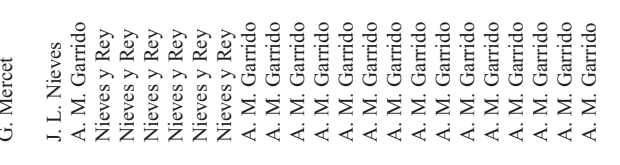 \\
\hline$\sum_{i=z}$ & 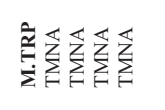 & 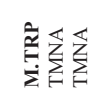 & 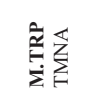 & $\stackrel{\tilde{z}}{\bar{z}}$ & 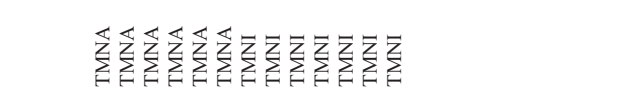 \\
\hline$\sum \cong \approx$ & 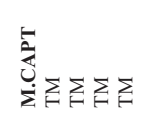 & 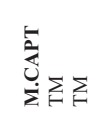 & 㤐 & 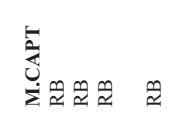 & 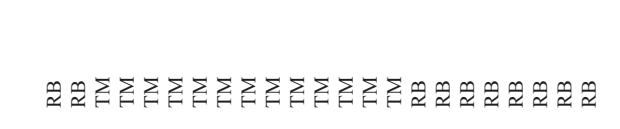 \\
\hline - & $\frac{\pi}{2}$ & $\frac{\pi}{2}$ & $\frac{\pi}{2}$ & $\frac{F}{2}--n-m$ & 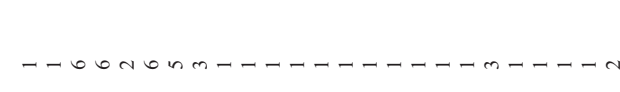 \\
\hline & 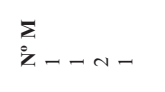 & $\bar{z} \frac{1}{2}-1$ & $\frac{\bar{z}}{z_{2}-}$ & $\bar{z}$ & \\
\hline 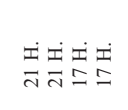 & 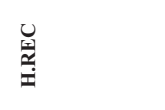 & $\stackrel{\underline{W}}{\ddot{X}}$ & $\stackrel{\mathscr{U}}{\ddot{E}}$ & $\stackrel{\breve{H}}{\ddot{M}}$ & 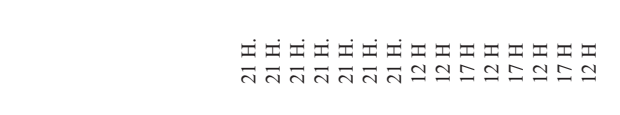 \\
\hline & 善 & 曽 & 譄 & 曽 & \\
\hline
\end{tabular}

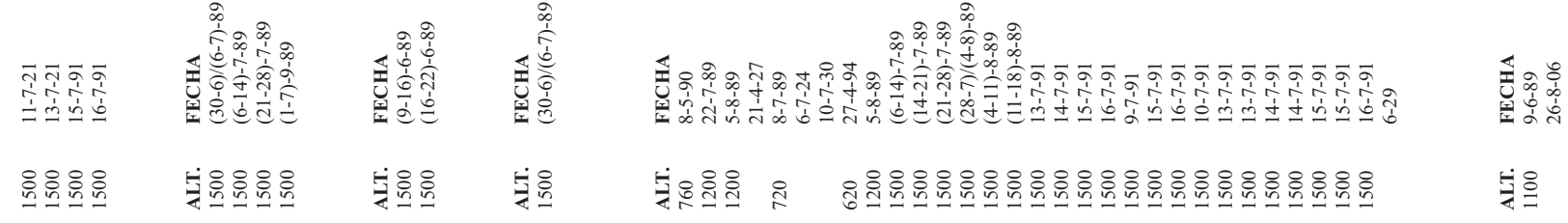

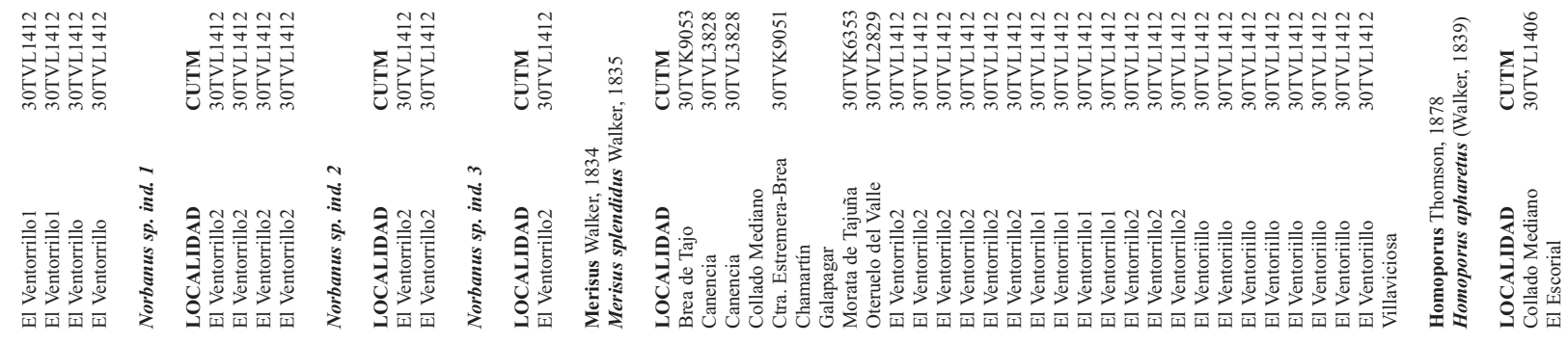




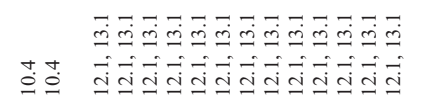

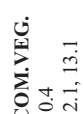

$\sum_{\substack{0 \\ \dot{j}}}^{0}$

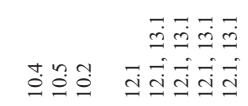

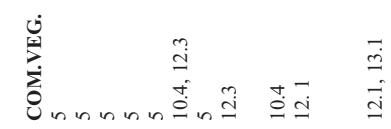

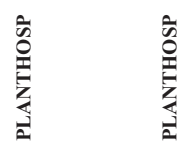

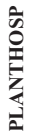

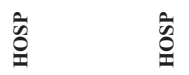

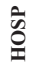

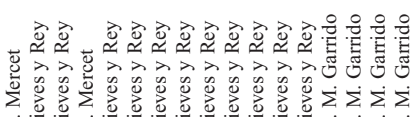

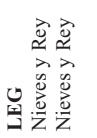

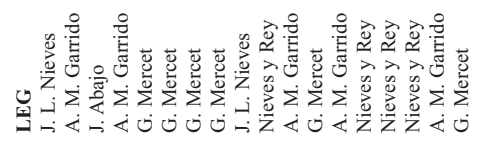

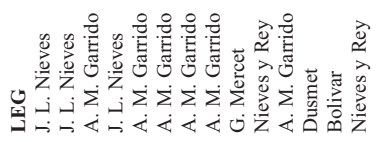

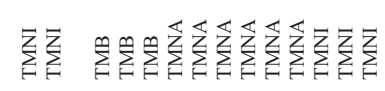

䋨

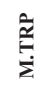

$\sum_{i}^{i} \quad \sum_{i=1}^{\infty} \sum_{i}^{\mathbb{z}}$

$\stackrel{\bar{z}}{\bar{z}}$

$\sum_{\xi} \sum_{k}^{\infty}$

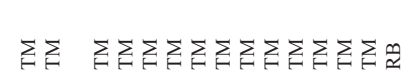

离

产

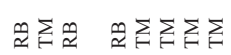

范

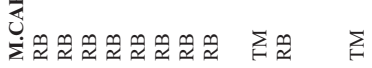

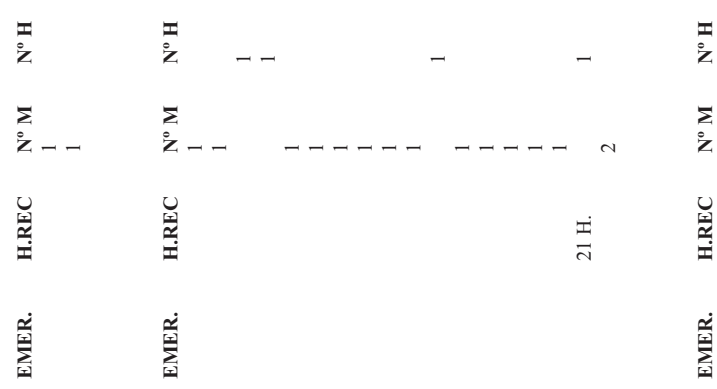

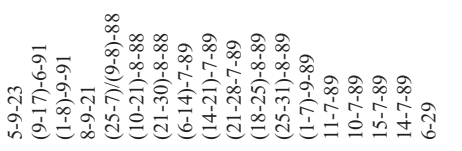

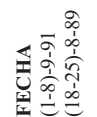

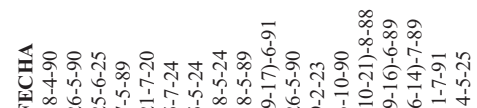

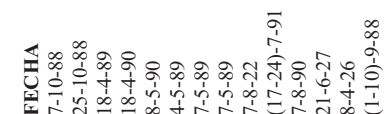

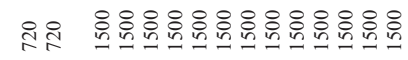

부웅융

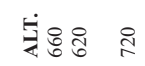

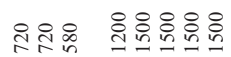

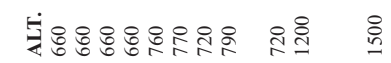

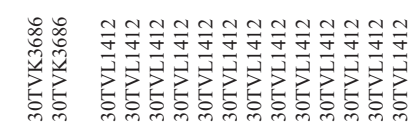

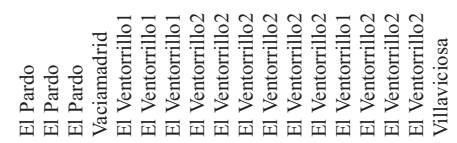
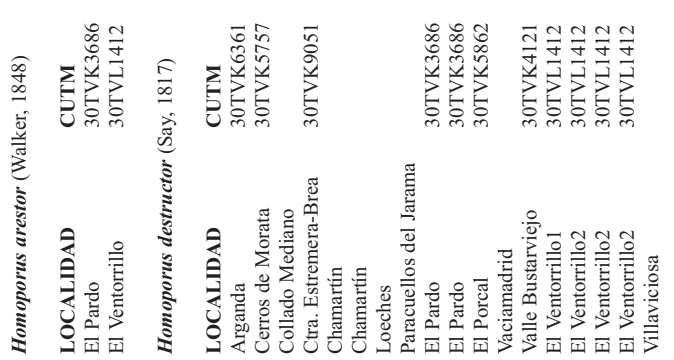

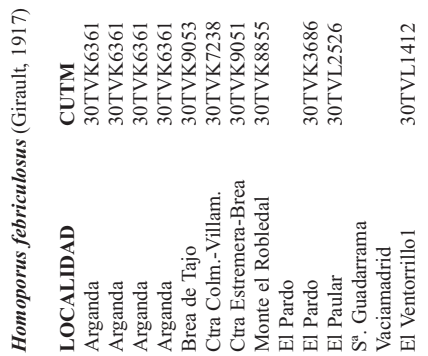




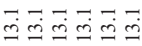

$\overrightarrow{\mathrm{i}} \mathrm{d} \dot{\mathrm{j}} \mathrm{i} \dot{\mathrm{i}} \mathrm{i}$

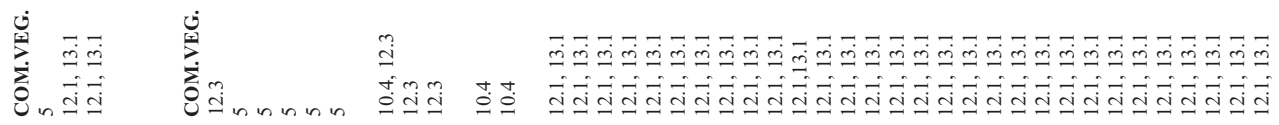

$\frac{5}{2}$

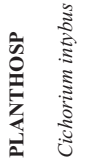

के

के

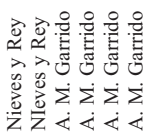

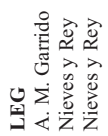

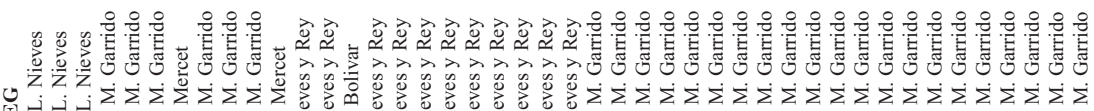

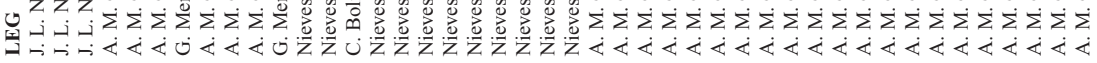

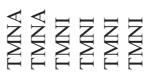

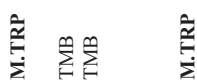

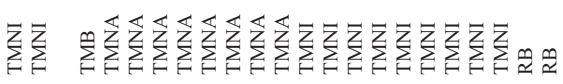

$\sum \sum \sum \sum \sum$

$\frac{2}{2}$

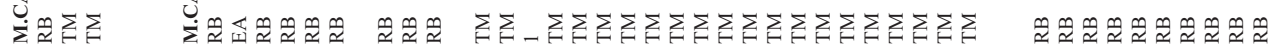

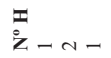

$\sum_{n-1}$

紊

i

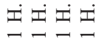

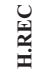

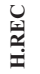

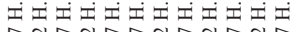

兽章离品

มัง

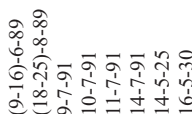

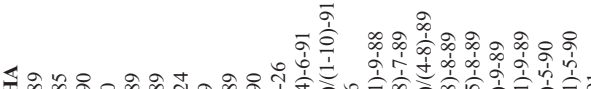

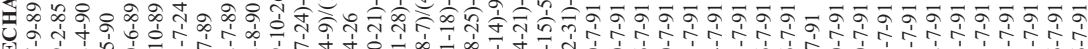

흥응응음음음

实路遂

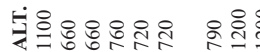

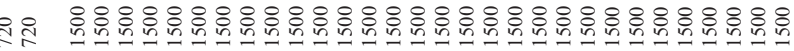
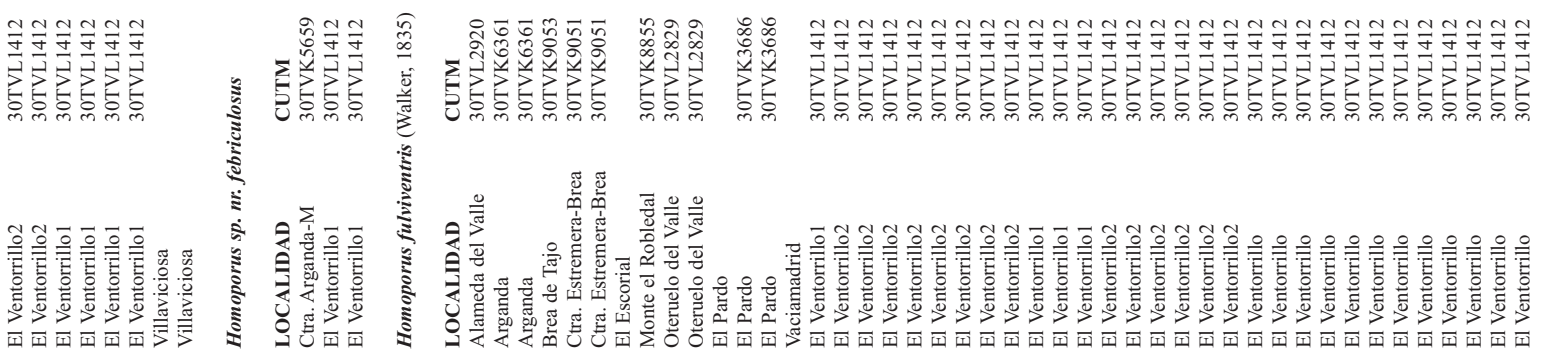


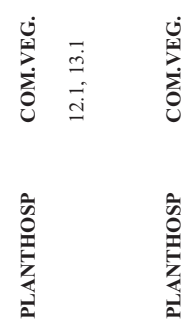

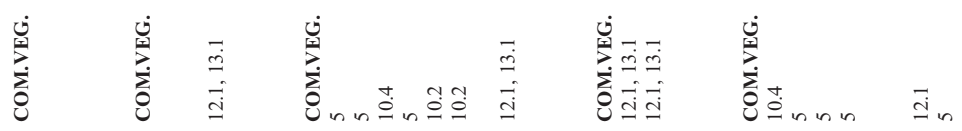

产

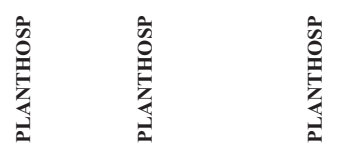

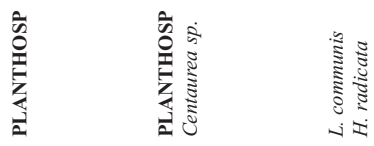

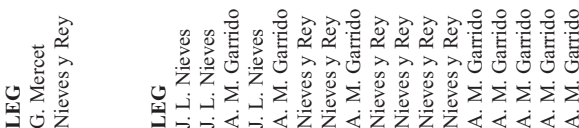

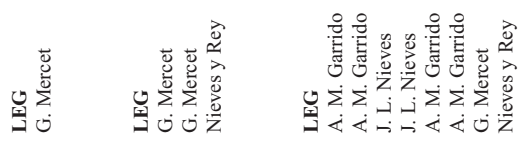

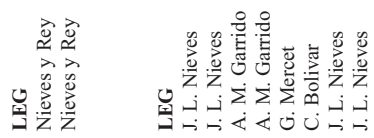

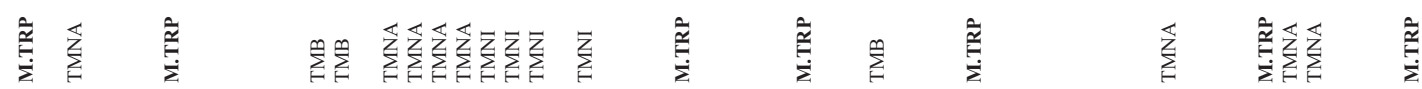

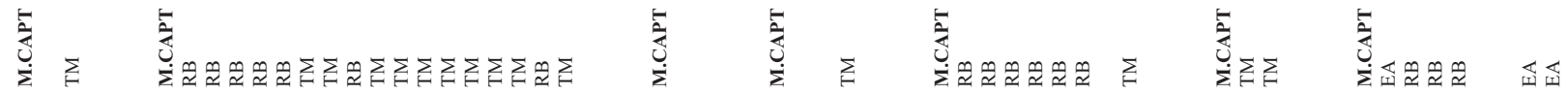

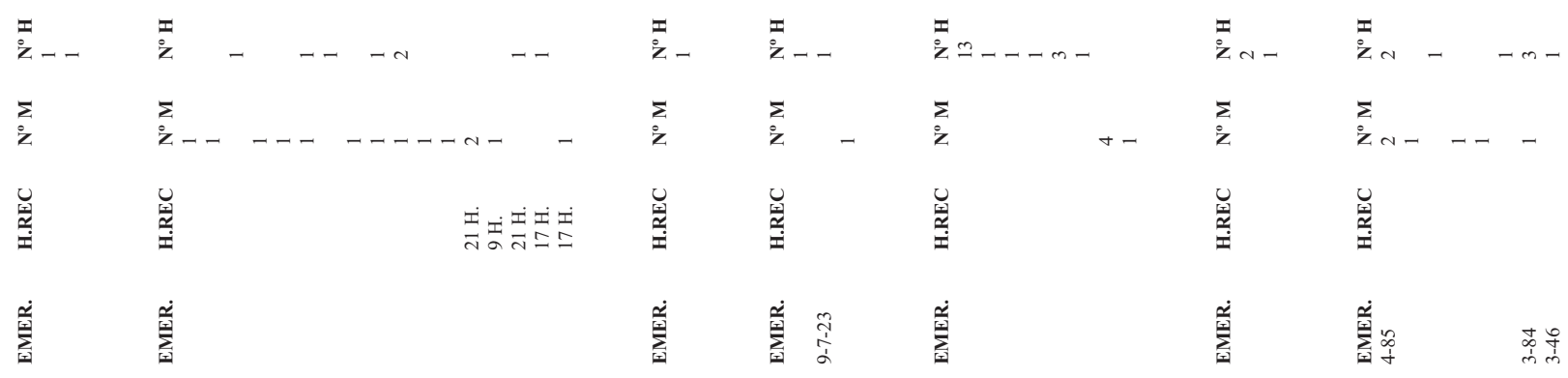

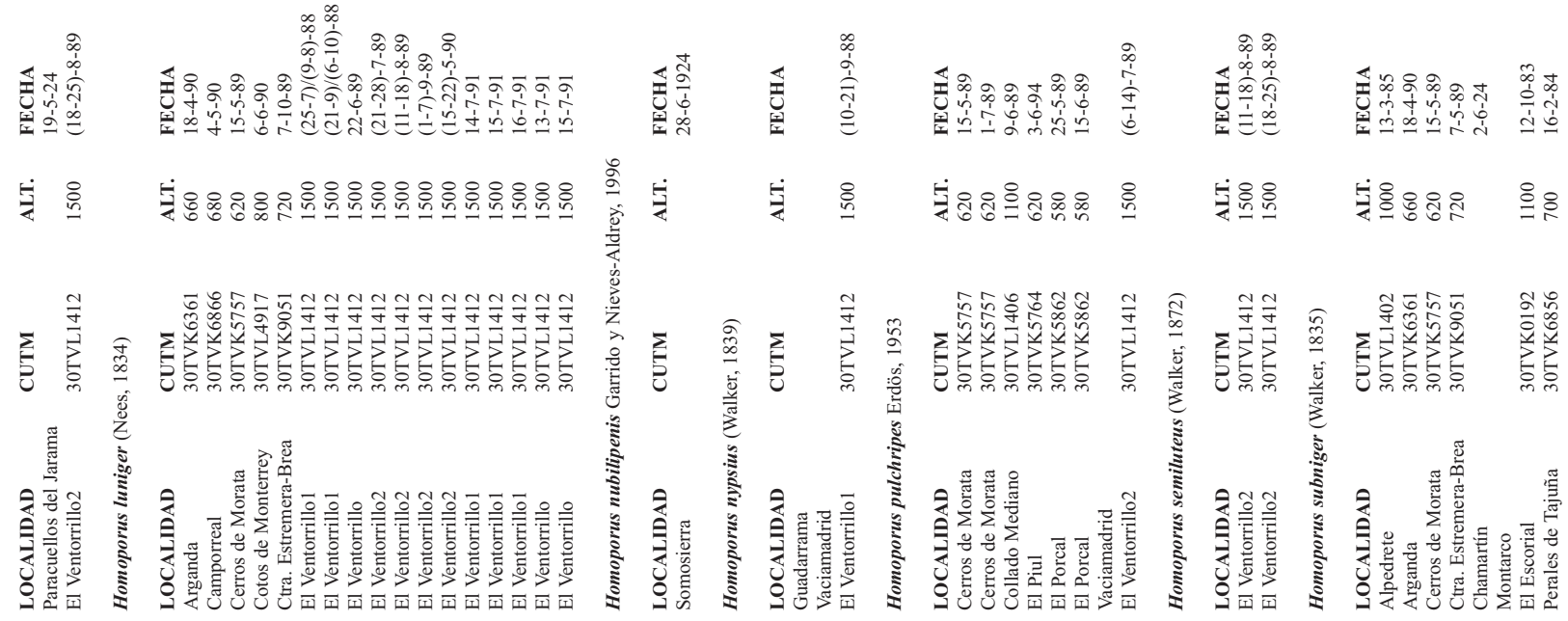




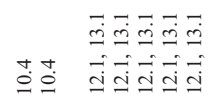

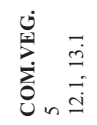

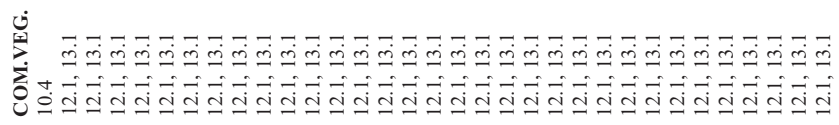

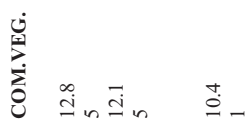

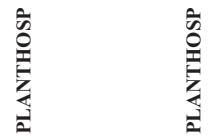

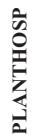

के

के

$\stackrel{\overline{0}}{\underline{\Xi}}$

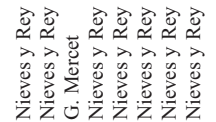

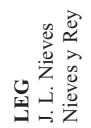

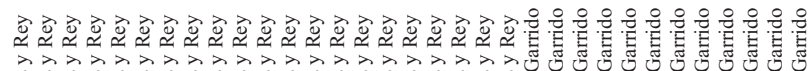

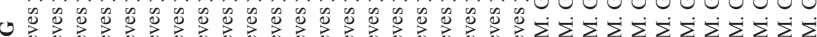

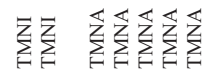

$\stackrel{\vec{z}}{\bar{x}}$

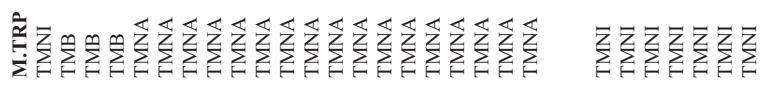

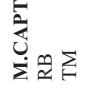

产

$\sum \sum \sum \sum \sum \sum \sum$

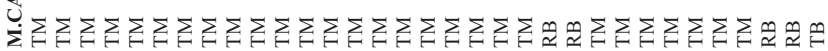

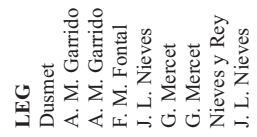

I

:

交

ह

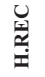

롶

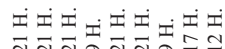

$\stackrel{\tilde{\xi}}{\bar{z}}$

$\underset{\sum}{\bar{z}}$

5

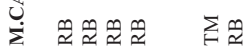

番

춥

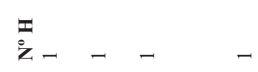

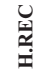

춥

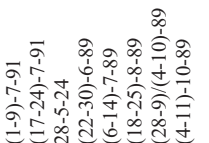

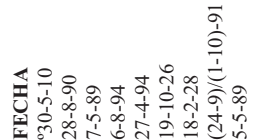

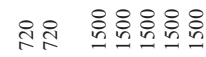

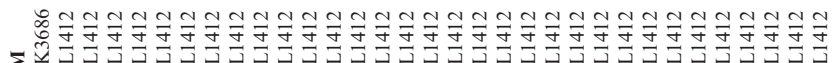

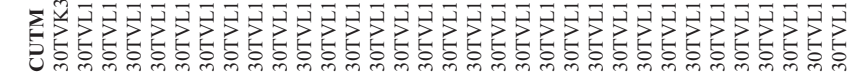

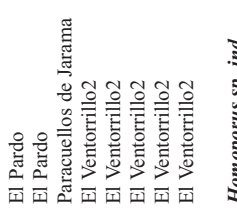




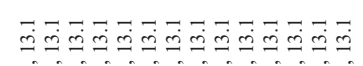

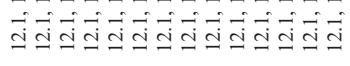

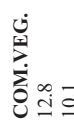

$$
\text { 宽 }
$$

ڤิ)

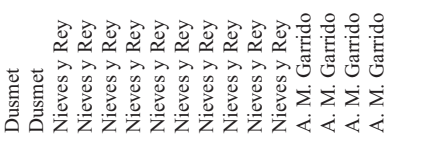

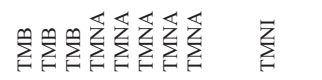

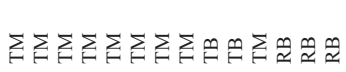

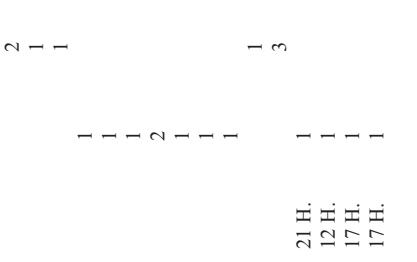

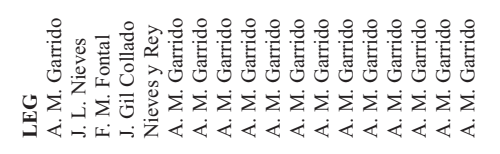

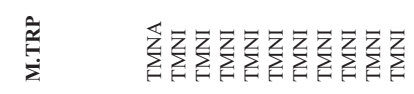

5

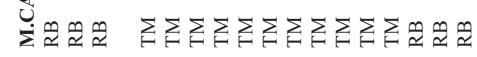

$\sum$

兽

タัง

兽

定。

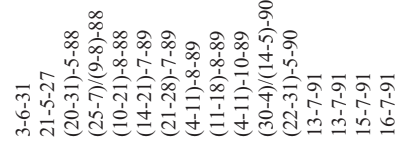

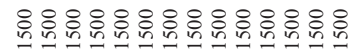

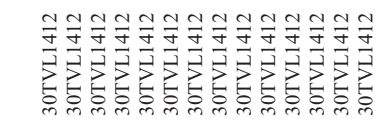

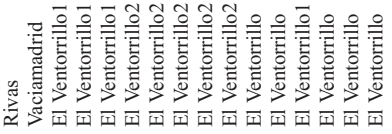

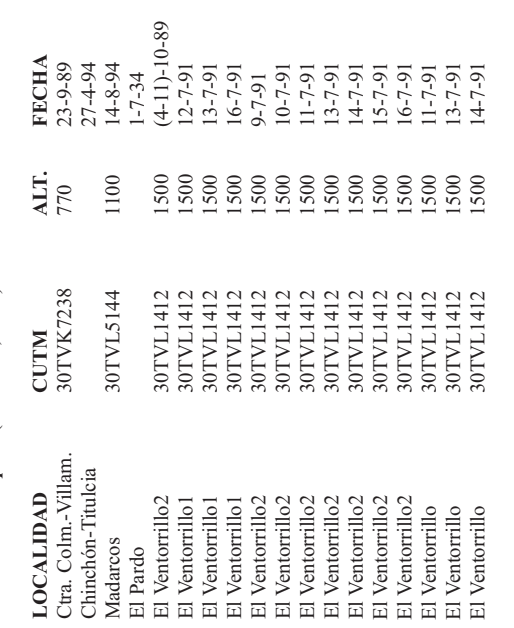

$\frac{5}{2}$

ธิ宀

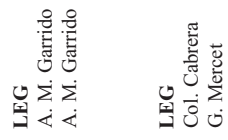

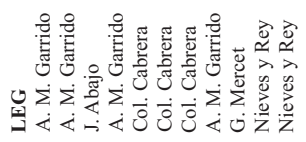

$\stackrel{\bar{z}}{\bar{z}}$

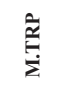

$\stackrel{\tilde{y}}{\bar{z}}$

$\sum_{i} \sum_{i}$

矛

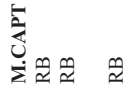

$\cong \sum \sum$

:

i

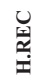

춥

$\stackrel{7}{2}$

否- - - - $-4-m$

:

춥

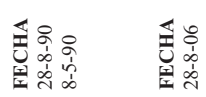

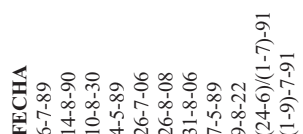

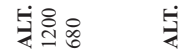

변웡유윰중

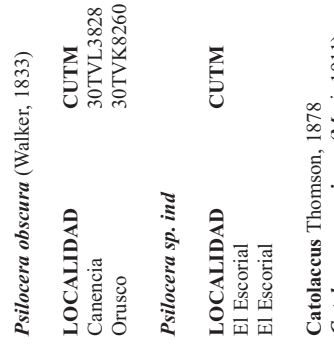

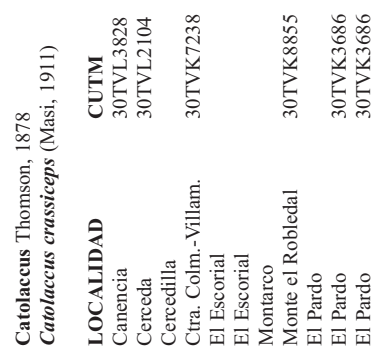




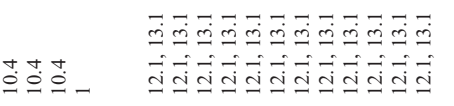

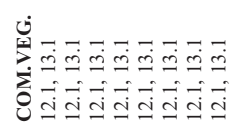

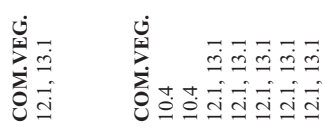

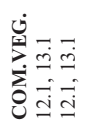

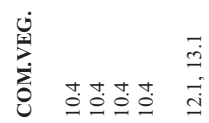

章

苍产

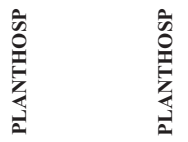

产

粍产

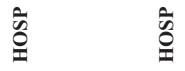

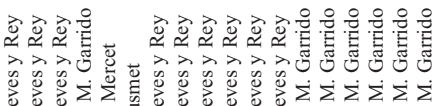

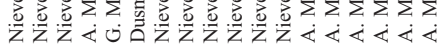

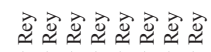

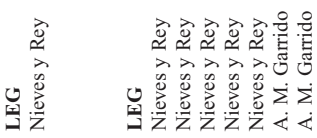

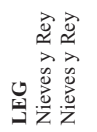

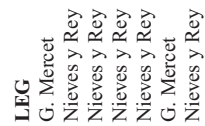

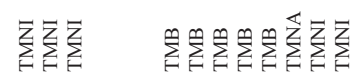

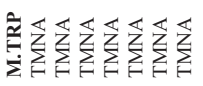

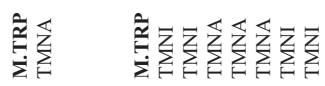

בิ

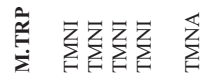

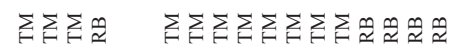

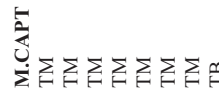

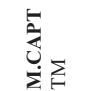

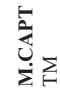

氙我电

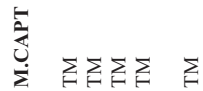
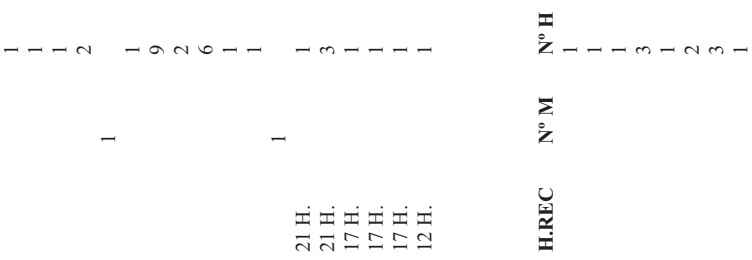

\section{:}

:

:

文

ह

$\sum_{0}$

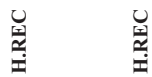

$\underset{4}{\frac{4}{4}}$

₹

莫

竞

畜畜

兽音
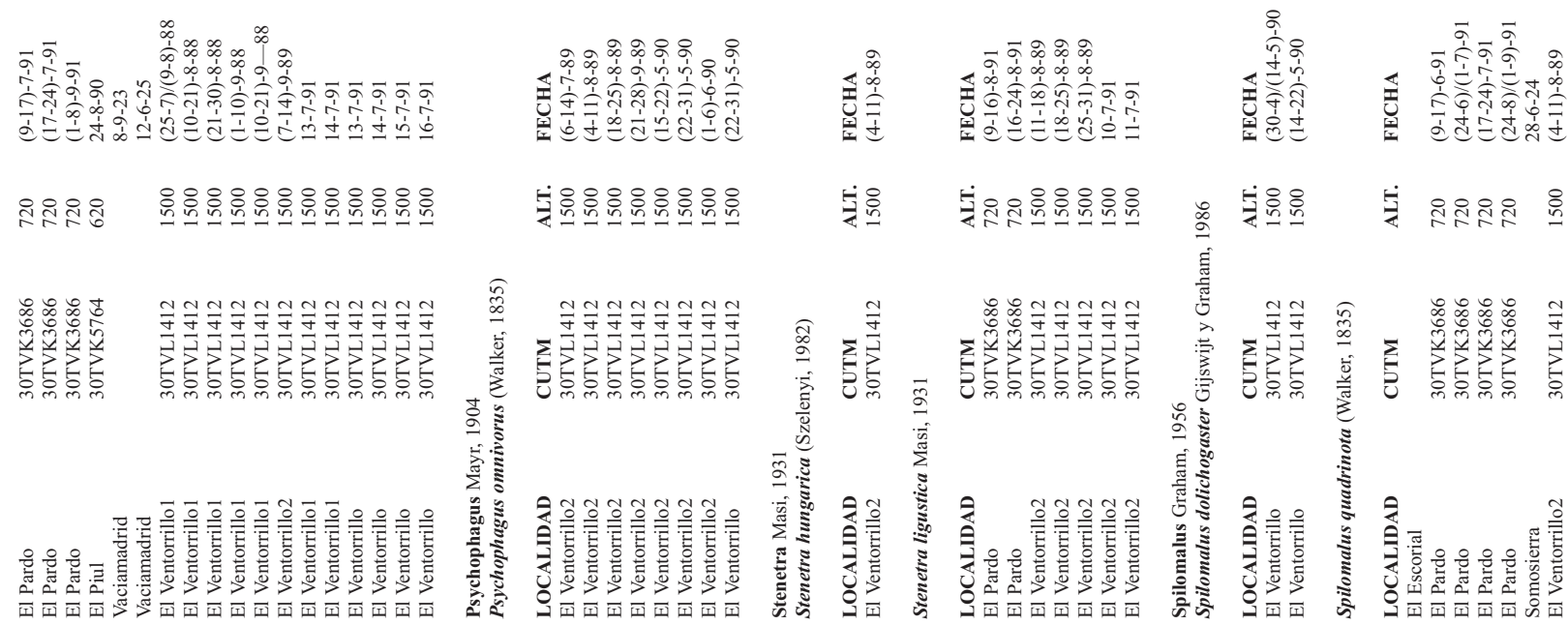

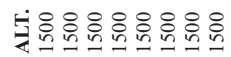

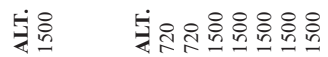

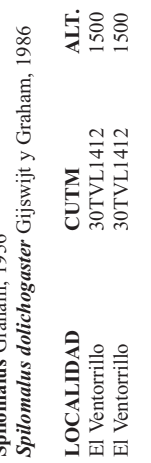

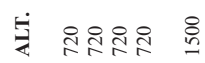
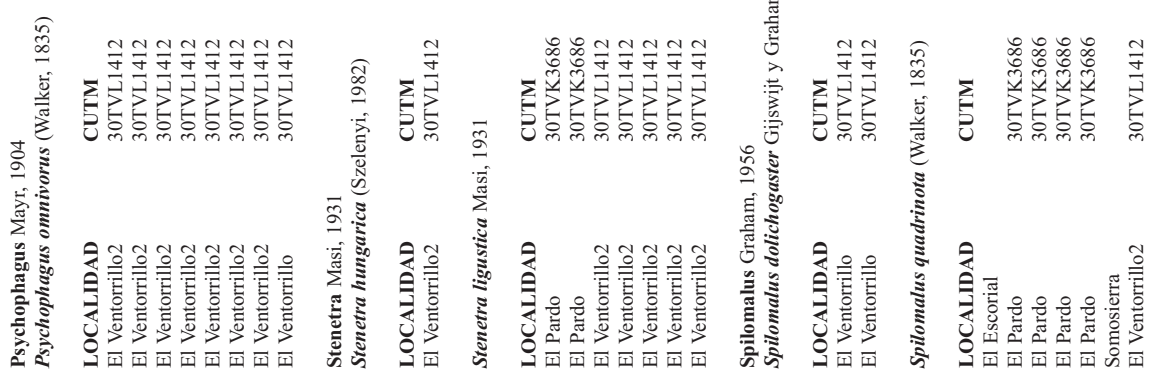

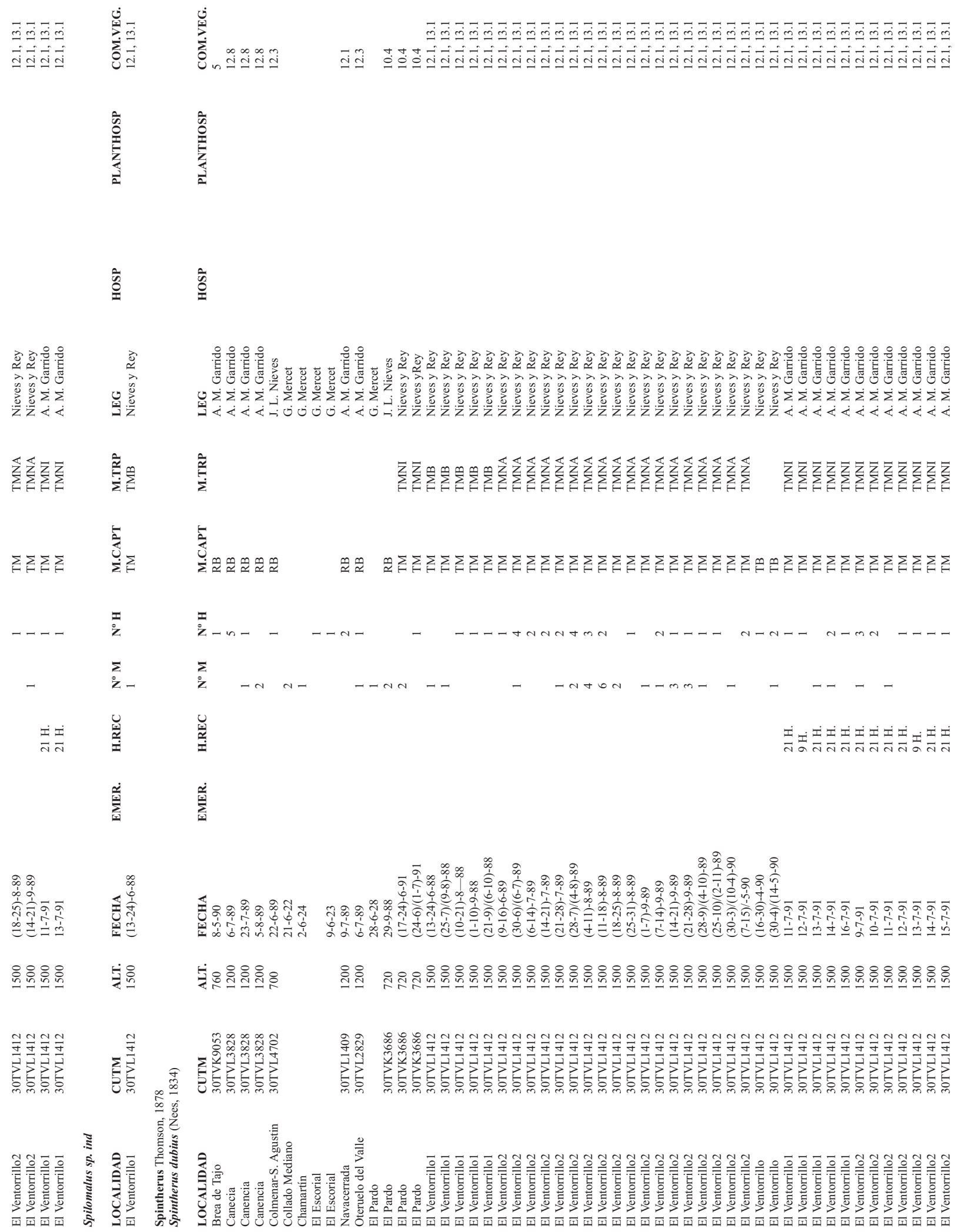


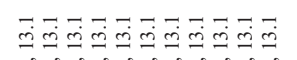

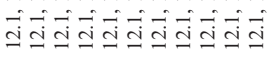

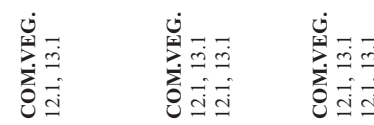

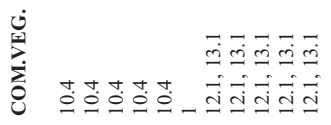

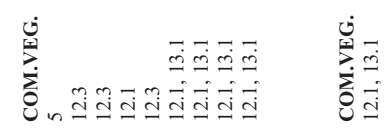

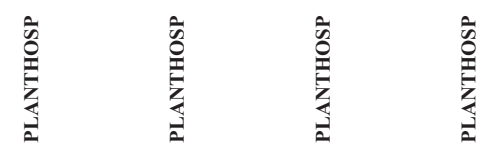

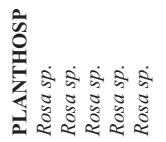

\section{药}

केष्ठ केष

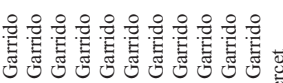

$\dot{\Sigma} \dot{\Sigma} \dot{\Sigma} \dot{\Sigma} \dot{\Sigma} \dot{\Sigma} \dot{\Sigma} \dot{\Sigma} \dot{\Sigma} \dot{\Sigma}$

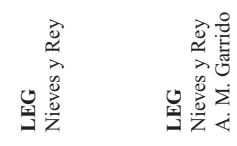

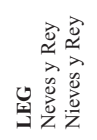

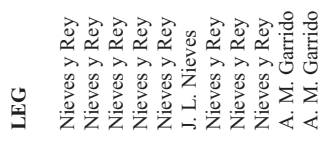

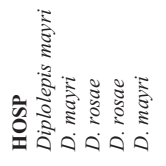

竎

$$
\text { Zin }
$$$$
\sum_{i}
$$

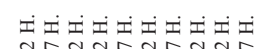
i

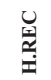

畄

$\sum_{i}$

产

离

蒫 $\frac{4}{4}$

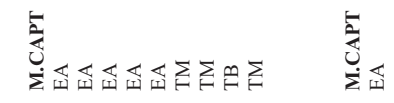

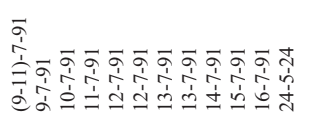



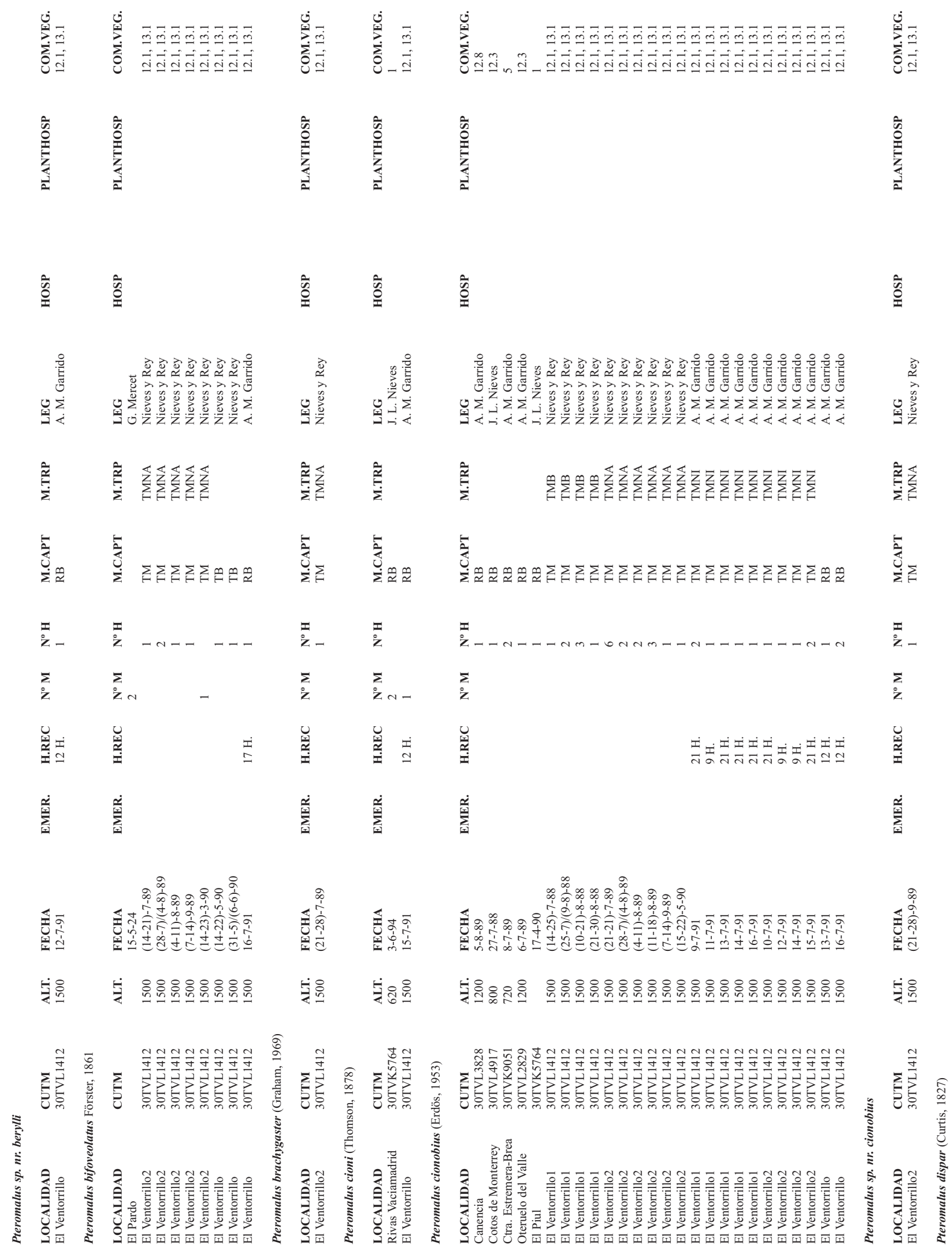


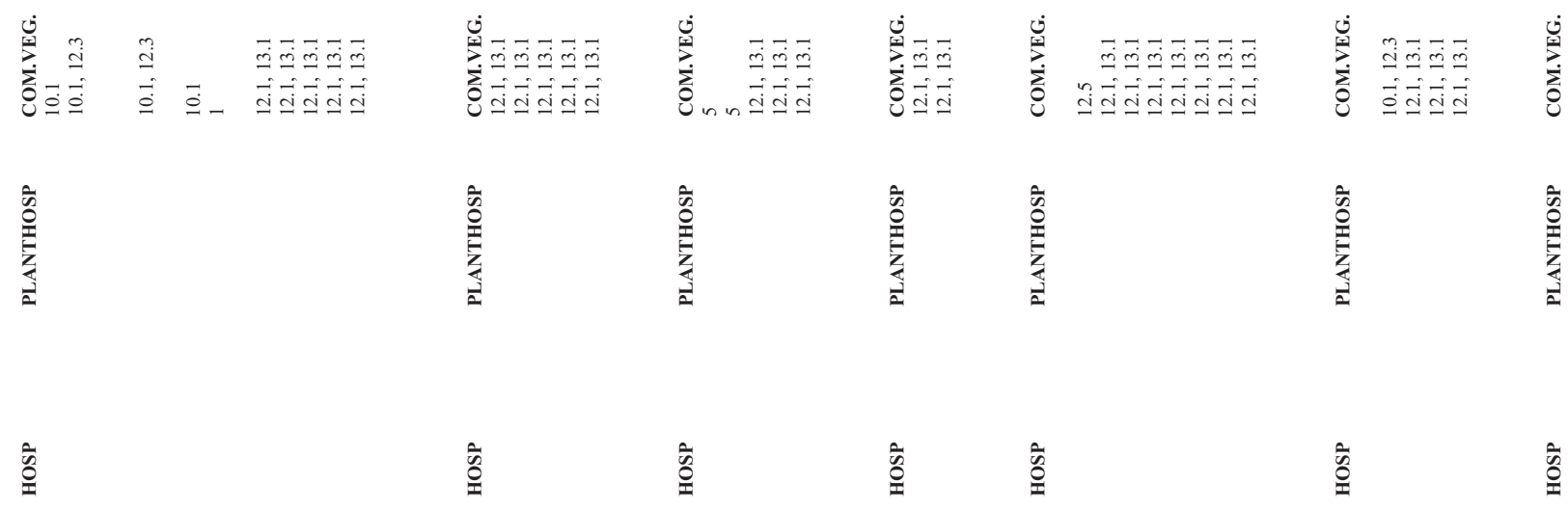

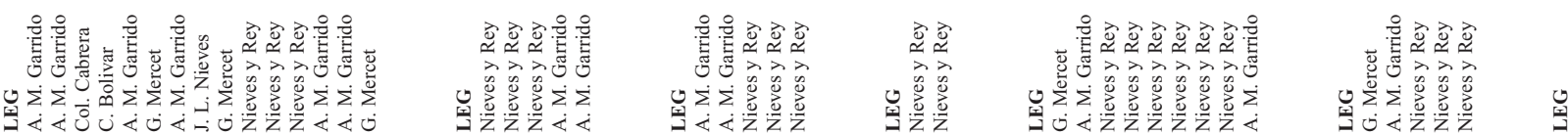

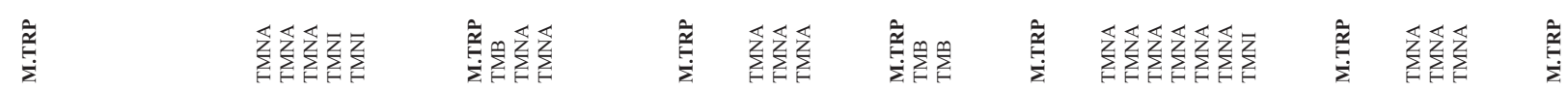

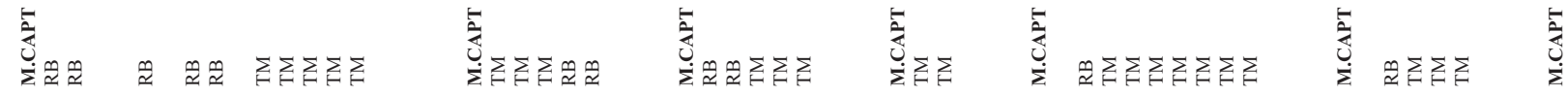

\begin{tabular}{|c|c|c|c|c|c|c|c|c|c|}
\hline$\sum_{\sin }^{2}$ & $-4 a-\simeq-4 m a-7$ & $\frac{\pi}{2}$ & $-\ldots$ & in & - & $\sum_{\operatorname{man}}^{2}-4$ & $\overbrace{z}^{2}$ & & 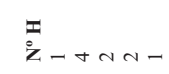 \\
\hline$\sum_{\bar{z}}^{\bar{z}}$ & - & $\sum_{\bar{z}}^{\Sigma}$ & & $\sum_{\bar{z}-4}$ & - & $\sum_{2}^{2}$ & 立 & & $\frac{\pi}{2}$ \\
\hline 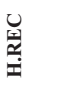 & $\stackrel{a}{a}$ & 惫 & 美至 & 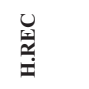 & & 惫 & 崂 & $\underset{\vec{N}}{\mathbb{N}}$ & 恖 \\
\hline$\ddot{*}$ & & 兽 & & 兽 & & 兽 & 兽 & & 畜 \\
\hline
\end{tabular}

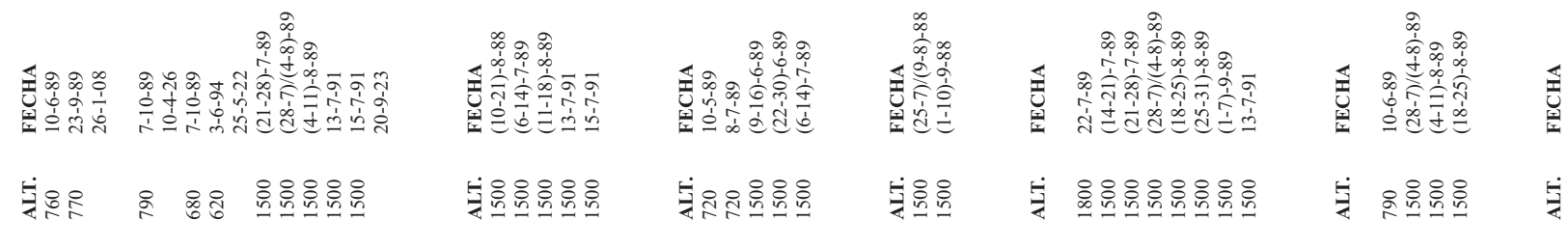

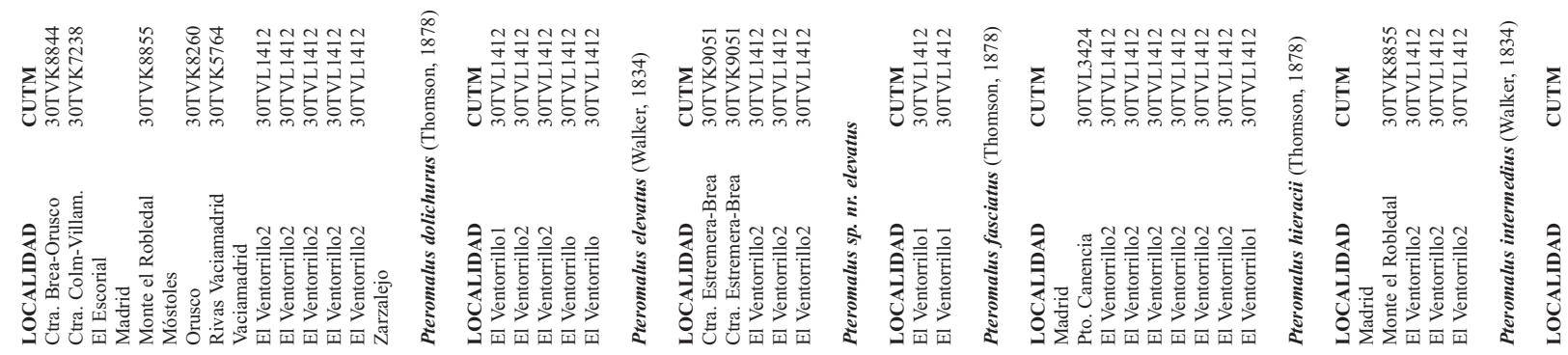




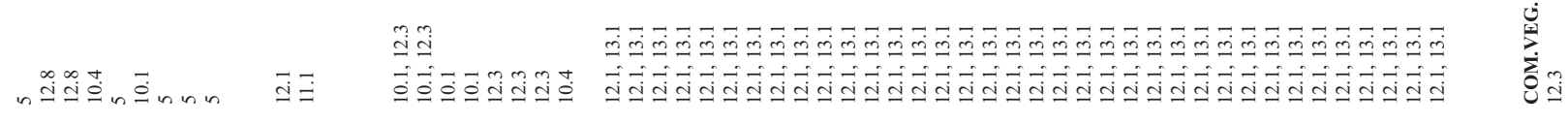<smiles>C1CCCCC1</smiles> 


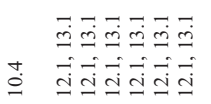
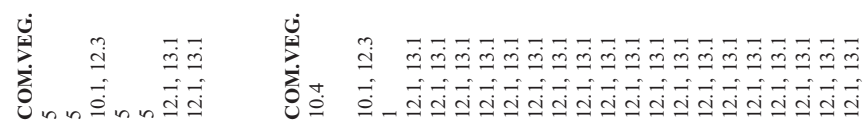

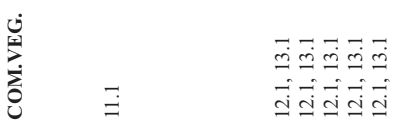

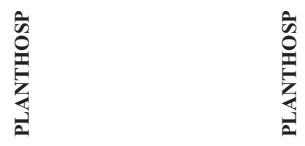

产

$\stackrel{\hat{s}}{\underline{3}}$

$\frac{\sqrt{2}}{3}$
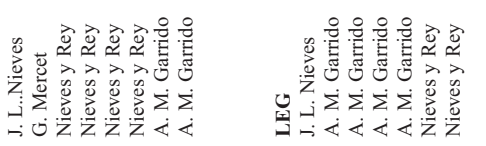

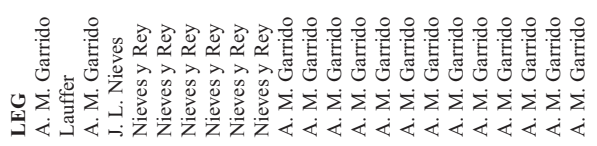

के

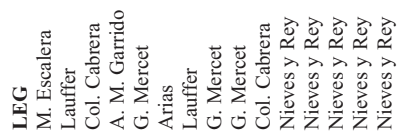

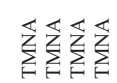

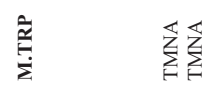

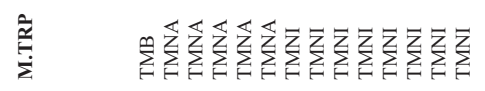

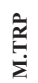

$\sum_{i=1}^{m} \sum_{i=1}^{m} \sum_{i}^{m}$

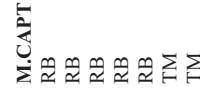

产

$\cong \sum \sum \sum \geqq \cong \Re$

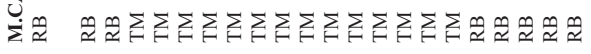
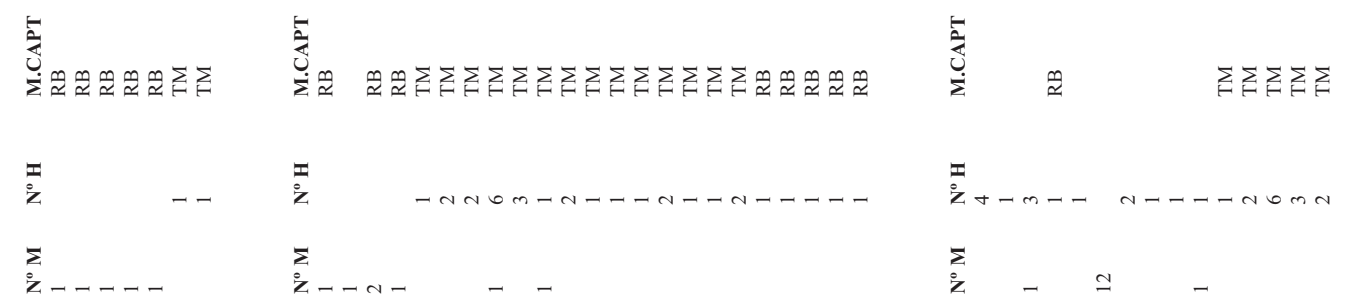

$\underset{\Xi}{\stackrel{I}{\Xi} \pm}$

曽

昡

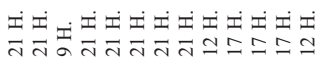

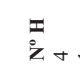

i

蕞

这

畜

춥

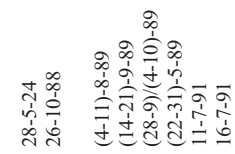

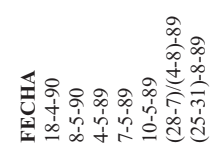

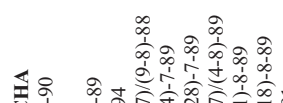

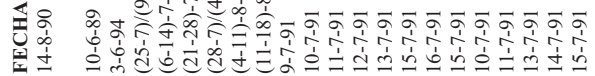

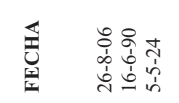

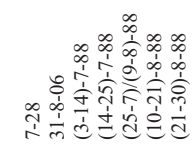

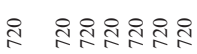

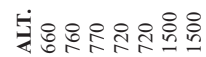

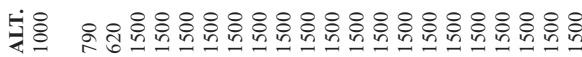

宗客

음응응음음
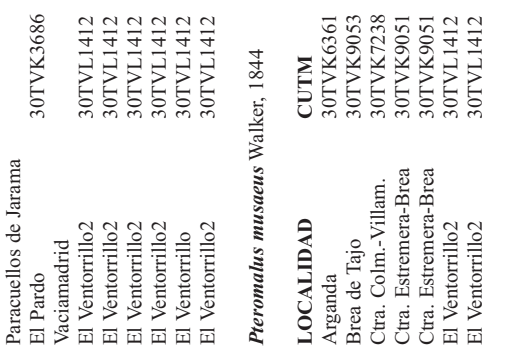

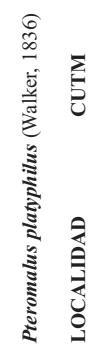
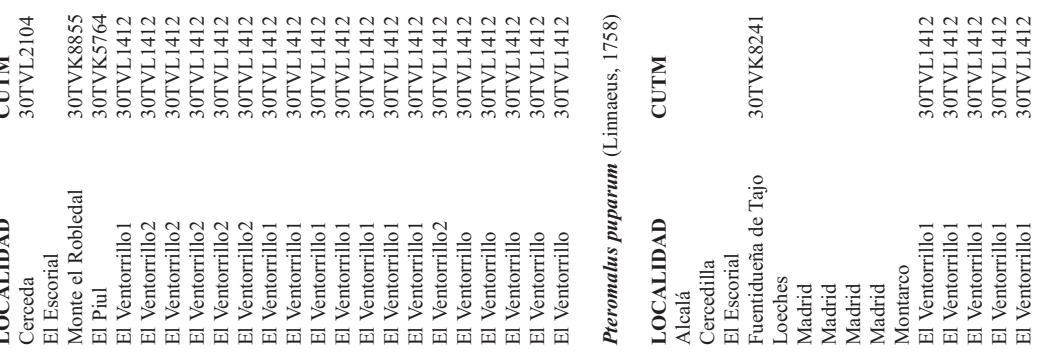

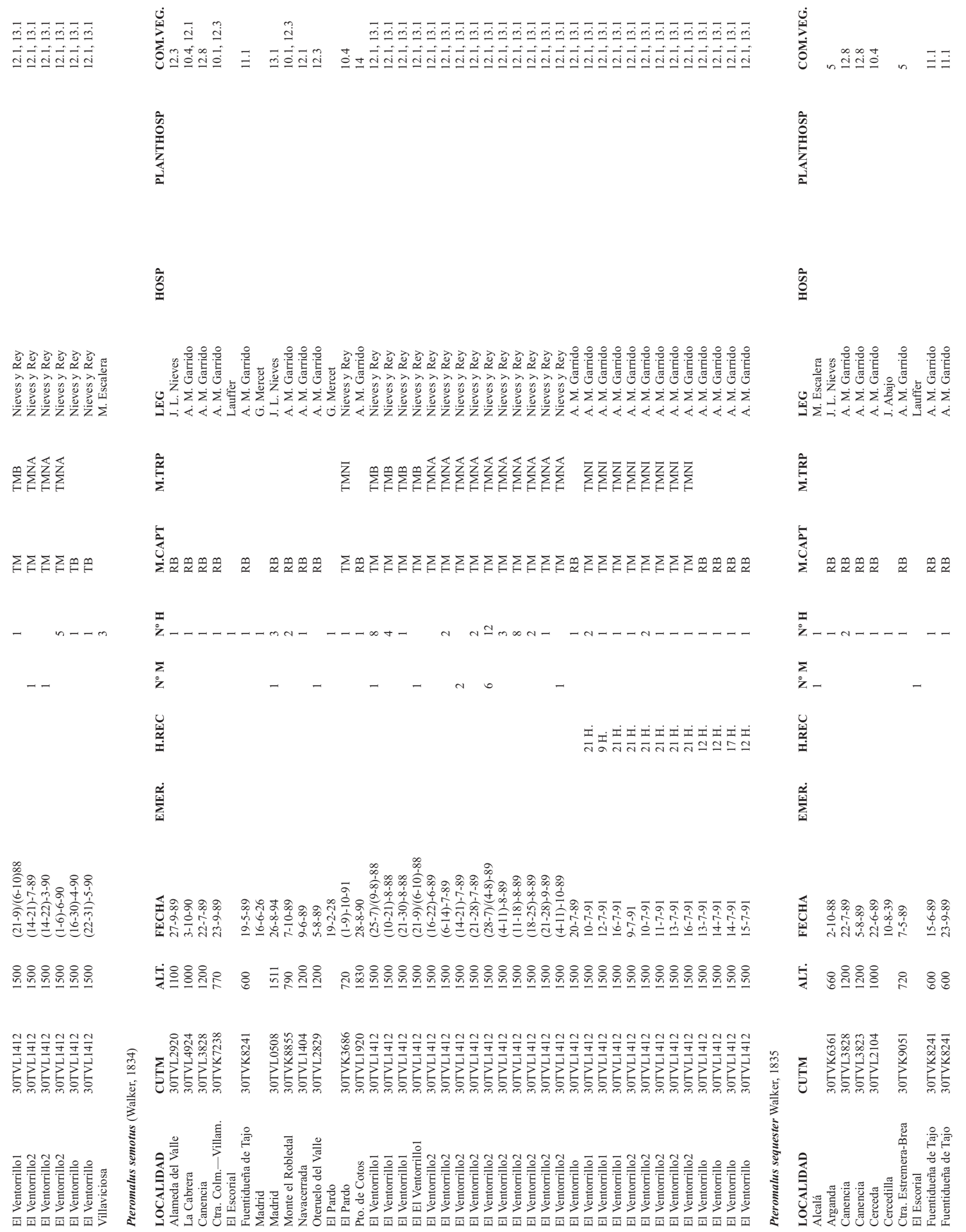
3

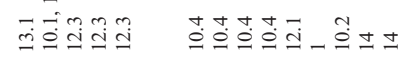

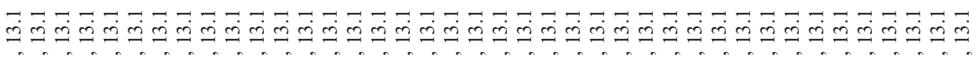

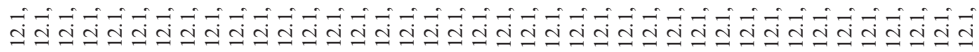

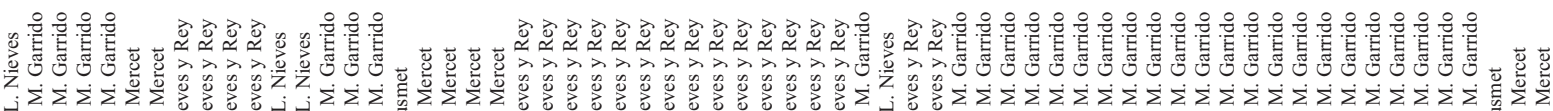

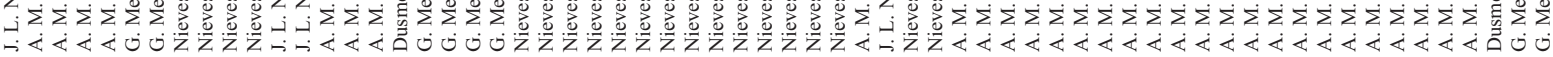

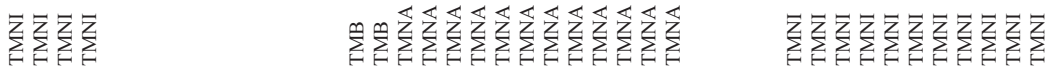

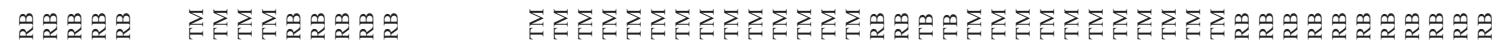

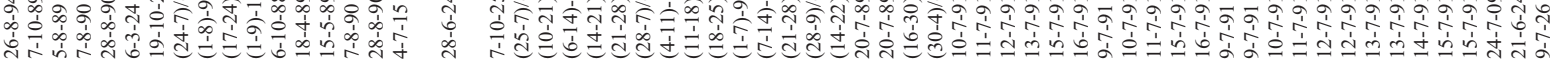

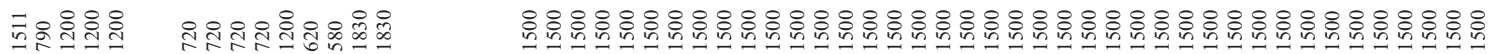

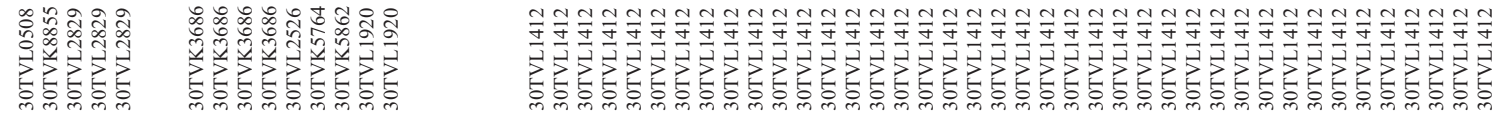

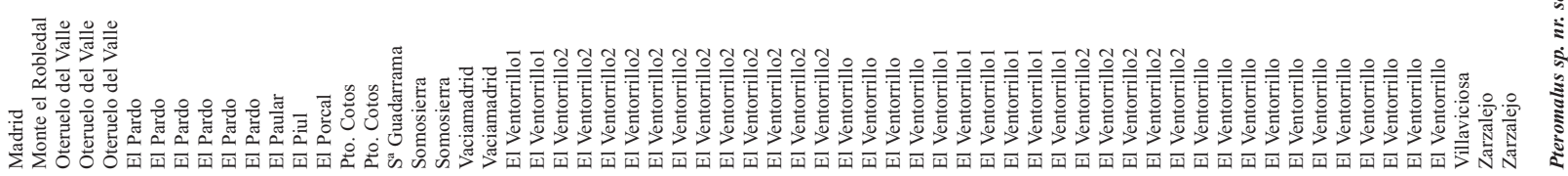




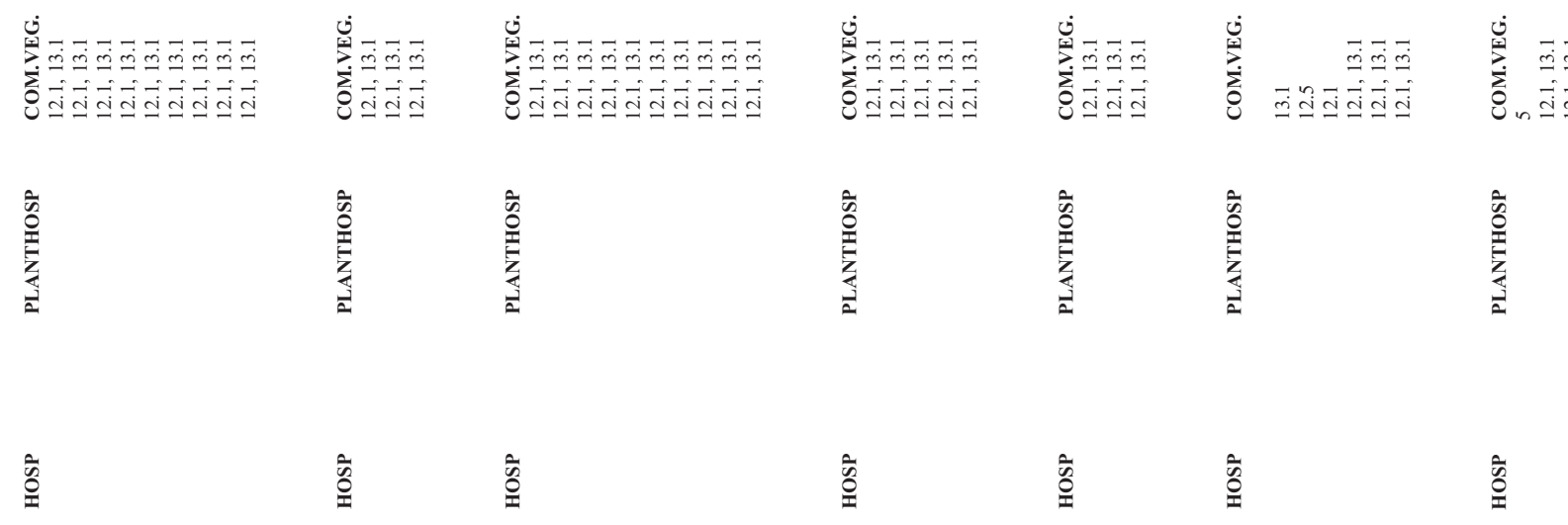

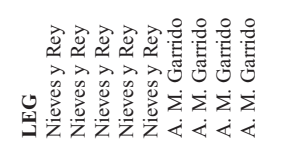

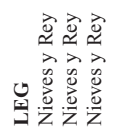

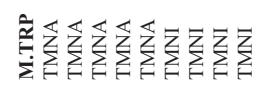

5

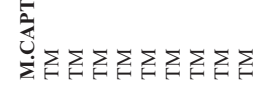$$
\text { 要 }
$$

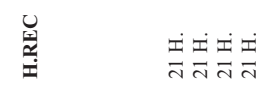

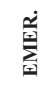
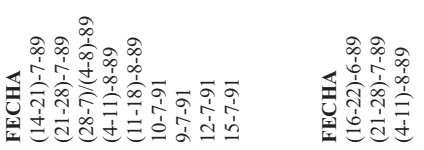

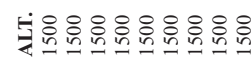

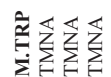

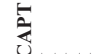

i

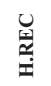

兽

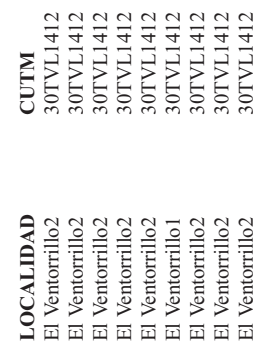

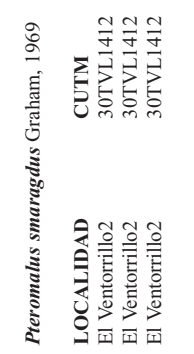

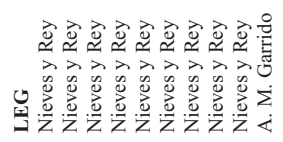

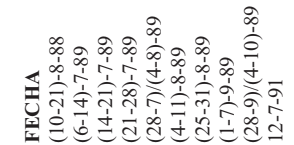

필

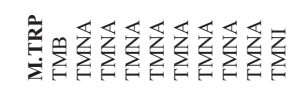

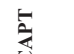

$\dot{z} \sum \sum \sum \sum \sum \sum \sum \sum \sum \sum$

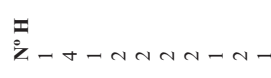

i

岂

商

鿷

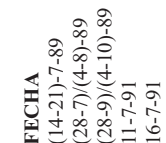

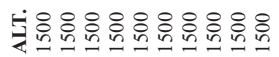

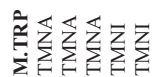

5

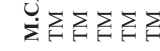

ż

ह

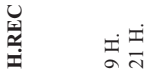

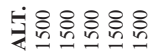
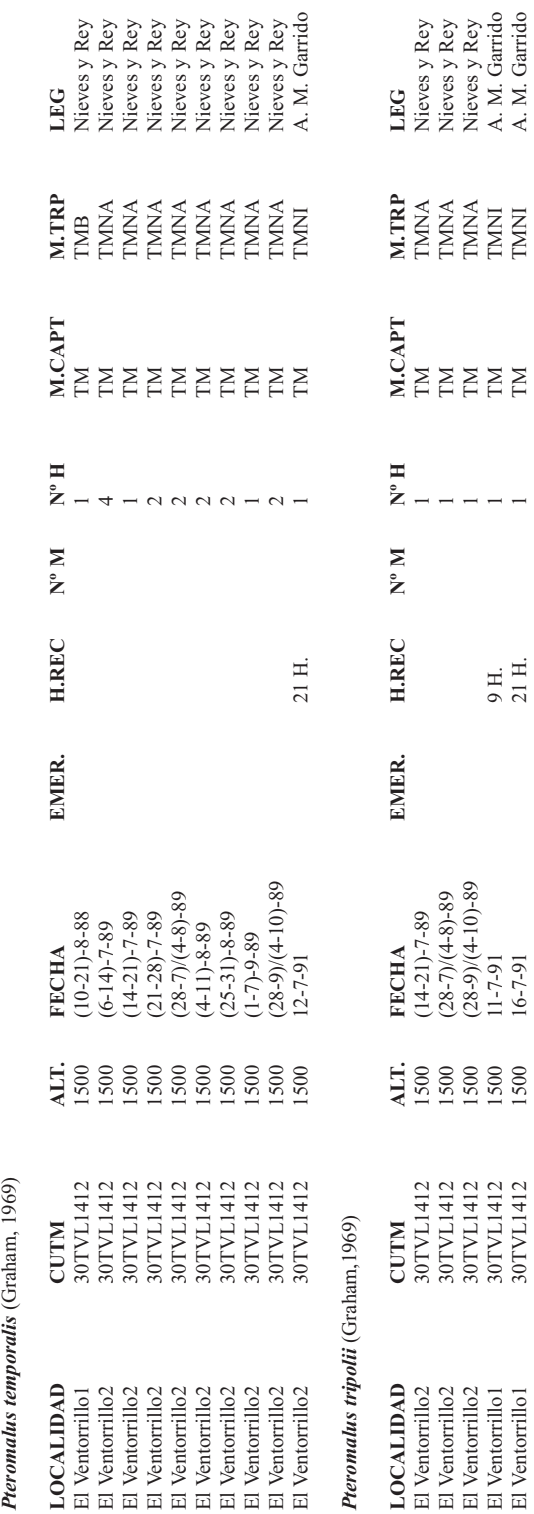

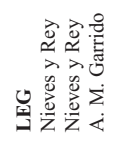

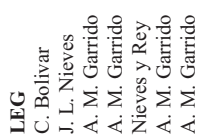

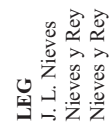

产发离

$\stackrel{\tilde{z}}{\bar{z}}$

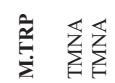

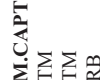

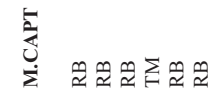

5

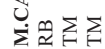
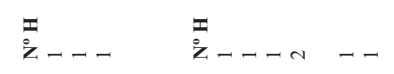

:

i

ż

$\Sigma_{\bar{z}}$

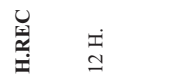

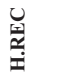

$\underset{\text { İ }}{\text { İ }}$

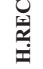

遆

兽

竎

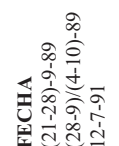

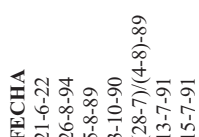

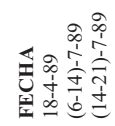

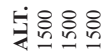

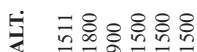

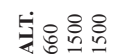
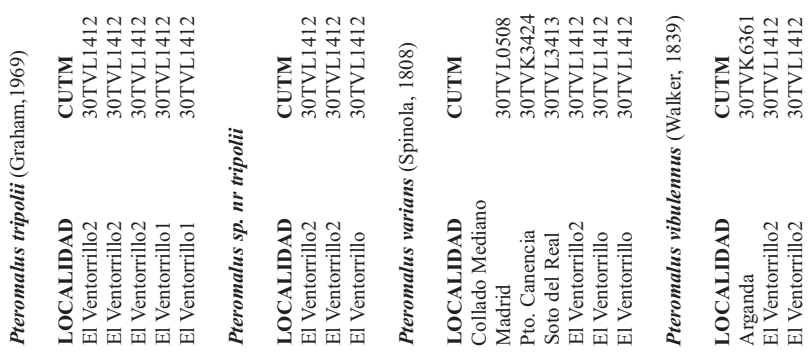


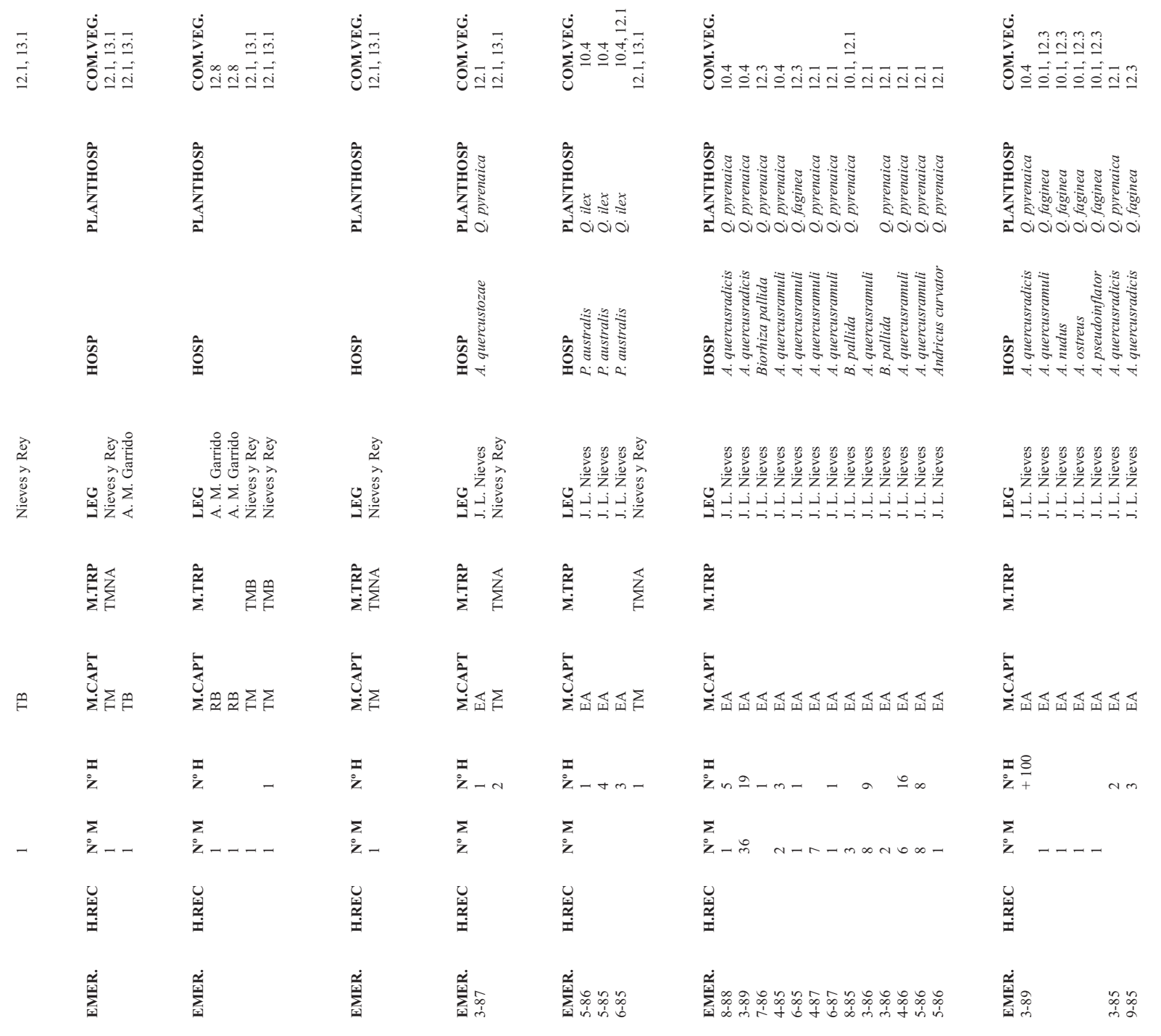

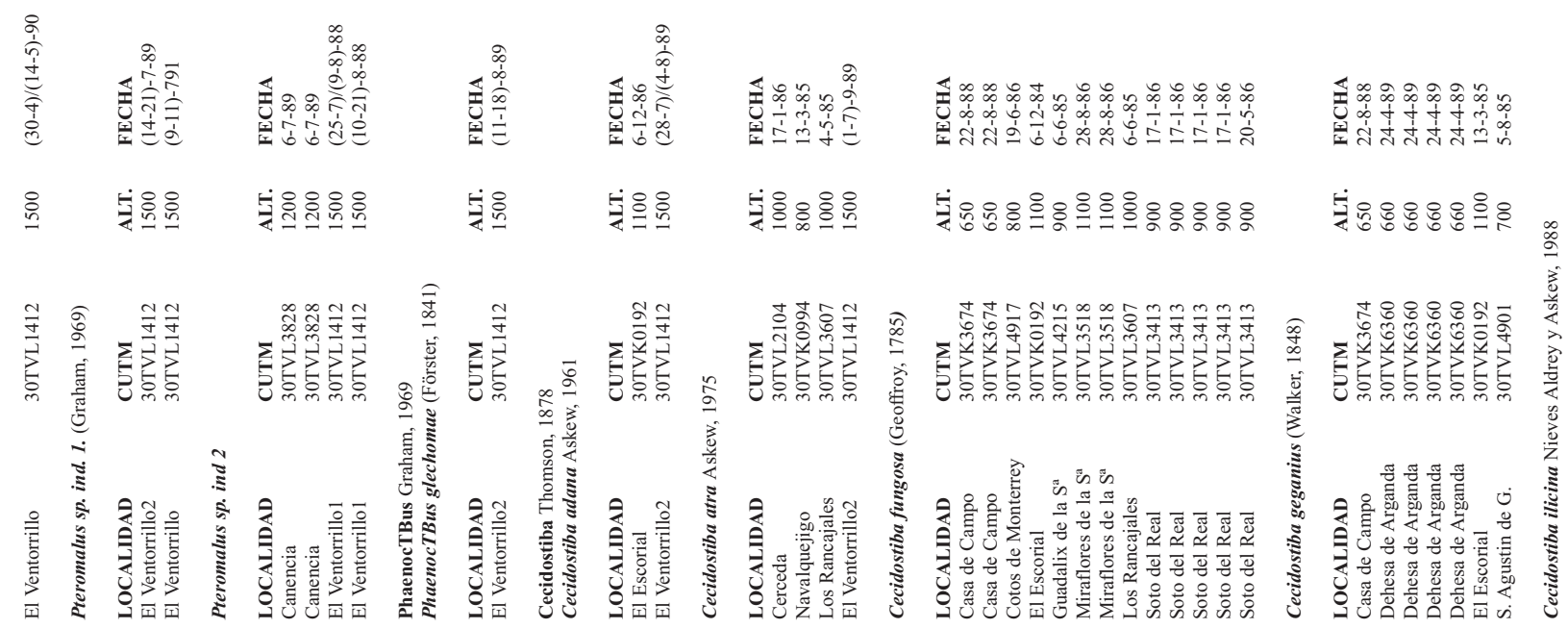




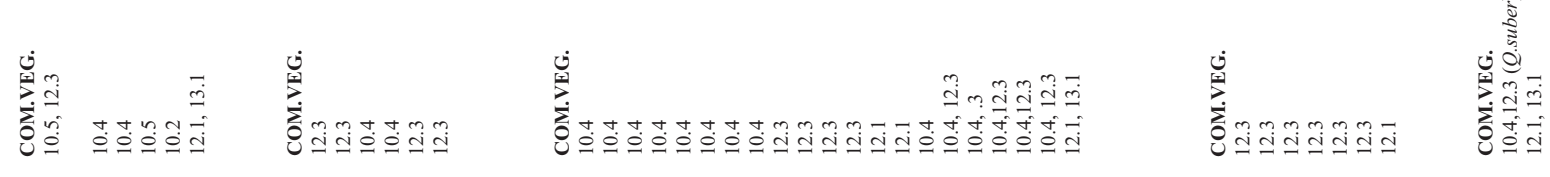

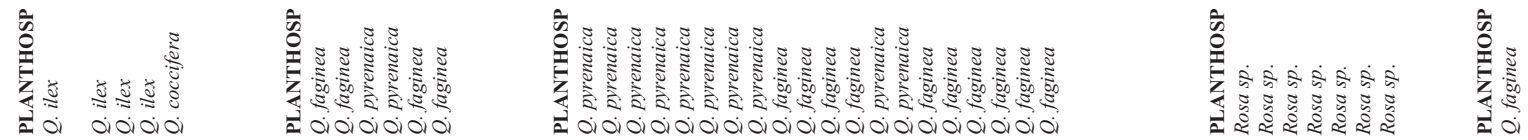

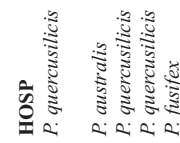
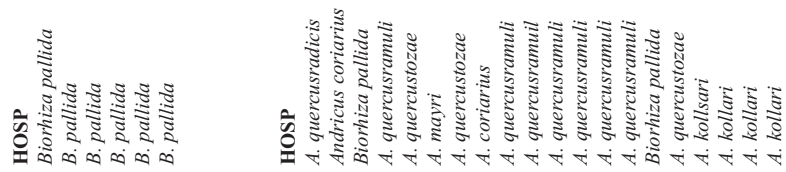

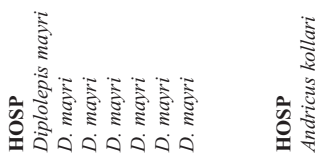
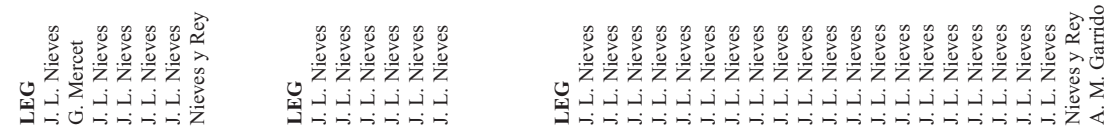

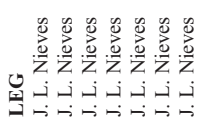

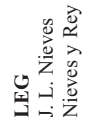

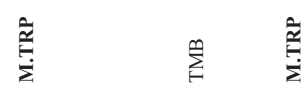

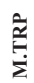

$\sum_{i=1}^{\infty}$

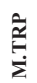

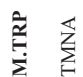

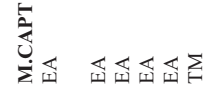

产

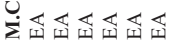

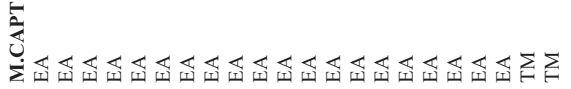

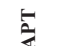

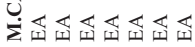

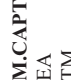

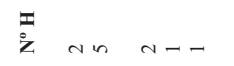

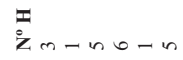

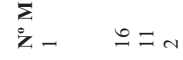

$\sum_{\dot{z}+-\simeq a}$

䓋 -

의

:

落

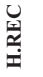

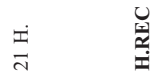

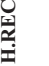

i

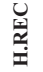

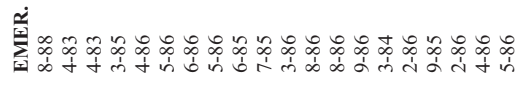

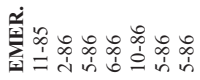

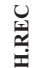

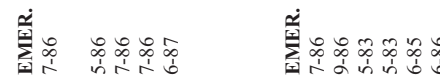

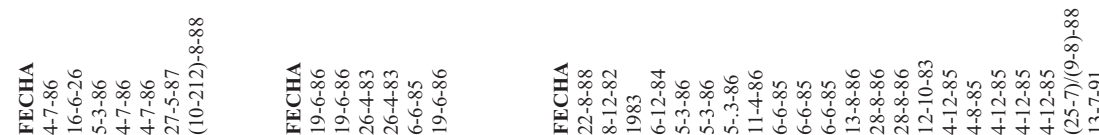

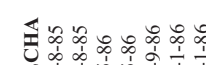

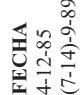

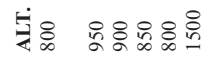




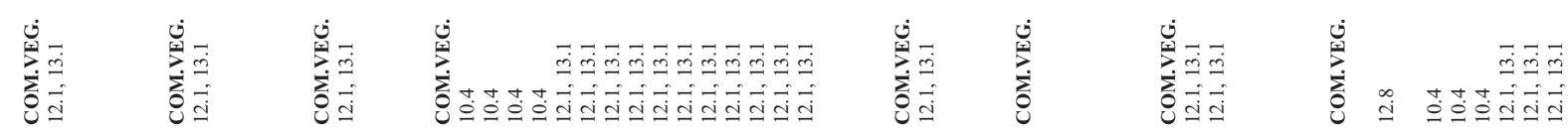

\begin{tabular}{|c|c|c|c|}
\hline 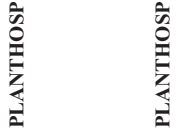 & 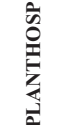 & 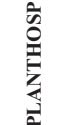 & \\
\hline
\end{tabular}

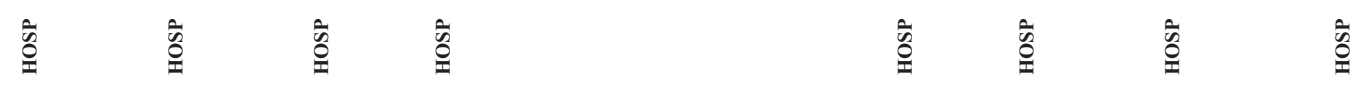

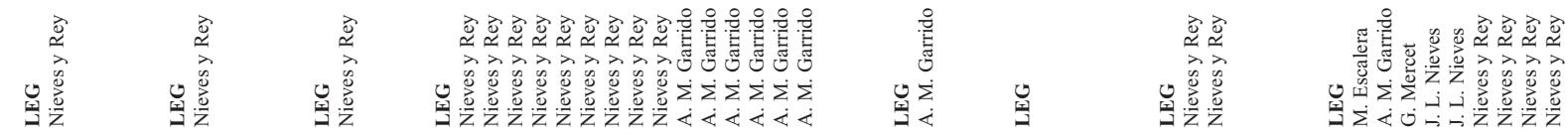

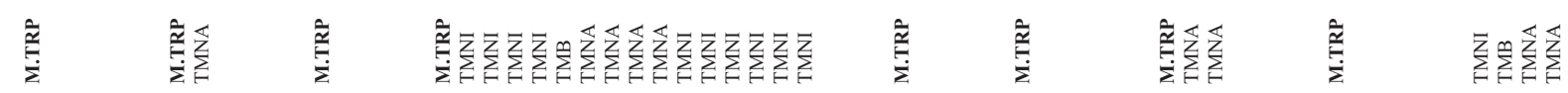

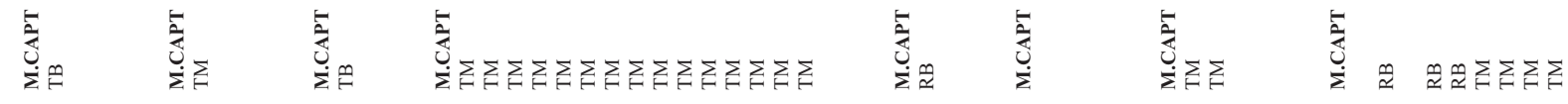

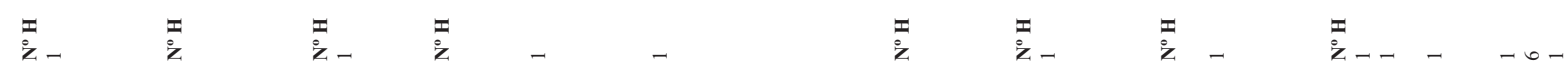

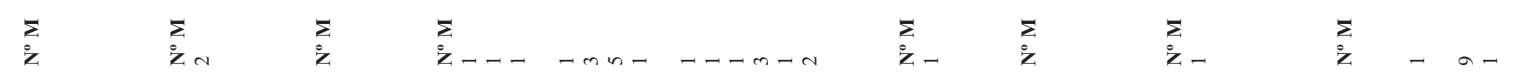

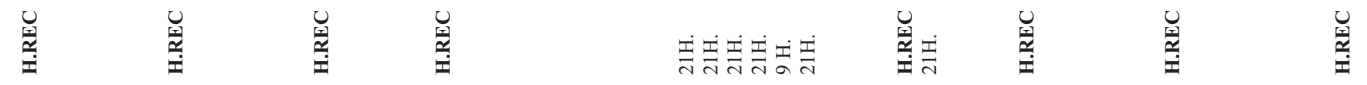

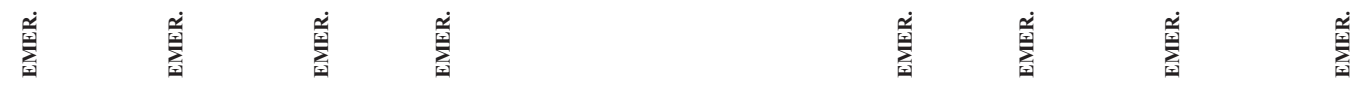

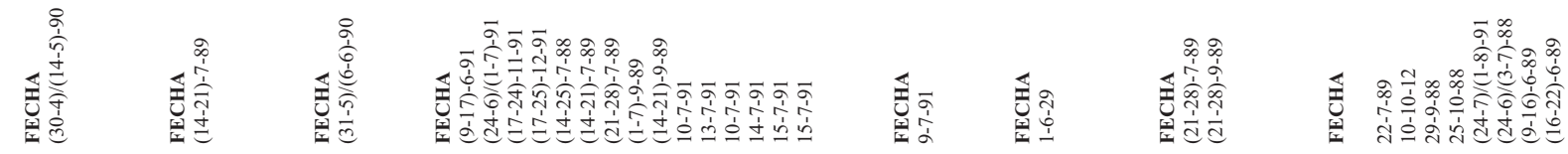

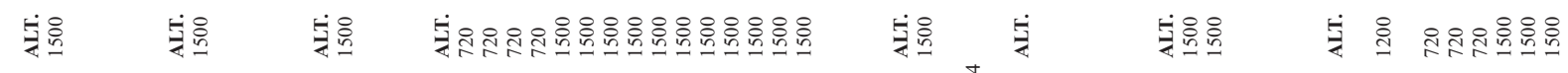

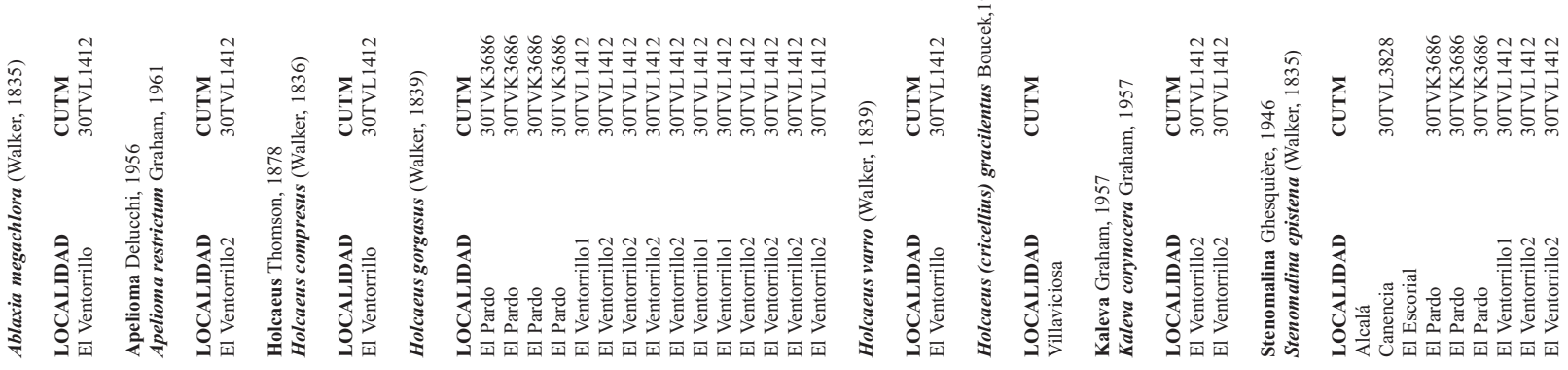




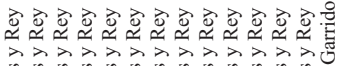

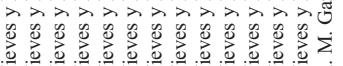

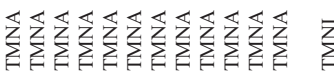

$\sum \sum \sum \sum \sum \sum \sum \sum \sum \sum \sum \sum 刃 \Xi$

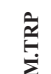

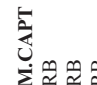

$\frac{\pi}{2}$

$\sum_{\bar{z}-\infty \circ}^{-10}$

$\stackrel{\text { M }}{\pi}$

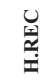

产

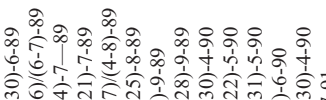

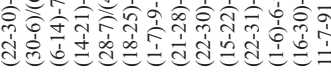

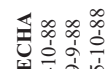

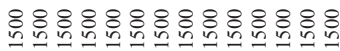

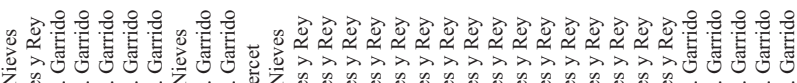

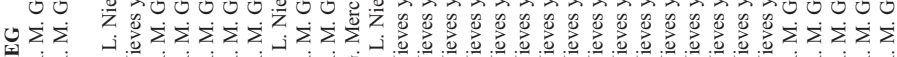

.

:

\&

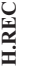

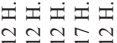

$\sum_{i=1}^{2}$

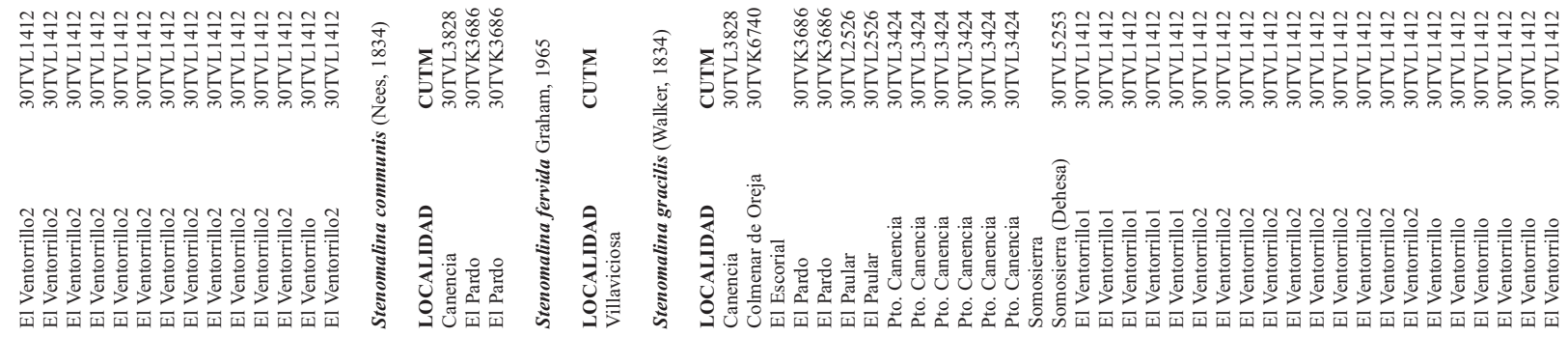




\begin{tabular}{|c|c|c|c|c|c|c|}
\hline $\begin{array}{l}\overrightarrow{\dot{m}} \\
\overrightarrow{\mathrm{d}}\end{array}$ & 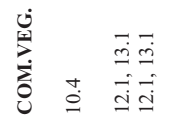 & 䆓 & 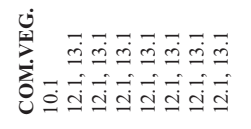 & 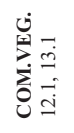 & 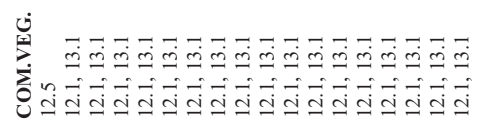 & 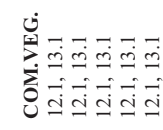 \\
\hline & 产 & 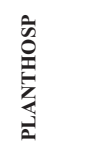 & 产 & 离 & $\frac{\bar{c}}{\stackrel{\bar{n}}{\sum_{2}}}$ & 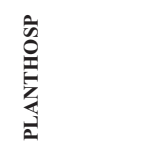 \\
\hline & tồ & 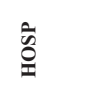 & के & फे & $\stackrel{\grave{s}}{\grave{x}}$ & $\stackrel{\bar{c}}{\grave{1}}$ \\
\hline 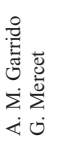 & 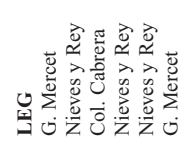 & 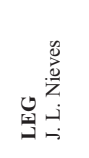 & 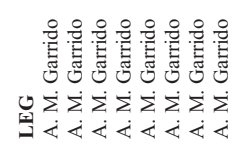 & 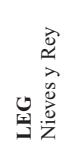 & 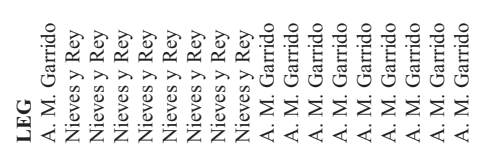 & 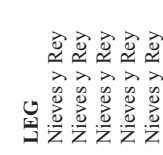 \\
\hline & $\underset{\bar{z}}{\bar{z}} \sum_{i} \sum_{i} \sum_{i}$ & $\stackrel{\tilde{\tilde{g}}}{\bar{\Sigma}}$ & 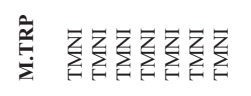 & 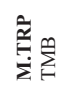 & 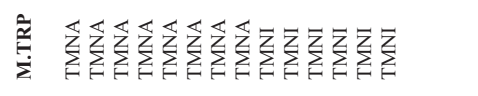 & 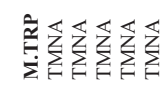 \\
\hline$\cong$ & 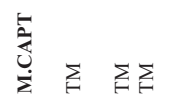 & 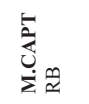 & 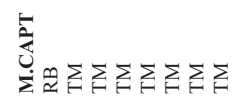 & 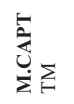 & 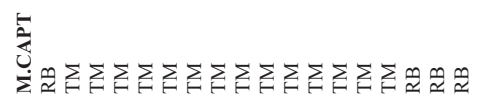 & 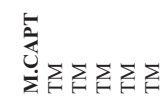 \\
\hline$\sim-$ & $\frac{\pi}{2}$ & $\frac{\pi}{2}$ & 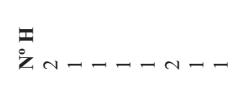 & $\frac{\pi}{\Sigma}$ & 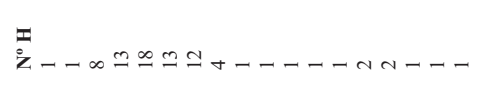 & $\sum_{\sin }^{\frac{\pi}{4}}$ \\
\hline & 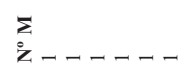 & $\sum_{\bar{z}}^{\Sigma}$ & $\sum_{\bar{z}}^{\bar{z}}$ & $\sum_{\dot{z}}^{2}$ & $\sum_{\bar{z}}^{2}$ & $\sum_{i}^{z}$ \\
\hline$\stackrel{ \pm}{I}$ & 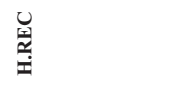 & 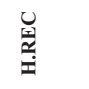 & 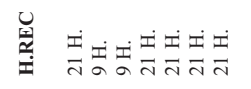 & 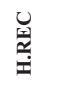 & 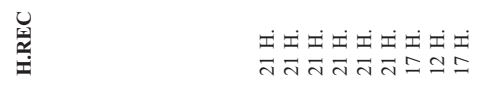 & 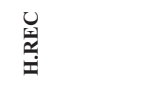 \\
\hline & 迸 & $\stackrel{\dot{\nu}}{\dot{x}}$ & $\dot{\ddot{y}}$ & $\frac{\dot{i}}{i=}$ & $\frac{\dot{x}}{\dot{x}}$ & $\stackrel{\dot{\alpha}}{\dot{x}}$ \\
\hline
\end{tabular}

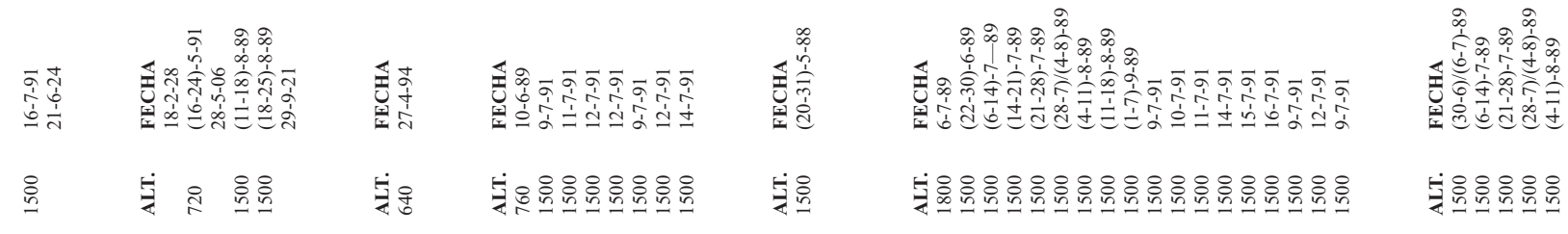

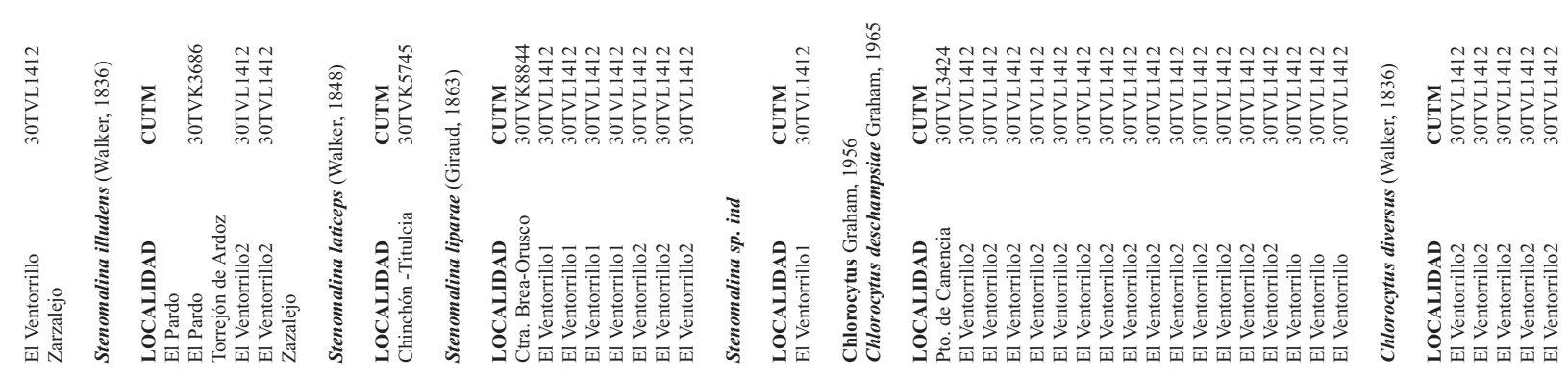




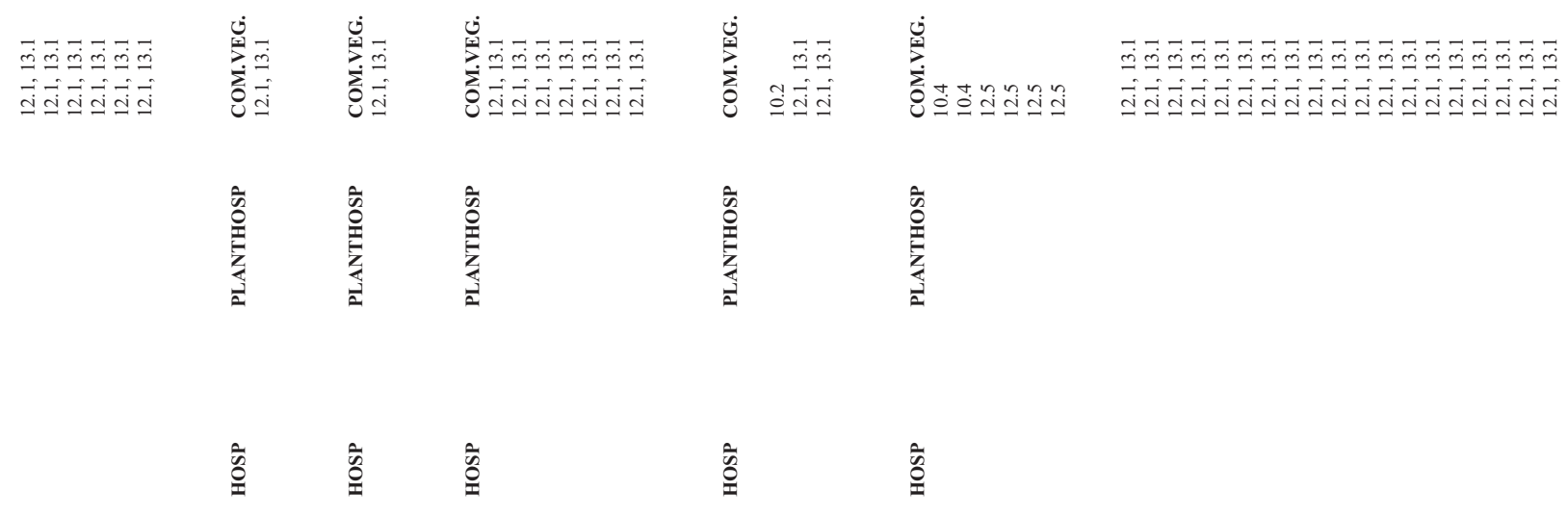

\begin{tabular}{|c|c|c|c|c|c|c|c|c|}
\hline 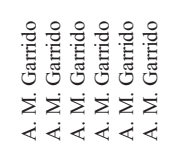 & 噌 & 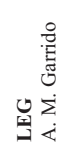 & 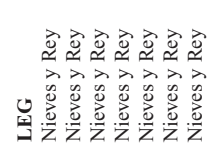 & نِ & 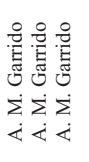 & 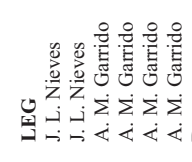 & 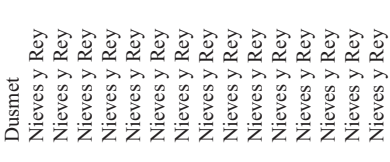 & 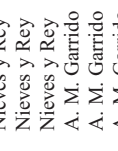 \\
\hline$\sum_{i=j} \sum_{i} \sum_{i}$ & $\stackrel{\bar{z}}{\bar{z}} \bar{z}$ & $\stackrel{\overline{\tilde{z}}}{\bar{z}}$ & 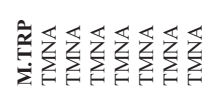 & 产 & 玄玄 & $\stackrel{\overline{\tilde{g}}}{\bar{z}}$ & 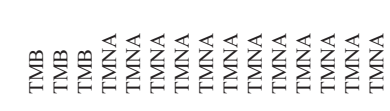 & $\sum_{i=1} \sum_{i}$ \\
\hline 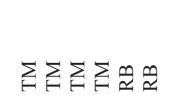 & 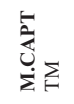 & 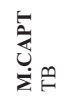 & 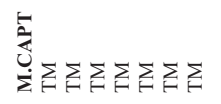 & 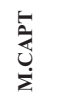 & $\cong \sum \geqq$ & 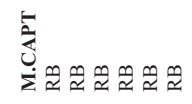 & 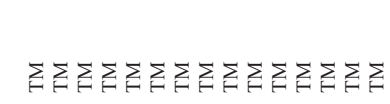 & $\sum \sum \sum \geqq \sum$ \\
\hline----- & $z_{-}$ & 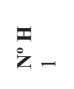 & $z_{z}^{z}--n--+m$ & in & --- & $\frac{\pi}{\pi}-6 e^{4}$ & $4---4$ & \\
\hline \multirow{3}{*}{ 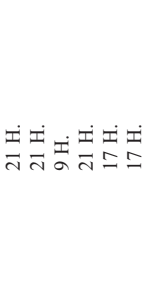 } & $\sum_{i}$ & $\sum_{i}$ & i & $\sum_{i}$ & & $\sum_{i}$ & $-\quad-$ & - \\
\hline & 递䒺 & 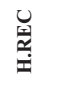 & 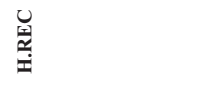 & 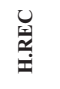 & & 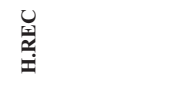 & & \\
\hline & 善 & 递 & $\stackrel{\dot{\varkappa}}{\dot{x}}$ & $\stackrel{\dot{\varkappa}}{\dot{x}}$ & & 曾 & & \\
\hline
\end{tabular}

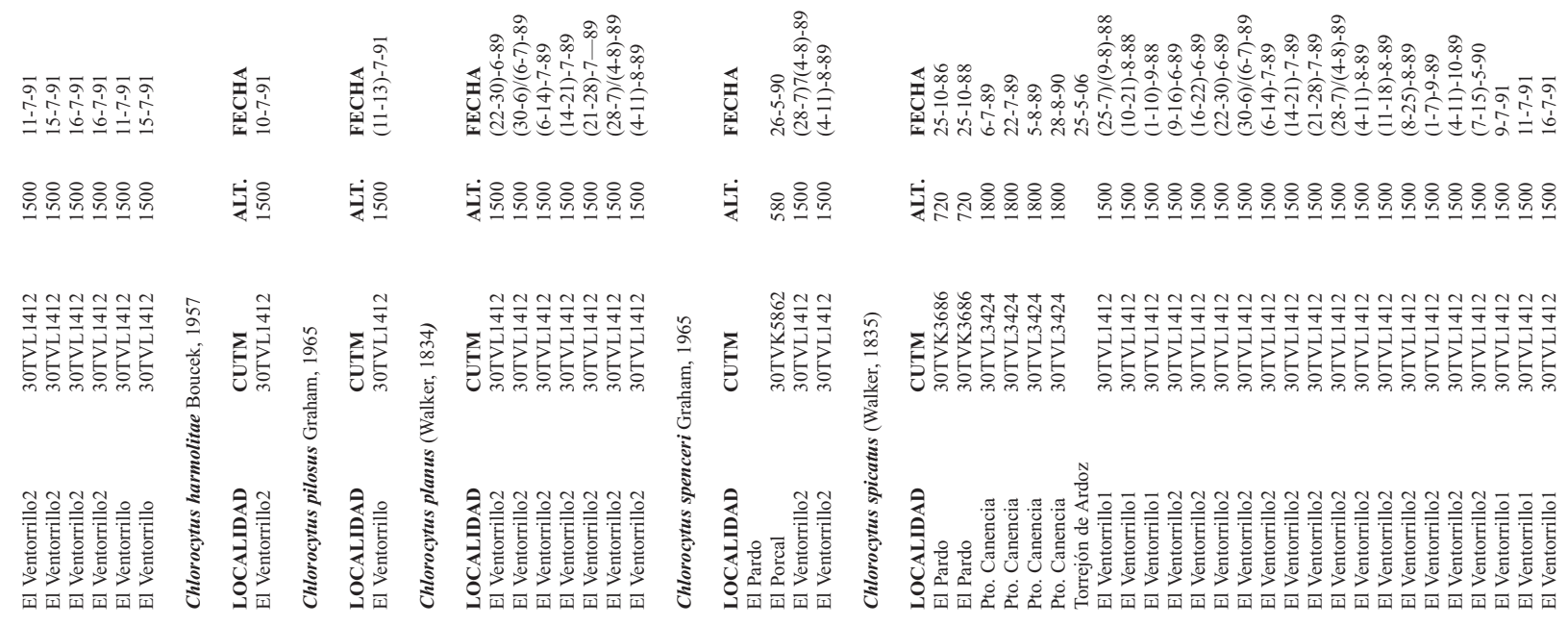




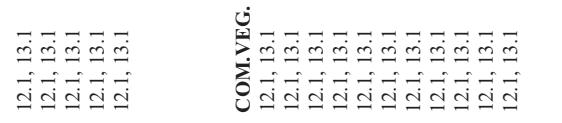
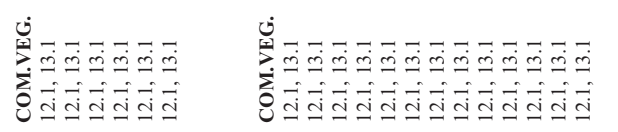

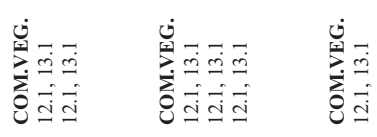
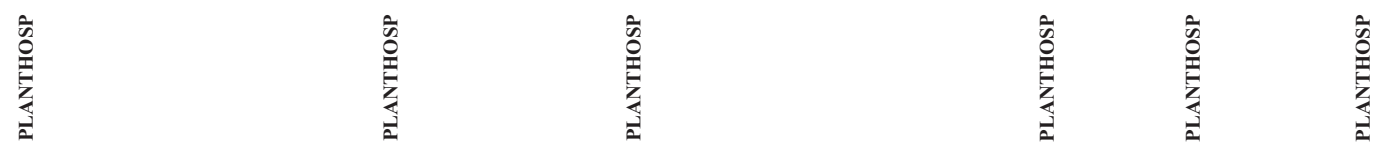

के

$$
\text { के }
$$

ڤั̀े

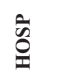

$\stackrel{\bar{s}}{\underline{x}}$

产
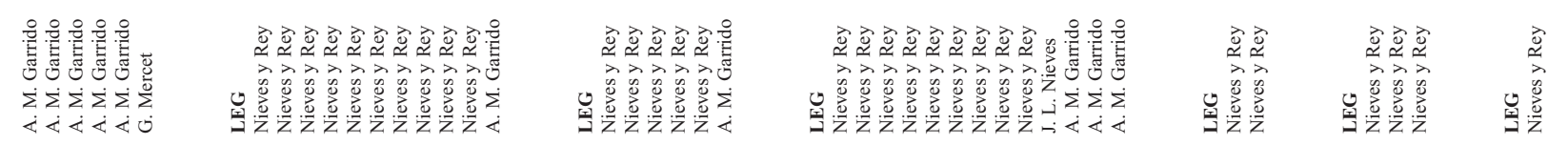

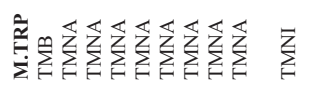

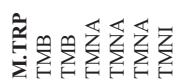

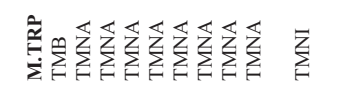

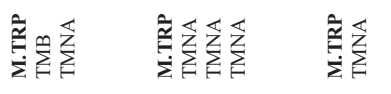

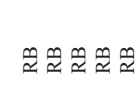

$$
\text { 氛 }
$$

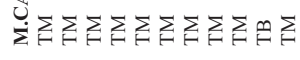

离

或

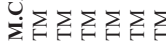

氮

氮引引
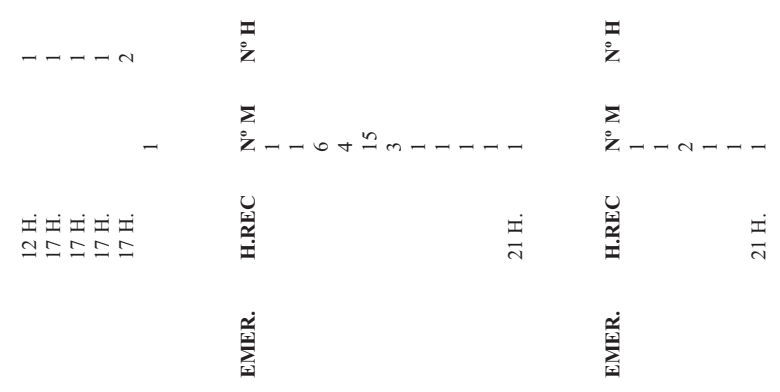

$\stackrel{1}{3}$

辰

紊

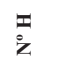

:

$\sum_{i}$

i

i

蒫

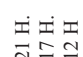

嵑

宸

突

兽

출

춥

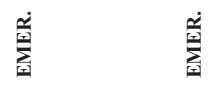
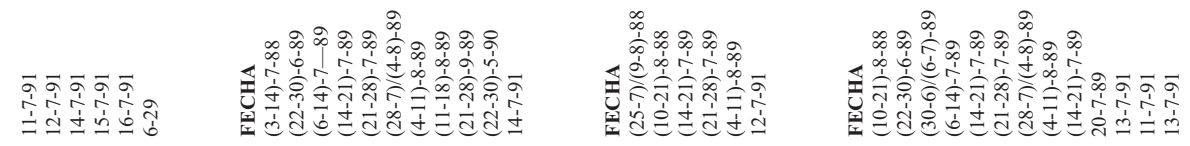

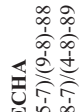

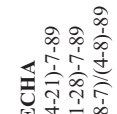

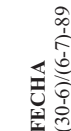

은 음음은

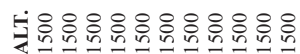

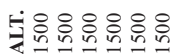

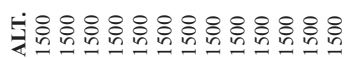

분음욤

분윰용

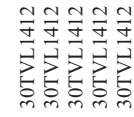

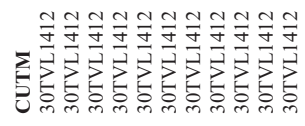

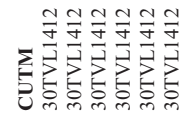

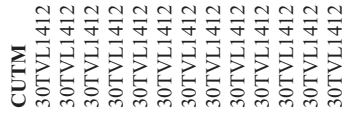

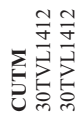

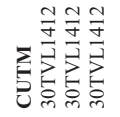

를
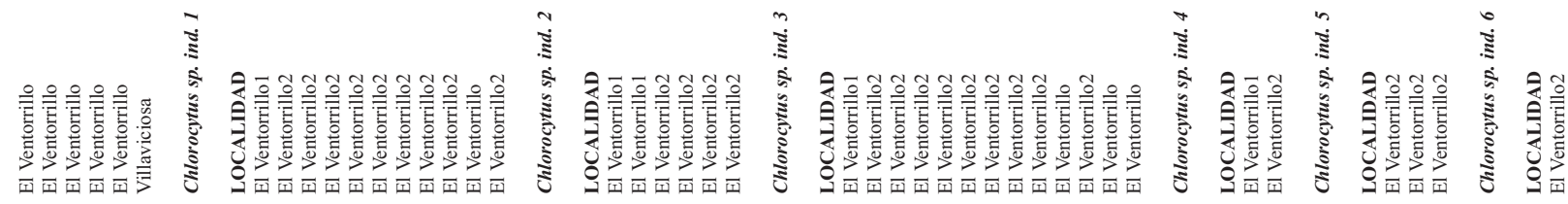


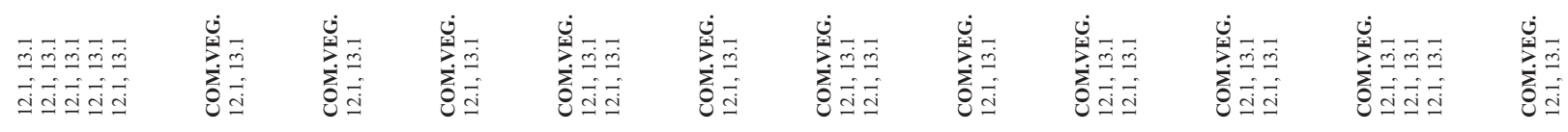

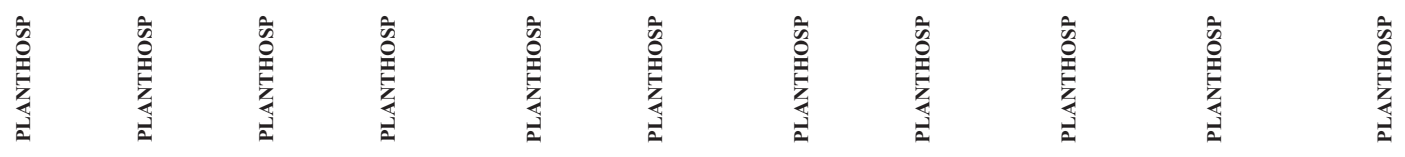

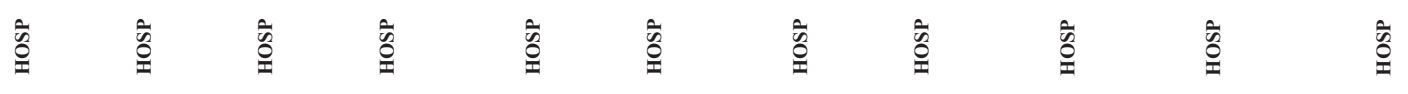

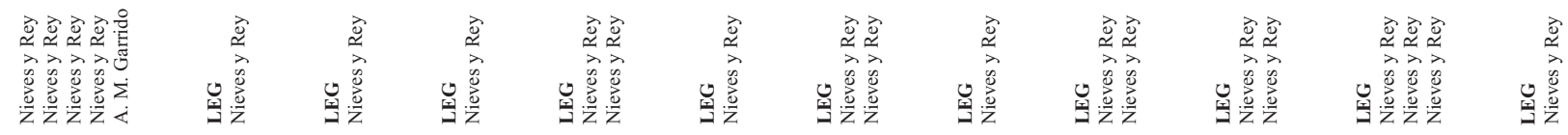

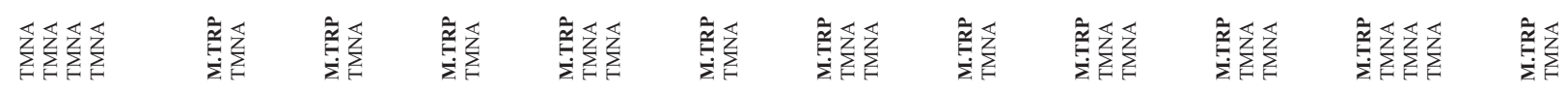

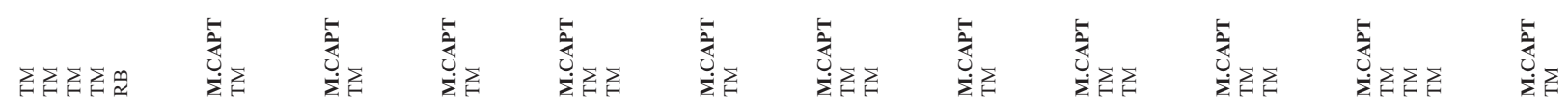

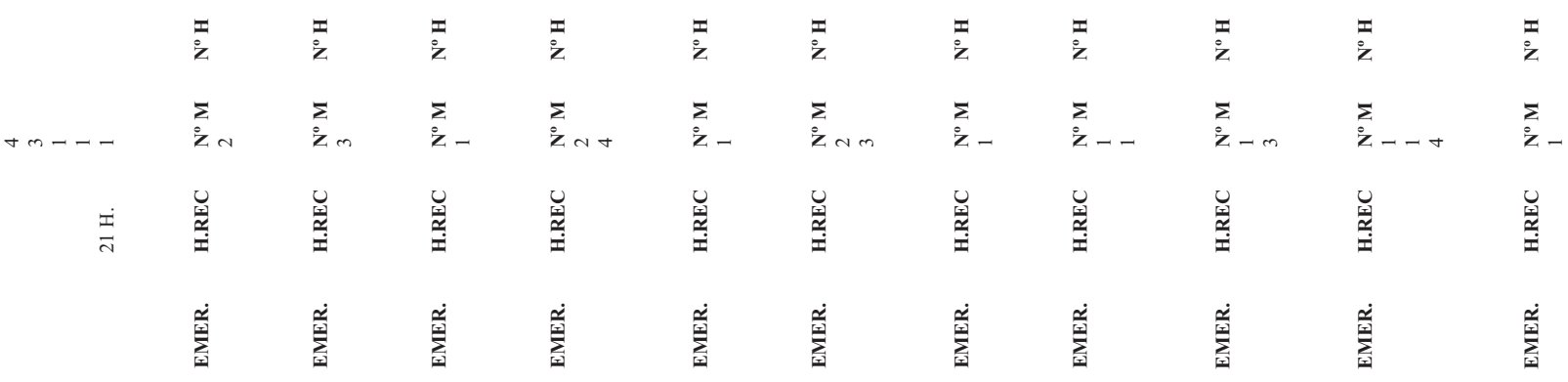

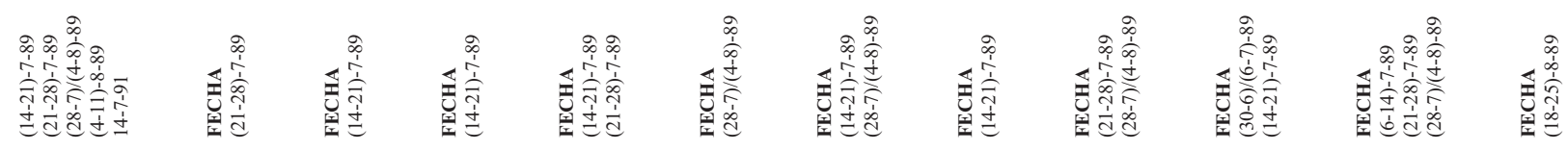

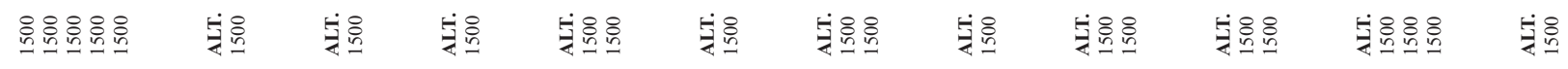

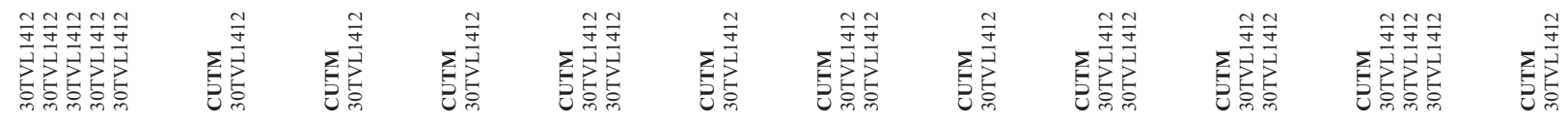

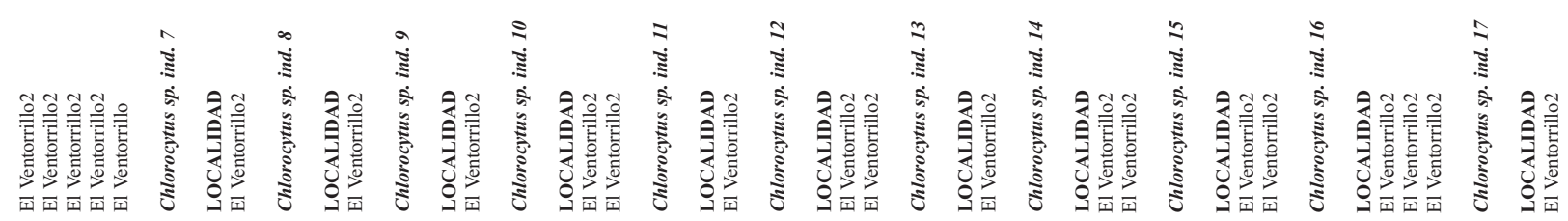




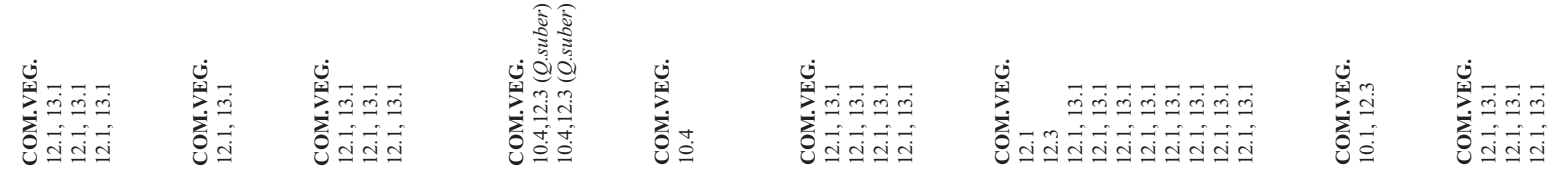

$|1| \||| l|l|$
产
के

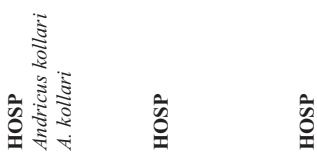

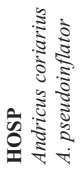

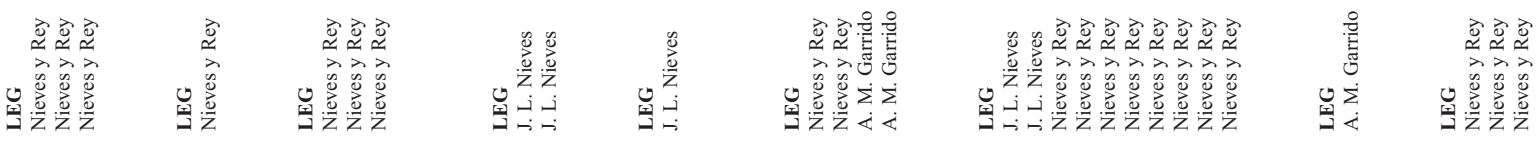

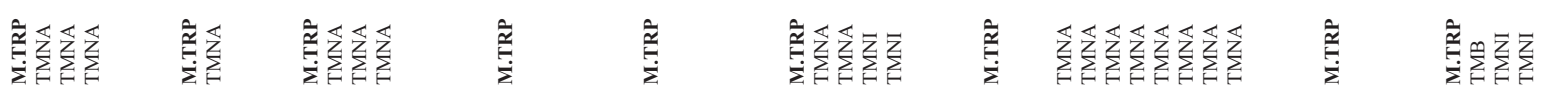

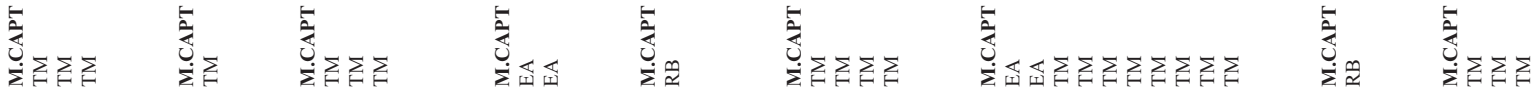

\begin{tabular}{|c|c|c|c|c|c|c|c|c|c|}
\hline $\begin{array}{l}7 \\
z \\
z\end{array}$ & $\stackrel{z}{z}$ & $\sum_{z}^{z}=$ & 紊 - - & $\sum^{m}$ & $\frac{\pi}{2}$ & - & $\operatorname{z}_{n}$ & + & $\begin{array}{l}z= \\
z\end{array}$ \\
\hline$\sum_{\Sigma_{z}}$ & $\frac{\pi}{2}$ & $\sum_{2}^{\pi}$ & $\frac{\pi}{2}$ & $\sum_{z}$ & $\begin{array}{l}\Sigma_{2} \\
\dot{z}_{2}\end{array}$ & & i & ---4 & $\sum_{z}$ \\
\hline ب & 辠 & 崂 & 兽 & 崂 & 崂 & $\stackrel{\nexists}{\vec{N}}$ & 崂 & & 总 \\
\hline 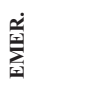 & 兽 & 畄 & 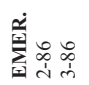 & 兽 & 迸 & & 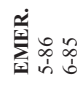 & & 兽 \\
\hline
\end{tabular}

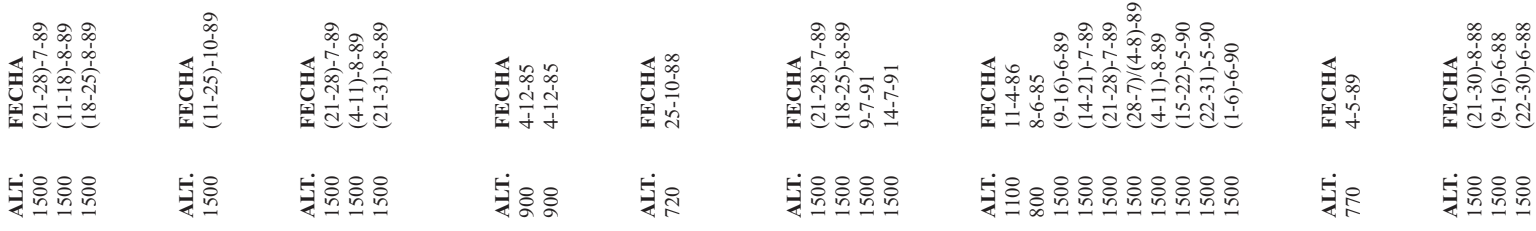

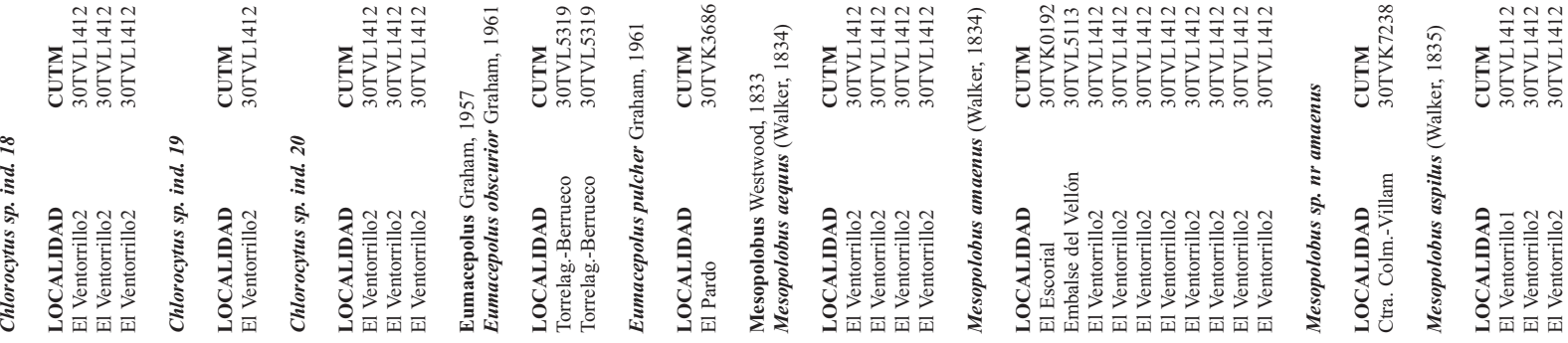




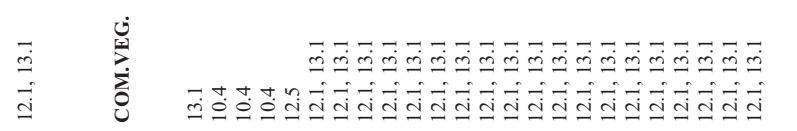

窟

के

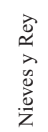

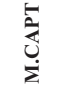

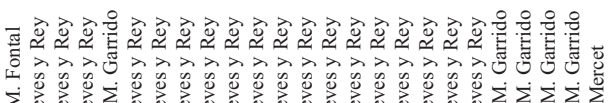

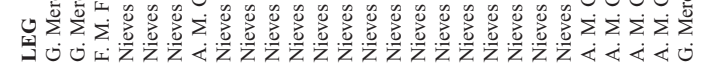

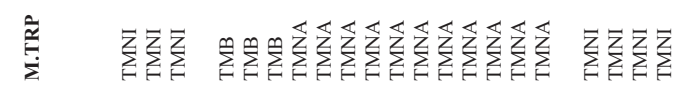

$$
\text { ì- }
$$

紊

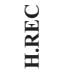

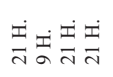

$\underset{i=1}{\stackrel{i}{x}}$

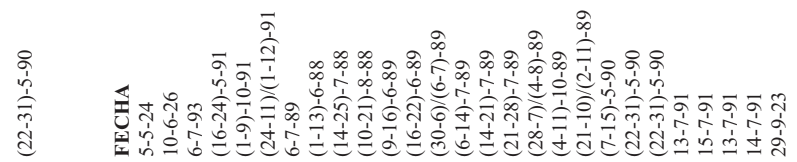

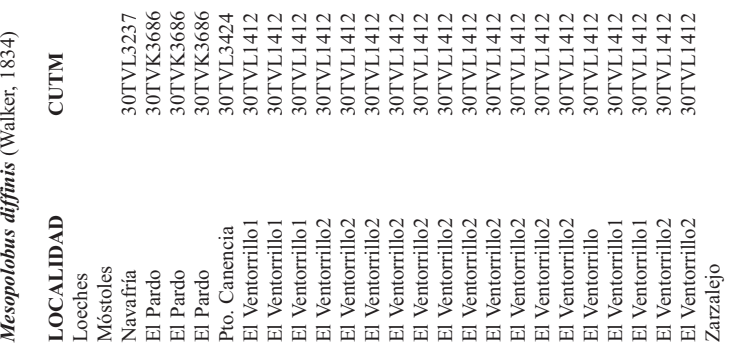

这然

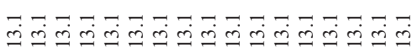

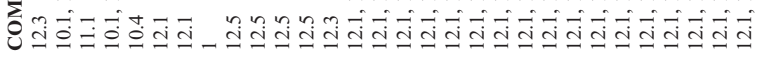

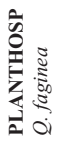

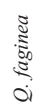

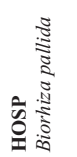

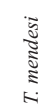

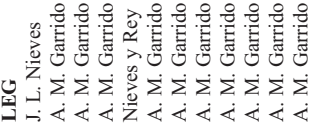

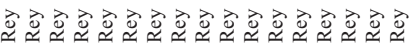
1 $\lambda \lambda \lambda \lambda \lambda \lambda \lambda \lambda \lambda \lambda \lambda \lambda \lambda \lambda \lambda \lambda$

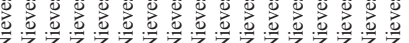

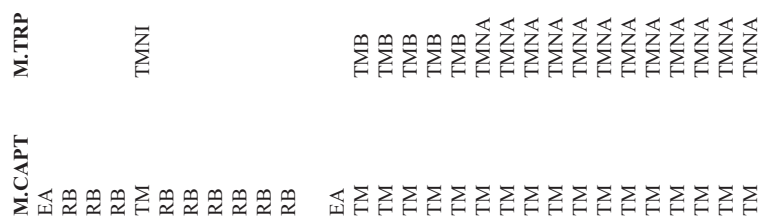

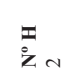

$\sum_{i}$

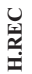

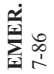

$\underset{\substack{\infty \\ \grave{i}}}{\infty}$

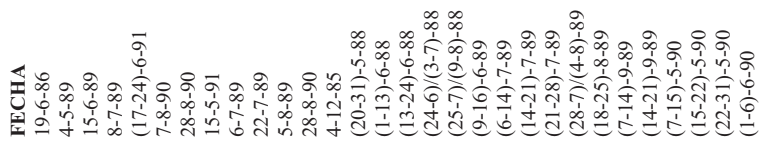

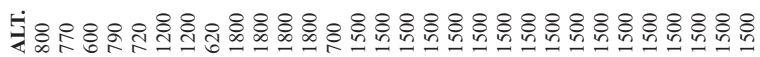

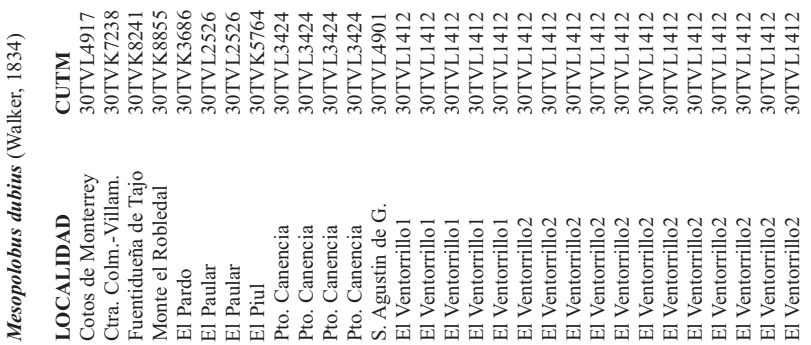




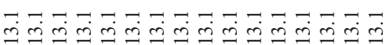

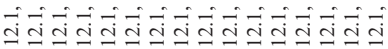

望

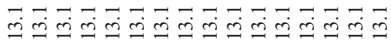

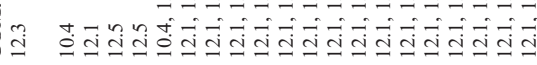<smiles>C1CCCCC1</smiles>

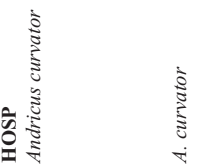

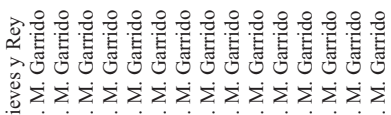

$\sum_{i} \sum_{i} \sum_{i} \sum_{i}$

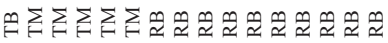

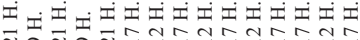

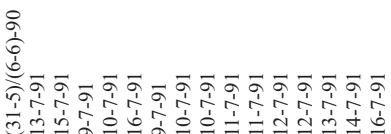

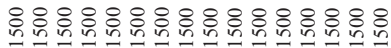

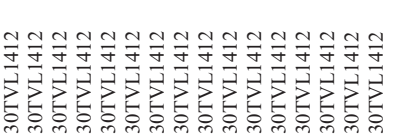

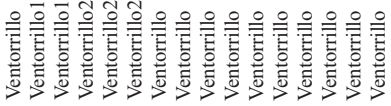

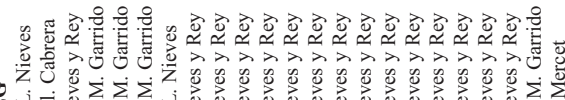

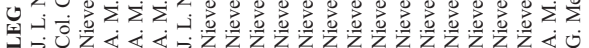

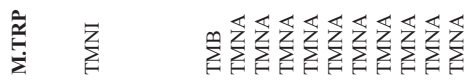

勾

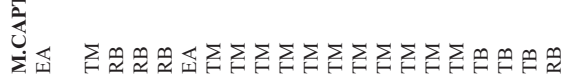

:

$\sum_{i}$

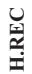

$\stackrel{2}{I}$

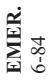

\%

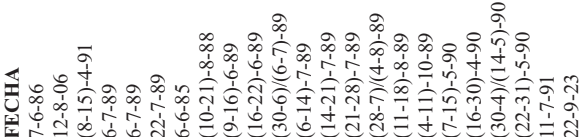

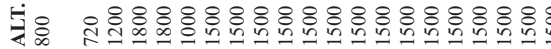

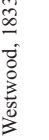

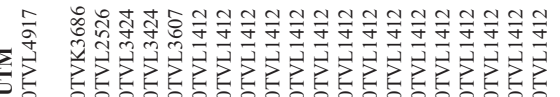

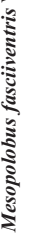

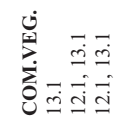

过

în

bे

\begin{tabular}{|c|c|}
\hline 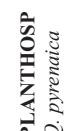 & 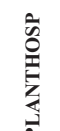 \\
\hline
\end{tabular}

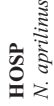

产

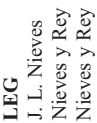

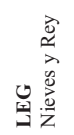

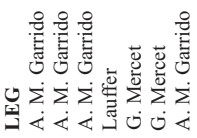

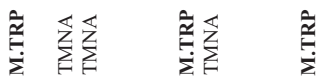

突

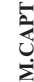

安

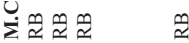

$\stackrel{\text { I }}{\mathrm{Z}-}$

$\sum_{\operatorname{Zn} m m-\alpha-}$

$\sum_{i}=$

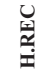

$\sum_{\dot{z}}^{\Sigma}---$

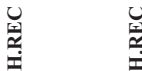

$\sum_{\substack{i=1 \\ i=1}}^{\infty}$

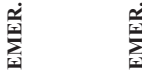

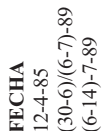

这章

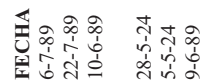

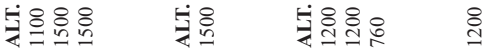

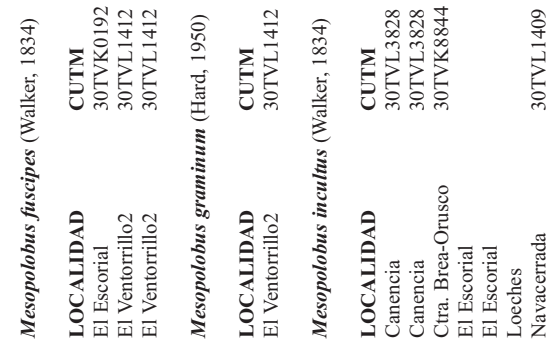




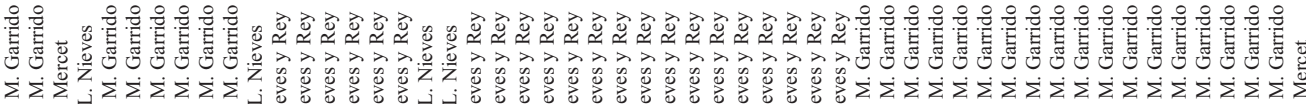

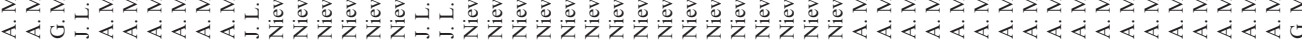

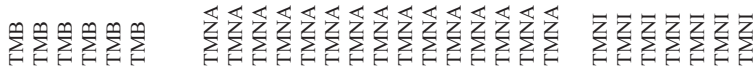

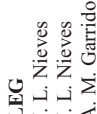

定 


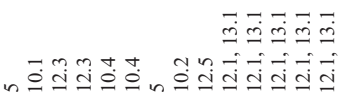

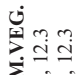

I

3

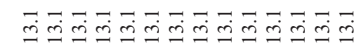

$$
\text { 要 }
$$

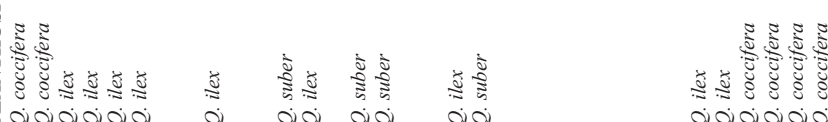

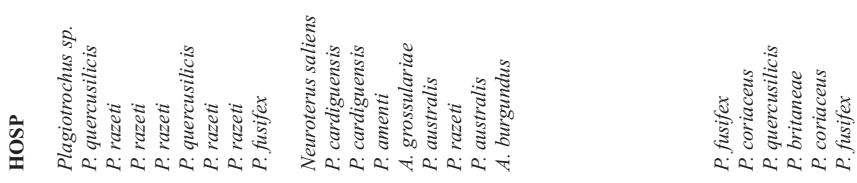

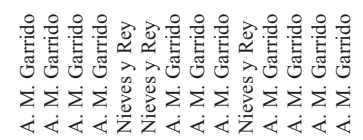

\section{$\sum_{i=}^{i} \sum_{i}^{\sharp}$}

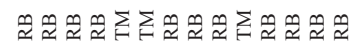

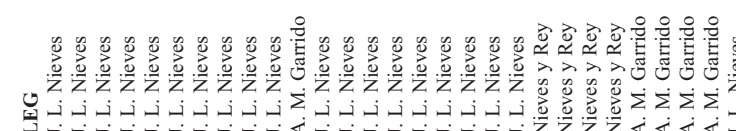

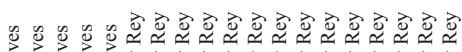

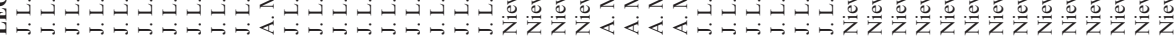

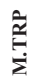

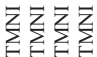

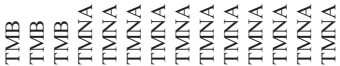

$\stackrel{\check{\Delta}}{\grave{j}}$

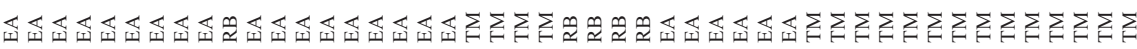

$\stackrel{2}{2}$

$\sum$

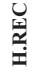

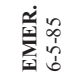

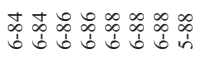

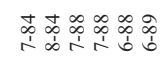

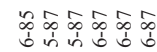

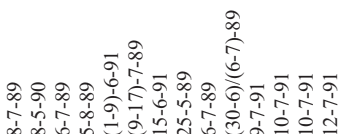

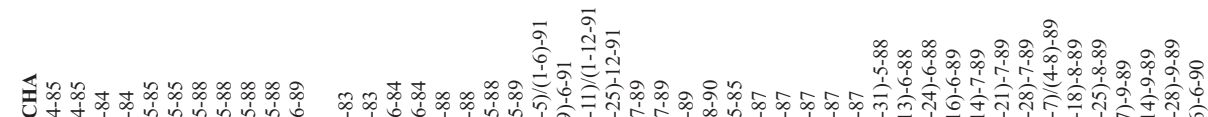

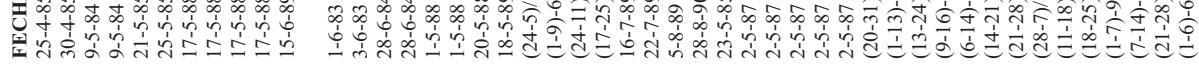

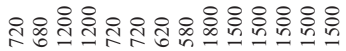

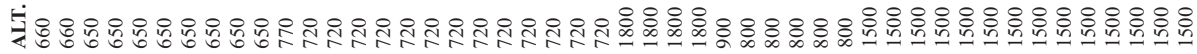

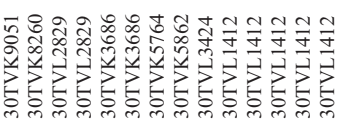

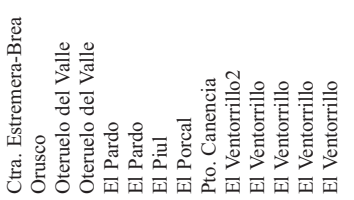

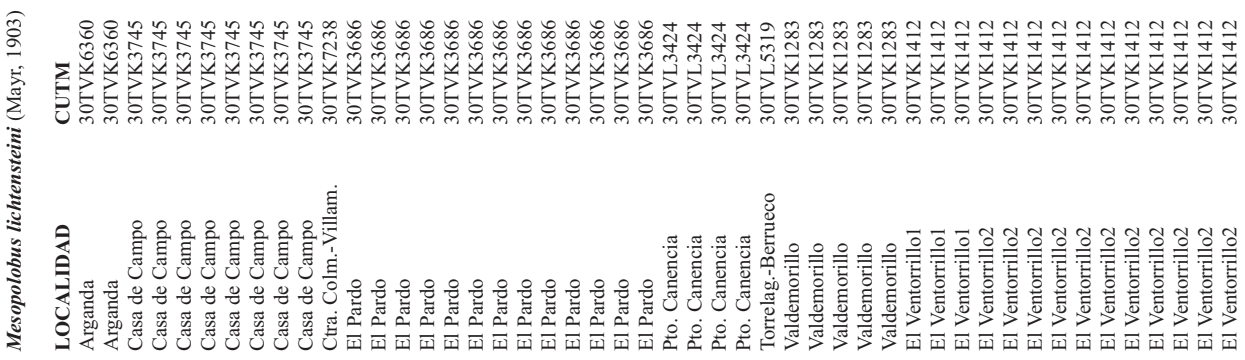




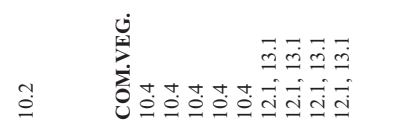

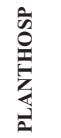

$$
\text { के }
$$

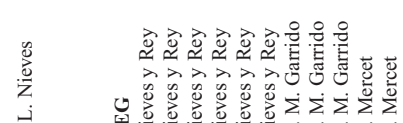

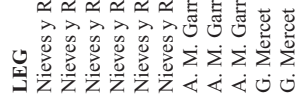

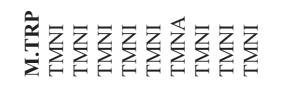

完
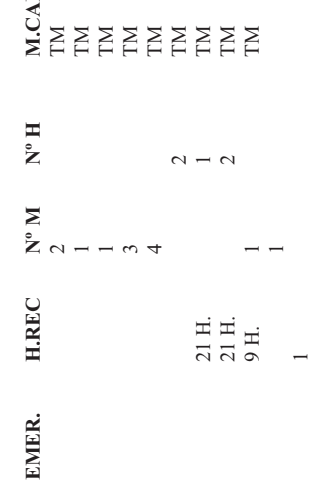

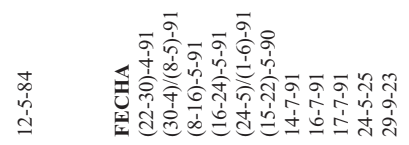

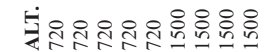

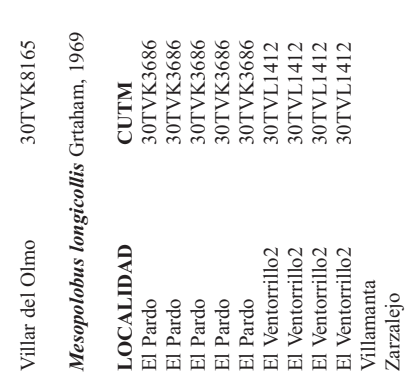

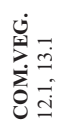

容

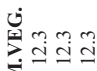

है.

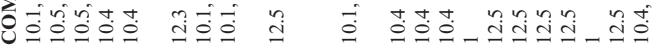

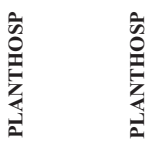

केष्ञ

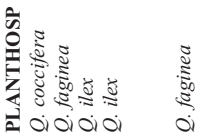

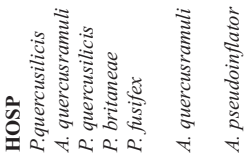

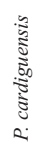

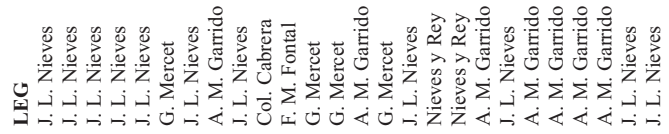

产

$\sum_{i=1}^{i}$

5

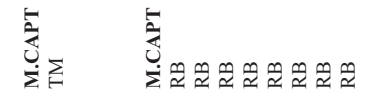

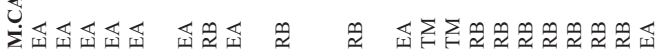

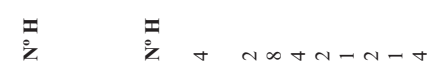

$\sum_{i}$

$\dot{z}_{+} \varrho_{m}$

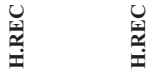

畜畜

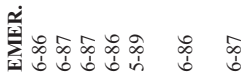

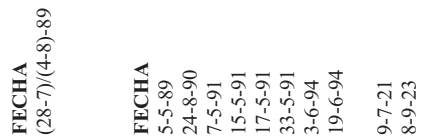

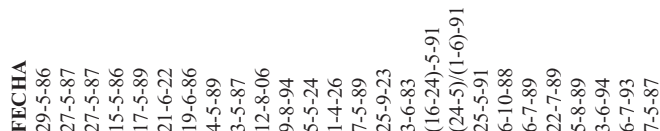

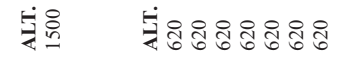

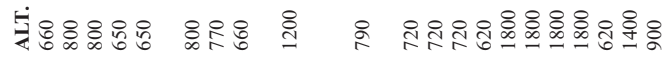

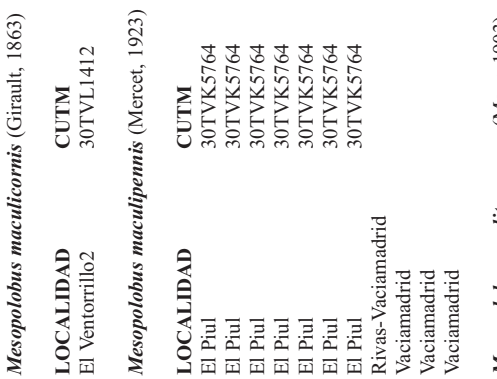




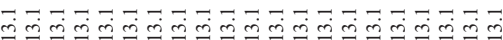

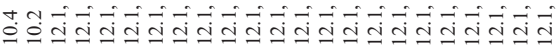<smiles>C1C2C3CC2C13</smiles>

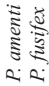

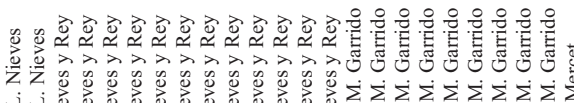

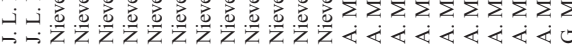

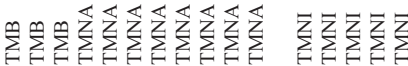

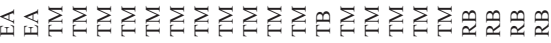

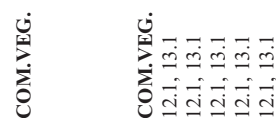

䒿

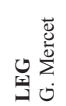

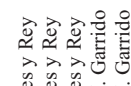

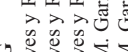

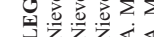

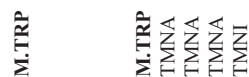

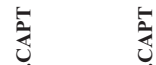

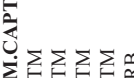

茫- 茫-

$\sum_{\bar{Z}} \sum_{\mathrm{Z}}$

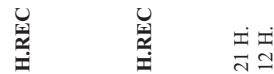

兽紊章

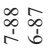

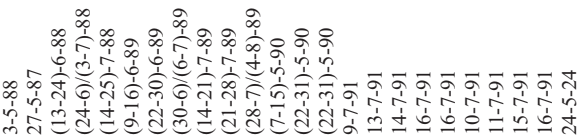

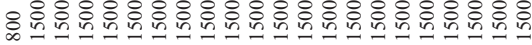

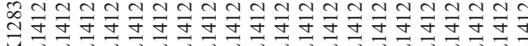

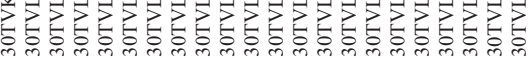

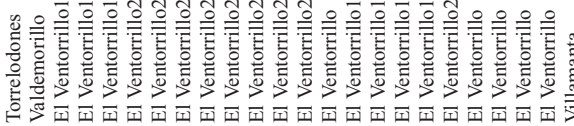

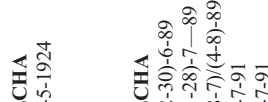

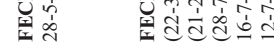

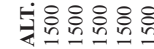

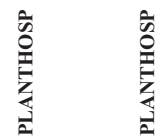

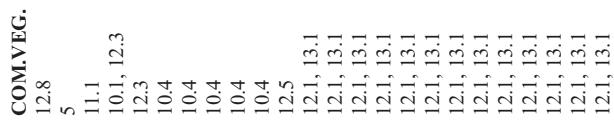

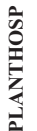

के

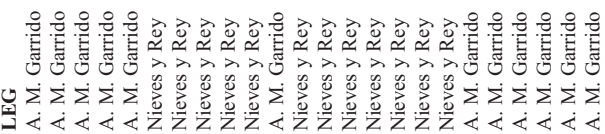

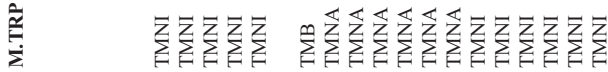

这

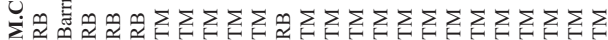

זั

$\sum$

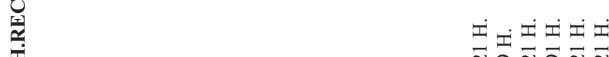

$\sum_{i=1}^{\infty}$

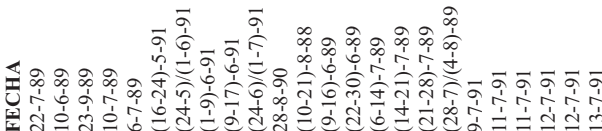

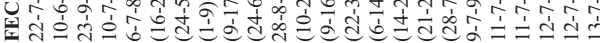

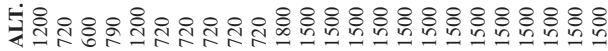

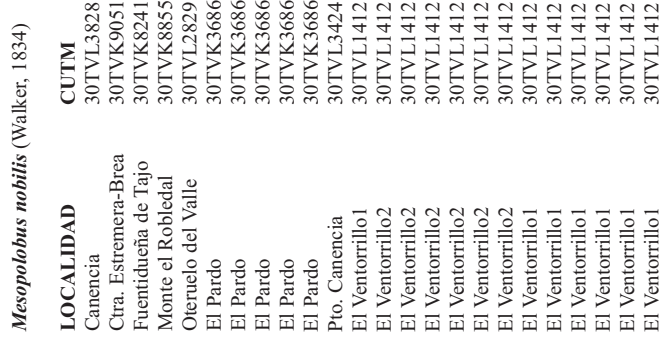




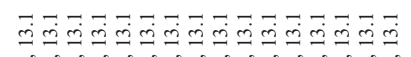

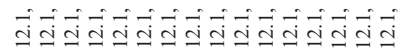

$$
\text { نे }
$$

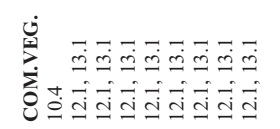

要过

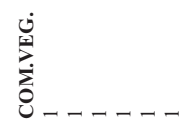

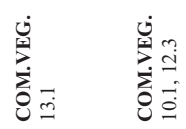

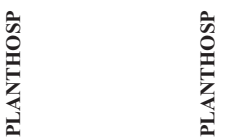

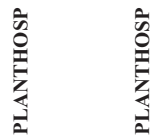

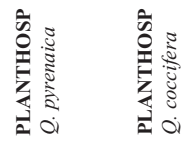

फे

के

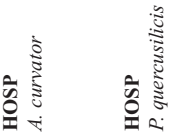

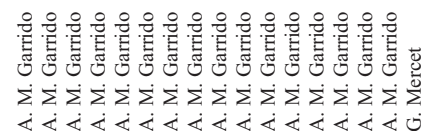

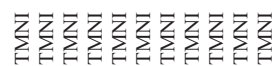

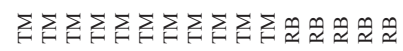

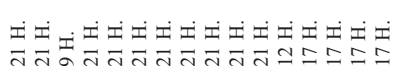

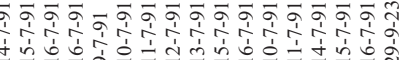

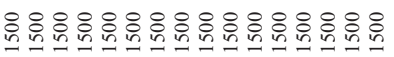

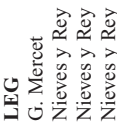

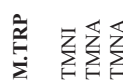

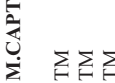

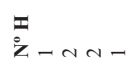

$\sum_{i}$

苜

$\sum_{i=1}^{\dot{i}}$

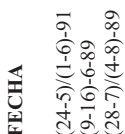

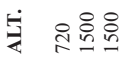

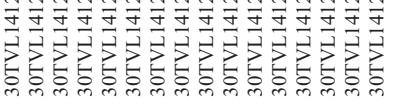

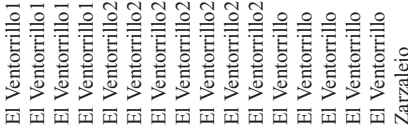

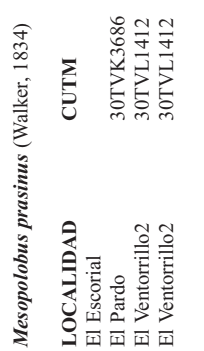

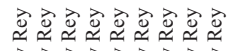

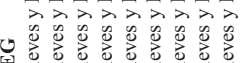

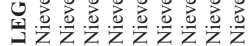

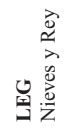

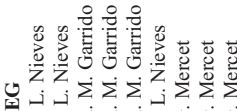

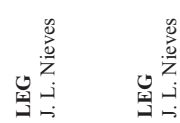

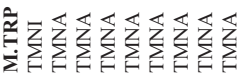

产

产

产

岂

岁

预

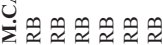

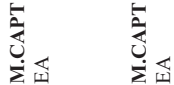

$\stackrel{z}{\mathbf{z}-}$

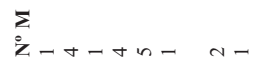

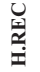

i

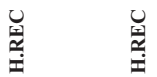

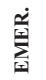

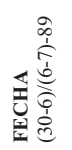

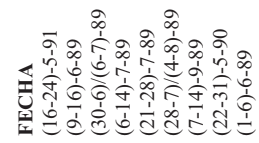

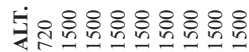

붕용

สิ

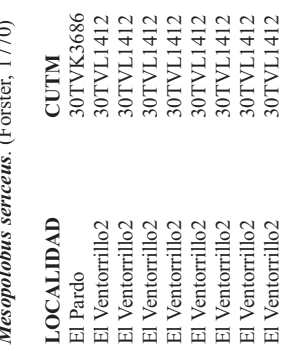

:

$\underset{i}{i}$

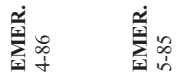

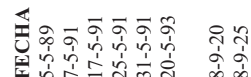

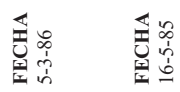

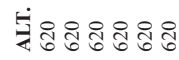

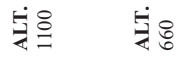

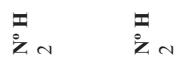

$\sum_{i} \quad \sum_{i}^{i}+$

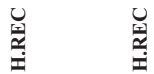

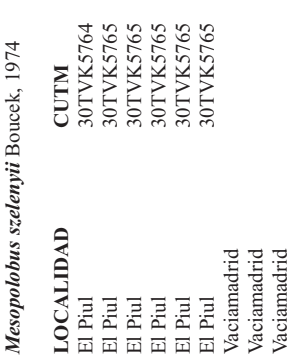

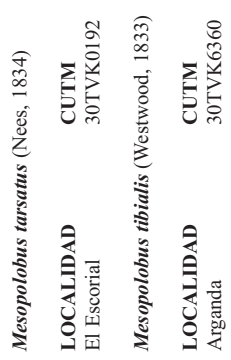


ำㄱำ

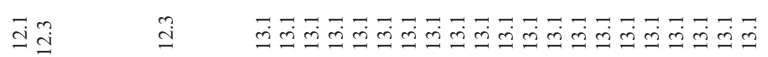

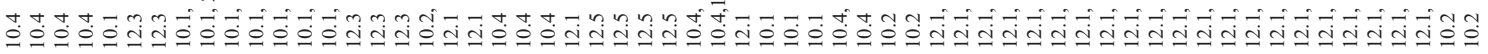
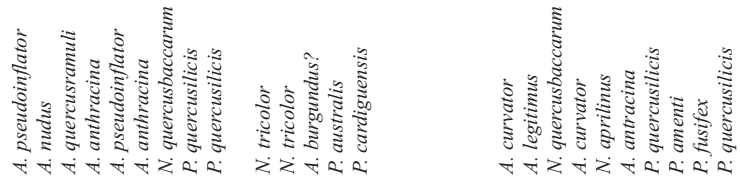

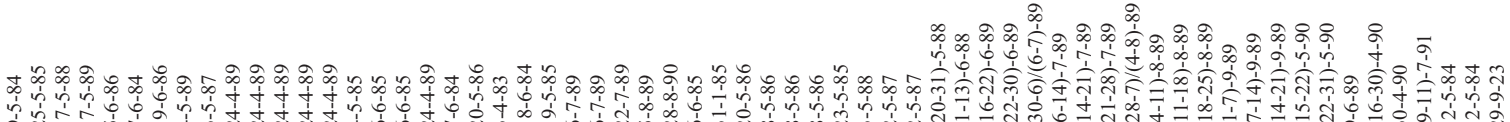




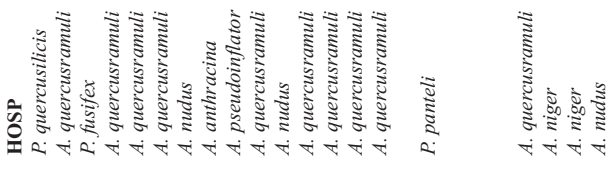

$$
\text { ż }
$$

$\sum^{2} \pi+n$

สิn+t $\cos$

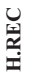

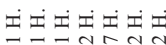

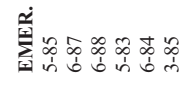

$\stackrel{z}{z}-\quad$ :

$\begin{array}{ll}\sum_{i} & \sum_{1} \\ \dot{Z} & \dot{Z}\end{array}$

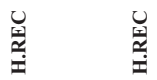

亲紊章

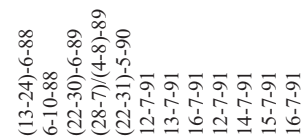

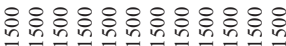

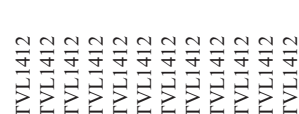

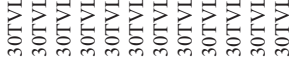

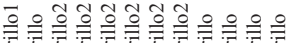

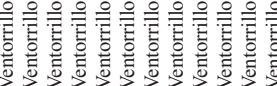

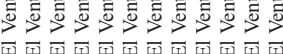

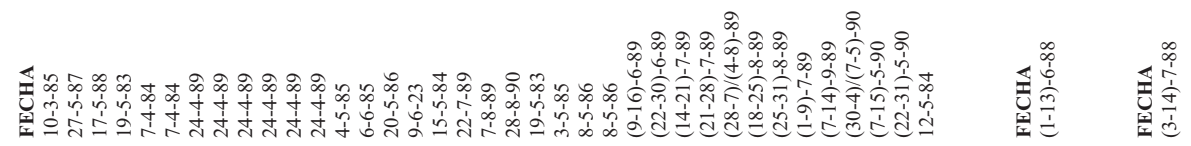

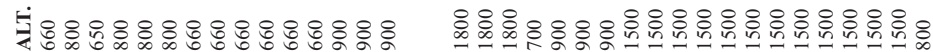

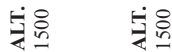

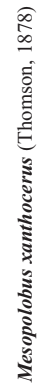

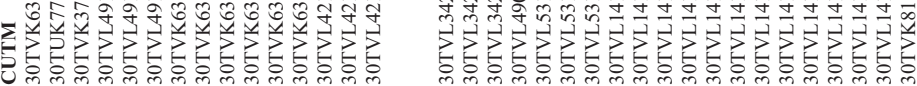




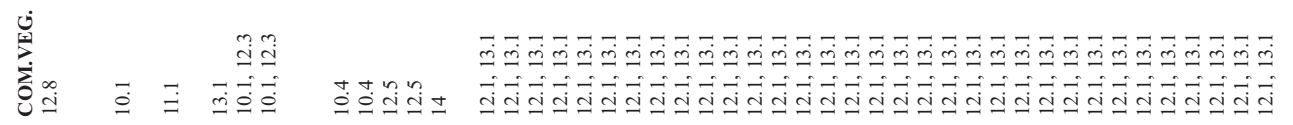

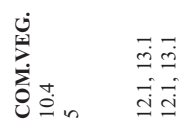

$\stackrel{\frac{\pi}{2}}{\frac{2}{2}}$

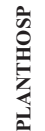

㙶

ڤิ

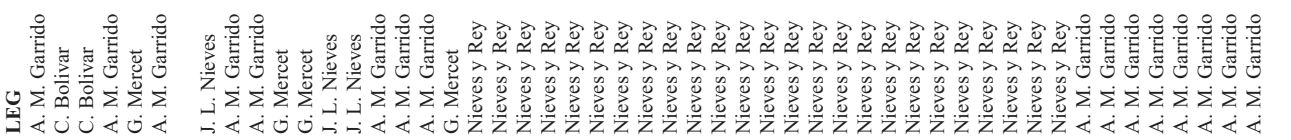

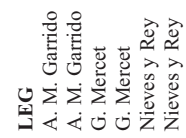

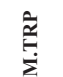

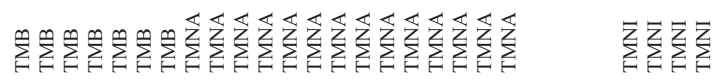

$\stackrel{\bar{z}}{\grave{z}}$

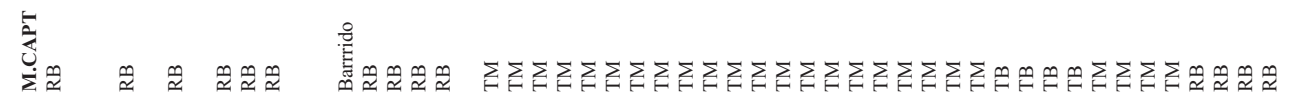

$\overline{5}$

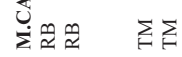

:

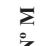

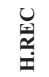

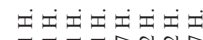

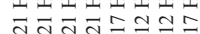

:

₹

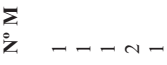

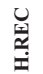

눕

$\underset{i=1}{\stackrel{i}{x}}$

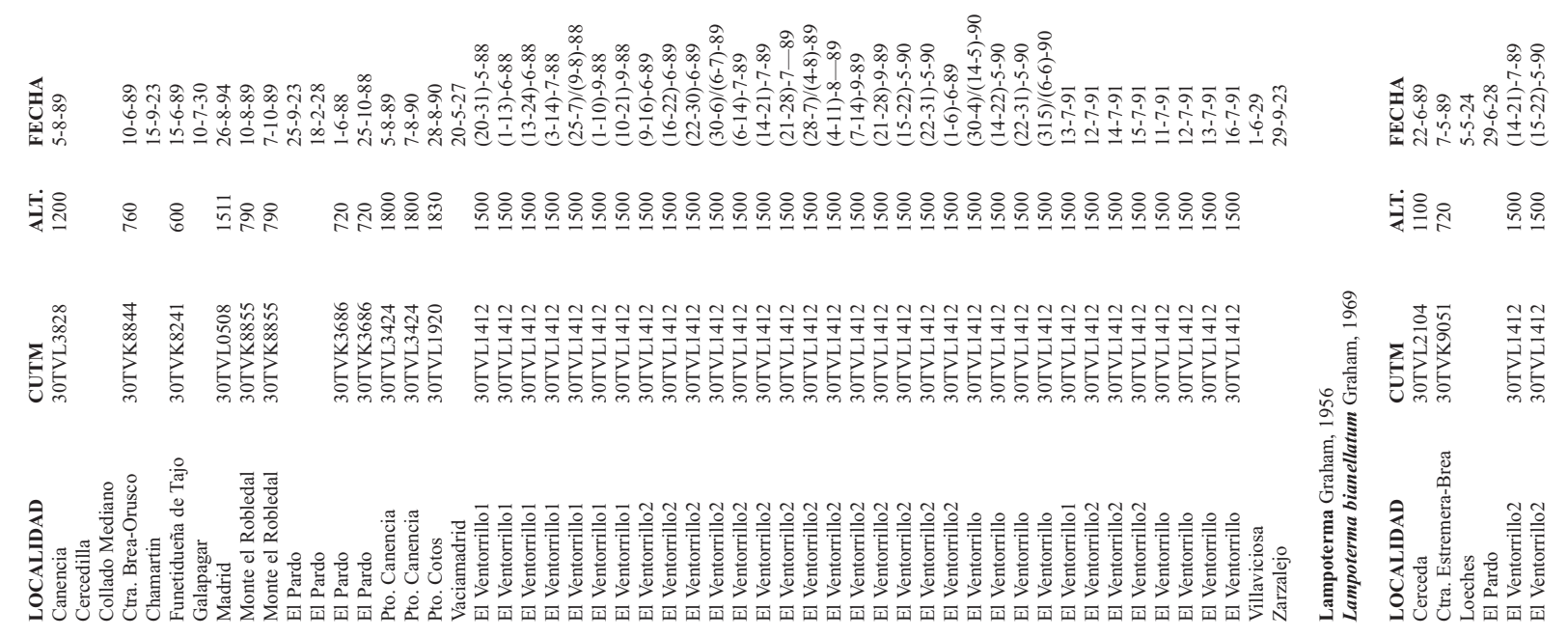




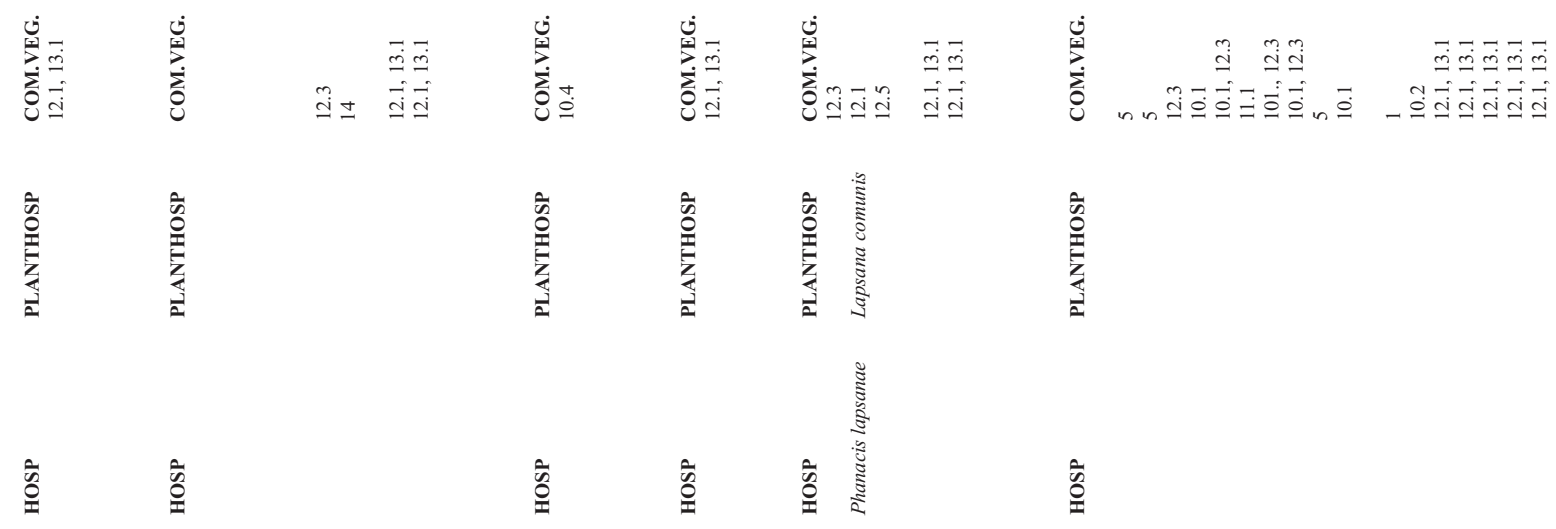

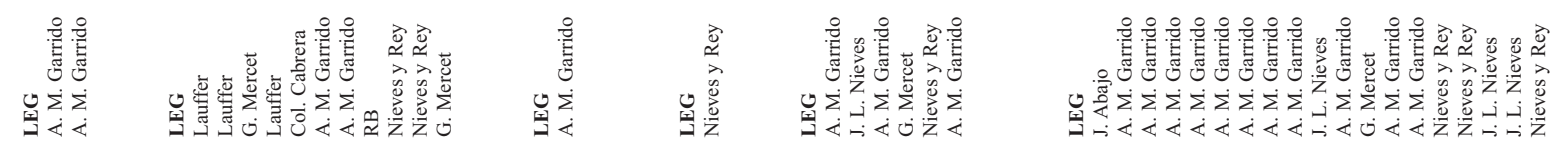

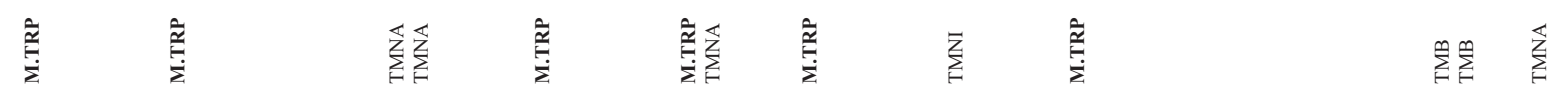

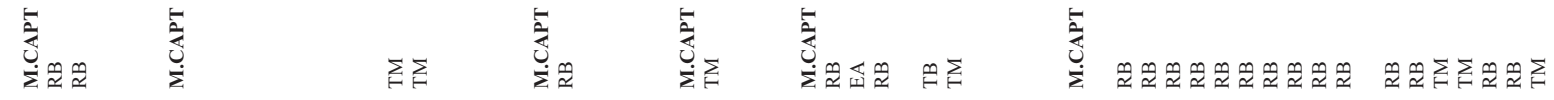

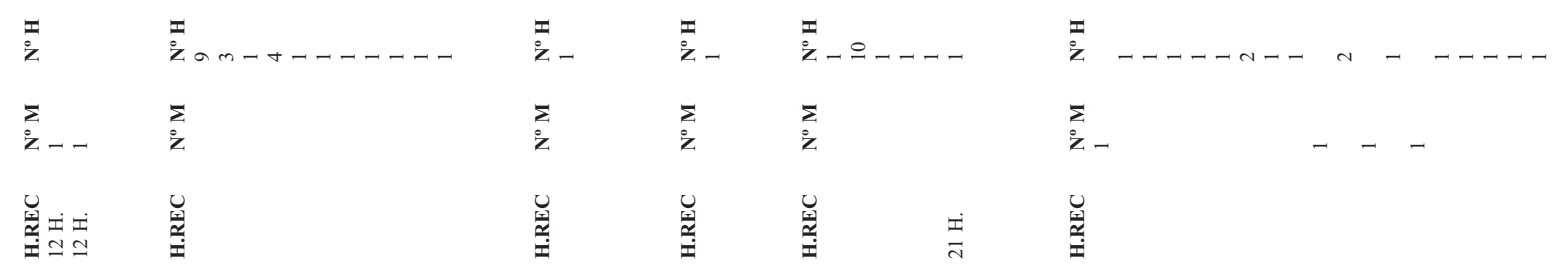

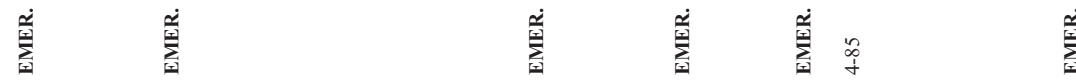

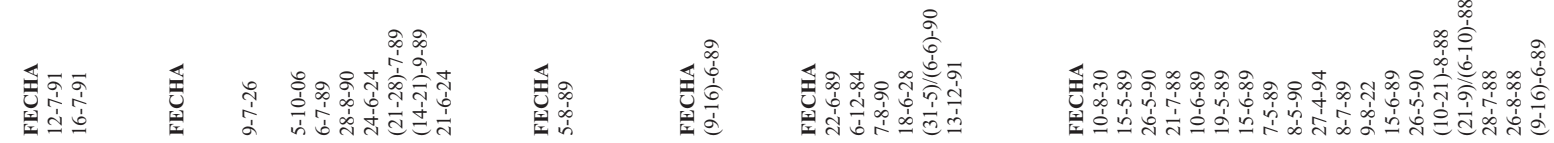

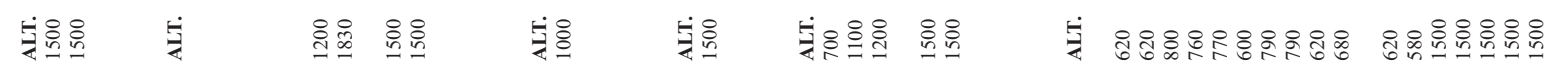

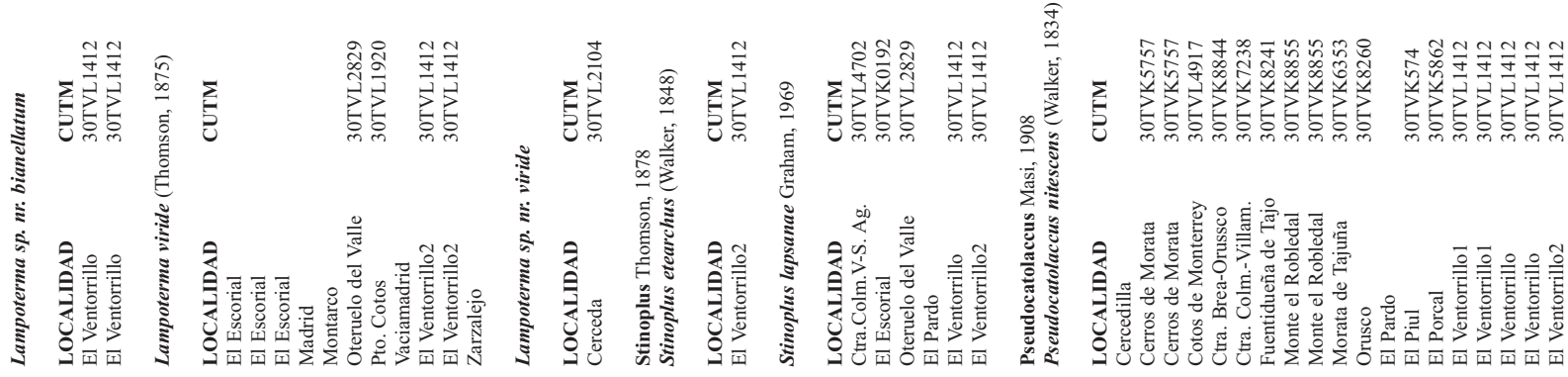




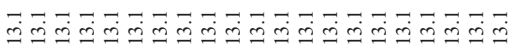

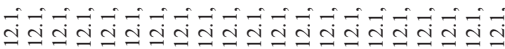

궁

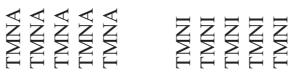

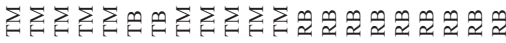

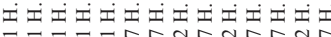

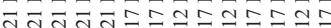

W

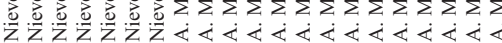

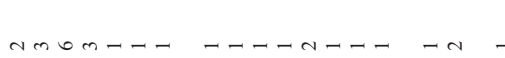

ن

के

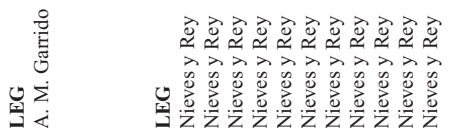

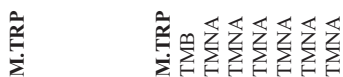

武

紋

:

$\sum_{i}$

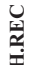

$\stackrel{\sim}{\frac{\sim}{*}}$

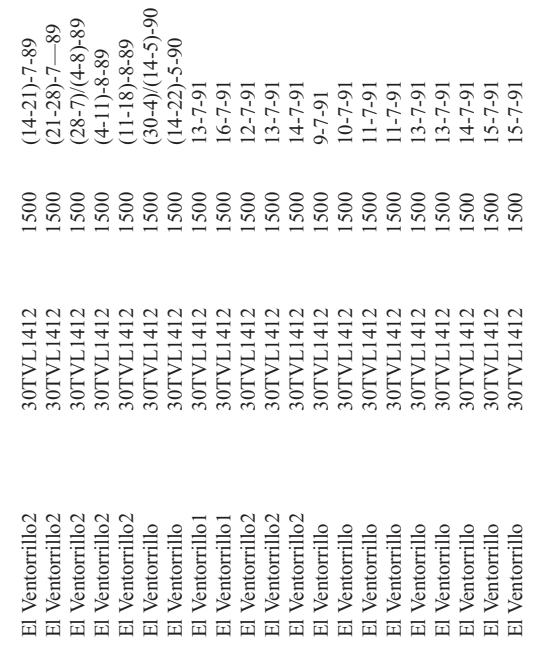

3

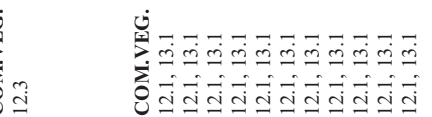

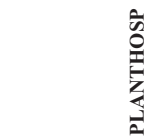

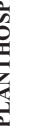

$\stackrel{5}{\stackrel{0}{1}}$

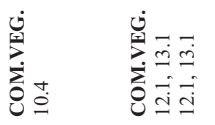

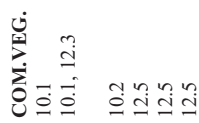

离

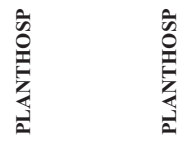

के है है है

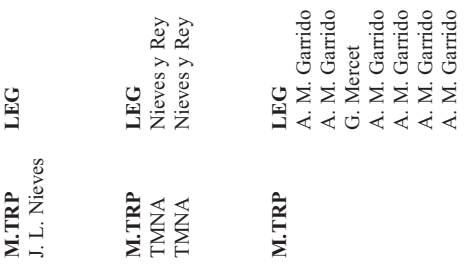

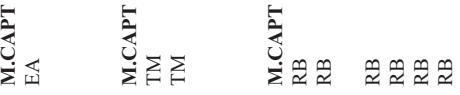

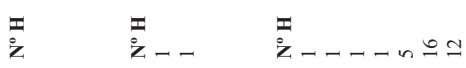

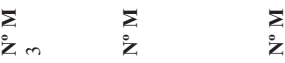

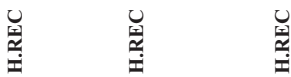

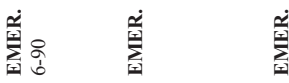

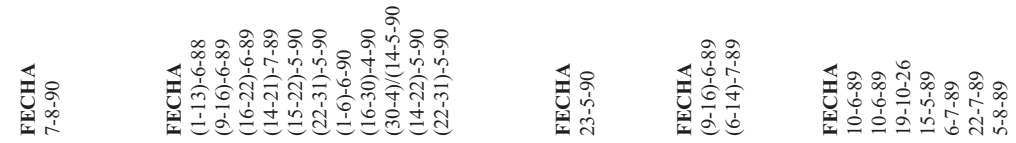

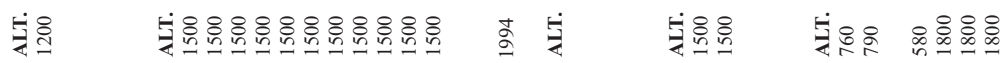

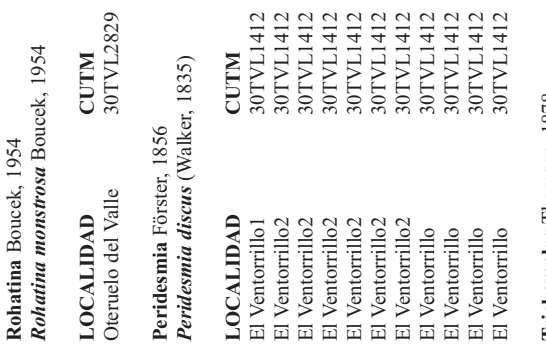

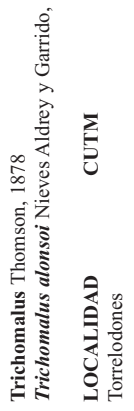

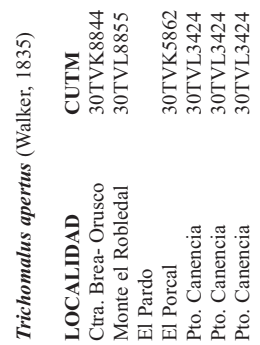




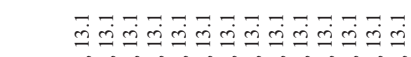

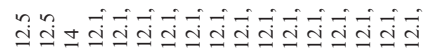

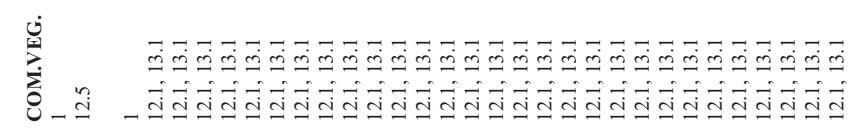

竞

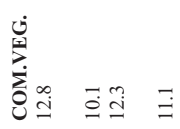

$\frac{\bar{c}}{2}$

है

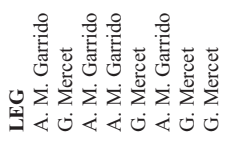

$\stackrel{\bar{z}}{\vec{z}}$

5

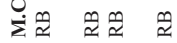

:

$\sum_{i}$

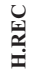

춥

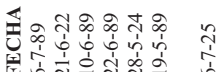

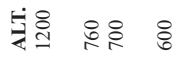

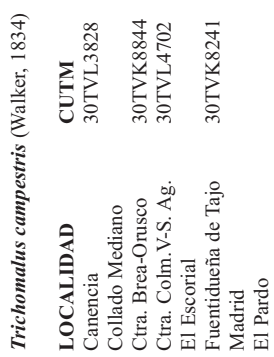




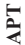

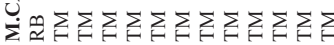

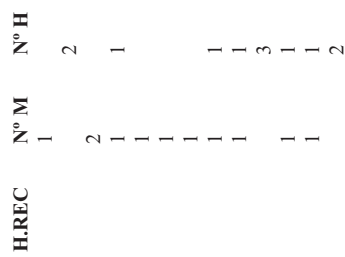

$\underset{\dot{x}}{\stackrel{i}{x}}$

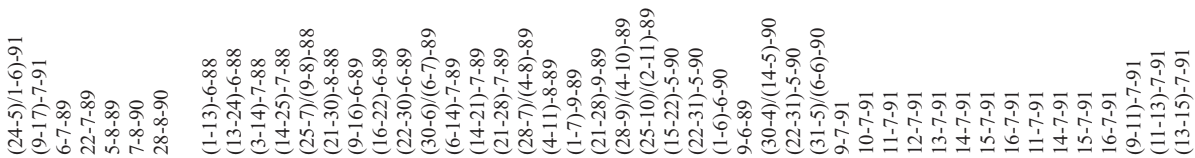

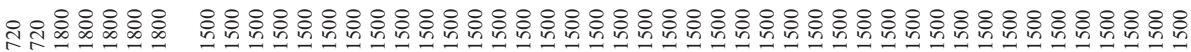

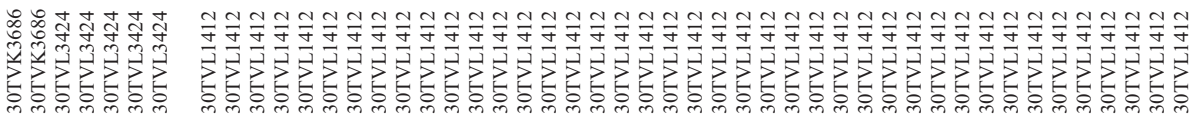

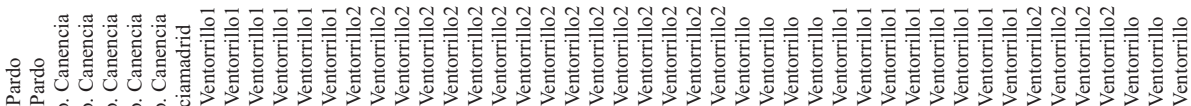

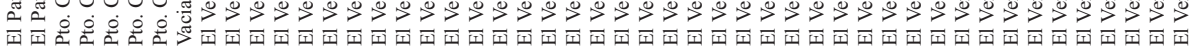

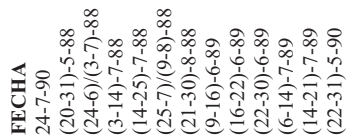

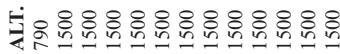

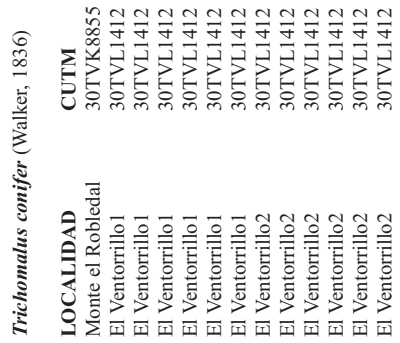




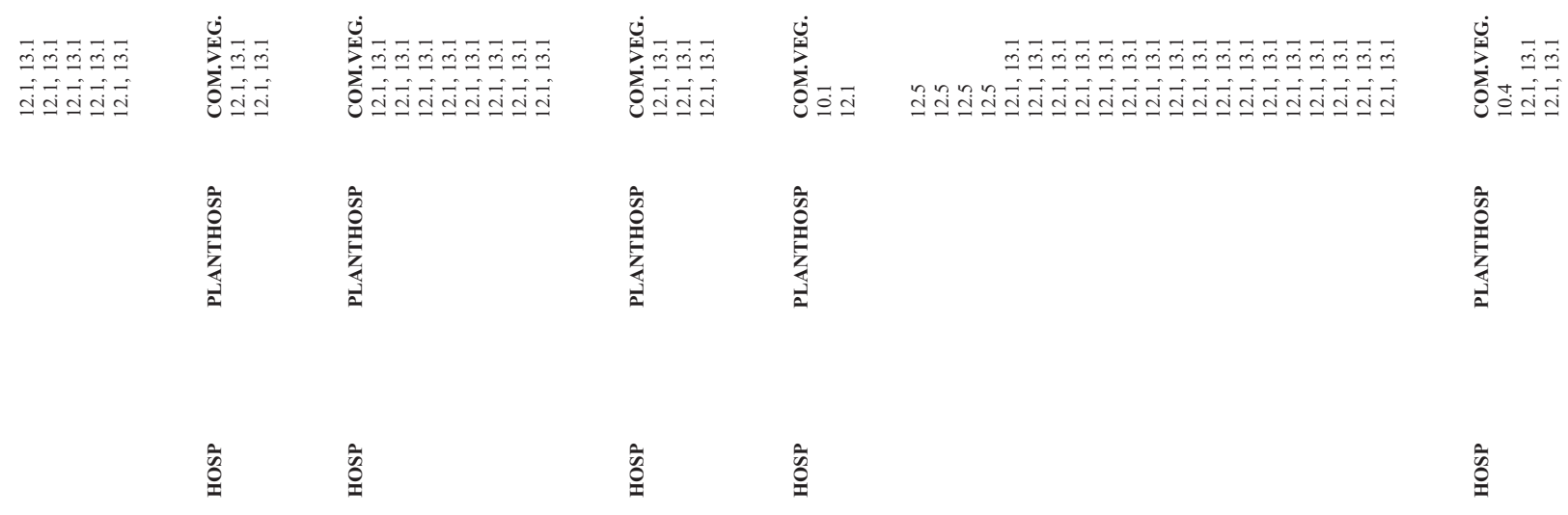

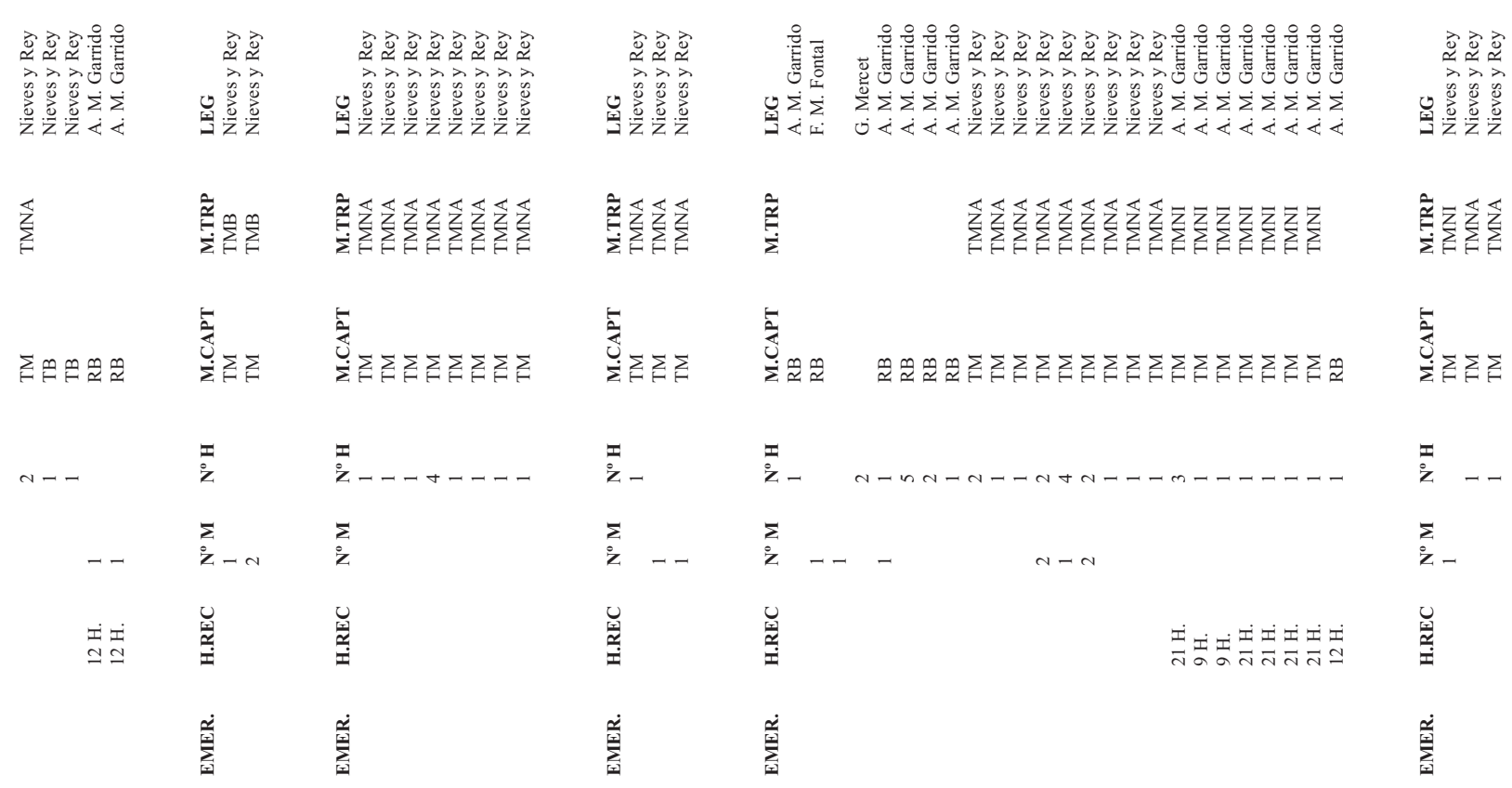

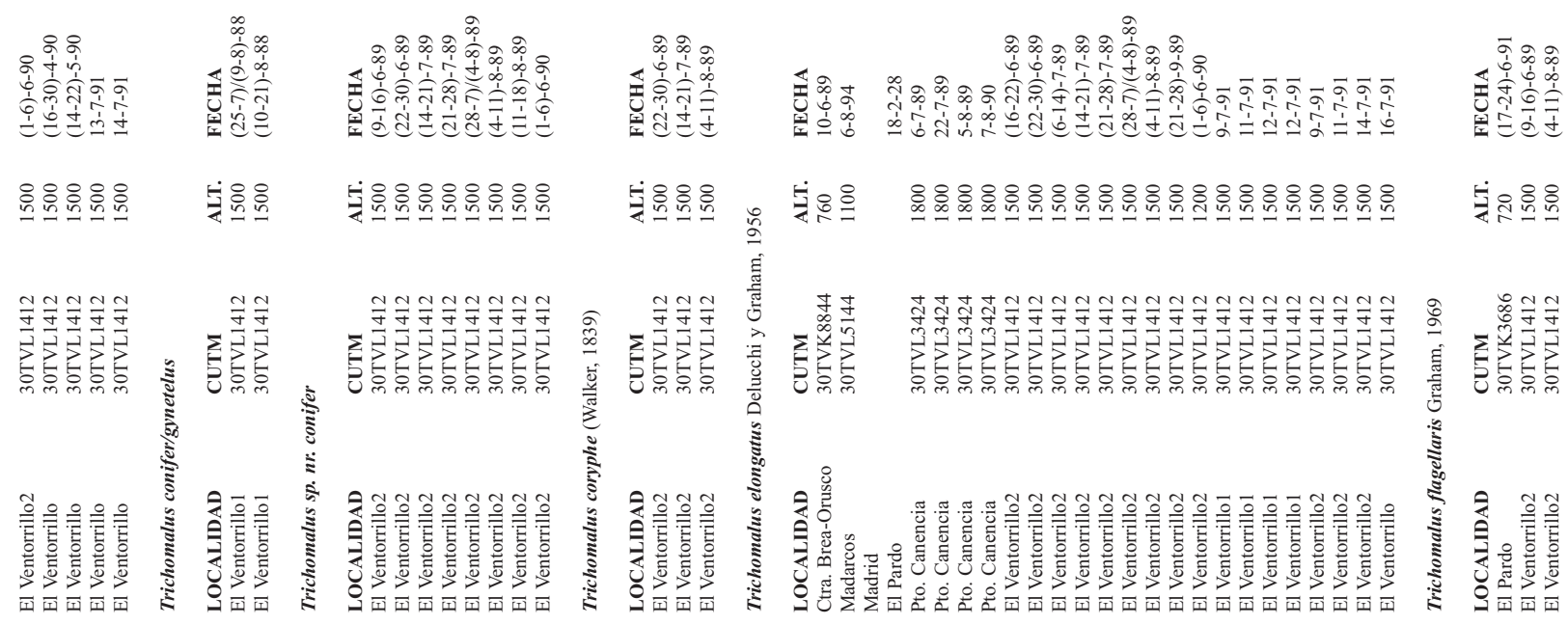



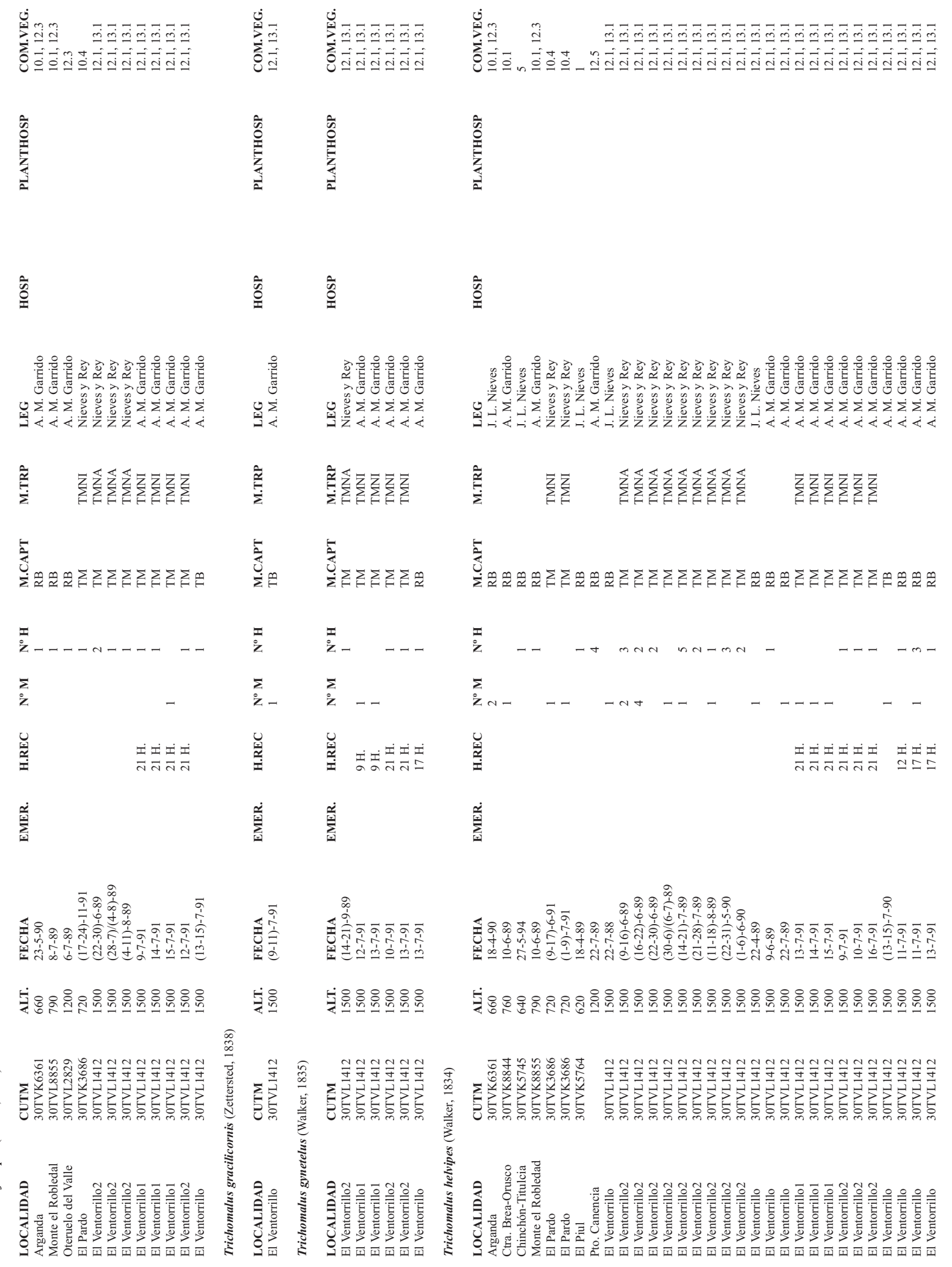


\begin{tabular}{|c|c|c|c|c|c|}
\hline 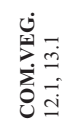 & 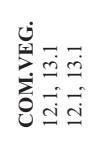 & 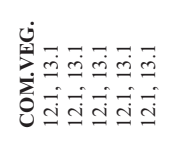 & 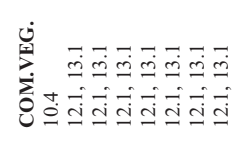 & 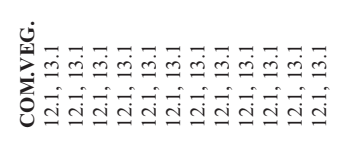 & 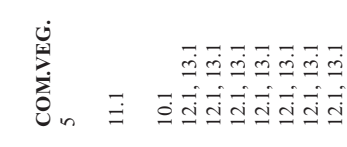 \\
\hline 悹 & 范 & 童 & 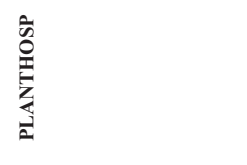 & 竞 & 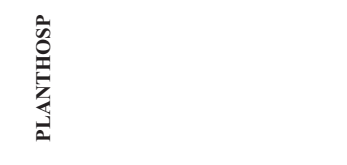 \\
\hline 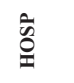 & 产 & 啇 & 啇 & 啇 & 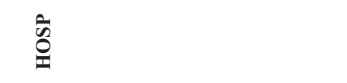 \\
\hline
\end{tabular}

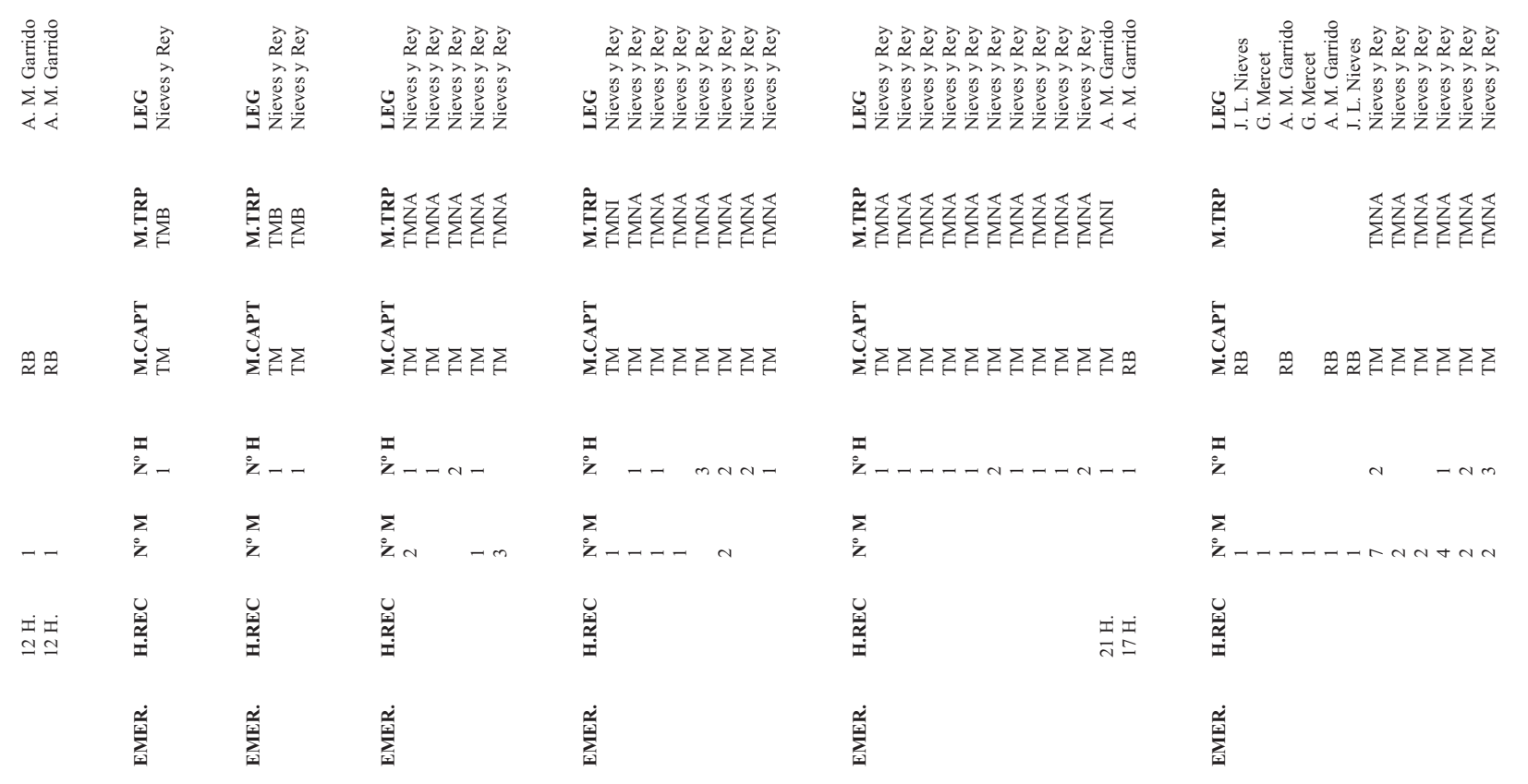

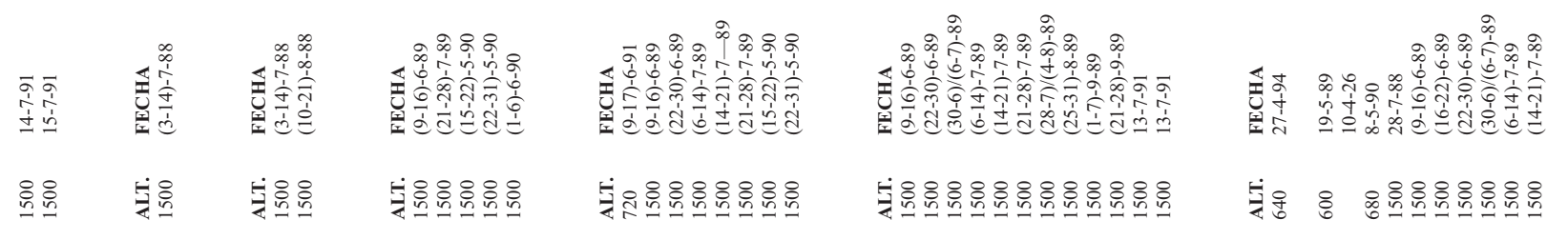

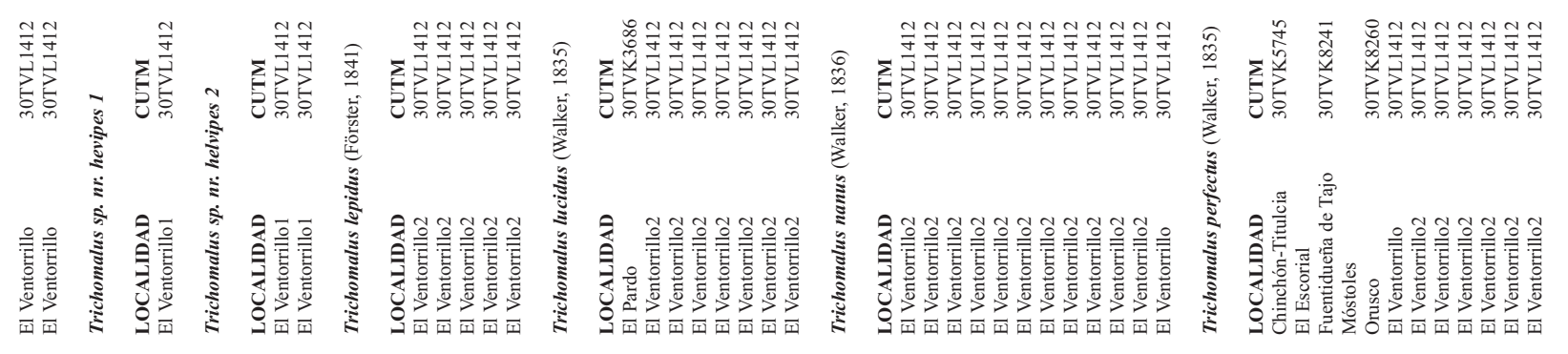




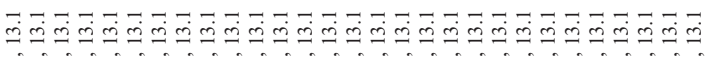

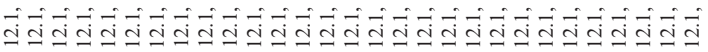

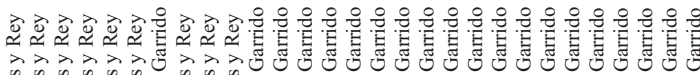
o

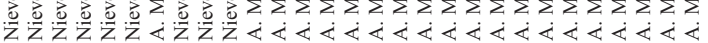

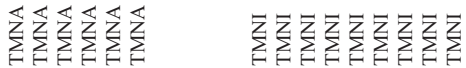

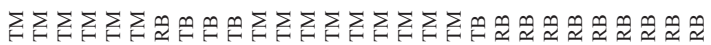

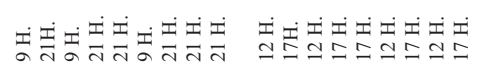

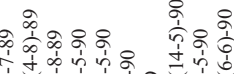

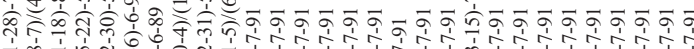

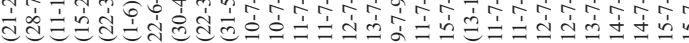

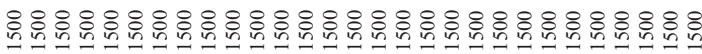

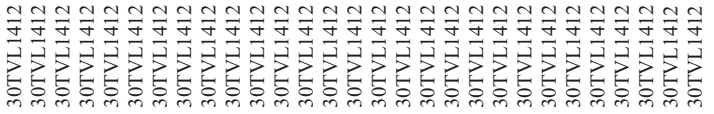

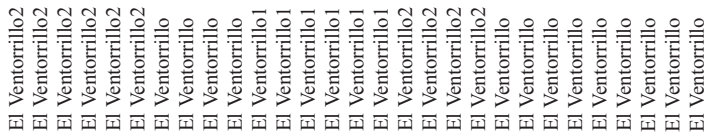

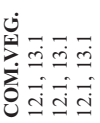

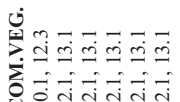

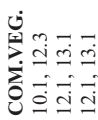

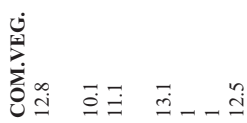

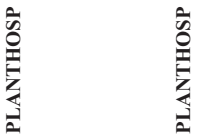

官

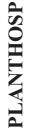

के

है

के
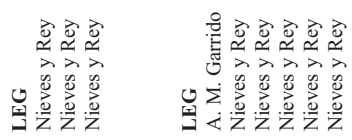

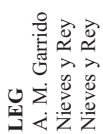

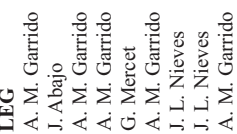

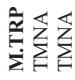

产

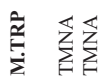

$\stackrel{\hat{z}}{\vec{z}}$

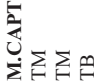

式

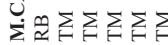

蓄

$\stackrel{2}{3}$

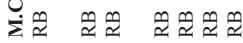

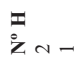

:

$\sum_{0}$

ํㅜㄹ

$\frac{\dot{2}}{2}$

$\sum_{i=1}^{\stackrel{i}{x}}$

i

$\sum_{i=1}^{\frac{d}{x}}$

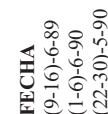

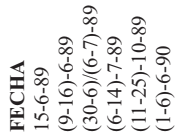

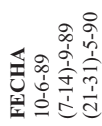

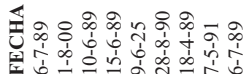

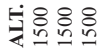

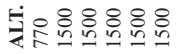

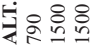

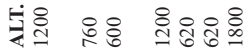

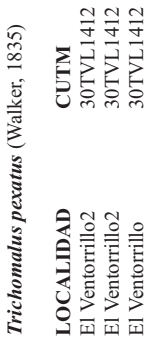

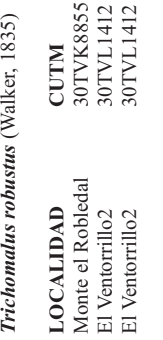

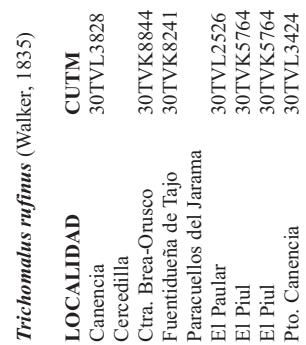




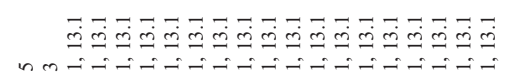

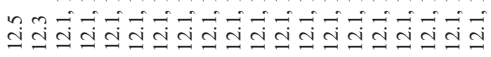

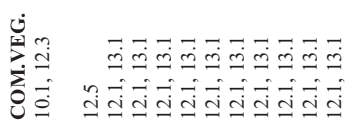

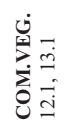

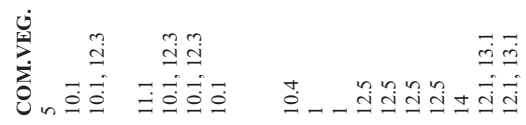

范

气ิ

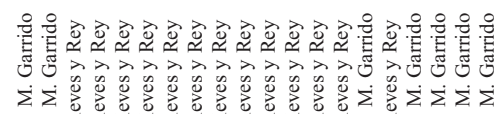

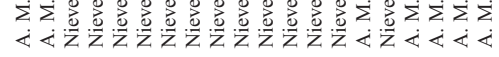

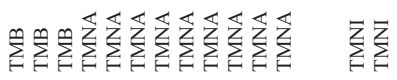

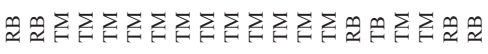
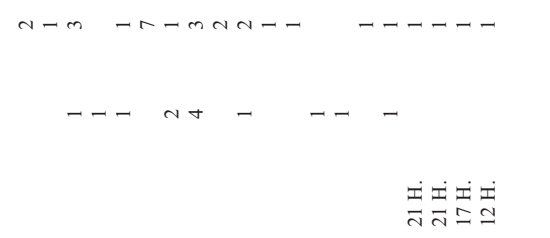

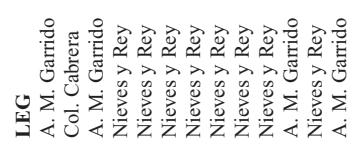

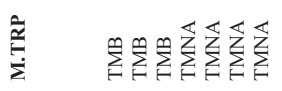

氙

岁乎

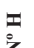

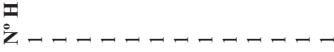

$\sum_{i}$

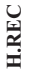

$\stackrel{\text { İ }}{\underline{9}}$

$\sum_{i=1}^{\stackrel{i}{x}}$

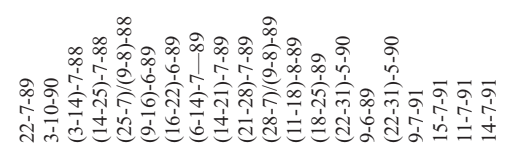

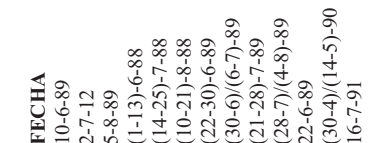

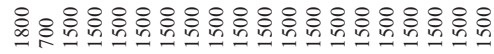

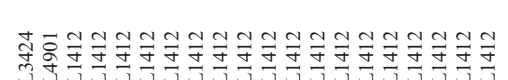

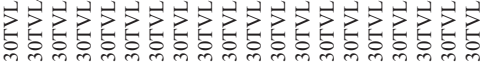

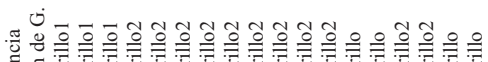

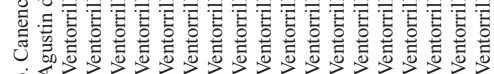

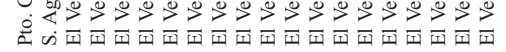

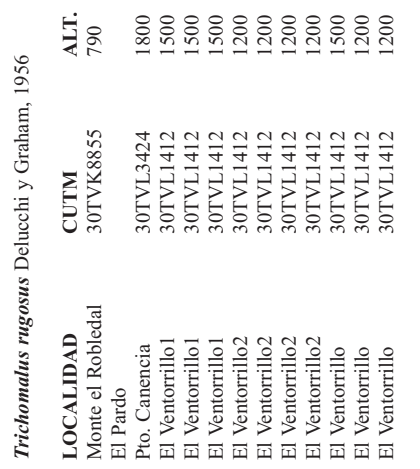

章

仓े

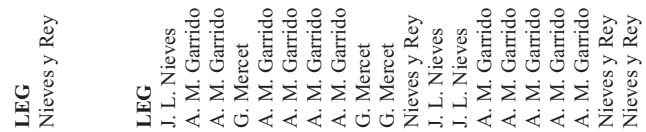

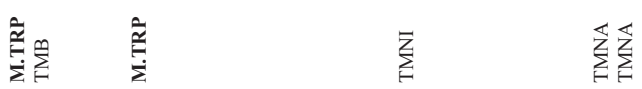

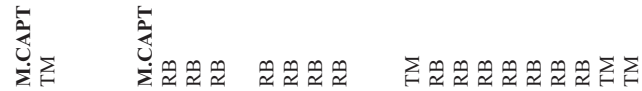
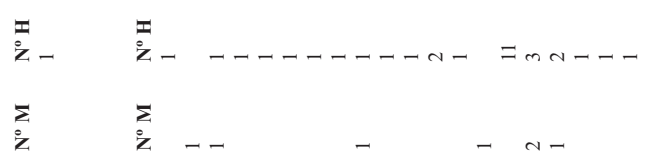

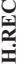

$\sum_{i=1}^{\infty}$

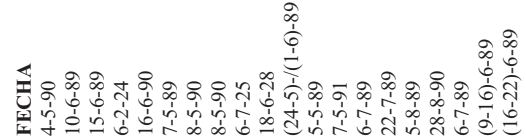

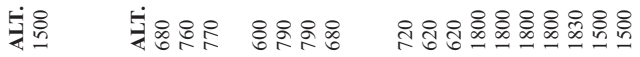

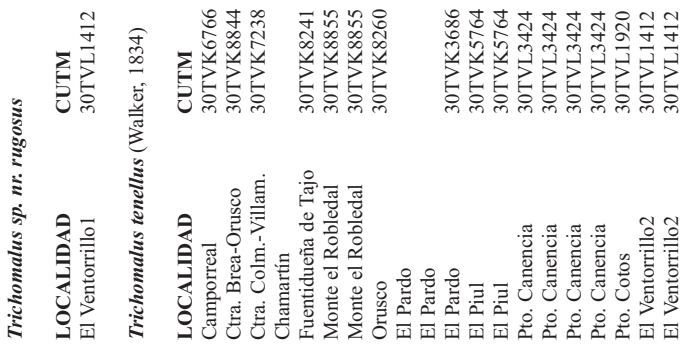




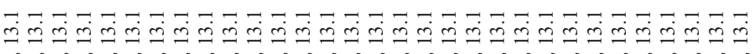

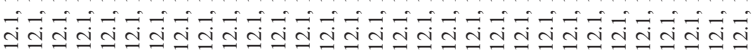

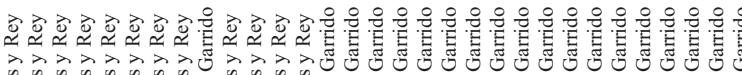
ô

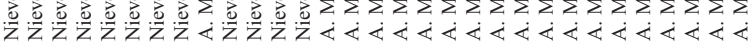

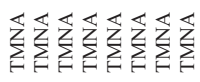

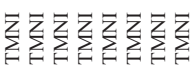

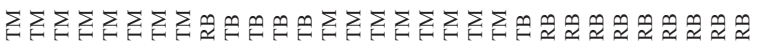

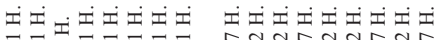

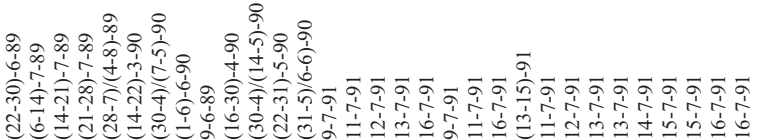

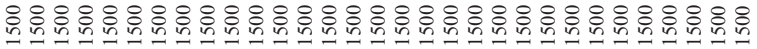

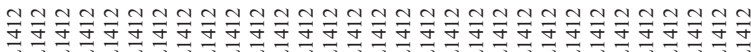

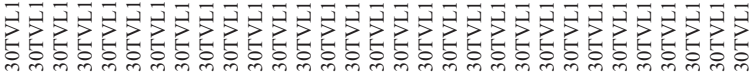

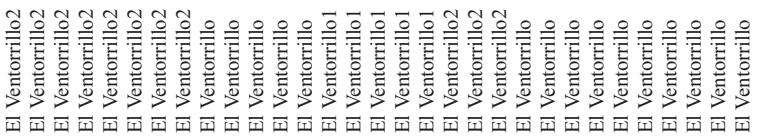

家

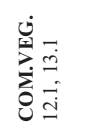

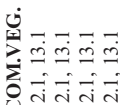

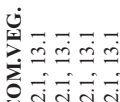

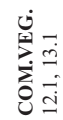

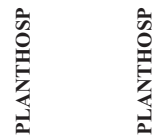

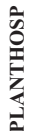

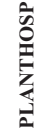

के

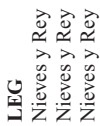

退

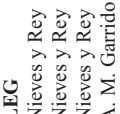

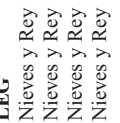

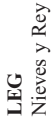

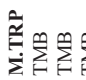

$\hat{\underline{x}}$

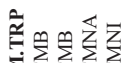

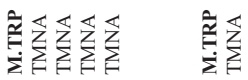

5

粶引引

这

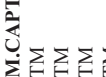

造

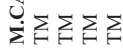

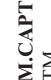

ביב

$\stackrel{7}{\mathrm{Z}}-$

i

:

$\sum_{i} \sum_{i} n-$

$\sum_{i}$

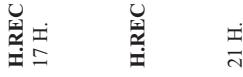

$\sum_{i=1}^{\frac{\dot{x}}{x}}$

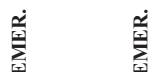

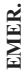

$\underset{\dot{x}}{i}$
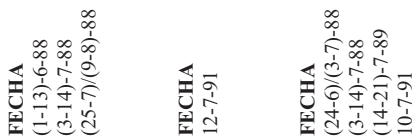

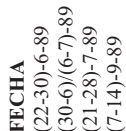

至站

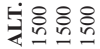

เ่ํำ

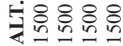

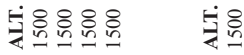

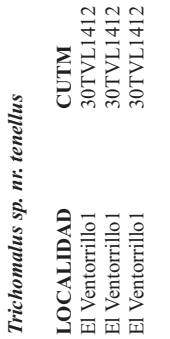

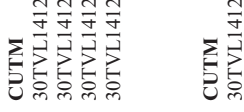

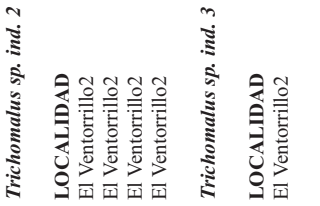




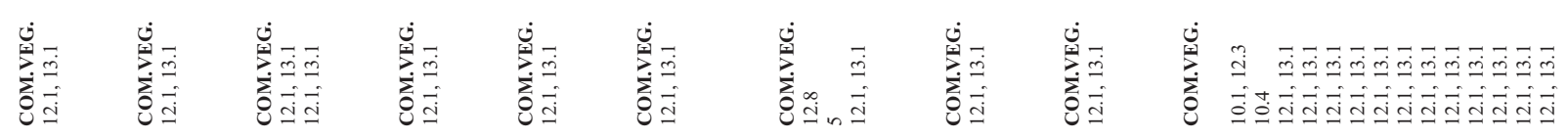

$1|1| 1|||| \mid$

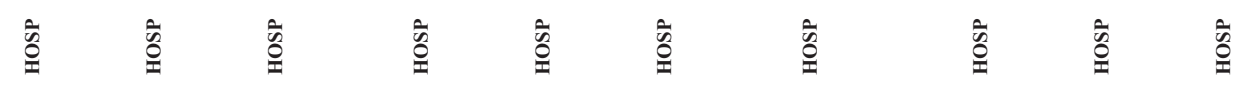

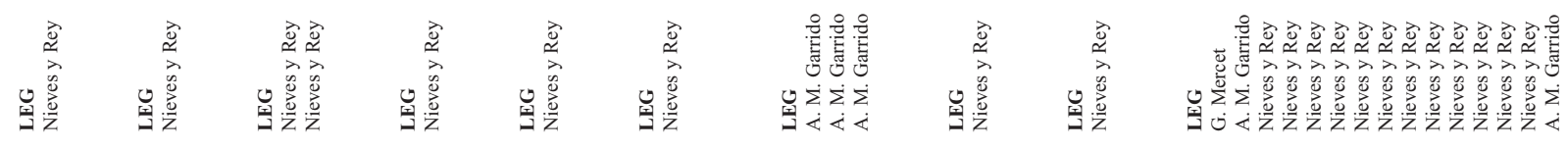

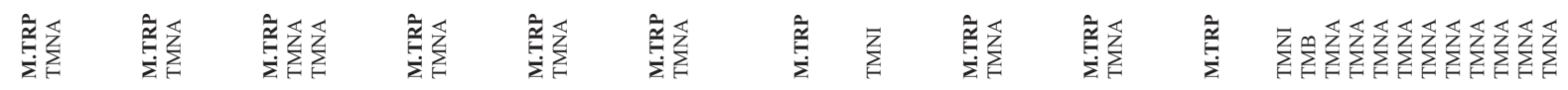

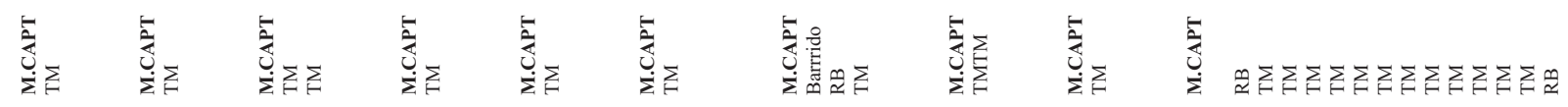

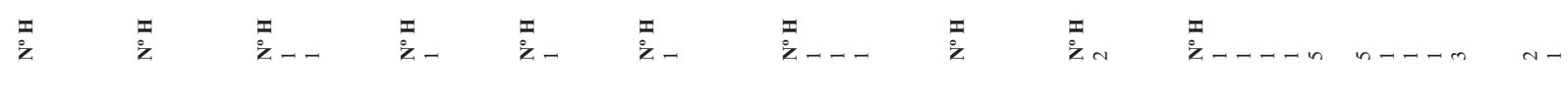

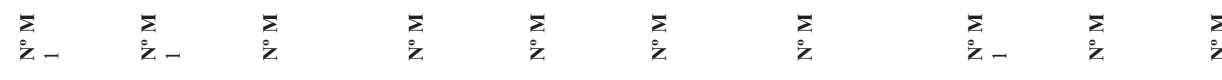

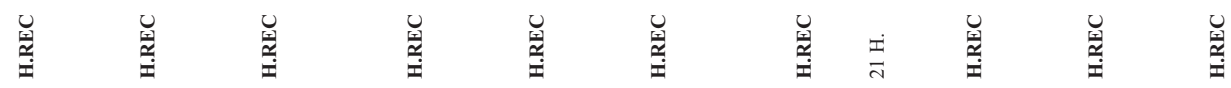

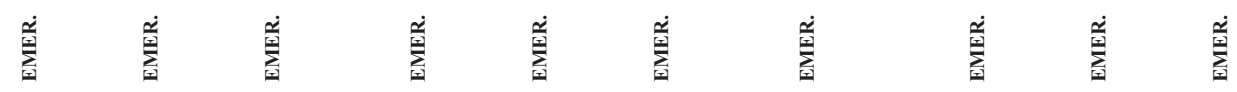

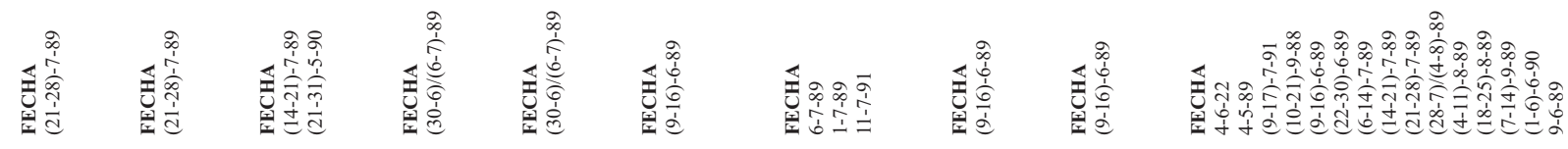

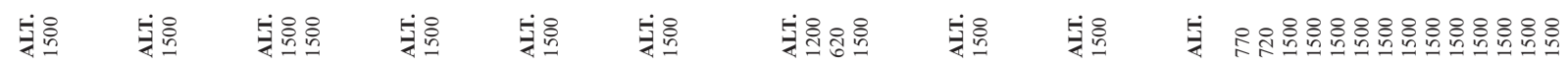

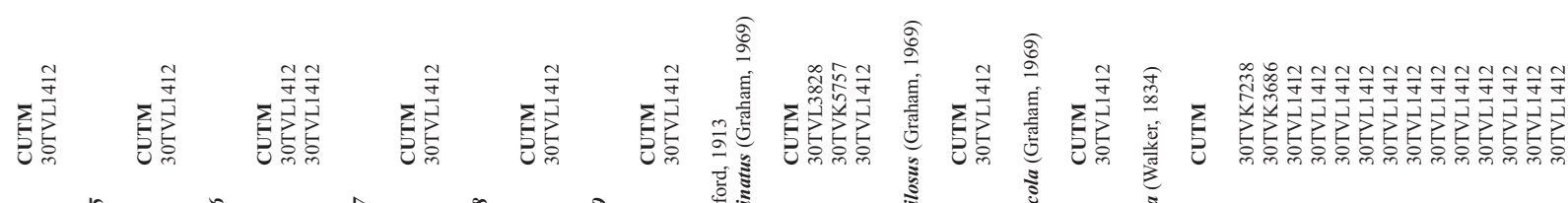

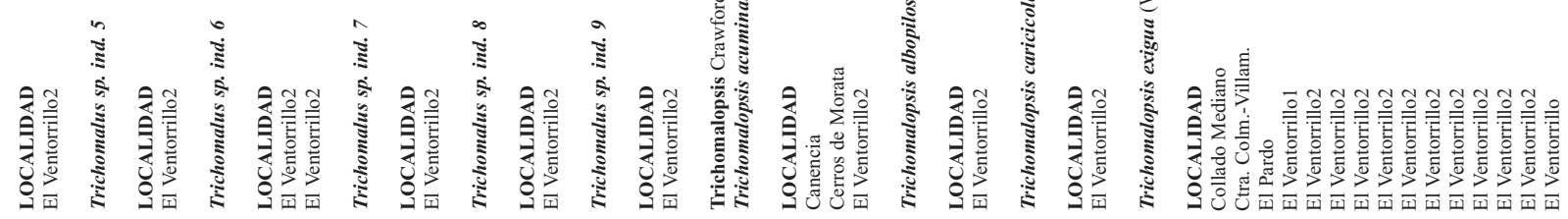




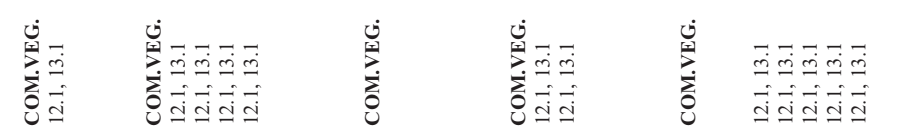

离

官

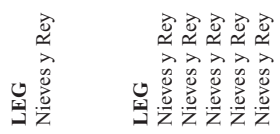

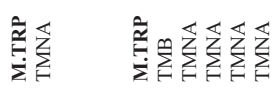

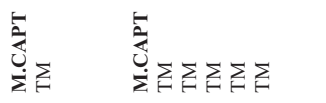

$\stackrel{ \pm}{\mathrm{Z}}$

$\sum_{i} \quad \sum_{i}$

葛

畺离

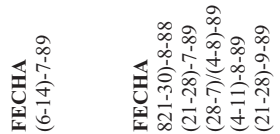

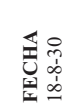

安

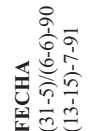

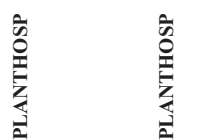

के के

产赵

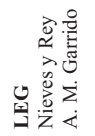

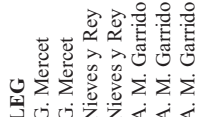

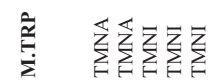

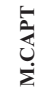

$\sum \sum \sum \sum$

$\stackrel{7}{\dot{Z}}-$

$\sum_{i=1}$

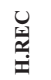

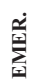

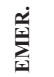

$\sum_{i=1}^{\stackrel{i}{x}}$

불욤욤

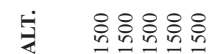

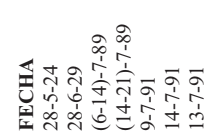

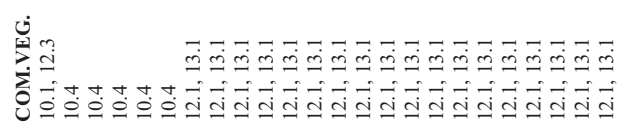

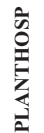

के

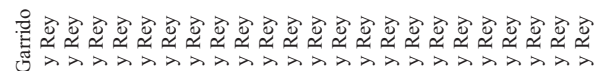

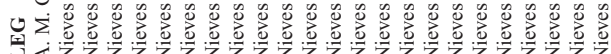

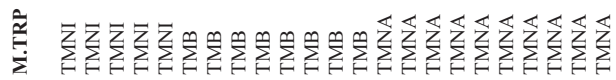

ڤั

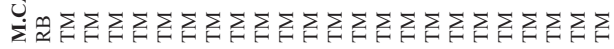

$\pm$

$\sum$

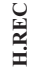

춥

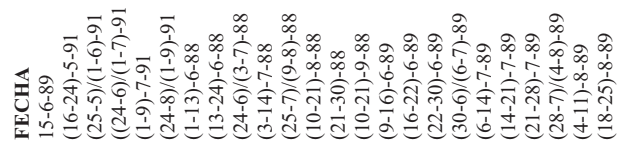

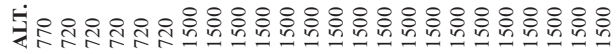

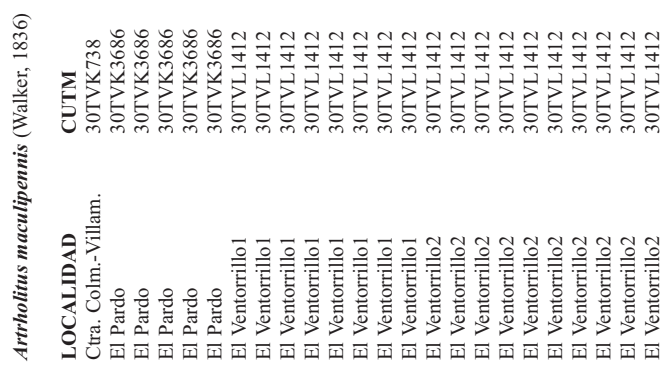




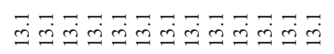

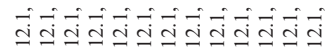

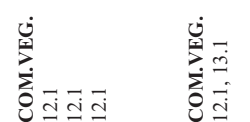

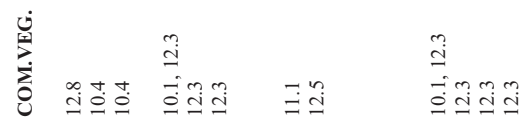

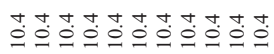

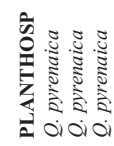

产

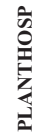

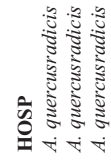

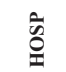

$\stackrel{\hat{n}}{\hat{0}}$

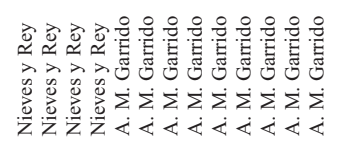

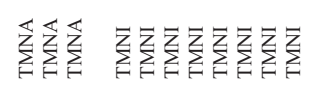

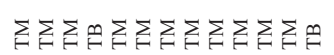

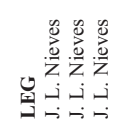

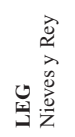

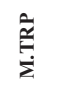

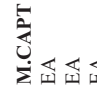

产玄

$\stackrel{\bar{z}}{\dot{z}}$

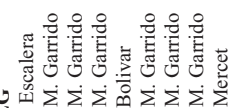

尊焉

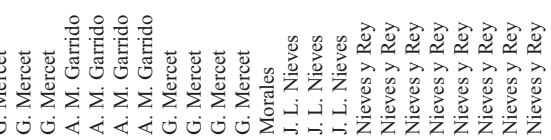

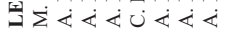

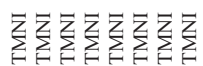
:

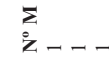

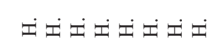
ลงสง

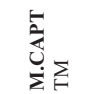

$\frac{5}{\dot{z}}$ $\approx \frac{2}{2}$

$\approx \frac{\cdots}{\simeq}$

$\stackrel{m}{\simeq}$

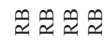

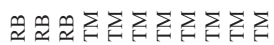

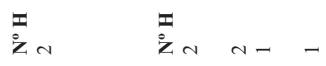

i

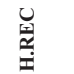

䍠

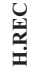

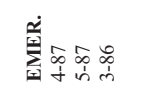

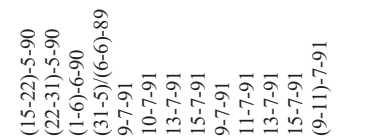

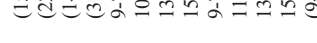

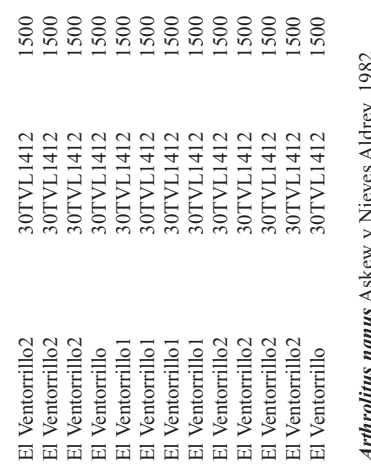

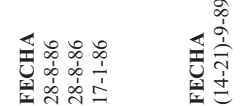

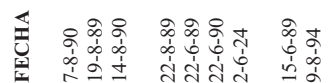

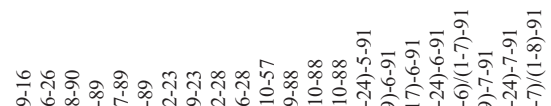

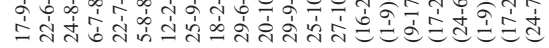

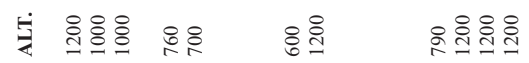

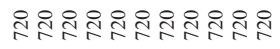

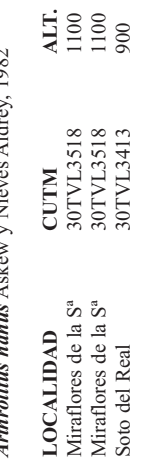

安各

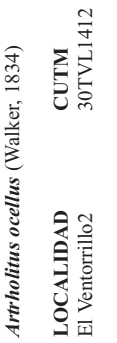

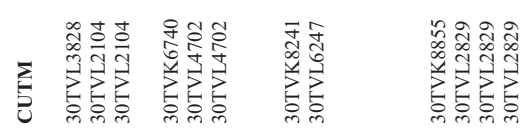

홇ํำ

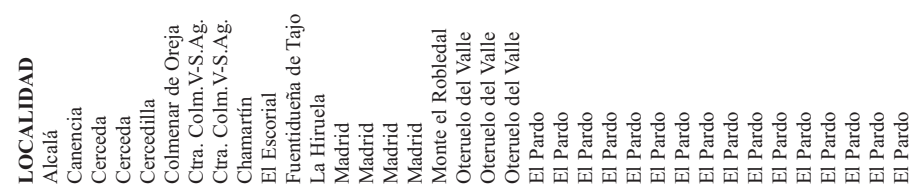




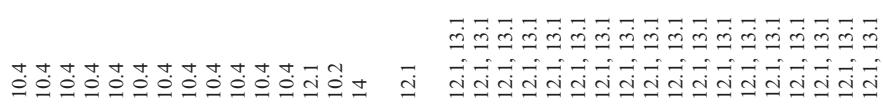

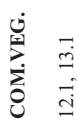

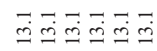

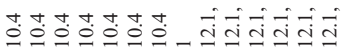

$\frac{\bar{c}}{3}$

$\frac{x^{2}}{3}$

$\stackrel{\bar{s}}{\cong}$

ڤิ宀

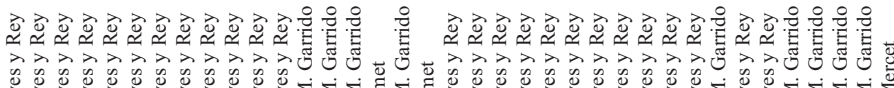

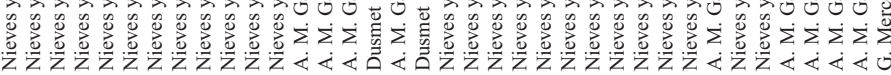

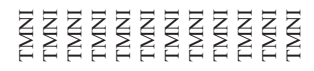

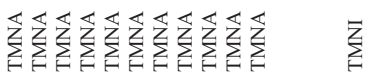

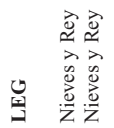

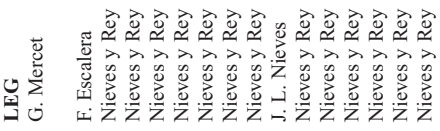

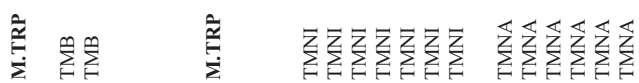

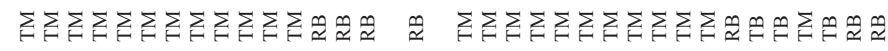

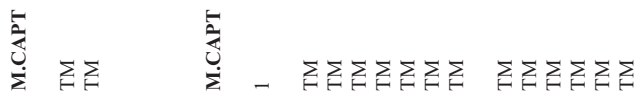

ฉั

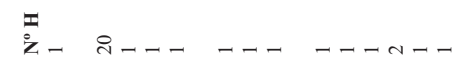

ì

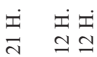

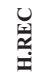

¿

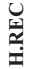

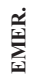

$\stackrel{\sim}{i}$

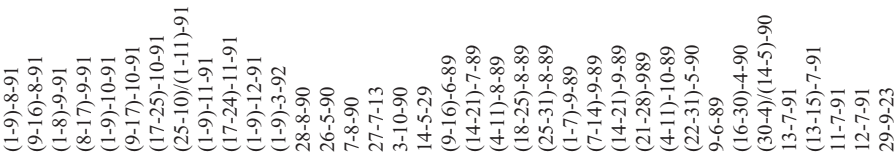

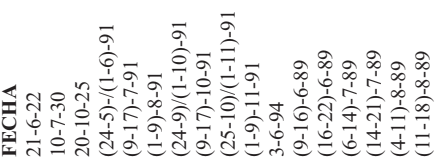

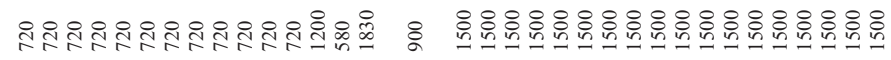

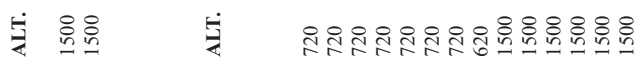

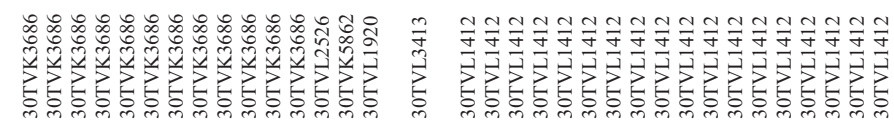

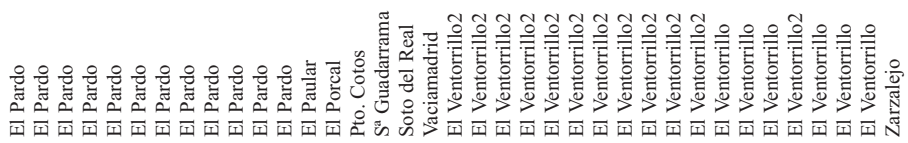

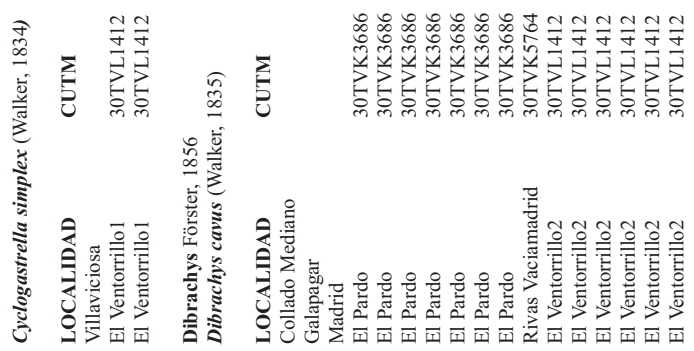




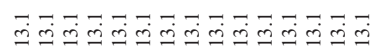

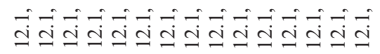
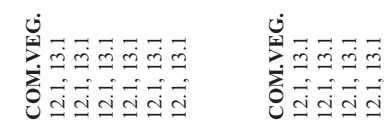

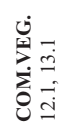

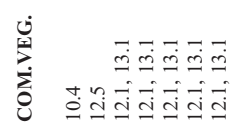

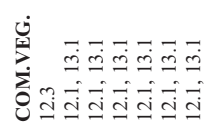

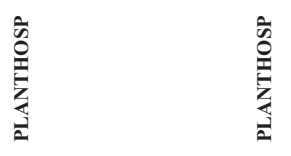

离

㐔

产

केष

ڤัे

$\stackrel{\bar{s}}{\Xi}$

$\stackrel{\hat{s}}{\underline{0}}$

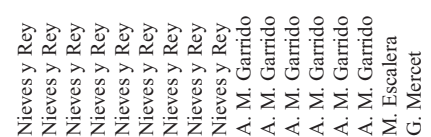

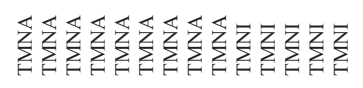

$\sum \sum \sum \sum \sum \sum \sum \sum \sum \sum \sum \sum \sum \cong$

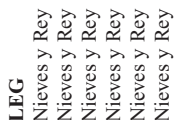

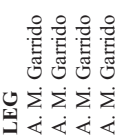

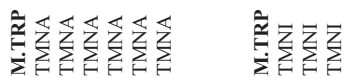

$\bar{y}$

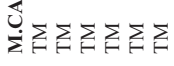

预

$\sum_{\sum^{2}}$

竞

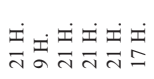

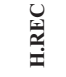

$\sum_{i=1}^{\stackrel{x}{x}}$

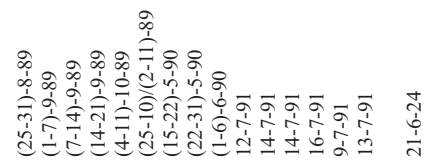

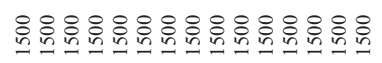

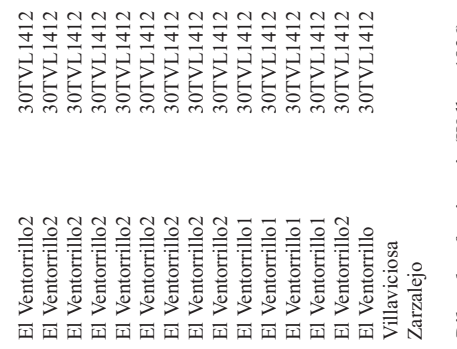

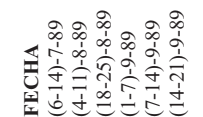

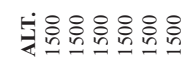

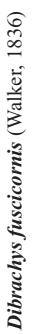

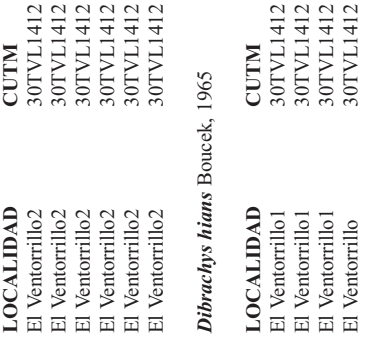

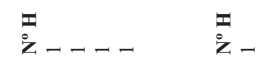

层

鵕地理

这

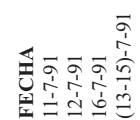

분흠응요을

$\sum_{i=1}^{\frac{i}{x}}$

5

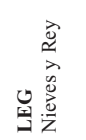

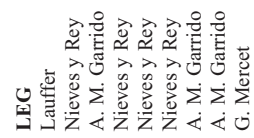

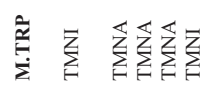

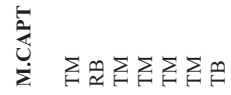

:

$\sum_{\substack{z \\ \vdots}}$

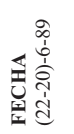

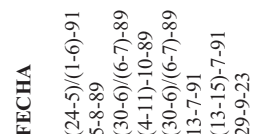

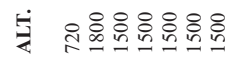

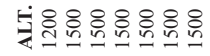

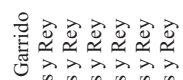

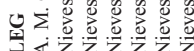

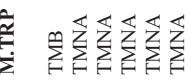

5

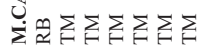

:

$\sum_{i}$

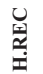

$\sum_{i=1}^{\dot{x}}$
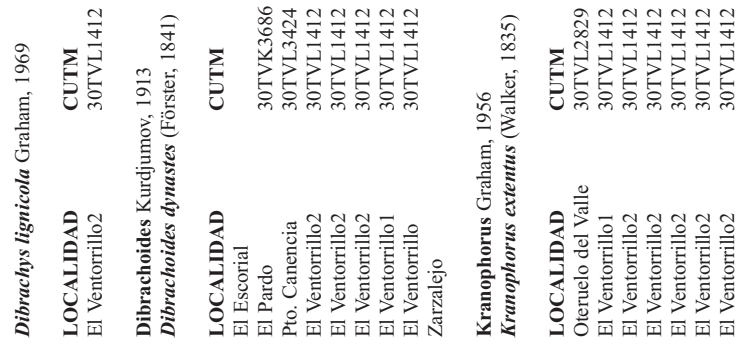


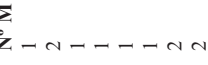




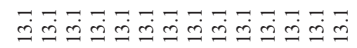

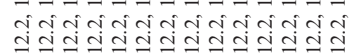

:

i

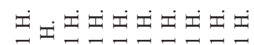

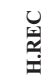

峞

$\stackrel{\dot{*}}{\frac{\dot{*}}{*}}$

i

兽

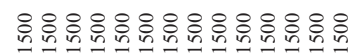

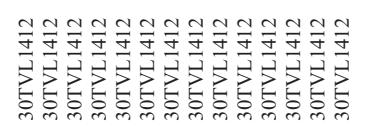




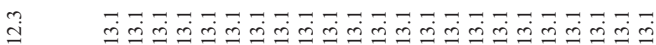

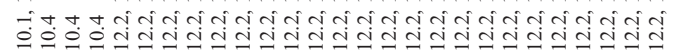

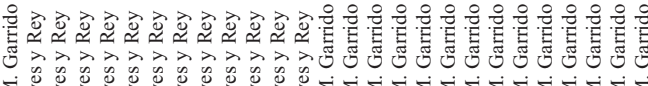
$\dot{\Sigma}$

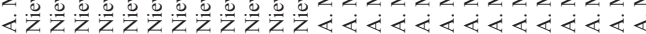

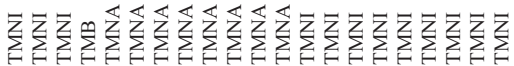

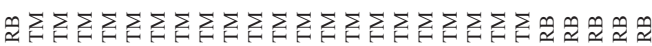$$
-
$$

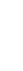

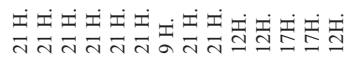

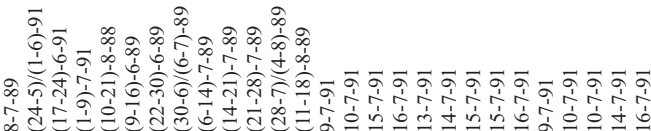

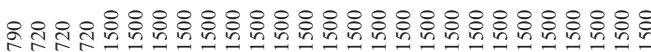

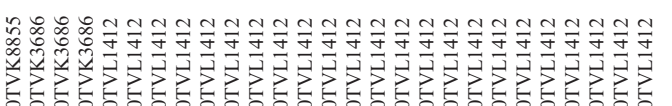

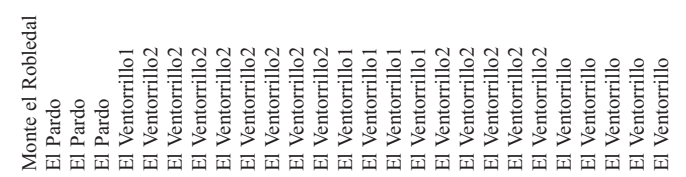

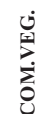

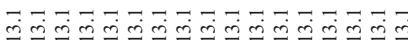

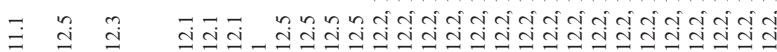

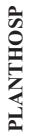

के

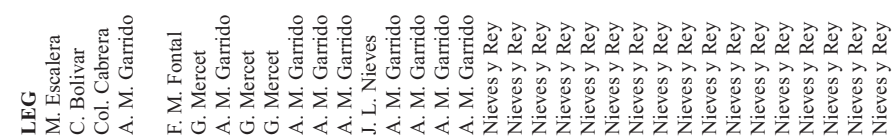

$\stackrel{\bar{\Sigma}}{\check{\Sigma}}$

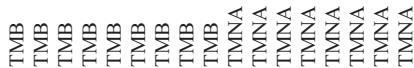

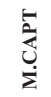

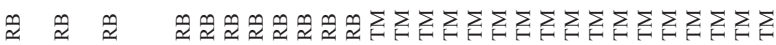

$\frac{\pi}{2}$

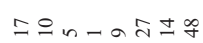

$\sum$

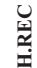

$\underset{i}{i}$

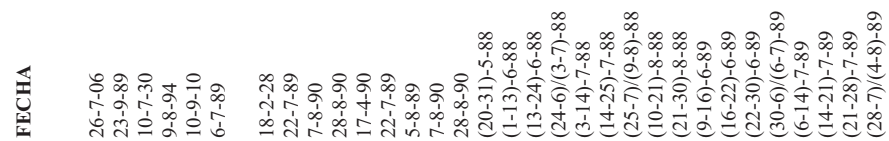

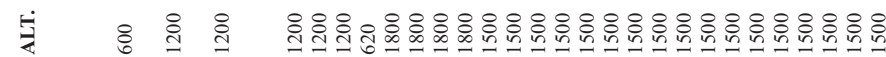

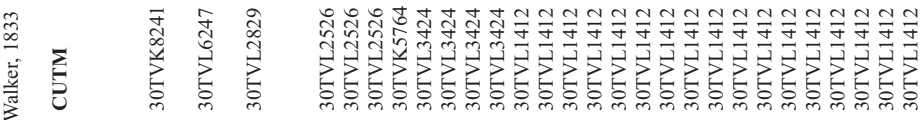

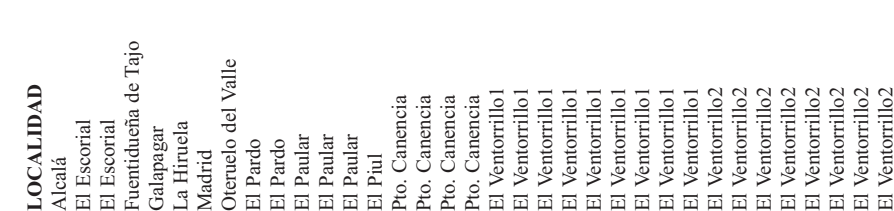




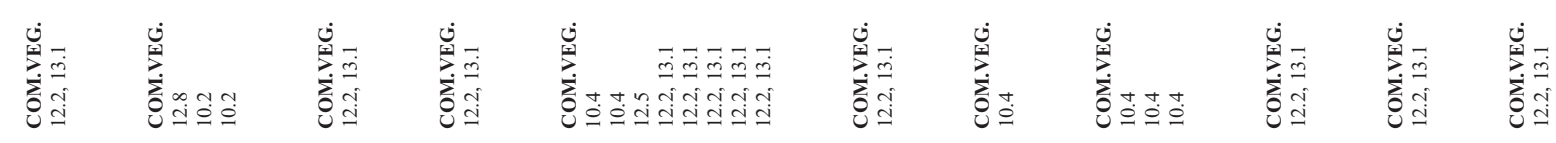

111111111

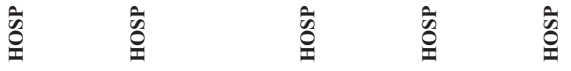
के के के के
के

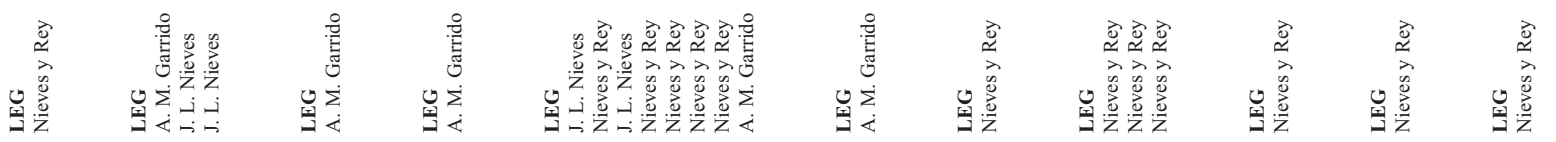

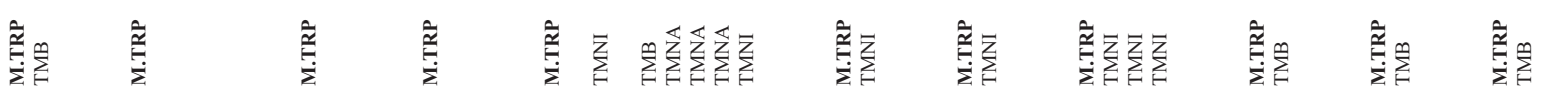

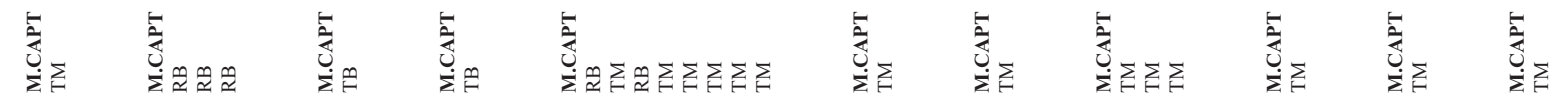

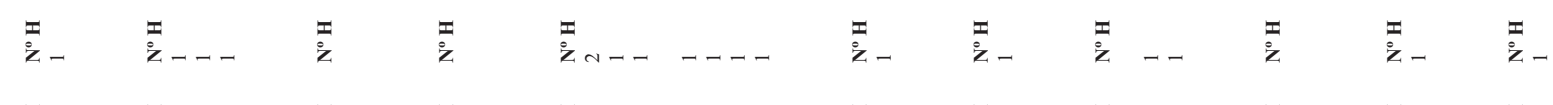

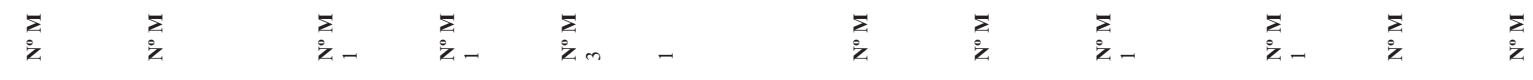

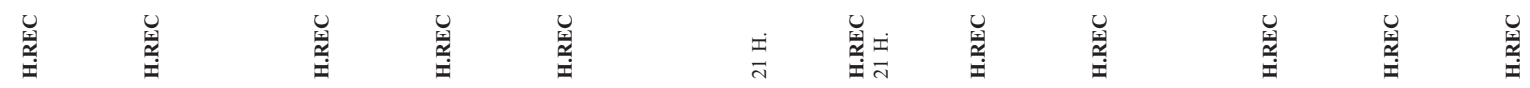

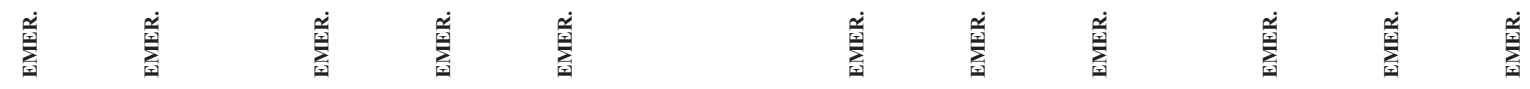

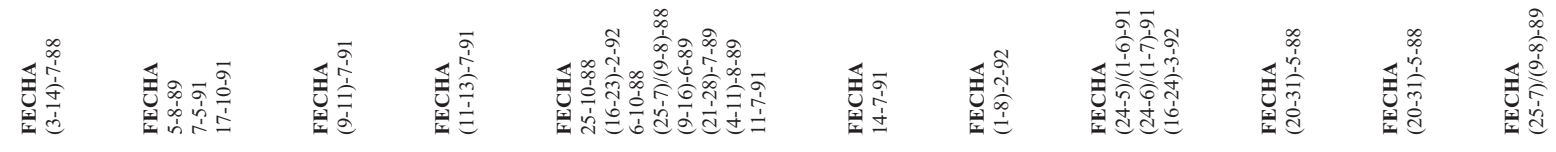

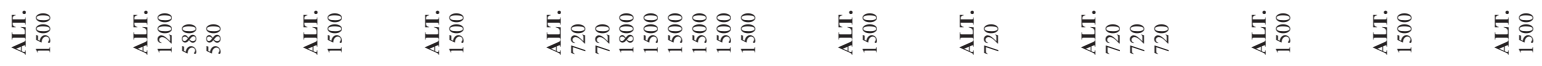

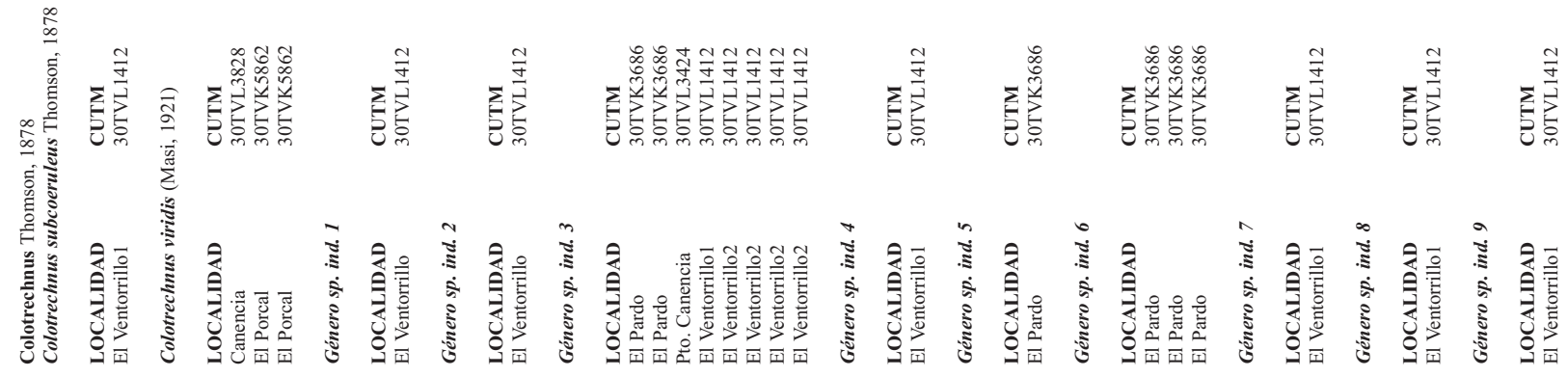




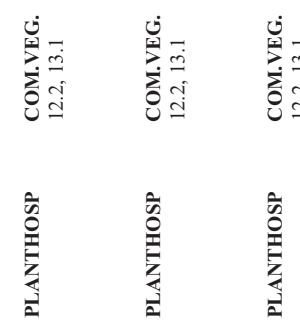

के के के के

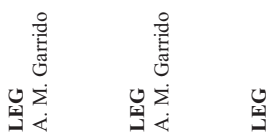

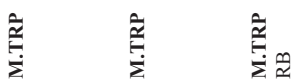

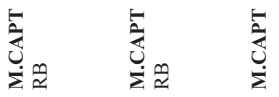

$\underset{z}{z} \quad \stackrel{z}{z} \quad \stackrel{z}{z}$

$\sum_{i} \quad \sum_{i} \quad \sum_{i}$

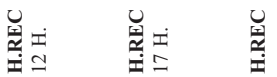

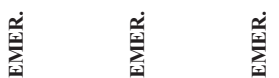

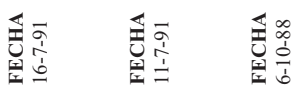

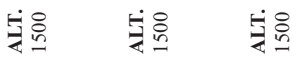

施

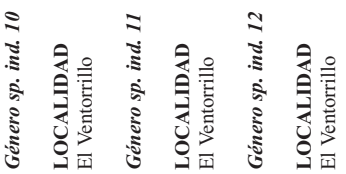

